Technical Report

December 1999

\title{
Coastal Mixing and Optics Experiment Moored Array Data Report
}

by

\author{
Nancy Galbraith \\ Albert Plueddemann \\ Steven Lentz \\ Steven Anderson \\ Mark Baumgartner \\ James Edson
}

December 1999
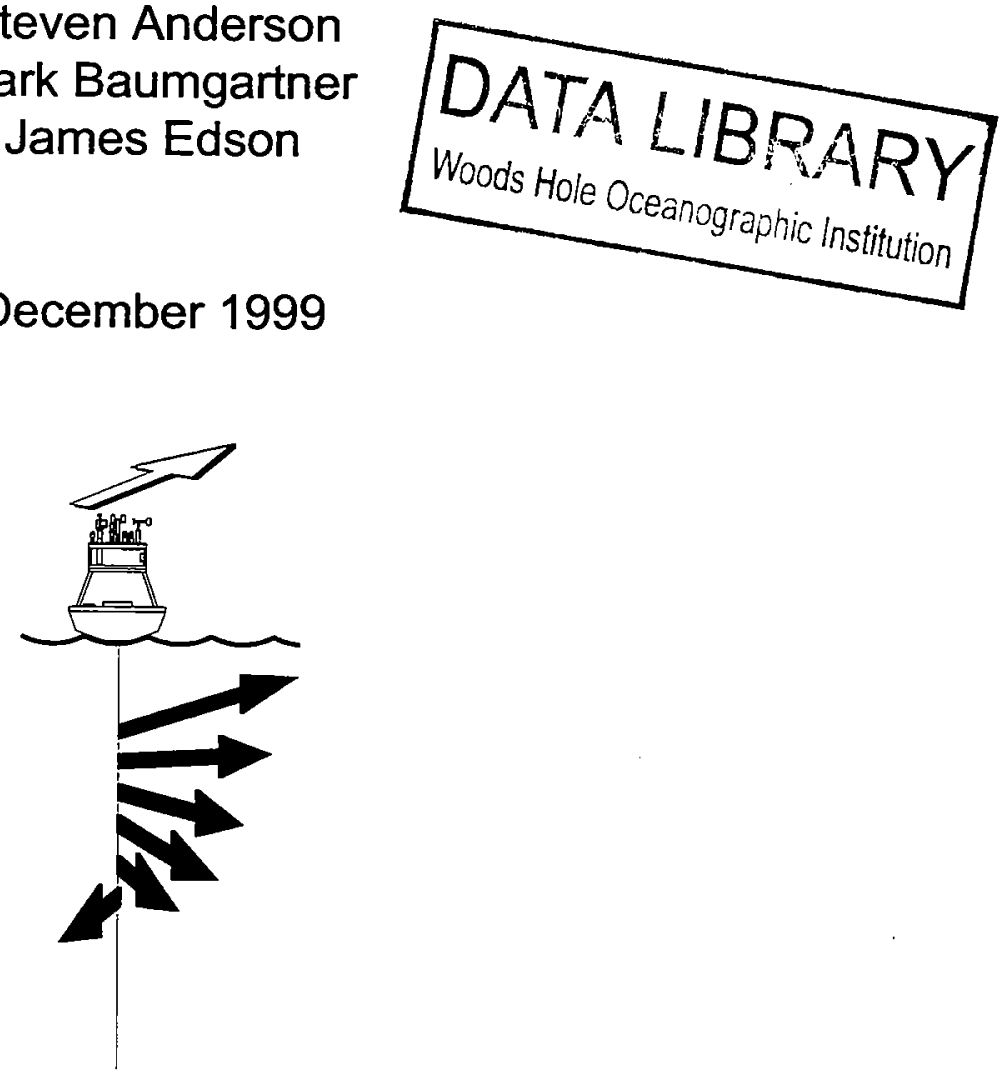

WHOI-99-15

UOP 99-03

\title{
Coastal Mixing and Optics Experiment Moored Array Data Report
}

\author{
by \\ Nancy Galbraith \\ Albert Plueddemann \\ Steven Lentz \\ Steven Anderson, \\ Mark Baumgartner \\ James Edson \\ Woods Hole Oceanographic Institution \\ Woods Hole, Massachusetts 02543 \\ December 1999
}

\section{Technical Report}

Funding was provided by the Office of Naval Research under Contract No. N00014-95-1-0339.

Reproduction in whole or in part is permitted for any purpose of the United States Government. This report should be cited as Woods Hole Oceanog. Inst. Tech. Rept., WHOI-99-15.

Approved for public release; distribution unlimited.

Approved for Distribution:

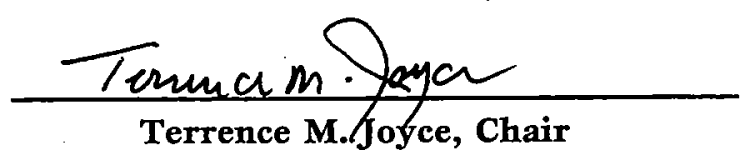

Department of Physical Oceanography 


\begin{abstract}
To investigate vertical mixing processes influencing the evolution of the stratification over continental shelves a moored array was deployed on the New England shelf from August 1996 to June 1997 as part of the Office of Naval Research's Coastal Mixing and Optics program. The array consisted of four mid-shelf sites instrumented to measure oceanic (currents, temperature, salinity, pressure, and surface gravity wave spectra) and meteorological (winds, surface heat flux, precipitation) variables. This report presents a description of the moored array, a summary of the data processing, and statistics and time-series plots summarizing the data. A report on the mooring recovery cruise and a summary of shipboard CTD surveys taken during the mooring deployment are also included.
\end{abstract}




\section{Table of Contents}

Page No.

Abstract
Table of Contents
List of Figures
List of Tables.

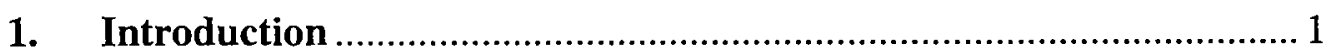

2. The Moored Array and Instrumentation........................................... 4

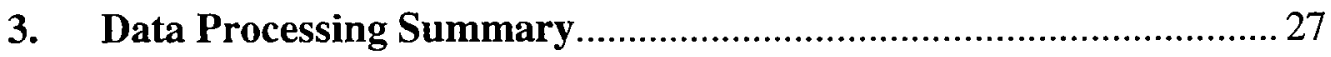

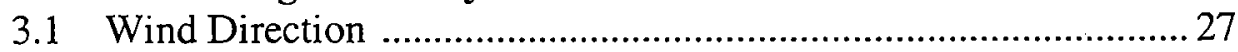

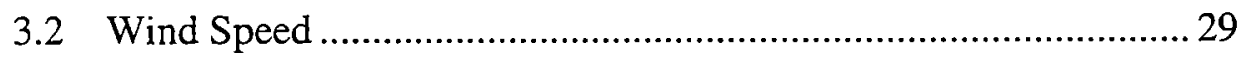

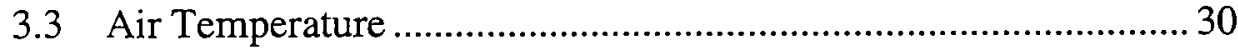

3.4 Barometric Pressure ................................................................... 31

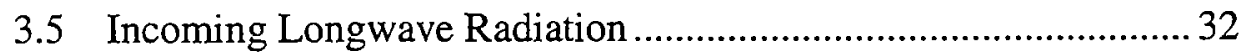

3.6 Relative Humidity ................................................................... 32

3.7 Sea Surface Temperature ……………………….......................... 33

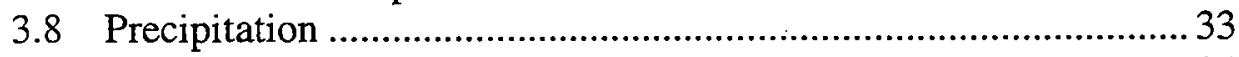

3.9 Incoming Shortwave Radiation ..................................................... 34

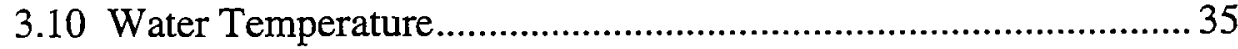

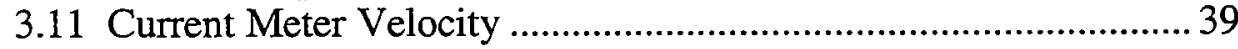

3.12 Conductivity and Salinity ............................................................... 43

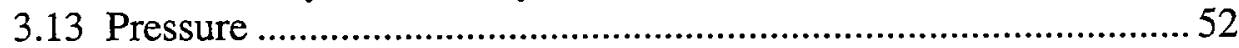

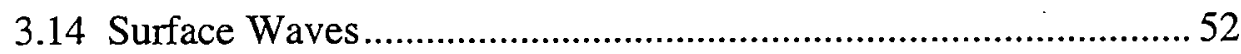

3.15 ADCP Velocity ......................................................................... 59

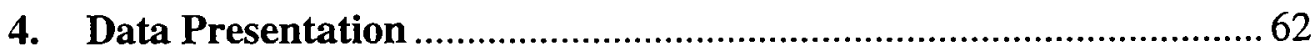

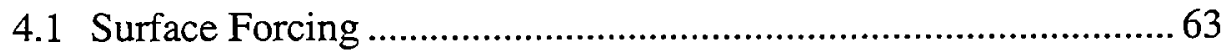

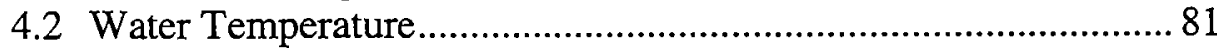

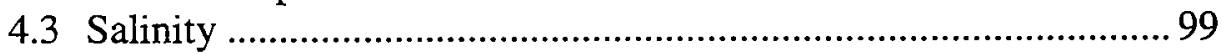

4.4 Bottom Pressure ………………............................................... 112

4.5 Water Velocity ..................................................................... 118

5. Mooring Recovery Cruise Report....................................................... 141

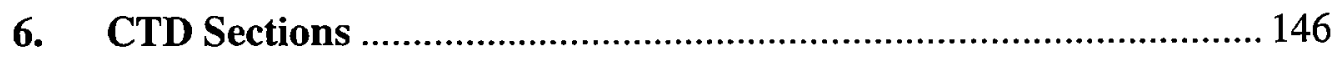

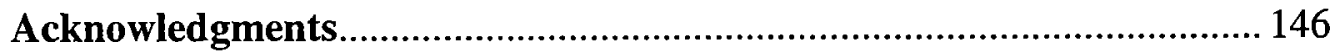

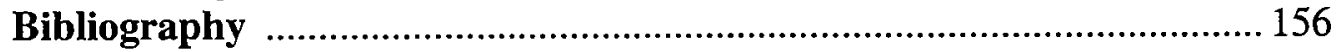




\section{List of Figures}

Page No.

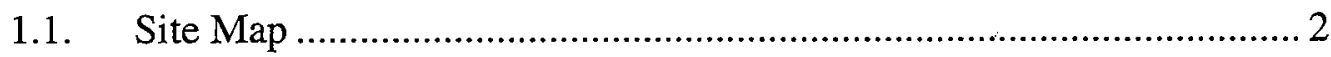

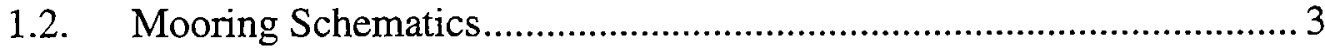

2.1-2.2 Central site plans ....................................................................... 5-6

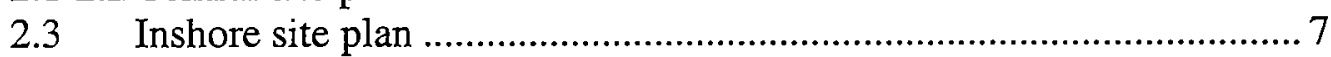

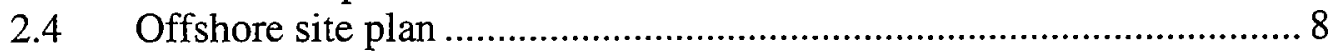

$2.5 \quad$ Alongshore site plan..................................................................

2.6-2.9 Mooring Diagrams, Central Site Moorings......................... 16-19

2.10-2.11 Mooring Diagrams, Inshore Site Moorings.........................20-21

2.12-2.13 Mooring Diagrams, Offshore Site Moorings .......................22-23

2.14-2.15 Mooring Diagrams, Alongshore Site Moorings..................24-25

2.16 Mooring Diagram, Guard Buoy ........................................................ 26

4.1.1 Surface Forcing Data Return, Central Site .........................................64 64

4.1.2-4.1.3 Meteorology time series, Central Site .................................67-68

4.1.4-4.1.5 Air-Sea Flux time series, Central Site .................................69-70

4.1.6-4.1.7 Surface Waves time series, Central Site...............................71-72

4.1.8-4.1.9 Meteorology time series, Inshore Site................................73-74

4.1.10-4.1.11 Meteorology time series, Offshore Site...............................75-76

4.1.12-4.1.13 Meteorology time series, Alongshore Site ......................... 77-78

4.1.14 Autospectra of meteorological parameters at Central Site................. 79

4.1.15 Autospectra of air-sea flux parameters at Central Site...................... 80

4.2.1-4.1.4 Water Temperature Data Return ........................................82-85

4.2.5-4.2.8 Temperature time series, Central Site ................................. 88-91

4.2.9-4.2.10 Temperature time series, Inshore Site ................................92-93

4.2.11-4.2.12 Temperature time series, Offshore Site..............................94-95

4.2.13-4.2.14 Temperature time series, Alongshore Site .........................96-97

4.2.15 Autospectra of temperatures at Central Site.................................... 98

4.3.1-4.3.2 Salinity Data Return .....................................................100-101

4.3.3-4.3.4 Salinity time series, Central Site ....................................103-104

4.3.5-4.3.6 Salinity time series, Inshore Site ....................................105-106

4.3.7-4.3.8 Salinity time series, Offshore Site ....................................107-108

4.3.9-4.3.10 Salinity time series, Alongshore Site …..........................109-110

4.3.11 Autospectra of salinity at Central Site............................................ 111

4.4.1 Bottom Pressure Data Return ........................................................ 113

4.4.2-4.4.3 Bottom Pressure time series ..........................................115-116

4.4.4 Autospectra of Bottom Pressure ................................................... 117

4.5.1-4.5.2 Water Velocity Data Return ..........................................119-120

4.5.3-4.5.6 Water Velocity time series, Central Site .........................125-128

4.5.7.-4.5.9 Water Velocity time series, Inshore Site ........................129-131

4.5.10-4.5.12 Water Velocity time series, Offshore Site......................132-134

4.5.13-4.5.14 Water Velocity time series, Alongshore Site ..................135-136 
Page No.

4.5.15 Progressive vectors from selected current meters at Central Site ........ 137

4.5.16-4.5.18 Autospectra of Water Velocities ............................................138-140

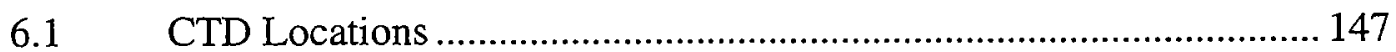

6.2-6.4 Cross-shelf CTD Sections, deployment cruise.............................148-150

6.5 Cross-shelf CTD Section, Ledwell cruise ............................................. 151

6.6. Cross-shelf CTD Section, Pickart cruise ……...................................... 152

6.7-6.9 Cross-shelf CTD Sections, recovery cruise ….............................153-155 


\section{List of Tables}

\section{Page No.}

2.1. Mooring Deployments and Recoveries ........................................ 10

2.2-2.6 Instrumentation Summaries..................................................... 11-15

3.1.1 Offsets between wind direction measurements ............................... 27

3.1.2 Wind direction sources by date ...................................................... 28

3.1.3 VOS, RUC, and AWR comparison ............................................... 29

3.2.1 Wind direction data sources .......................................................... 30

3.3.1 Air Temperature comparison ........................................................ 30

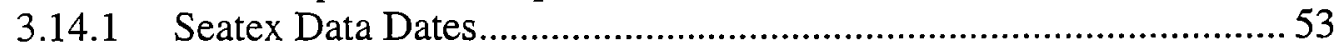

3.14.2 Recorded Wave Parameters .....................................................54-55

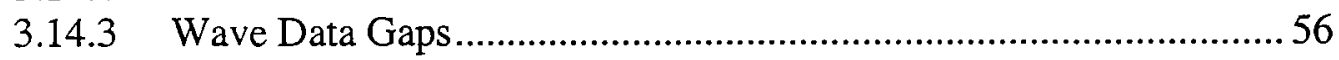

3.14.4 Seatex compass correction evaluation...............................................5 57

3.14.5 Comparison of Seatex and NDBC buoy data................................... 59

3.14.6 Non-directional wave parameter sources .......................................... 59

4.1.1 Surface Forcing Statistics...............................................................6

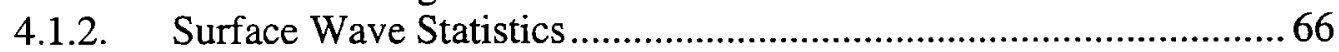

4.2.1. Temperature Statistics ........................................................... 86-87

4.3.1. Salinity Statistics ................................................................. 102

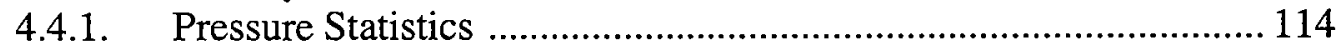

4.5.1-4.5.2 VMCM Water Velocity Statistics ...................................121-122

4.5.3-4.5.4 ADCP Water Velocity Statistics .......................................123-124 


\section{Introduction}

A moored array was deployed on the New England shelf from August 1996 to June 1997 as part of the Office of Naval Research's Coastal Mixing and Optics program. The primary objective of this component of the program is to identify and understand the dominant vertical mixing processes influencing the evolution of stratification on continental shelves. The moored array consisted of four sites located in the middle of the New England continental shelf, about $100 \mathrm{~km}$ south of Cape Cod, Massachusetts (Figure 1.1).

This site was chosen for several reasons. There is a large seasonal variation in both stratification and atmospheric forcing (Beardsley and Boicourt, 1981). In summer, winds are weak, surface heating is strong, and the water column is strongly stratified. In winter, winds are strong, there is often strong cooling at the surface, and the water column is typically unstratified. The shelf at this site is wide, the isobaths at mid shelf are fairly straight, and the bottom is relatively flat and featureless. These factors should simplify interpretation of the observations, by reducing the likelihood of complications associated with complex bathymetry.

Previous studies in this region provided a basis for planning and a broader temporal context to the observations from this study. The mid shelf location was chosen as roughly halfway between the the complex bathymetry onshore and the shelfbreak front offshore. The shelfbreak front is a narrow region of sharp temperature and salinity contrasts separating the fresher, cooler shelf water from the warmer, saltier slope water.

The moored array was deployed from August 1996 to June 1997 to capture the breakdown of the stratification in fall and the redevelopment of the stratification in spring. The moored array consisted of a heavily instrumented Central site on the $70-\mathrm{m}$ isobath and three more lightly instrumented surrounding sites (Figures 1.1 and 1.2). The Inshore site is about $11 \mathrm{~km}$ onshore of the Central site in $64 \mathrm{~m}$ of water, the Offshore site is about $12.5 \mathrm{~km}$ offshore of the Central site in $86 \mathrm{~m}$ of water, and the Alongshore site is $14.5 \mathrm{~km}$ along-isobath toward the east from the Central site. The separations between sites were chosen so the array would be coherent but the sites would be far enough apart to resolve subtidal temperature and salinity gradients based on historical data.

Temperature, conductivity, and current sensors spanning the water column were deployed on surface/subsurface mooring pairs at each site. The Central site discus buoy also supported a redundant suite of meteorological sensors to estimate wind stress, surface heat flux, and freshwater flux. This included sensors to measure wind speed and direction, air temperature, near-surface water temperature, relative humidity, incoming short and longwave radiation, atmospheric pressure, and precipitation. A sonic anemometer and motion package were also mounted on the buoy to make direct covariance estimates of stress (Martin, 1998). A Seatex Wavescan wave buoy was deployed at the Central site to measure surface gravity wave spectra. An upward-looking fanbeam acoustic Doppler current profiler (ADCP) was deployed to monitor the presence of Langmuir circulation. Bottom pressure gauges were deployed on the anchors of the three surrounding sites to estimate pressure gradients. Wind, air temperature, relative humidity, and atmospheric pressure sensors were also deployed on the surface buoys at each of the surrounding sites. 


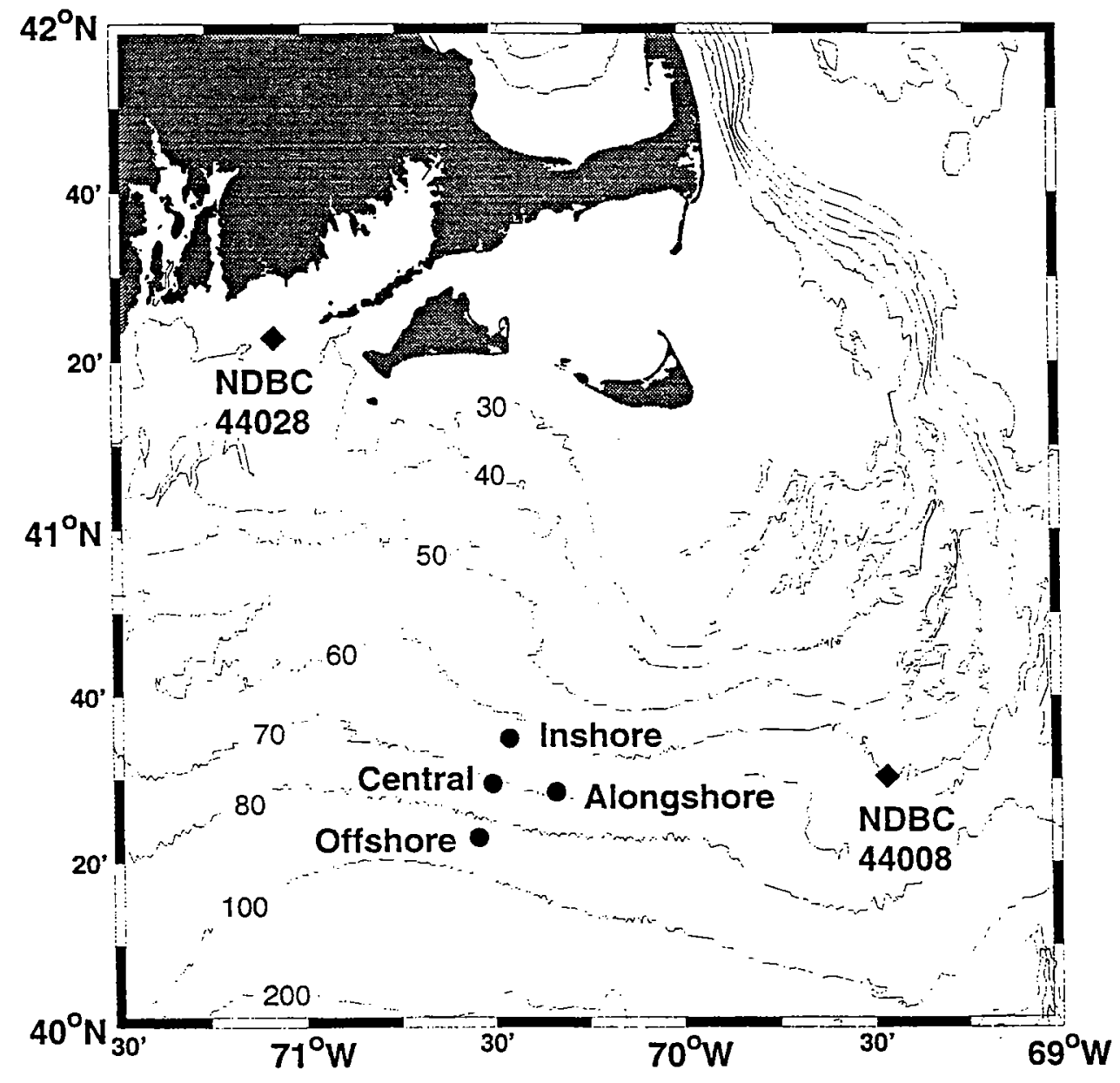

Figure 1.1. Site Map 


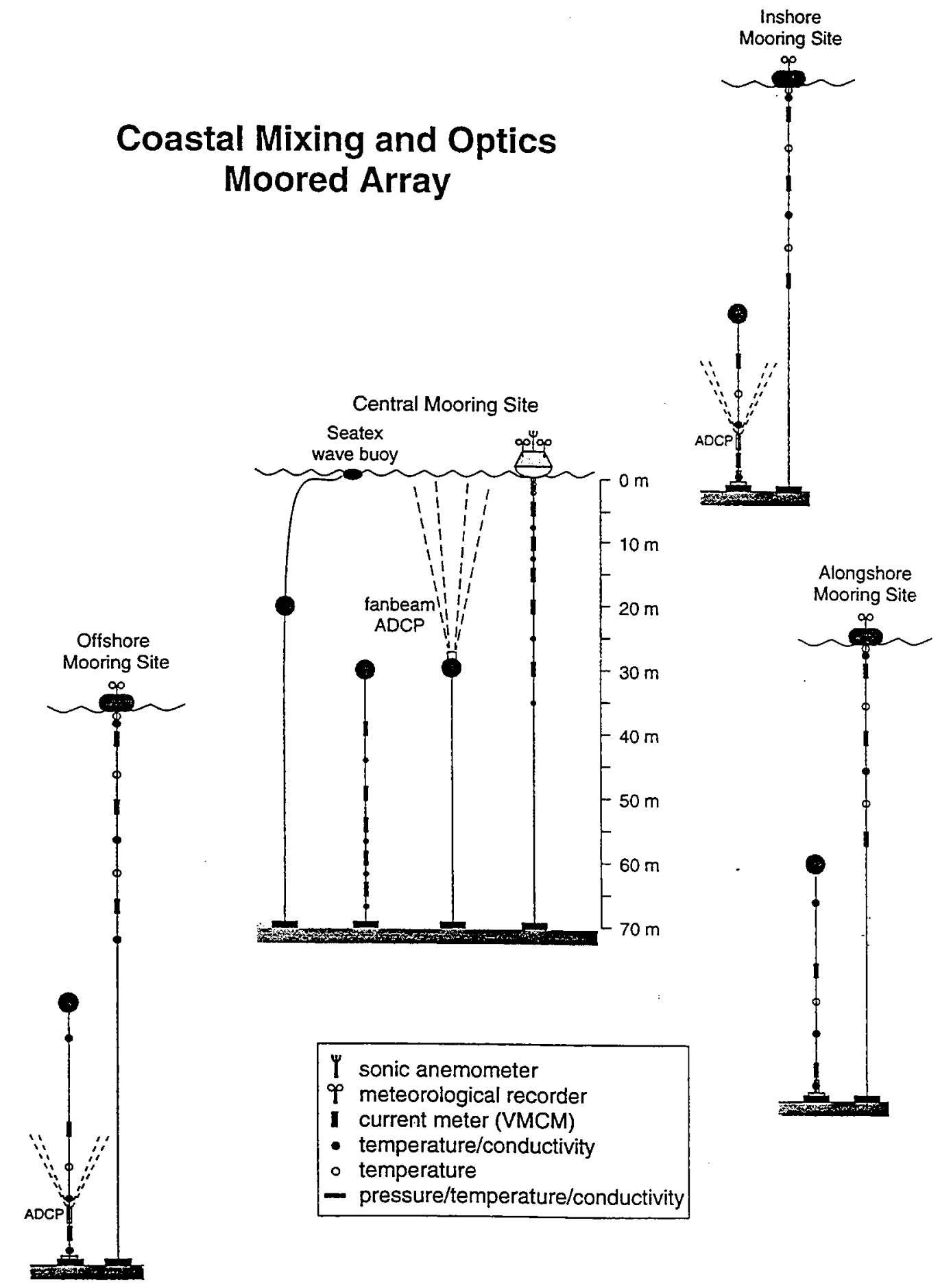

Figure 1.2. Mooring Schematics 


\section{The Moored Array and Instrumentation}

To avoid losses due to the heavy shipping and fishing activity in this region, subsurface moorings and tripods were surrounded by the surface instrumented mooring and two additional guard buoys within a few hundred meters or less (Figures 2.1-2.5.). This strategy was effective as no moorings were lost to shipping or fishing. At the Central site, bottom tripods and physical/bio-optical moorings were also deployed by other investigators. Both the tripods and the bio-optical moorings were recovered and redeployed every 3 months to clean sensors and download data. Consequently the mooring and tripod locations at the Central site changed over the period of the study. The relative locations of the various moorings and bottom tripods at different times are shown in Figures 2.1-2.2.

The locations, deployment and recovery times for each element of the moored array are listed in Table 2.1. Most of the moorings were deployed July 30-August 3, 1996 and recovered June 10-16, 1997, with the following exceptions. A toroid was deployed at the Central site from July 31 to August 3 to compare the wind measurements from the discus and toroid buoys. It was then redeployed at the Alongshore site. The Fan Beam mooring was restricted to a sixmonth deployment because of both memory and power limitations. It was deployed September 27, recovered April 9, and redeployed April 17. The acoustic release on the Inshore surface mooring inexplicably fired on September 18. The mooring was recovered and reset on September 26. The acoustic release on the Alongshore surface mooring slipped in its bracket and released on October 9. It was recovered October 16 and redeployed November 2, 1996. The Seatex mooring failed twice. The first failure occurred September 1 during the passage of hurricane Edouard. The failure occurred at the connection between the mooring chain and the buoy. The buoy was recovered September 4 and redeployed September 26. The Seatex buoy failed again on January 24 , this time due to parting of the buoyant surface tether. It was recovered February 6 and redeployed April 17. A guard buoy with a VOS wind sensor was deployed at the Central site April 8 to provide additional wind measurements because of the failure of the VAWR wind sensors.

The depths (or heights), serial numbers, and sample rates for each sensor at each site are listed in Tables 2.2-2.6. Detailed mooring diagrams indicating the mooring hardware and the locations of each of the sensors on the moorings are presented in Figures 2.6 through 2.16. 
CMO central mooring site

July 30 - September 27, 1996

Discus buoy at $40^{\circ} 29.53^{\prime} \mathrm{N} 70^{\circ} 30.17^{\prime} \mathrm{W}$

water depth $\sim 70 \mathrm{~m}$

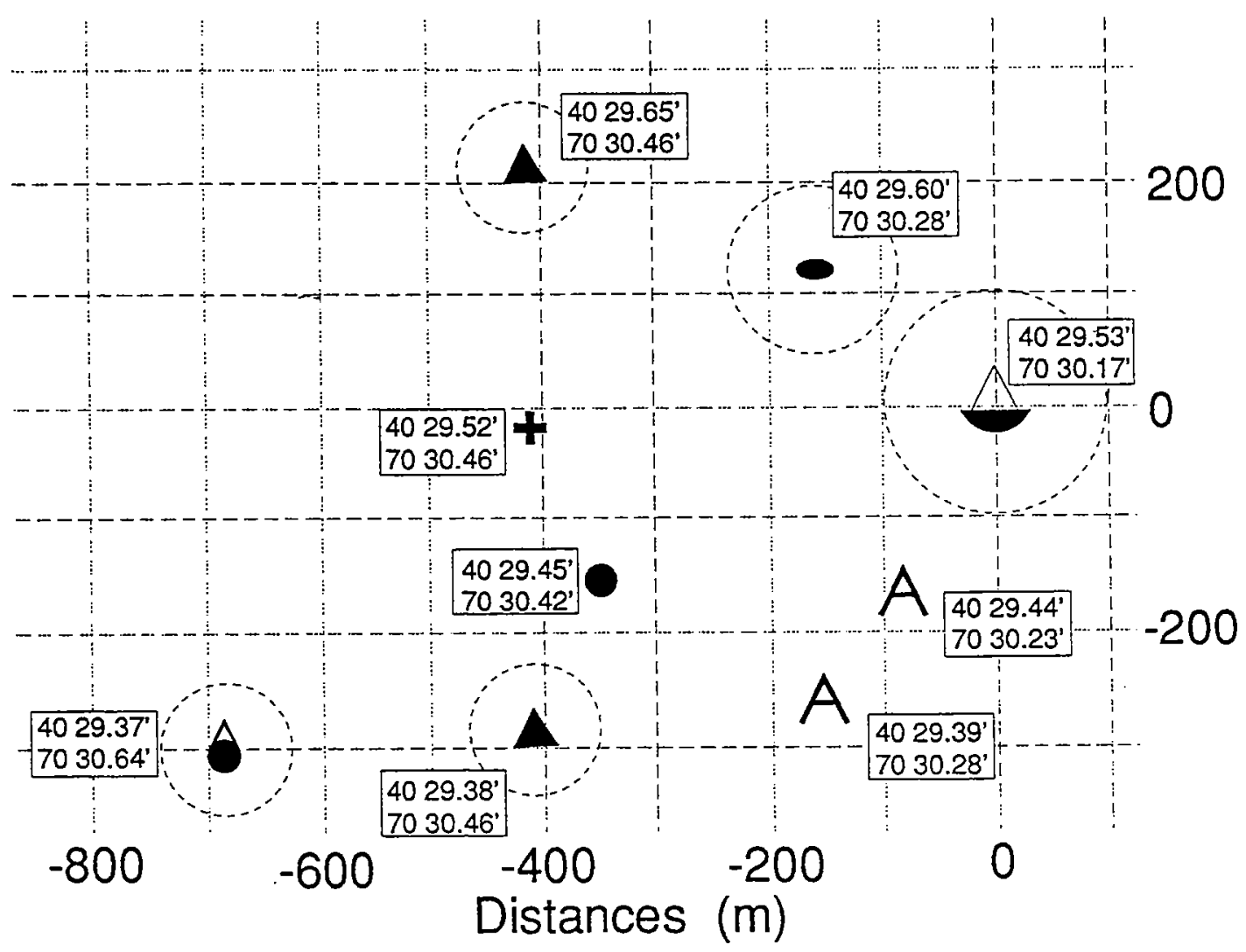

$\triangle$ surface discus buoy

$\triangle$ Oregon State University (OSU) surface mooring

+ OSU subsurface mooring w/surface spar

A guard buoy

- subsurface mooring

- Seatex Wavescan wave buoy

A bottom tripods

Figure 2.1. Central Site Plan, through September 1996. 
CMO central mooring site

September 27, 1996 - July 12, 1997

Discus buoy at $40^{\circ} 29.53^{\prime} \mathrm{N} 70^{\circ} 30.17^{\prime} \mathrm{W}$

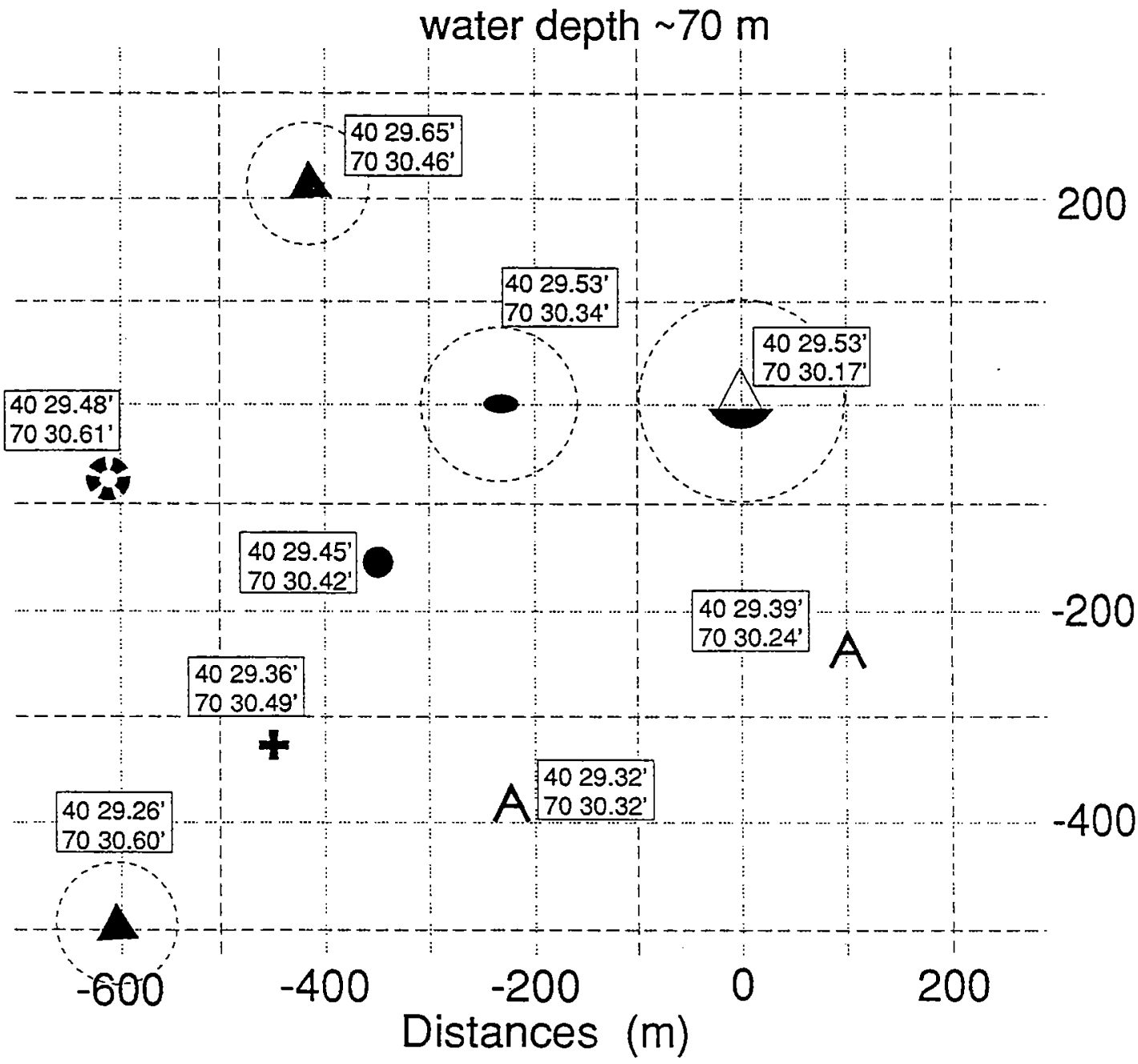

$\triangle$ surface discus buoy

+ UC Santa Barbara subsurface mooring

- fanbeam ADCP

A guard buoy

- subsurface mooring

- Seatex Wavescan wave buoy

A bottom tripods

Figure 2.2. Central Site Plan through July 1997 


\section{$\mathrm{CMO}$ inshore mooring site}

water depth $\sim 64 \mathrm{~m}$

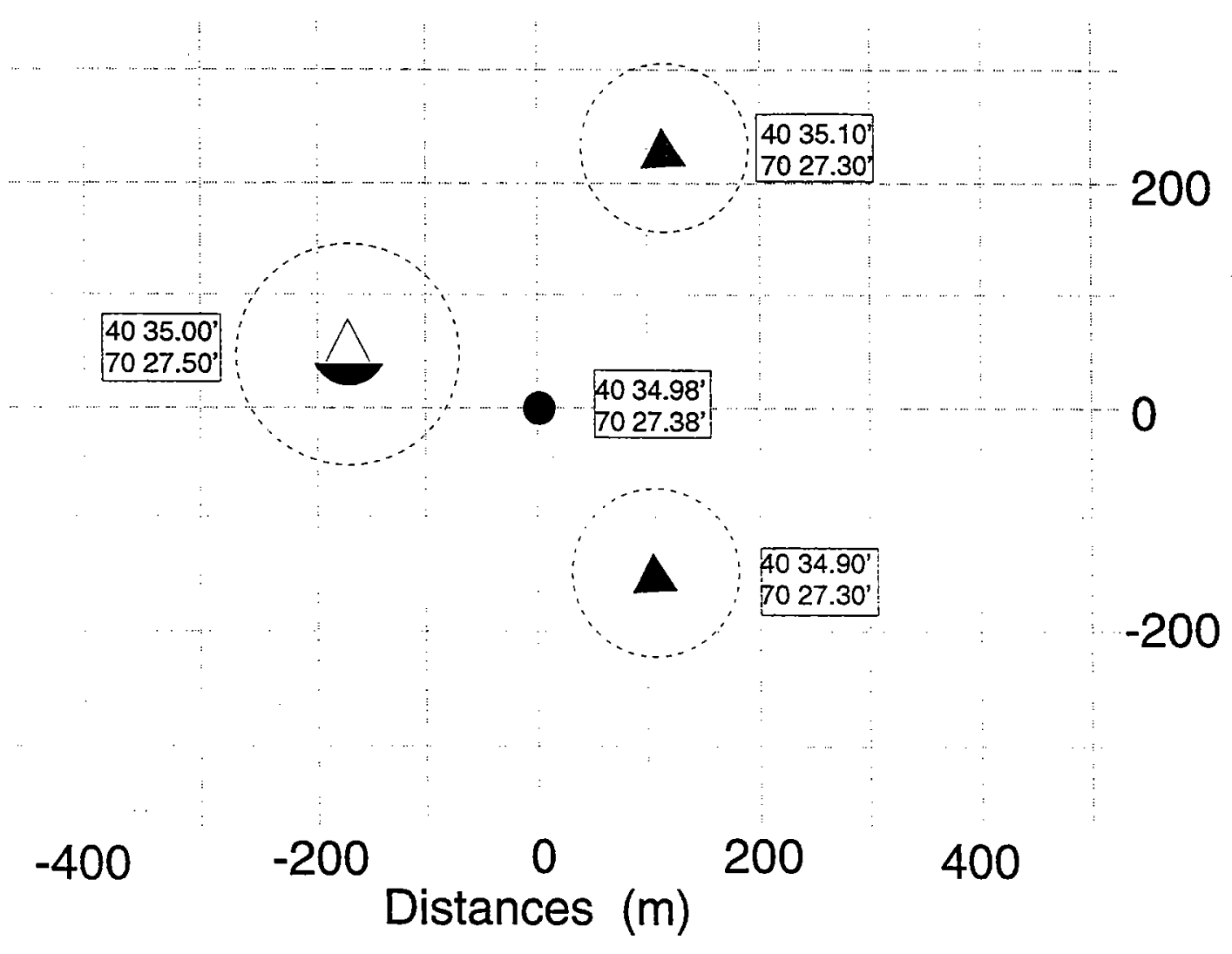

$\Delta$ surface toroid buoy

A guard buoy

- subsurface mooring

Figure 2.3. Inshore Site Plan 
$\mathrm{CMO}$ offshore mooring site water depth $\sim 86 \mathrm{~m}$

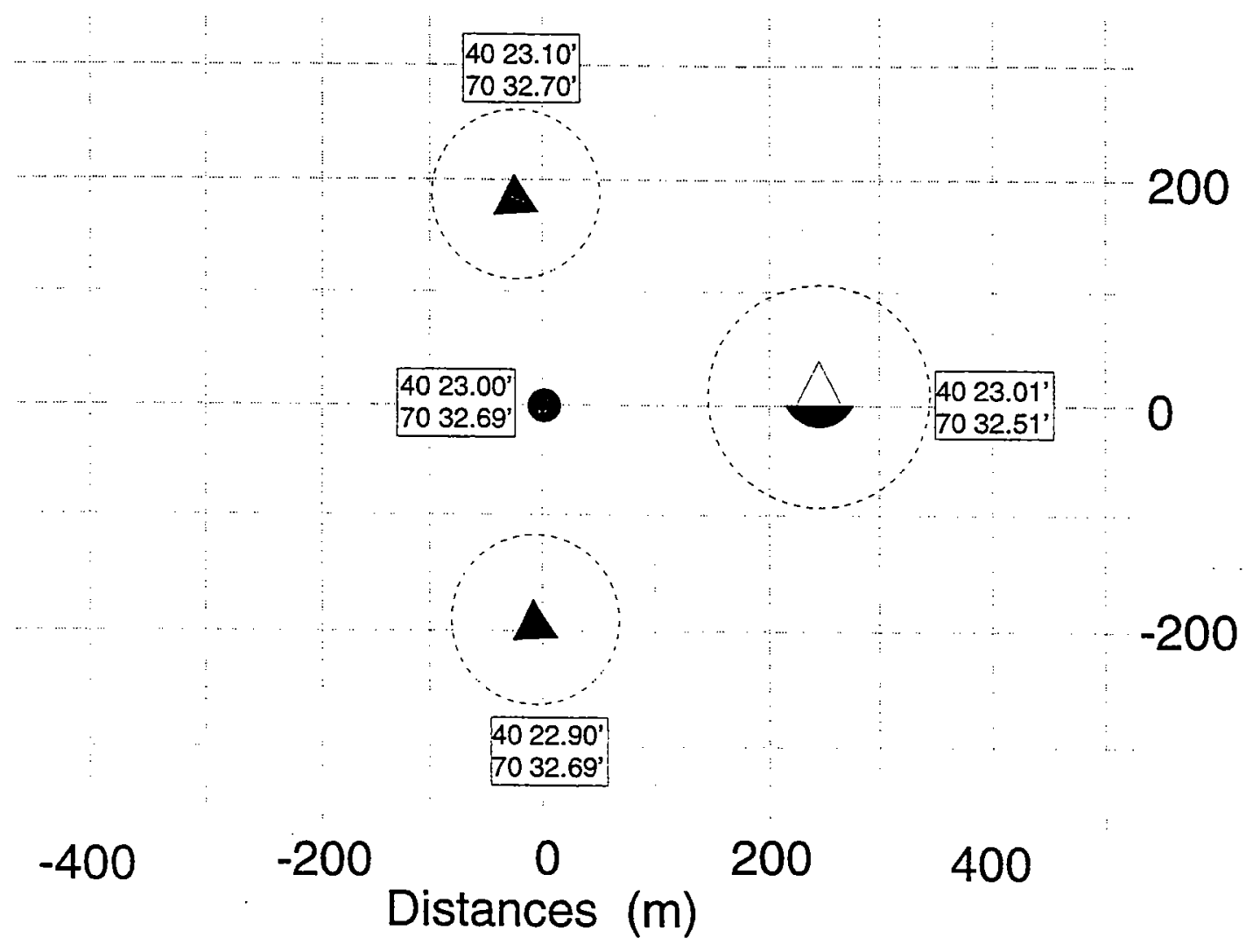

$\triangle$ surface toroid buoy

A guard buoy

- subsurface mooring

Figure 2.4. Offshore Site Plan 


\section{$\mathrm{CMO}$ alongshore mooring site water depth $\sim 70 \mathrm{~m}$}

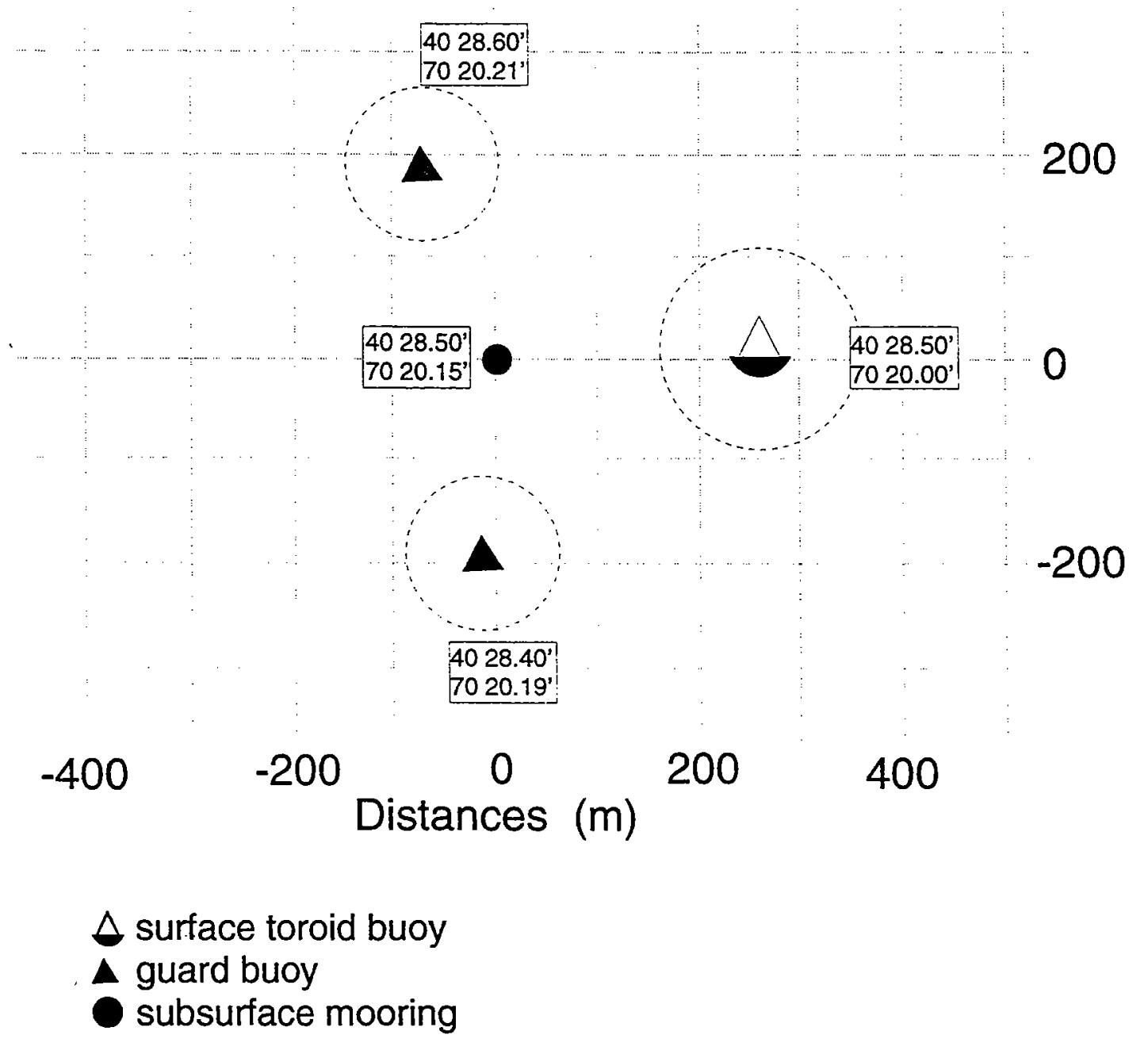

Figure 2.5. Alongshore Site Plan 


\section{Central}

\begin{tabular}{|c|c|c|c|c|c|c|}
\hline Number & Buoy & Set & Recover & Depth & Lat & Long \\
\hline 1000 & Discus & $96-07-30 \quad 15: 14$ & $97-06-13 \quad 13: 59$ & 65.0 & 4029.5 & 7030.2 \\
\hline 1001 & Subsurface & $96-07-30 \quad 18: 32$ & $97-06-12 \quad 19: 17$ & 70.0 & 4029.5 & 7030.4 \\
\hline 1002 & Seatex & $96-07-30 \quad 21: 28$ & 96-09-04 21:00 & \multicolumn{3}{|c|}{ Offstation 96-09-01 18:30 } \\
\hline 1002 & deployment 2 & $96-09-2623: 39$ & $97-02-06 \quad 17: 00$ & \multicolumn{3}{|c|}{ Offstation 97-01-24 21:35 } \\
\hline 1002 & deployment 3 & 97-04-17 $04: 31$ & $97-06-12 \quad 21: 26$ & 71.0 & 4029.6 & 7030.3 \\
\hline 1003 & Toroid & $96-07-31 \quad 00: 16$ & $96-08-03 \quad 12: 18$ & 70.0 & 4029.4 & 7030.2 \\
\hline 1012 & FanBeam & $96-09-27 \quad 16: 46$ & 97-04-09 $14: 31$ & 70.0 & 4029.5 & 7030.6 \\
\hline 1012 & deployment 2 & $97-04-17 \quad 12: 52$ & $97-06-12 \quad 18: 24$ & 70.0 & 4029.5 & 7030.6 \\
\hline
\end{tabular}

Offshore

\begin{tabular}{|l|l|l|l|l|l|l|}
\hline Number & Buoy & Set & Recover & Depth & Lat & Long \\
\hline 1004 & Toroid & $96-07-31 \quad 13: 50$ & $97-06-16 \quad 17: 25$ & 87.0 & 4023.0 & 7032.5 \\
\hline 1005 & Subsurface & $96-07-31 \quad 18: 38$ & $97-06-16 \quad 12: 15$ & 86.0 & 4023.0 & 7032.7 \\
\hline
\end{tabular}

Inshore

\begin{tabular}{|c|c|c|c|c|c|c|}
\hline Number & Buoy & Set & Recover & Depth & Lat & Long \\
\hline 1006 & Toroid & 96-08-02 $14: 04$ & $96-09-25 \quad 20: 25$ & \multicolumn{3}{|c|}{ offstation $96-09-18 \quad 18: 50$} \\
\hline 1010 & deployment 2 & $96-09-26 \quad 15: 15$ & $97-06-12 \quad 14: 50$ & 64.0 & 4035.0 & 7027.5 \\
\hline 1007 & Subsurface & 96-08-02 $18: 25$ & $97-06-12 \quad 10: 32$ & 63.0 & 4035.0 & 7027.4 \\
\hline
\end{tabular}

\section{Alongshore}

\begin{tabular}{|c|c|c|c|c|c|c|}
\hline Number & Buoy & Set & Recover & Depth & Lat & Long \\
\hline 1008 & Toroid & $96-08-03 \quad 15: 51$ & 96-10-16 $09: 15$ & \multicolumn{3}{|c|}{ offstation 96-10-09 06:00 } \\
\hline 1008 & deployment 2 & $96-11-02 \quad 20: 37$ & $97-06-10 \quad 15: 24$ & 70.0 & 4028.5 & 7020.0 \\
\hline 1009 & Subsurface & $96-08-03 \quad 19: 39$ & $97-06-10 \quad 10: 42$ & 69.5 & 4028.5 & 7020.2 \\
\hline
\end{tabular}

Table 2.1. Mooring Deployments and Recoveries 


\begin{tabular}{|l|l|l|l|}
\hline \multicolumn{5}{|c}{ Central Discus } \\
\hline depth $(\mathbf{m})$ & type & sn & sample rate \\
\hline-3.4 & longwave radiation & $28872-704$ & $15 \mathrm{~m}$ \\
\hline-3.4 & longwave radiation & $28380-720$ & $15 \mathrm{~m}$ \\
\hline-3.4 & shortwave radiation & $25418-704$ & $15 \mathrm{~m}$ \\
\hline-3.4 & shortwave radiation & $28315-720$ & $15 \mathrm{~m}$ \\
\hline-3.3 & wind speed & 704 & $15 \mathrm{~m}$ \\
\hline-3.3 & wind speed & 720 & $15 \mathrm{~m}$ \\
\hline-3.3 & sonic anemometer & 80 & $15 \mathrm{~m}$ every $30 \mathrm{~m}$ \\
\hline-3.1 & precipitation & 001 & $3.75 \mathrm{~m}$ \\
\hline-3.1 & precipitation & 002 & $3.75 \mathrm{~m}$ \\
\hline-3.0 & wind direction & 704 & $15 \mathrm{~m}$ \\
\hline-3.0 & wind direction & 704 & $15 \mathrm{~m}$ \\
\hline-2.9 & relative humidity & 004 & $3.75 \mathrm{~m}$ \\
\hline-2.9 & relative humidity & 005 & $3.75 \mathrm{~m}$ \\
\hline-2.7 & barometric pressure & $46398-704$ & $15 \mathrm{~m}$ \\
\hline-2.7 & barometric pressure & $50252-720$ & $15 \mathrm{~m}$ \\
\hline-2.7 & relative humidity & $037-704$ & $15 \mathrm{~m}$ \\
\hline-2.7 & relative humidity & $034-720$ & $15 \mathrm{~m}$ \\
\hline-2.6 & air temperature & $5811-704$ & $15 \mathrm{~m}$ \\
\hline-2.6 & air temperature & $5812-720$ & $15 \mathrm{~m}$ \\
\hline 1.0 & sea surface temperature & $5101-720$ & $15 \mathrm{~m}$ \\
\hline 1.5 & sea surface temperature & $5115-704$ & $15 \mathrm{~m}$ \\
\hline 2.0 & seacat & 927 & $7.5 \mathrm{~m}$ \\
\hline 3.0 & tension & 43390 & $25 \mathrm{~m}$ every $12 \mathrm{~h}$ \\
\hline 4.0 & mtr & 3250 & $30 \mathrm{~m}$ \\
\hline 4.5 & vmcm & 54 & $7.5 \mathrm{~m}$ \\
\hline 7.5 & seacat & 1875 & $7.5 \mathrm{~m}$ \\
\hline 10.0 & vmcm & 001 & $7.5 \mathrm{~m}$ \\
\hline 12.5 & seacat & 1877 & $7.5 \mathrm{~m}$ \\
\hline 15.0 & vmcm & 003 & $7.5 \mathrm{~m}$ \\
\hline 20.0 & vmcm & 041 & $7.5 \mathrm{~m}$ \\
\hline 25.0 & seacat & 1879 & $7.5 \mathrm{~m}$ \\
\hline 30.0 & vmcm & 51 & $7.5 \mathrm{~m}$ \\
\hline 35.0 & seacat-p & 885 & $15 \mathrm{~m}$ \\
\hline & & & \\
\hline & & 5 & \\
\hline
\end{tabular}

Table 2.2. Instrumentation Summary, Central Discus; instrument depths, serial numbers and timing. 


\begin{tabular}{|l|l|l|l|}
\hline \multicolumn{3}{|c|}{ Central Subsurface } \\
\hline depth (m) & type & sn & sample rate \\
\hline 40.0 & vmcm & 27 & $7.5 \mathrm{~m}$ \\
\hline 45.0 & seacat & 1882 & $45 \mathrm{~s}^{*}$ \\
\hline 50.0 & vmcm & 42 & $7.5 \mathrm{~m}$ \\
\hline 55.0 & vmcm & 43 & $7.5 \mathrm{~m}$ \\
\hline 57.5 & seacat & 73 & $7.5 \mathrm{~m}$ \\
\hline 60.0 & vmcm & 50 & $7.5 \mathrm{~m}$ \\
\hline 62.5 & seacat & 72 & $7.5 \mathrm{~m}$ \\
\hline 65.0 & vmcm & 35 & $7.5 \mathrm{~m}$ \\
\hline 67.5 & seacat & 1878 & $7.5 \mathrm{~m}$ \\
\hline
\end{tabular}

*Seacat 1882 recorded at 45 seconds until 961030 , then recorded at 7.5 minutes until memory was filled.

\begin{tabular}{|l|l|l|l|}
\hline \multicolumn{5}{|c|}{ Central Toroid (Temporary) } \\
\hline depth $(\mathbf{m})$ & type & sn & sample rate \\
\hline tower & WeatherPak & 648 & $5 \mathrm{~m}$ every $15 \mathrm{~m}$ \\
\hline-3.1 & wind & 648 & $5 \mathrm{~m}$ every $15 \mathrm{~m}$ \\
\hline-2.8 & relativehumidity & 648 & $5 \mathrm{~m}$ every $15 \mathrm{~m}$ \\
\hline-2.8 & air temperature & 648 & $5 \mathrm{~m}$ every $15 \mathrm{~m}$ \\
\hline-2.8 & barometric pressure & 648 & $5 \mathrm{~m}$ every $15 \mathrm{~m}$ \\
\hline 1.0 & tpod & 3274 & $30 \mathrm{~m}$ \\
\hline 2.0 & seacat & 142 & $7.5 \mathrm{~m}$ \\
\hline 7.0 & chlam & 126 & \\
\hline
\end{tabular}

Table 2.3. Instrumentation Summary, Central Subsurface and Central Toroid; instrument depths, serial numbers and timing. 


\begin{tabular}{|l|l|l|l|}
\hline \multicolumn{4}{|c|}{ Inshore Toroid } \\
\hline depth (m) & type & sn & sample rate \\
\hline tower & WeatherPak & 714 & $5 \mathrm{~m}$ every $15 \mathrm{~m}$ \\
\hline-3.3 & wind & 714 & $5 \mathrm{~m}$ every $15 \mathrm{~m}$ \\
\hline-3.0 & relativehumidity & 714 & $5 \mathrm{~m}$ every $15 \mathrm{~m}$ \\
\hline-3.0 & air temperature & 714 & $5 \mathrm{~m}$ every $15 \mathrm{~m}$ \\
\hline-3.0 & barometric pressure & 714 & $5 \mathrm{~m}$ every $15 \mathrm{~m}$ \\
\hline 1.0 & tpod & 3830 & $30 \mathrm{~m}$ \\
\hline 2.0 & seacat & 146 & $7.5 \mathrm{~m}$ \\
\hline 4.5 & vmcm & 10 & $7.5 \mathrm{~m}$ \\
\hline 10.0 & tpod & 4493 & $30 \mathrm{~m}$ \\
\hline 15.0 & vmcm & 45 & $7.5 \mathrm{~m}$ \\
\hline 20.0 & seacat & 71 & $7.5 \mathrm{~m}$ \\
\hline 25.0 & tpod & 3301 & $30 \mathrm{~m}$ \\
\hline 30.0 & vmcm & 22 & $7.5 \mathrm{~m}$ \\
\hline
\end{tabular}

\begin{tabular}{|l|l|l|l|}
\hline Inshore Subsurface & sn & \\
\hline depth (m) & type & 28 & sample rate \\
\hline 42.0 & vmcm & 3271 & $7.5 \mathrm{~m}$ \\
\hline 47.5 & tpod & 1874 & $30 \mathrm{~m}$ \\
\hline 52.5 & seacat & 100 & $45 \mathrm{~s}^{*}$ \\
\hline 55.5 & adcp & 30 & $3 \mathrm{~m}$ \\
\hline 57.0 & vmcm & 1880 & $7.5 \mathrm{~m}$ \\
\hline 59.5 & seacat & 46 & $7.5 \mathrm{~m}$ \\
\hline 62.0 & tidegauge & $5 \mathrm{~m}$ \\
\hline
\end{tabular}

*Seacat 1874 recorded at 45 seconds until 961030 , then recorded at 7.5 minutes until memory was filled.

Table 2.4. Instrumentation Summary, Inshore Moorings; instrument depths serial numbers and timing. 


\begin{tabular}{|l|l|l|l|}
\hline \multicolumn{5}{|c|}{ Offshore Toroid } \\
\hline depth $(\mathbf{m})$ & type & sn & sample rate \\
\hline tower & WeatherPak & 713 & $5 \mathrm{~m}$ every $15 \mathrm{~m}$ \\
\hline-3.1 & wind & 713 & $5 \mathrm{~m}$ every $15 \mathrm{~m}$ \\
\hline-2.8 & relativehumidity & 713 & $5 \mathrm{~m}$ every $15 \mathrm{~m}$ \\
\hline-2.8 & air temperature & 713 & $5 \mathrm{~m}$ every $15 \mathrm{~m}$ \\
\hline-2.8 & barometric pressure & 713 & $5 \mathrm{~m}$ every $15 \mathrm{~m}$ \\
\hline 1.0 & tpod & 3291 & $30 \mathrm{~m}$ \\
\hline 2.0 & seacat & 141 & $7.5 \mathrm{~m}$ \\
\hline 4.5 & vmcm & 34 & $7.5 \mathrm{~m}$ \\
\hline 10.0 & tpod & 3763 & $30 \mathrm{~m}$ \\
\hline 15.0 & vmcm & 23 & $7.5 \mathrm{~m}$ \\
\hline 20.0 & seacat & 1873 & $7.5 \mathrm{~m}$ \\
\hline 25.0 & tpod & 3308 & $30 \mathrm{~m}$ \\
\hline 30.0 & vmcm & 17 & $7.5 \mathrm{~m}$ \\
\hline 35.0 & seacat-p & 884 & $15 \mathrm{~m}$ \\
\hline
\end{tabular}

\begin{tabular}{|l|l|l|l|}
\hline \multicolumn{5}{|c|}{ Offshore Subsurface } \\
\hline depth $(\mathbf{m})$ & type & sn & sample rate \\
\hline 50.5 & seacat & 1881 & $45 \mathrm{~s}^{*}$ \\
\hline 64.0 & vmcm & 40 & $7.5 \mathrm{~m}$ \\
\hline 69.5 & tpod & 4428 & $30 \mathrm{~m}$ \\
\hline 74.5 & seacat & 70 & $7.5 \mathrm{~m}$ \\
\hline 77.0 & adcp & 593 & $3 \mathrm{~m}$ \\
\hline 79.0 & vmcm & 002 & $7.5 \mathrm{~m}$ \\
\hline 81.5 & seacat & 1876 & $7.5 \mathrm{~m}$ \\
\hline 84.0 & tidegauge & 45 & $5 \mathrm{~m}$ \\
\hline
\end{tabular}

*Seacat 1881 recorded at 45 seconds until 961030 , then recorded at 7.5 minutes until memory was filled.

Table 2.5. Instrumentation Summary, Offshore Moorings; instrument depths, serial numbers and timing. 


\begin{tabular}{|l|l|l|l|}
\hline \multicolumn{4}{|c|}{ AlongshoreToroid } \\
\hline depth (m) & type & sn & sample rate \\
\hline tower & WeatherPak & 648 & $5 \mathrm{~m}$ every $15 \mathrm{~m}$ \\
\hline-3.1 & wind & 648 & $5 \mathrm{~m}$ every $15 \mathrm{~m}$ \\
\hline-2.8 & relativehumidity & 648 & $5 \mathrm{~m}$ every $15 \mathrm{~m}$ \\
\hline-2.8 & air temperature & 648 & $5 \mathrm{~m}$ every $15 \mathrm{~m}$ \\
\hline-2.8 & barometric pressure & 648 & $5 \mathrm{~m}$ every $15 \mathrm{~m}$ \\
\hline 1.0 & tpod & 3274 & $30 \mathrm{~m}$ \\
\hline 2.0 & seacat & 142 & $7.5 \mathrm{~m}$ \\
\hline 4.5 & vmcm & 53 & $7.5 \mathrm{~m}$ \\
\hline 10.0 & tpod & 3837 & $30 \mathrm{~m}$ \\
\hline 15.0 & vmcm & 55 & $7.5 \mathrm{~m}$ \\
\hline 20.0 & seacat & 68 & $7.5 \mathrm{~m}$ \\
\hline 25.0 & tpod & 3299 & $30 \mathrm{~m}$ \\
\hline 30.0 & vmcm & 24 & $7.5 \mathrm{~m}$ \\
\hline
\end{tabular}

\begin{tabular}{|l|l|l|l|}
\hline \multicolumn{4}{|c|}{ AlongshoreSubsurface } \\
\hline depth (m) & type & sn & sample rate \\
\hline 40.5 & seacat & 883 & $15 \mathrm{~min}$ \\
\hline 50.0 & vmcm & 12 & $7.5 \mathrm{~m}$ \\
\hline 55.5 & tpod & 3833 & $30 \mathrm{~m}$ \\
\hline 60.5 & seacat & 882 & $15 \mathrm{~min}$ \\
\hline 65.0 & vmcm & 44 & $7.5 \mathrm{~m}$ \\
\hline 67.5 & seacat & 144 & $7.5 \mathrm{~m}$ \\
\hline 70.0 & tidegauge & 49 & $5 \mathrm{~m}$ \\
\hline
\end{tabular}

Table 2.6. Instrumentation Summary, Alongshore Moorings; instrument depths, serial numbers and timing. 


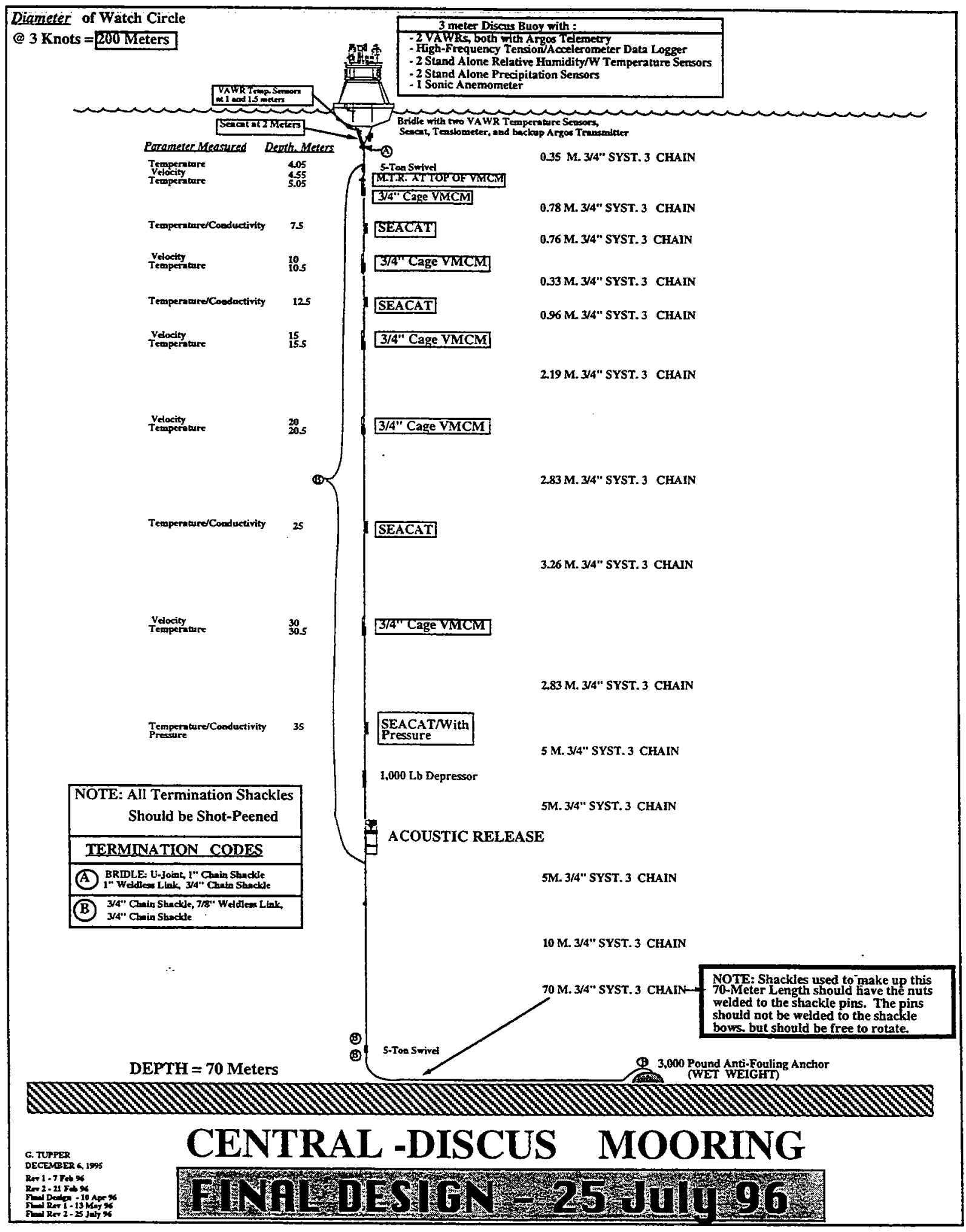

Figure 2.6. Mooring Diagram, Central Discus 


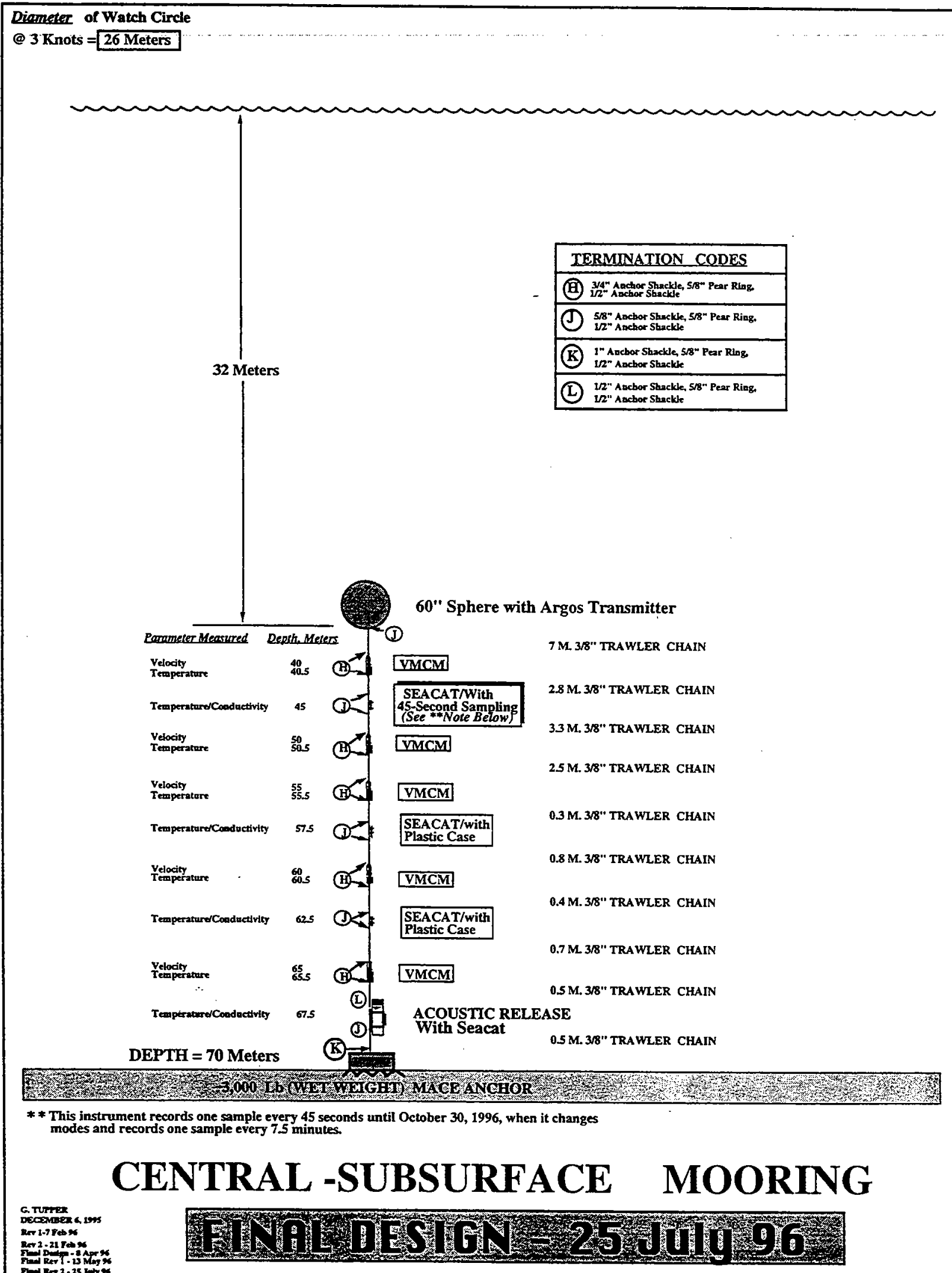

Figure 2.7. Mooring Diagram, Central Subsurface 


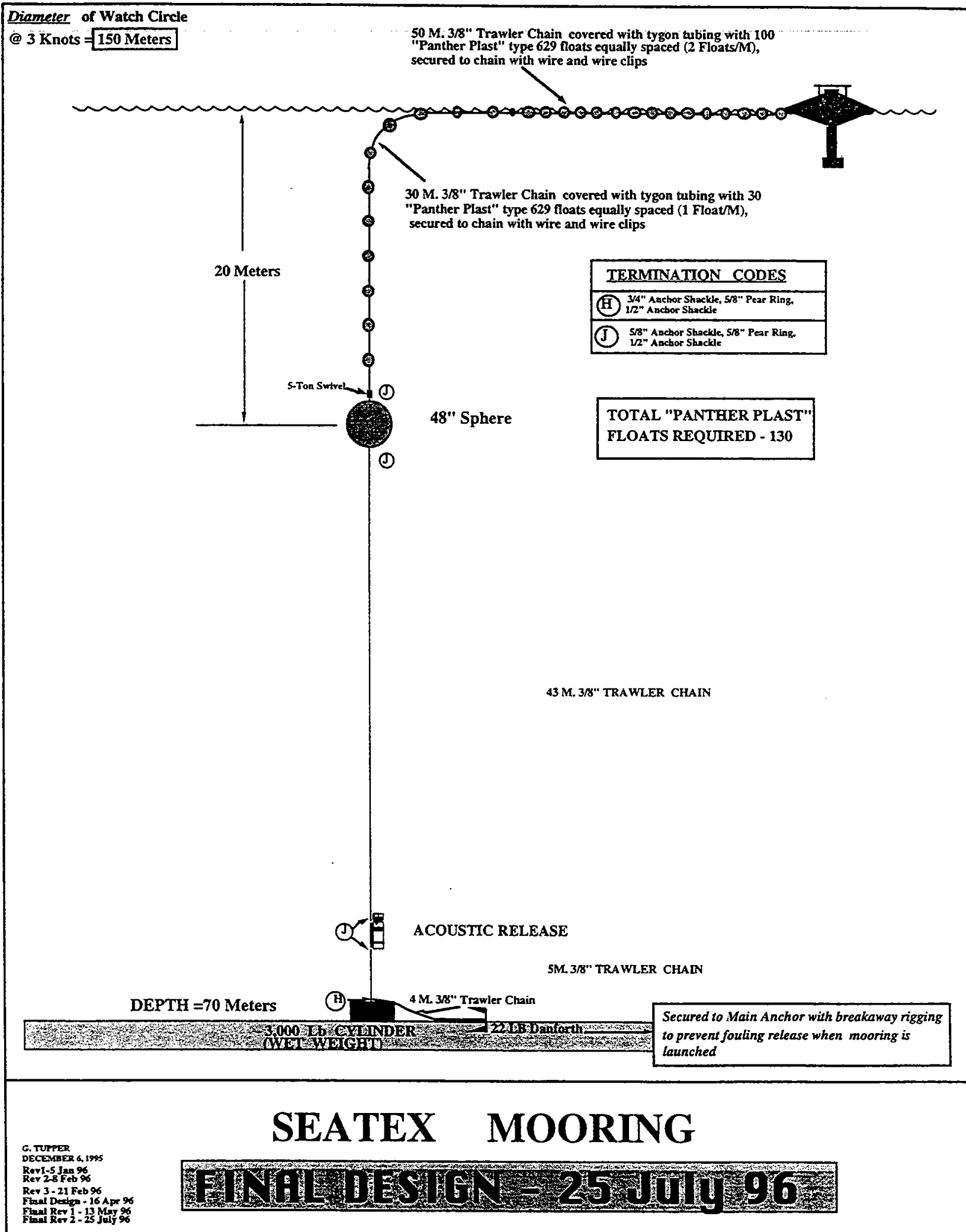

Figure 2.8. Mooring Diagram, Seatex Wavescan 
Diameter of Watch Circle

(a) 3 Knots $=16$ Meters

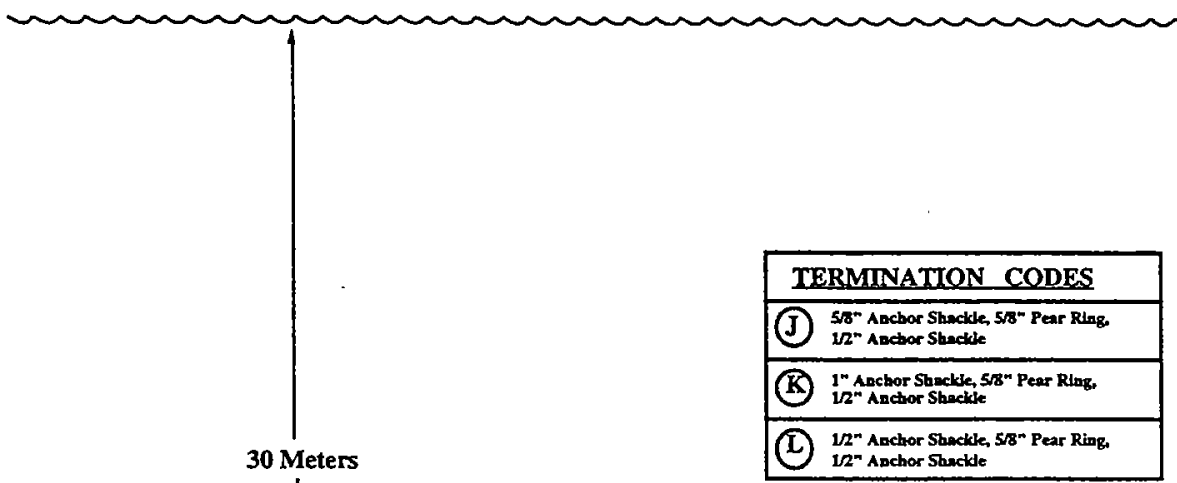

30 Meters 12" Anchor Shackde

60" Sphere with Fan Beam ADCP and Argos Transmitter

30 M. 36" PROOF COIL CHAIN

..

(2)

ACOUSTIC RELEASE

(I)

6 M. 3/8" PROOF COIL CHAIN

(2)

DEPTH $=70$ Meters

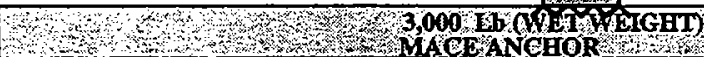

ACE ANCHOR

\section{CENTRAL -Fan Beam Mooring}

Figure 2.9. Mooring Diagram, Central Fan Beam 


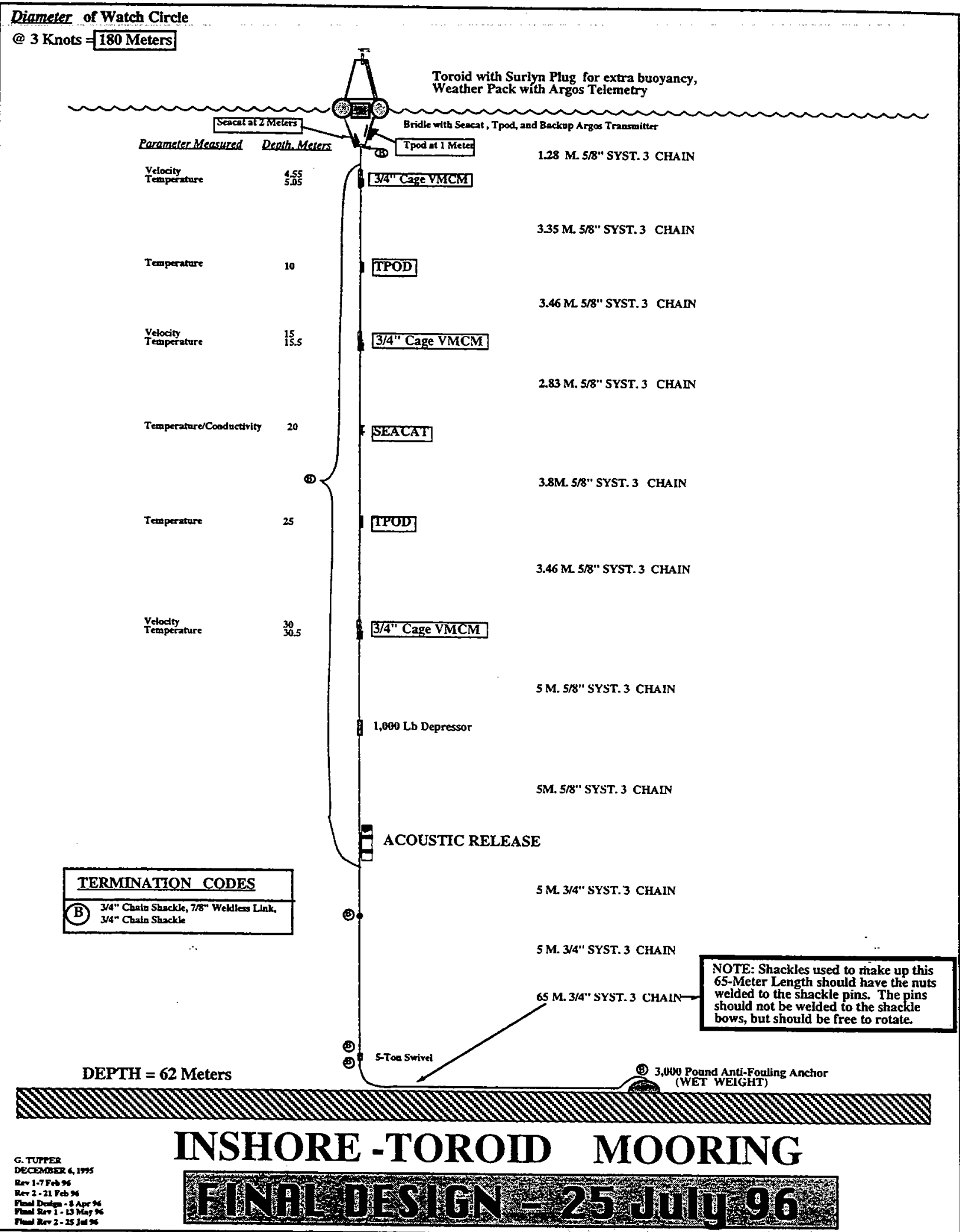

Figure 2.10. Mooring Diagram, Inshore Toroid 
Diameter of Watch Circle

$@ 3$ Knots $=12$ Meters

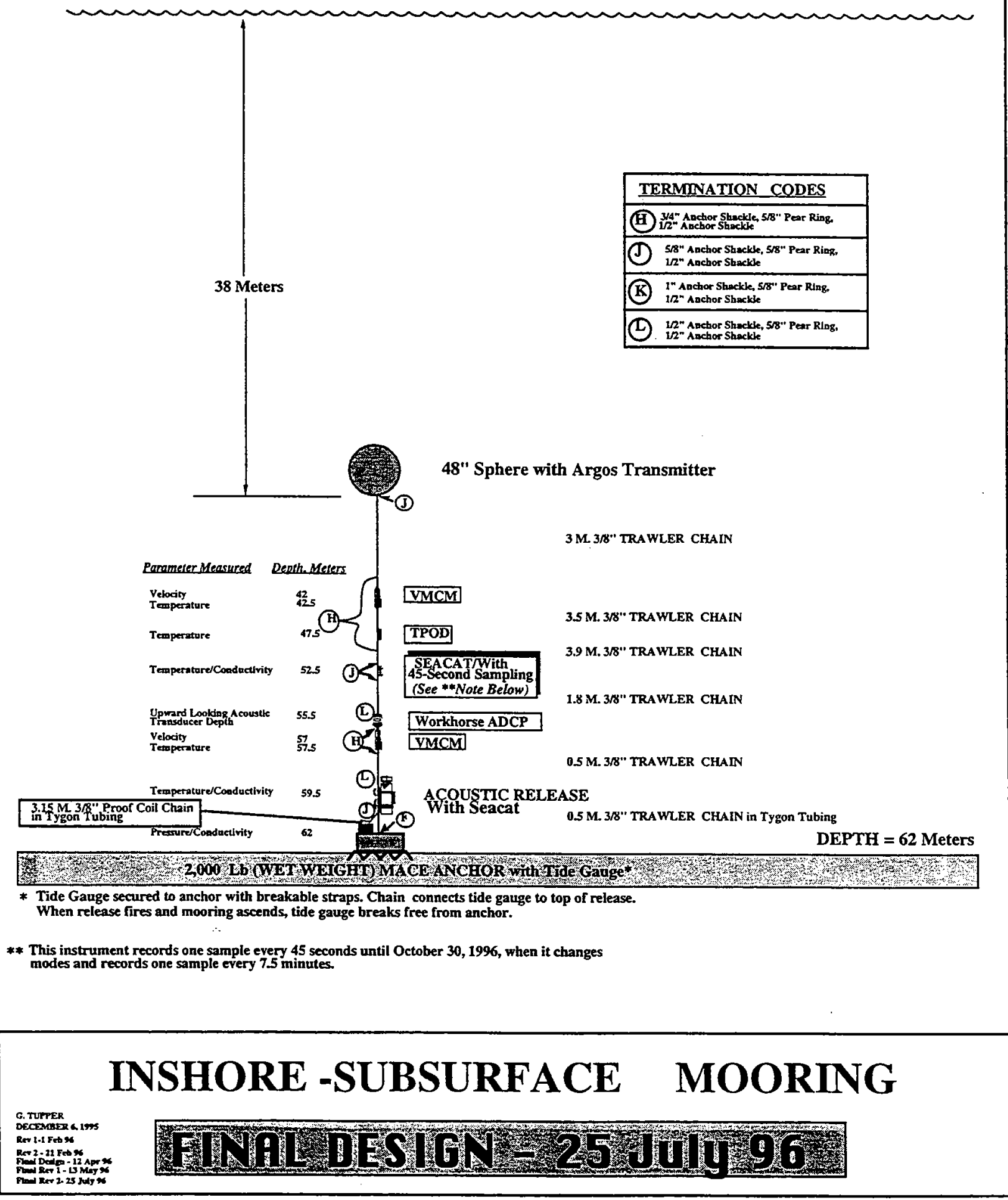

Figure 2.11. Mooring Diagram, Inshore Subsurface 


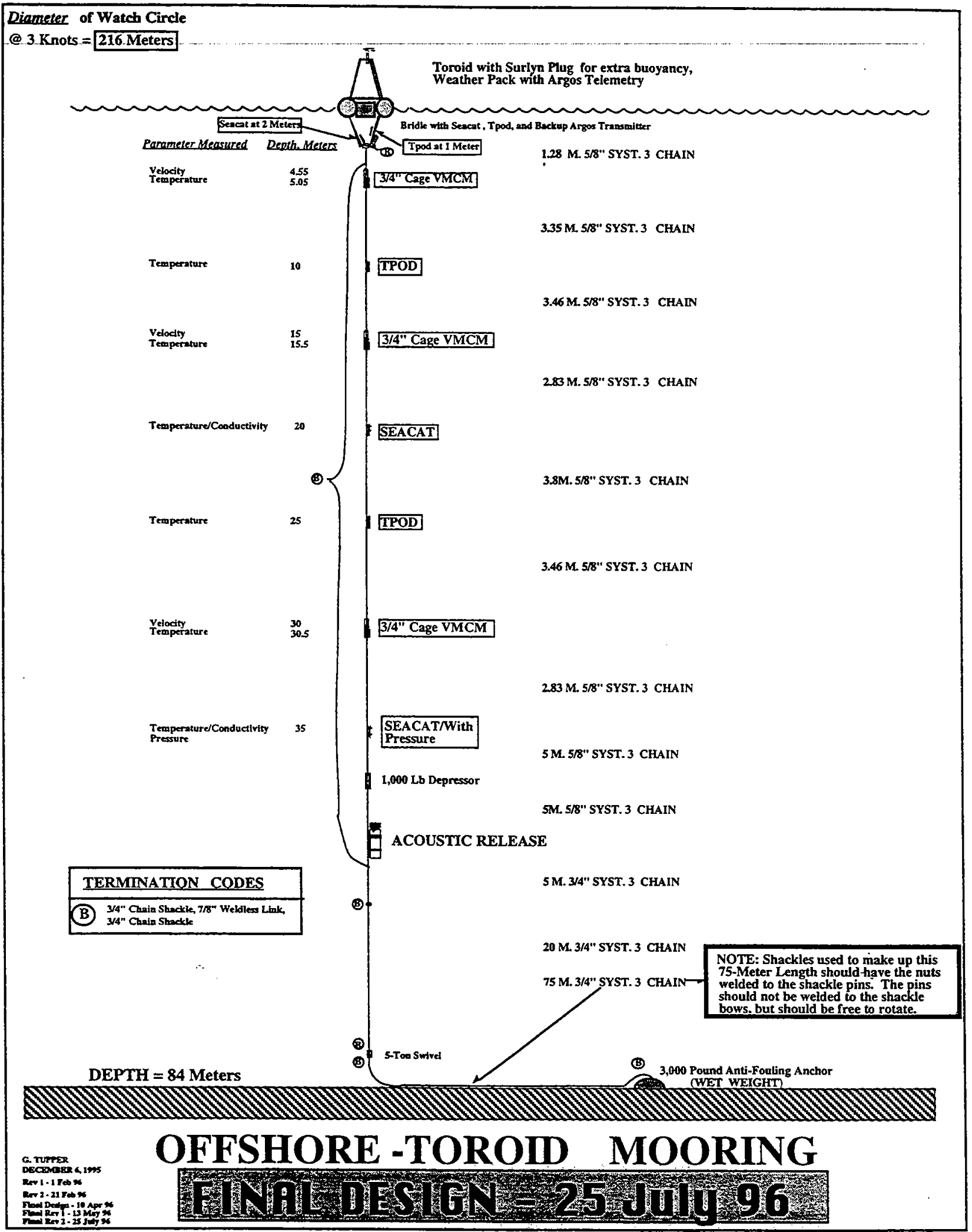

Figure 2.12. Mooring Diagram, Offshore Toroid 


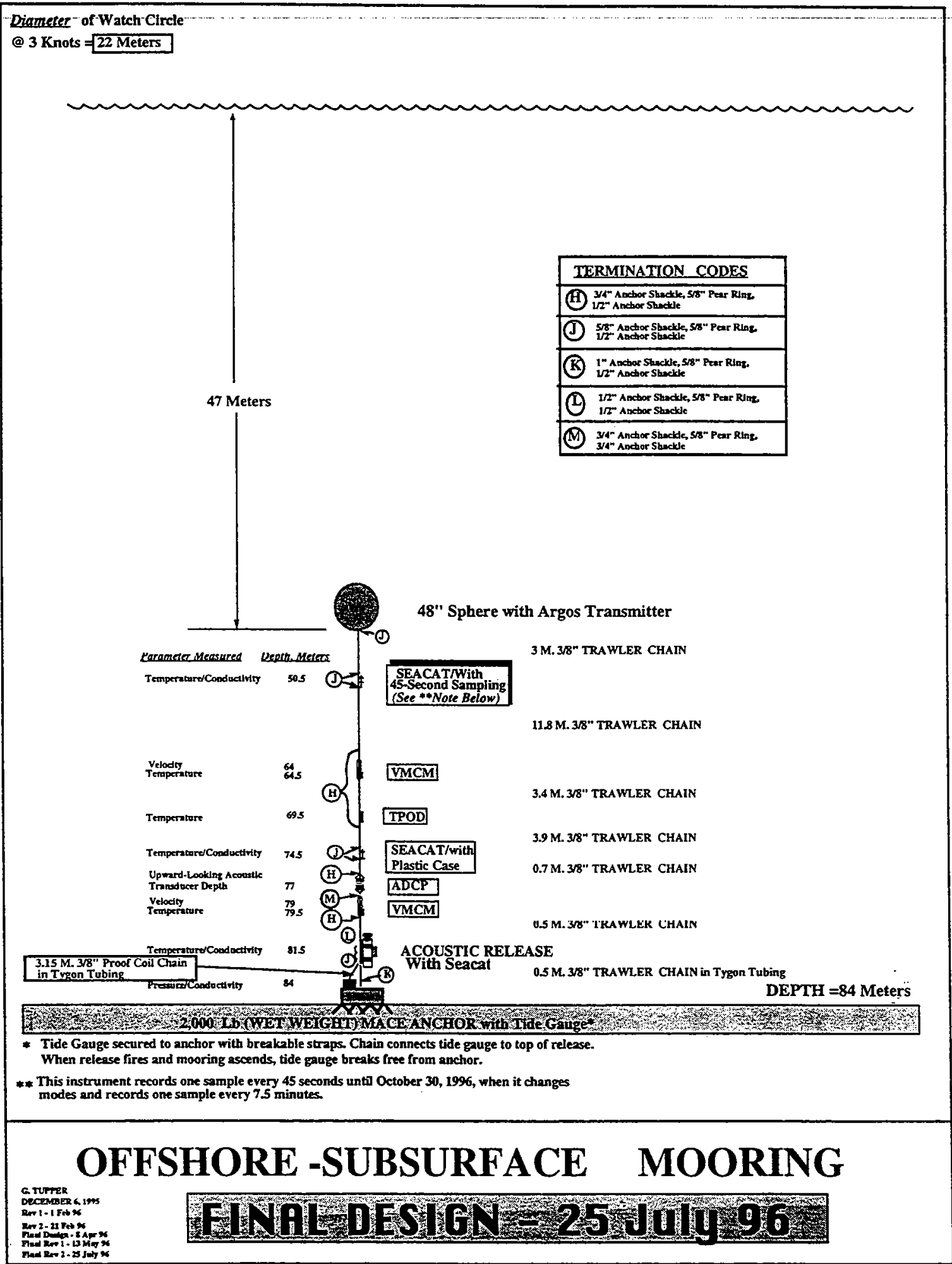

Figure 2.13. Mooring Diagram, Offshore Subsurface 


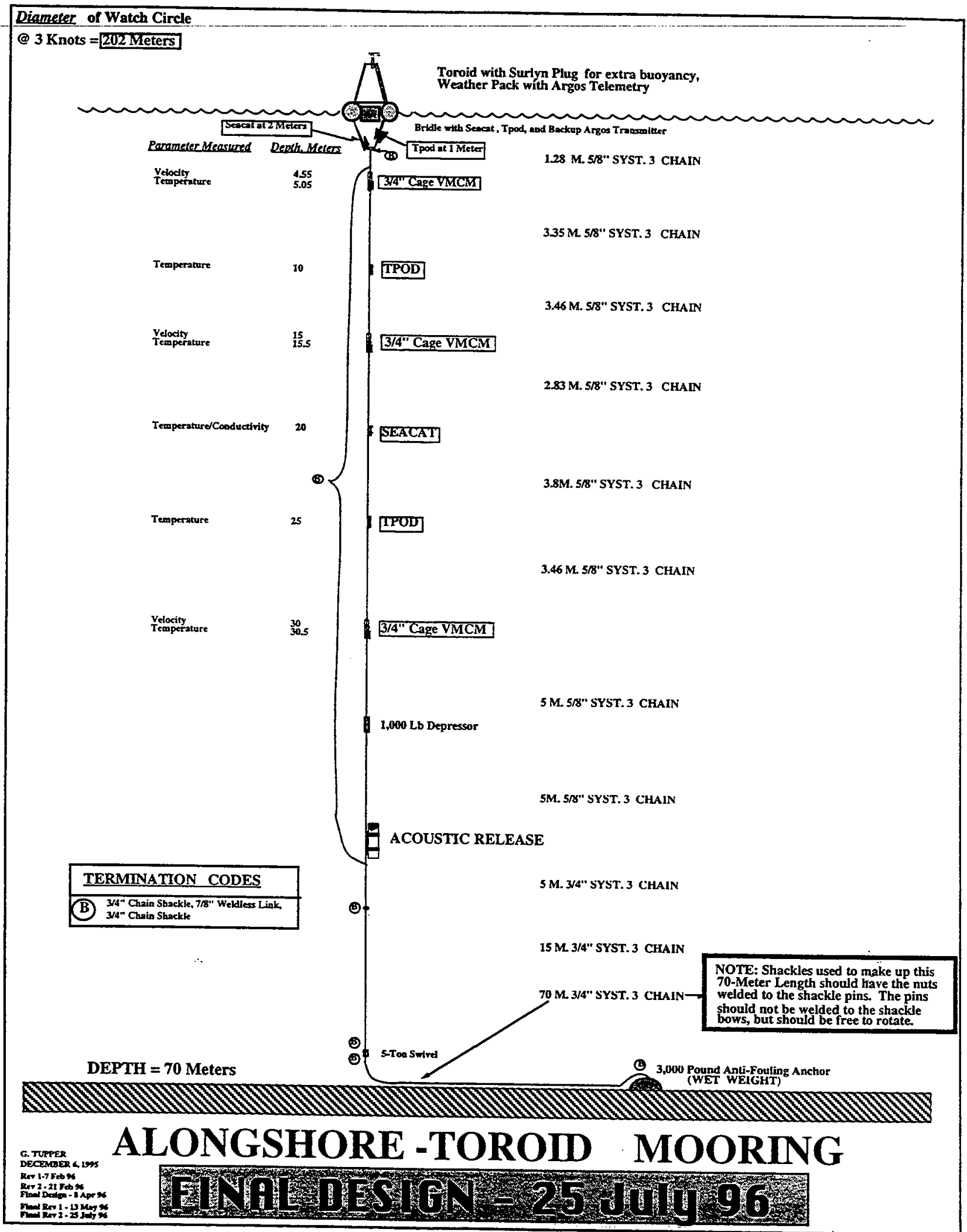

Figure 2.14. Mooring Diagram, Alongshore Toroid 
Diameter of Watch Circle

@-3-Knots $=19 \cdot$ Meters

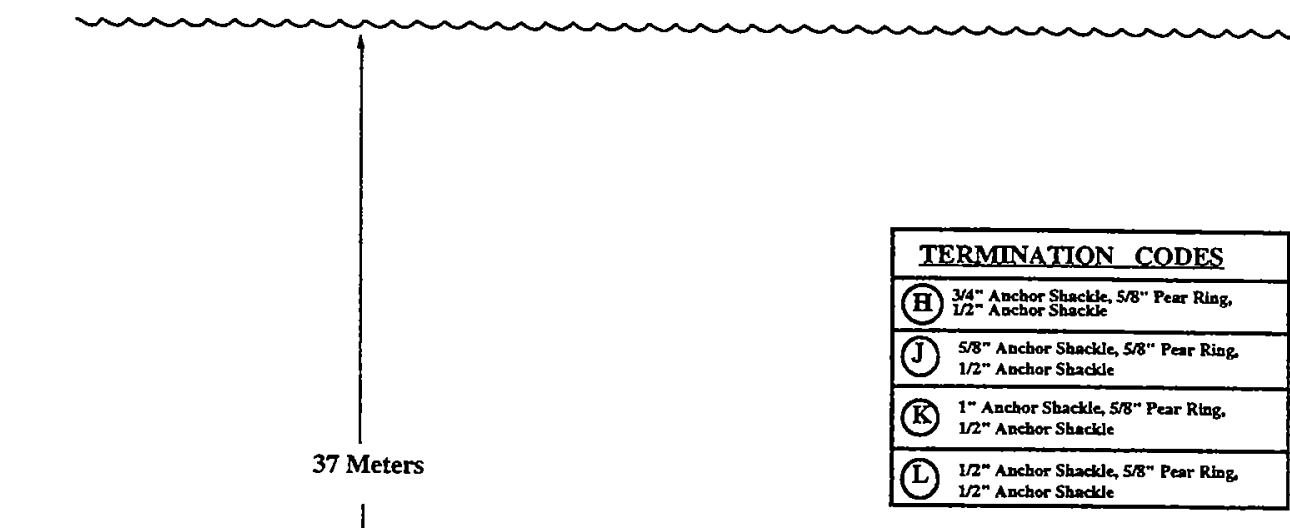

48" Sphere with Argos Transmitter

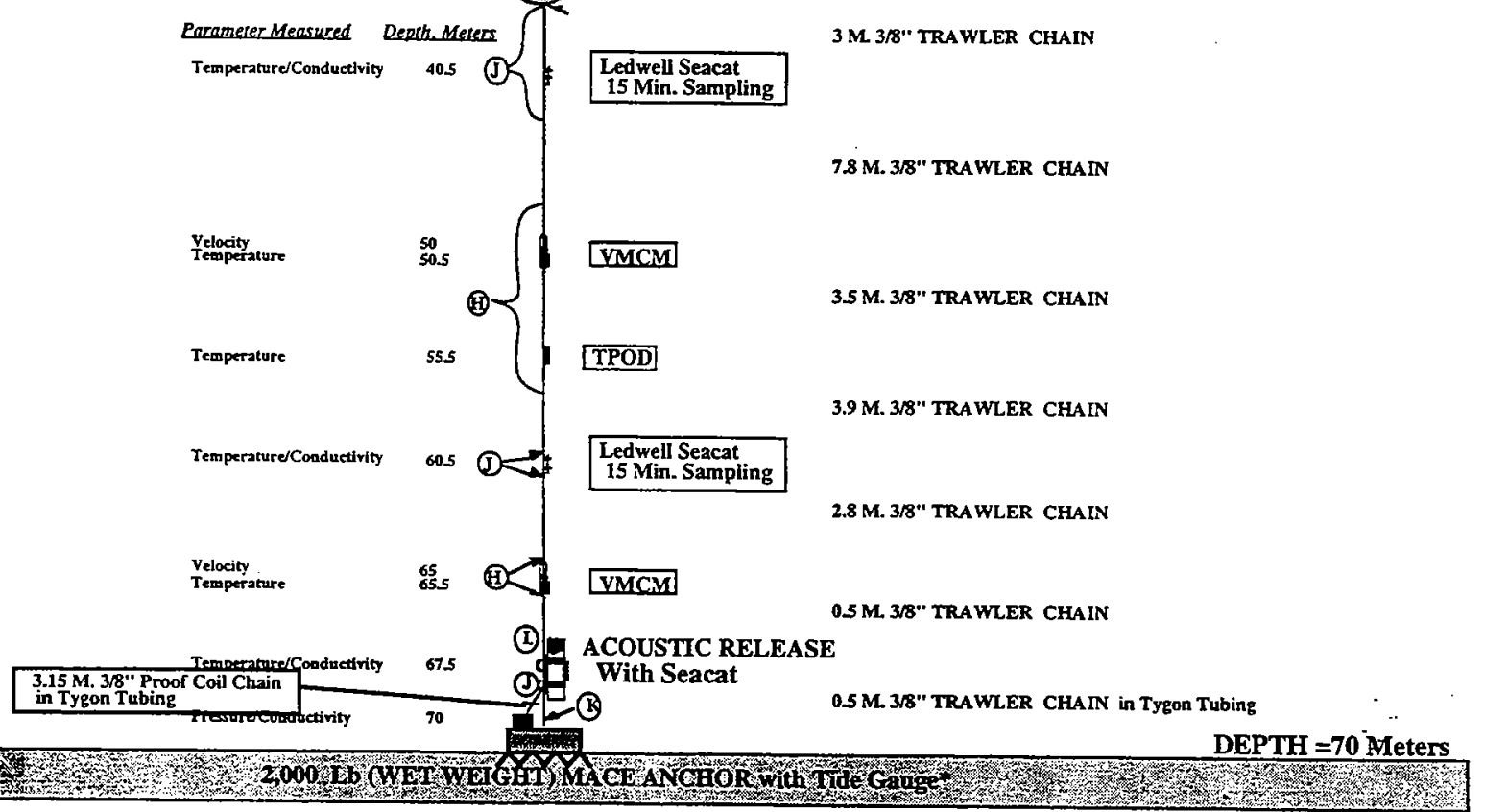

* Tide Gauge secured to anchor with breakable straps. Chain connects tide gauge to top of release.

When release fires and mooring ascends, tide gauge breaks free from anchor.

\section{ALONGSHORE -SUBSURFACE MOORING} CETUTER $\lim _{i \rightarrow 600}$

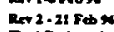
niming

Figure 2.15. Mooring Diagram, Alongshore Subsurface 


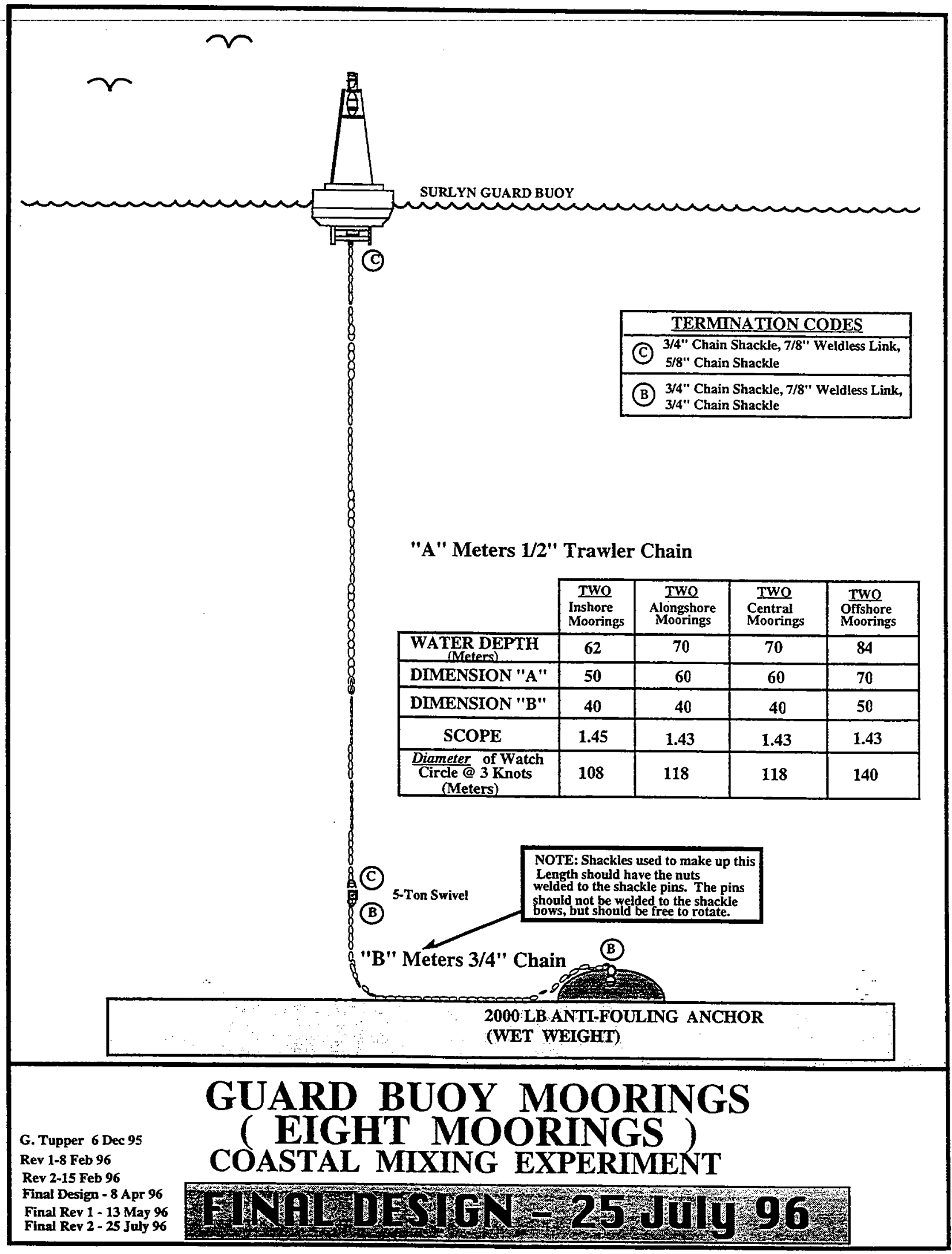

Figure 2.16. Mooring Diagram, Guard Buoy 


\section{Data Processing Summary}

\subsection{Wind Direction}

The comparison between VAWR 704 and 720 showed an average 10.33 degree offset between the two wind direction measurements. Comparisons with the WeatherPak 648 while the alongshore buoy was deployed next to the central buoy between 7/31/96 00:00 and 8/3/96 12:00 UTC showed an average offset of -0.70 and -12.82 degrees for the VAWR 704 and 720, respectively. Comparisons of the guard buoy VOS wind with VAWR 704 between 4/18/97 and 5/7/97 showed an average offset of 3.40 degrees. All of the comparisons are shown in the table below where positive offsets indicate the "other winds" are rotated to the east of the VAWR winds. The comparisons are shown in the order of reliability meaning that the local WPAK 648 and VOS are better comparisons than the other WPAK comparisons since these are not side-by-side comparisons and some part of the offset may be due to real spatial variability. Likewise, the comparisons with the numerical weather prediction (NWP) model winds are even less reliable and due to the low accuracy of the NDBC wind directions (10 degrees), the NDBC buoy comparison is considered the least reliable.

\begin{tabular}{|c|c|c|}
\hline Other Winds & VAWR 704 & VAWR 720 \\
\hline WPAK 648 (local) & -0.70 & -12.82 \\
\hline VOS & 3.40 & \\
\hline WPAK 648 & -2.18 & -12.40 \\
\hline WPAK 713 & -9.12 & -19.83 \\
\hline WPAK 714 & 6.63 & -3.84 \\
\hline Eta NWP Model & 10.41 & 2.37 \\
\hline RUC NWP Model & 12.50 & 3.80 \\
\hline NDBC Buoy 44008 & -9.60 & -19.53 \\
\hline
\end{tabular}

Table 3.1.1. Offsets between wind direction measurements, in degrees

If the model and NDBC buoy comparisons are disregarded, there is a relatively consistent picture of the VAWR 720 wind directions being at least 10 degrees off to the west. The VAWR 704 wind direction offsets seem to be within or close to the 5.6 degree accuracy of the VAWR.

The VAWR 704 wind directions will be used as the primary wind direction measurement. No adjustment was made to these winds. During the two periods when the sonic anemometer winds were used to fill gaps in the VAWR 704 record (2/09/97 23:00 - 4/17/97 14:00 UTC and 5/07/97 18:00 end of deployment), the VAWR 704 compass was applied to the sonic wind direction to get earth-relative wind directions. The VAWR 704 compass failed on 5/12/97 03:30 UTC, however, and the only remaining wind direction measurements at the central site were taken by the VOS on the central guard buoy. These wind directions were patched into the sonic anemometer wind directions so that after 5/12/97 03:30 UTC, the wind speeds are from the sonic anemometer and the wind directions are from the VOS. The processing of the sonic and VOS wind directions are discussed below. The central guard buoy was recovered on $6 / 10 / 97$, so wind directions from 6/10/97 20:00 UTC to the end of the deployment 2.75 days 
were interpolated from the Rapid Update Cycle (RUC) model. The RUC wind directions were rotated -12.5 degrees to force agreement with the VAWR 704 winds.

Bad values were detected over a 16 hour gap in the sonic anemometer record from 4/7/97 06:45 to 4/7/97 22:45 UTC. This gap was filled with data from the RUC numerical weather prediction model. The RUC wind components were forced to agree with the surrounding sonic data by adjusting the RUC data so that the slope of the filled values matched the slope of the line between the good points surrounding the gap. This approach preserved the variability in the RUC time series but applies a linearly changing (in time) offset to force agreement at the endpoints of the filled data. The east and north wind components were forced to agree separately and the wind speed and direction were computed from the filled components.

The dates and duration of each sensor's contribution to the wind direction time series is summarized in the following table.

\begin{tabular}{|l|l|l|r|}
\hline Start Date & End Date & Days & Sensor from which WDIR derived \\
\hline $96 / 07 / 3015: 15$ & $97 / 02 / 0922: 45$ & 194.3 & VAWR 704 \\
\hline $97 / 02 / 0923: 00$ & $97 / 04 / 0706: 30$ & 56.3 & Sonic with VAWR 704 compass \\
\hline $97 / 04 / 0706: 45$ & $97 / 04 / 0722: 45$ & 0.7 & RUC model fitted at endpoints \\
\hline $97 / 04 / 0723: 00$ & $97 / 04 / 1714: 00$ & 9.6 & Sonic with VAWR 704 compass \\
\hline $97 / 04 / 1714: 15$ & $97 / 05 / 0717: 45$ & 20.1 & VAWR 704 \\
\hline $97 / 05 / 0718: 00$ & $97 / 05 / 1203: 15$ & 4.4 & Sonic with VAWR 704 compass \\
\hline $97 / 05 / 1203: 30$ & $97 / 06 / 1019: 45$ & 29.7 & VOS rotated -3.40 \\
\hline $97 / 06 / 1020: 00$ & $97 / 06 / 1314: 00$ & 2.8 & RUC model rotated -12.5 \\
\hline
\end{tabular}

Table 3.1.2. Wind Direction sources.

All other missing east and north wind components were linearly interpolated. Wind speeds and directions were computed from the interpolated components.

\section{Sonic Anemometer and VOS Processing}

The sonic anemometer is in a left-handed coordinate system while VAWR is right-handed. To match the VAWR, the sonic wind was rotated 60 degrees west of north and then the sign of the north component was reversed.

Since the sonic anemometer has no compass, the VAWR 704 compass is used to get earthrelative coordinates. When the buoy fin is facing north, the VAWR compass reads $\sim 183$ degrees. When the sonic wind blows toward the buoy fin, the sonic wind direction is $\sim 180$ degrees relative to the buoy. The offset between the two is therefore -3.0 degrees (compass + sonic wind direction + offset $=0.0$ [north]). The magnetic variation applied to the compass is 15.417. The sonic winds are rotated an additional 7.3 degrees to force agreement with the VAWR wind directions. Agreement was forced since the sonic winds were used to fill gaps in the VAWR wind record. The rotation, then, is as follows:

Sonic wind direction $=\quad$ Sonic direction relative to the buoy

+ VAWR compass

+ offset between sonic and compass $(-3.0)$

+ magnetic variation $(-15.417)$

+ forced offset $(7.3)$ 
From 5/12/97 3:30 UTC to the end of the deployment, the VAWR 704 compass malfunctioned. This leaves good wind speeds from the sonic anemometer, but no wind directions. Wind directions from the guard buoy VOS anemometer were used to fill this gap. The VOS winds were rotated by 3.40 degrees east of north to force agreement with the VAWR 704 when both were sampling simultaneously (4/17/97 17:14 - 5/7/97 17:45 UTC). The VOS anemometer was deployed until 6/10/97 10:21 UTC, so no wind directions for the last few days of the central mooring deployment are available.

A problem was detected in the VOS vane encoder on recovery, making the VOS wind directions suspect. However, it is unknown when the vane encoder began to malfunction. To check this, the VOS wind directions were compared to the VAWR 704 during the time when they were functioning simultaneously. This comparison suggests that while there is a mean offset of 3.40 degrees between the two sensors, no drift in the VOS wind directions was detected and the VOS replicates the variability seen in the VAWR winds well.

Beyond the time that the VAWR compass failed (after 5/12/97), the only comparison possible is between the VOS winds and those of the RUC numerical weather prediction model. This comparison suggests that despite a bias in the directions, there is no appreciable drift. The VOS and the RUC variability match well and the correlation coefficient and the standard deviation of the difference between the two are quite similar to what was reported in the CMO atmospheric model technical report for the VAWR:

\begin{tabular}{|l|l|l|r|r|}
\hline Comparison & Start & End & Correlation Coefficient & $\begin{array}{c}\text { Standard } \\
\text { Deviation }\end{array}$ \\
\hline VAWR vs RUC & $96 / 8 / 01$ & $97 / 2 / 01$ & 0.924 & 43.24 \\
\hline VOS vs RUC & $97 / 4 / 09$ & $97 / 6 / 09$ & 0.939 & 40.46 \\
\hline
\end{tabular}

Table 3.1.3. VOS, RUC, and AWR comparison.

\subsection{Wind Speed}

VAWR 704 and 720 comparison showed that up until the 720 winds failed around 1/1/97, the 704 wind speeds were only $2.1 \%$ higher than the 720 speeds. Edson's sonic anemometer agreed very well with the 704 wind speeds - sonic winds were only $1.6 \%$ lower than the 704 wind speeds. Considering that the VAWR cups should overestimate winds by about $5 \%$, the good agreement between the sonic and VAWR lends more credibility to the accuracy of the VAWR winds. The close agreement between the two VAWRs and the sonic anemometer suggest that the VAWR 704 wind speeds are accurate.

The VAWR 704 winds will be used as the primary wind measurement. No adjustment to the VAWR 704 winds was necessary. The VAWR 704 winds failed on 2/9/97 23:00 UTC. The cups were replaced and good data began again on 4/17/97 17:14 UTC, but the winds failed again on 5/7/97 18:00 UTC. The two periods when the VAWR anemometer failed (2/09/97 23:00 - 4/17/97 14:00 UTC and 5/07/97 18:00 - end of deployment) were filled with the sonic anemometer wind speed observations. The sonic winds are measured every 30 minutes, so 
linear interpolation was used to match the sonic winds with the 15 minute time base of the VAWR.

Bad values were detected over a 16 hour gap in the sonic anemometer record from 4/7/97 06:45 to 4/7/97 22:45 UTC. This gap was filled with data from the RUC numerical weather prediction model. The RUC wind components were forced to agree with the surrounding sonic data by adjusting the RUC data so that the slope of the filled values matched the slope of the line between the good points surrounding the gap. This approach preserved the variability in the RUC time series but applies a linearly changing (in time) offset to force agreement at the endpoints of the filled data. The east and north wind components were forced to agree separately and the wind speed and direction were computed from the filled components.

The dates and duration of each sensor's contribution to the wind direction time series is summarized in the following table.

\begin{tabular}{|l|l|r|l|}
\hline Start Date & End Date & Days & Sensor from which WSPD derived \\
\hline $96 / 07 / 3015: 15$ & $97 / 02 / 0922: 45$ & 194.3 & VAWR 704 \\
\hline $97 / 02 / 0923: 00$ & $97 / 04 / 0706: 30$ & 56.3 & Sonic anemometer \\
\hline 97/04/07 06:45 & $97 / 04 / 0722: 45$ & 0.7 & RUC model fitted at endpoints \\
\hline 97/04/07 23:00 & $97 / 04 / 1714: 00$ & 9.6 & Sonic anemometer \\
\hline 97/04/17 14:15 & $97 / 05 / 0717: 45$ & 20.1 & VAWR 704 \\
\hline 97/05/07 18:00 & $97 / 06 / 1314: 00$ & 36.8 & Sonic anemometer \\
\hline
\end{tabular}

Table 3.2.1. Sources of Wind Direction

All other missing east and north wind components were linearly interpolated. Wind speeds and directions were computed from the interpolated components.

\subsection{Air Temperature}

The VAWR 720 air temperature failed intermittently and from comparisons with the standalone and WeatherPak 648 when it was deployed alongside of the central buoy, it looks to be about $\sim 0.3^{\circ} \mathrm{C}$ too low. The VAWR 704 air temperature agrees well with the standalone and the WPak 648 - the mean offsets were 0.017 and $-0.022^{\circ} \mathrm{C}$, respectively, which are right around the accuracy of $0.02^{\circ} \mathrm{C}$. The comparisons are summarized in the following table where the value is the average of the VAWR subtracted from the standalone or WPak in degrees C.

\begin{tabular}{|l|r|r|}
\hline Comparator & VAWR 704 & VAWR 720 \\
\hline Standalone (postcal) & 0.017 & 0.234 \\
\hline WPak 648 & -0.022 & 0.369 \\
\hline
\end{tabular}

Table 3.3.1. VAWR average subtracted from the standalone or WPak, in degrees $\mathrm{C}$.

A drift is most likely present in the VAWR 704 air temperature beginning in early May 1997 due to a dying battery. This drift was detected in both the VAWR 704 sea temperature and the shortwave radiation. Intercomparisons with WeatherPak 648 and 714 and with the RUC and Eta NWP models did not conclusively show a drift, however. The comparison with WPAK 
648 shows no drift at all and since this is probably the most reliable of all the intercomparisons, no action was taken to remedy the suspected drift.

The VAWR 704 air temperature will be considered the primary air temperature measurement. No adjustment to this air temperature was necessary. The VAWR 704 tape data ended on $06 / 02 / 9700: 30$, so from 06/02/97 00:45 to the end of the deployment (06/13/97 14:00), the air temperature was recovered from the ARGOS data. Gaps in the ARGOS data were linearly interpolated.

A 21 hour gap in the VAWR 704 record for air temperature from 5/27/97 15:15 to 5/28/97 11:45 UTC was found in both the tape and ARGOS data. This gap was filled with data from the RUC numerical weather prediction model. The RUC data were forced to agree with the surrounding VAWR data by adjusting the RUC data so that the slope of the filled values matched the slope of the line between the good points surrounding the gap. This approach preserves the variability in the RUC time series, but applies a linearly changing (in time) offset to force agreement with the VAWR 704 at the endpoints of the filled data.

After filling the large gap between 5/27/97 15:15 and 5/28/97 11:45 UTC, all missing data were linearly interpolated.

\subsection{Barometric Pressure}

The VAWR 704 vs. 720 comparison for barometric pressure shows that when the points with bad air temperatures are removed, the agreement between the two is very good (the barometric pressure has an air temperature correction and the VAWR 720 air temperature failed intermittently). The offset between the two VAWRs was 0.171 which is less than the stated accuracy of $+/-0.2$ mbar.

The VAWR 704 barometric pressure will be considered the primary pressure measurement. The VAWR 704 tape data ended on 06/02/97 00:30, so from 06/02/97 00:45 to the end of the deployment (06/13/97 14:00), the barometric pressure was recovered from the ARGOS data. Gaps in the ARGOS data were linearly interpolated.

A 21 hour gap in the VAWR 704 record for barometric pressure from 97/05/2715:00 to 97/05/28 12:00 UTC was found in both the tape and ARGOS data. This gap was filled with data from the RUC numerical weather prediction model. The RUC data were forced to agree with the surrounding VAWR data by adjusting the RUC data so that the slope of the filled values matched the slope of the line between the good points surrounding the gap. This approach preserves the variability in the RUC time series, but applies a linearly changing (in time) offset to force agreement at the endpoints of the filled data.

After filling the large gap between 5/27/97 15:00 and 5/28/97 12:00 UTC, all missing data were linearly interpolated. 


\subsection{Incoming Longwave Radiation}

Agreement between the VAWR 704 and 720 incoming longwave was quite good - the mean bias between the two was $3.38 \mathrm{~W} / \mathrm{m}^{2}$ with a standard deviation of the difference of only 3.57 $\mathrm{W} / \mathrm{m}^{2}$. The VAWR 720 longwave measurement suffered from the same failings as the air and sea temperatures, so there are large periods of bad data.

The VAWR 704 will be considered the primary longwave radiation measurement. No adjustment to the longwave was performed. Gaps longer than 65 minutes were filled with a 3 hour local average and gaps longer than 20 minutes were filled with a 1 hour local average. A large gap from 5/27/97 15:15 - 5/28/97 11:45 UTC was filled with a 24 hour local average. All other gaps (20 minutes or less) were linearly interpolated.

\subsection{Relative Humidity}

Two standalone RH sensors were deployed, but there was no data from RH 005.

The relative humidities recorded by VAWR 704 and 720 had a mean bias relative to one another of $1.23 \% \mathrm{RH}$ which is within the accuracy of the Vaisala Humicap sensor. The mean biases between the VAWR 704 and standalone instrument 004 (both post- and pre-cal) were within the combined accuracies of each sensor as were the biases between the VAWR 720 and the standalone. The postcalibrated standalone agreed best with the two VAWR sensors during moist conditions, but measured too dry by about $\sim 6-7 \%$ RH at other times. The VAWR 704 relative humidity time series was the longest, but the instrument failed around 5/8/97 13:00 UTC.

The initially processed 704 data used calibration coefficients from 24 October 1994, not the more up to date calibrations for sensor V-037-01 taken on 5 March 1996. R. Payne recomputed linear calibration coefficients from the CMO pre-deployment cal data. This linear calibration was applied to the data for version 2 of the met data. The differences between the new calibration and the old are relatively small; maximum differences are at low humidities at $40 \% \mathrm{RH}$ the difference is about $1.5 \% \mathrm{RH}$. The differences between the pre-cal linear and non-linear calibration curves are even smaller; maximum differences less than $0.5 \% \mathrm{RH}$.

The VAWR 704 will be considered the primary relative humidity measurement. No adjustment was necessary.

The gap at the end of the time series, from 5/8/97 13:15 UTC to the end of the deployment, was filled with data from the RUC numerical weather prediction model. These data were adjusted to force agreement with the VAWR 704 relative humidity during the period before the VAWR 704 sensor failed. The RUC correction was as follows:

$$
\text { Adjusted RUC RH }=0.664436 * \mathrm{RUC} \text { RH }+33.6203
$$

Since the RUC data is available hourly, the samples at 15,30 and 45 minutes past the hour were linearly interpolated. There was a significant discontinuity between where the VAWR 704 ended and the RUC data began on 5/8/97 13:15 UTC. This jump was smoothed over by 
replacing the VAWR 704 data up to 12 hours previous to $13: 15$ by a weighted average of the VAWR and RUC data. The weighted average favored the VAWR 704 data at 01:15 and linearly increased the weight toward favoring the RUC data until 13:15. This was accomplished with the following equation:

New RH = VAWR RH + p * (RUC_RH - VAWR_RH)

where $\mathrm{p}$ increased in time from 0 (at $01: 15$ ) to 1 (at 13:15).

All other missing data were linearly interpolated.

\subsection{Sea Surface Temperature}

The VAWR 720 sea temperature failed intermittently and was measuring considerably lower than the VAWR 704 when reasonable values were obtained. The VAWR 704 sea temperature agrees well with the instruments just below it. The mean offset between Seacat 927 at $2 \mathrm{~m}$ depth and the VAWR 704 sea temperature was $-0.0037^{\circ} \mathrm{C}$ when the comparison was constrained to points measured between local midnight and sunrise. A similar comparison with MTR 3250 at $4 \mathrm{~m}$ depth yielded a mean offset of $0.0002^{\circ} \mathrm{C}$. The precals and the postcals for Seacat 927 agreed very well, so these temperatures seem reliable and do not show any evidence of drift. The VAWR 704 sea temperature does show a drift starting in the beginning of May 1997 and continuing almost linearly to the end of the deployment. This drift causes the VAWR 704 sea temperatures to be about $0.03^{\circ} \mathrm{C}$ too warm at the end of the deployment.

The VAWR 704 sea temperature is considered the primary sea temperature measurement. No offsets were applied to the data, however the drift detected at the beginning of May 1997 was corrected. The adjustment took the form of a 2 nd order polynomial and was as follows:

VAWR 704 STMP = VAWR 704 STMP + 3.92223530E-03 +

$$
\text { 9.63761961E-04*X+-8.72664811E-06*X } * \mathrm{X}
$$

where $\mathrm{X}$ is the number of days since 5/1/97 00:00 UTC

The adjustment was applied to all VAWR 704 sea temperatures on and after 4/27/97 01:45 UTC $(\mathrm{X}=-3.9270833)$.

All missing data from the VAWR 704 sea temperature record were filled with data from Seacat 927. This includes the 21 hour gap from 5/27/97 15:00 to 5/28/97 12:00 UTC.

\subsection{Precipitation}

Two R. M. Young rain gauges with a tattletale data logger designed by B. Way were deployed on the Central discus buoy. These sampled every 3.75 minutes. Note that no heater was used so there may at times have been freezing of water in the gauge reservoir. Data logger BPRC001 flooded but B. Way managed to read the data out of the logger and recover a full data record. Data logger BPRC002 functioned the full time. Pre and post calibrations were conducted on both units. The data from BPRC001 looks good. Pre and post calibrations agree to within 3.5\%. There are some spikes in the record in August prior to the first major rain event. 
Data from BPRC002 looks a bit noisy throughout the record. This noise is most noticeable with the reservoir in nearly empty (i.e., April 7-12). Pre and post cals agree to within $2 \%$. BPRC001 recorded a net rainfall of $891 \mathrm{~mm}$ over the deployment. BPRC002 recorded a net rainfall of $697 \mathrm{~mm}$ over the deployment. (Net is average of post and pre cal timeseries). This is a difference of $25 \%$ between the two instruments. This does not appear to be an electronic calibration problem. The records show that BPRC001 fills up and empties faster than BPRC002 (i.e., April 2-May 2). This appears to be consistent for the whole record. Although they both clearly see the same events, BPRC001 was chosen as the CMO rain record since its record was less noisy.

The level was first differenced in time. Any changes that where larger than $10 \mathrm{~mm}$ or smaller than $-10 \mathrm{~mm}$ between $3.75 \mathrm{~min}$ samples were set to zero. This would remove the periods when the gauge siphons. Then time series was integrated up again in time to provide a cumulative rainfall record.

The cumulative rainfall record was then multiplied by a scaling factor so that the total rainfall at the end of the deployment equals $794 \mathrm{~mm}$. This is the average cumulative amount for BPRC001 and BPRC002 pre and post cal data records using the $10 \mathrm{~mm}$ threshold.

Remaining precipitation issues:

- No attempt has been made to identify or correct time drifts.

- There are times when the gauges empty between events (i.e., April 1, 1997).

- BPRC001 fills up and empties faster than BPRC002.

\subsection{Incoming Shortwave Radiation}

The VAWR 704 was used as the primary incoming shortwave radiation measurement. Its shortwave record was processed twice. The Version 2 data were processed with a postrecovery calibration taken on 24 September 1997 . This value was 10.89 , compared to 10.52 used in Version 1, resulting in a reduction of the incoming shortwave by $3.4 \%$. Using the postcals, VAWR 704 measured only $0.9 \%$ lower than the VAWR 720 unit. This difference is well within the $3 \%$ accuracy (combined) of the VAWR pyranometers.

A mean nighttime bias of $3.33 \mathrm{~W} / \mathrm{m}^{2}$ (minimum of $2.60 \mathrm{~W} / \mathrm{m}^{2}$ ) was detected, and an offset of $2.6 \mathrm{~W} / \mathrm{m}^{2}$ was removed from the shortwave time series. The same drift detected in the VAWR 704 sea temperature at the end of April and beginning of May 1997 was detected in the nighttime shortwave bias. Since this bias reduced the incoming shortwave by, at most, 0.8 $\mathrm{W} / \mathrm{m}^{2}$, this drift was ignored. The drift is likely the result of decreasing output from a dying battery on VAWR 704.

The VAWR 704 tape data ended on 97/06/02 00:30, so from 97/06/02 00:45 to the end of the deployment (97/06/13 14:00), the shortwave radiation was recovered from the Argos data. The Argos data was processed with an older version of the shortwave radiation equation:

SW_argos $=\left(\mathrm{x}-\mathrm{Z} \_\mathrm{SW}\right) * \mathrm{MVHZ} / \mathrm{cal} \_\mathrm{sW}$

where $Z \_S W=4.0$ (from the table file) 
whereas the tape data was processes with the following equation:

SW_tape $=\left((\mathrm{x} * \mathrm{MVHZ})-\mathrm{Z} \_S W\right) /$ cal_sw

where Z_SW $=20.0$ (hard-coded).

These equations are not equivalent and result in a bias. The tape processing equation is considered the correct version. The correction is as follows:

$$
\text { sw_tape }=\mathrm{sw} \_ \text {argos } * \mathrm{Co} / \mathrm{Cn}+(4 * \mathrm{MVHZ}-20) / \mathrm{Cn}
$$

where Co is the old calibration coefficient (10.52), used in ARGOS processing

$\mathrm{Cn}$ is the new calibration coefficient (10.89) and MVHZ is 15.0.

This correction was applied to the ARGOS incoming shortwave radiation before it was patched into the VAWR 704 tape data.

All gaps in the VAWR 704 time series were interpolated based on the cloudiness of the surrounding good points. The cloudiness is defined as the ratio between the observed incoming shortwave radiation and the theoretical incoming shortwave with the atmospheric transmission coefficient set to 1.0. The cloudiness is linearly interpolated over the gap and the missing shortwave is replaced by the interpolated cloudiness multiplied by the theoretical incoming shortwave. While during mid-morning and mid-afternoon this interpolation looks linear, it replicates the shape of the theoretical incoming shortwave at sunrise, local noon and sunset.

If the $\mathrm{p} 0$ and $\mathrm{p} 1$ are the indices of good values before and after a gap, then the algorithm to interpolate across that gap is as follows:

$$
\begin{array}{ll}
\text { cloud } 0=\operatorname{srad}(\mathrm{p} 0) / \text { srad_theory }(\mathrm{p} 0) & ; \text { Cloudiness at first good point } \\
\text { cloud } 1=\operatorname{srad}(\mathrm{p} 1) / \operatorname{srad} \text { theory }(\mathrm{p} 1) & ; \text { Cloudiness at next good point } \\
\text { slope }=(\text { cloud } 1-\operatorname{cloud} 0) / \text { float }(\mathrm{p} 1-\mathrm{p} 0) & ; \text { Compute slope } \\
\text { intercept }=\text { cloud } 1-\operatorname{slope} * \text { float }(\mathrm{p} 1) & ; \text { Compute intercept } \\
\mathrm{i}=(\mathrm{p} 0+1)+\operatorname{lindgen}(\mathrm{p} 1-\mathrm{p} 0-1) & \text {; Indices of missing points } \\
\text { cloud }=\text { slope } * \text { float }(\mathrm{i})+\text { intercept } & \text {; Interpolate cloudiness } \\
\text { srad }(\mathrm{i})=\text { srad_theory }(\mathrm{i}) * \text { cloud } & \text {; Compute estimated shortwave }
\end{array}
$$

When one of the good values was a nighttime value (srad_theory $=0$ ), the cloudiness was estimated from the daytime value and assumed to be constant over the gap. If both values were nighttime values, then the gap was at nighttime and was filled with the averaged of the two surrounding good values.

A 21 hour gap in the VAWR 704 record for all sensors from 97/05/27 15:00 - 97/05/28 12:00 UTC was found in both the tape and ARGOS data. This gap was interpolated in a similar manner as discussed above. The interpolated values were estimated using a mean cloudiness from the morning before the gap.

\subsection{Water Temperature}

Processing of temperature was relatively simple because of stable sensors and careful predeployment calibrations. Some instruments stopped recording early, a few required 
adjustments to calibrations, but the majority of sensors performed well within specs and the temperatures could be used with minimal, standard processing techniques.

Notes on processing of Seacats:

1. Seacats were read on a Macintosh using Seabird's PC software, which generated slightly malformatted .cnv files with bad timing information in headers. These files were converted into EPIC using a customized program called scattofix, which hard-wired the record interval and start time. This program also allowed processing of partial files using usersupplied times and record number limits, to handle instruments which changed speed during the experiment.

2. Instruments 1874,1881 , and 1882 were configured for fast sampling, running at 45 seconds until 961030 , then going to 7.5 seconds. These stopped recording early, ending on 961229 . They were processed in 2 pieces, with fast segment being subsampled back to 450 seconds so they could be merged for further processing.

3. Seacats $882,883,884 \mathrm{p}$, and $885 \mathrm{p}$ sampled at 15 minutes, and were gridded to 7.5 minutes for creating the $2 \mathrm{D}$ temperature files, using $\mathrm{C}$ program gridepic.

4. Comparison of temperatures from VMCMs, Seacats and Brancker Tpods, plus lab tests of the sample interval timing for VMCMs, resulted in the conclusion that the timing of the Seacats is in error by less than one "standard" sample interval (+/- 3.75 min). Clock drift was not checked, but is assumed to be of order $10 \mathrm{sec} / \mathrm{month}$.

5. The calibration adjustments done to date assure a reasonable degree of self-consistency among T-S measured from all Seacats on a given mooring (e.g., eliminate density inversions, and match T-S from instruments within a well-mixed surface or bottom layer). Independent measures of accuracy (e.g., shipboard CTDs and SeaSoar surveys) have not been considered.

Note on Seabird Seagauge:

These instruments recorded at 5 minute intervals. Temperature data was gridded to 7.5 minutes using $\mathrm{C}$ program gridepic. Gridding rather than filtering was used because Seacats and Seagauges use an instantaneous single sample rather than an average value. Our gridding program uses a table lookup, which should mimic an instrument set up with a slower record rate.

Note on Brancker Temperature Recorders (TPODs):

All TPODs recorded at 30 minutes and were gridded to 7.5 minutes for inclusion in 2 dimensional temperature files. They all stopped at 970601 12:00 UTC because of limited internal storage.

Time and VMCMs: Temperature is sampled at the start of the record interval, and the VMCM processing software revision made for handling this dataset assigns that time to each record. 


\subsection{0.a. Central Site}

Central temperatures are available for the period 960730 19:07 to 970612 18:22 at 7.5 minutes. There are 60859 records at 21 depth bins from $1.5 \mathrm{~m}$ to $67.5 \mathrm{~m}$.

Start time for Seacats 927,1875 , and 1879 (at $2 \mathrm{~m}, 7.5 \mathrm{~m}$, and 25m) was hardwired to 960720 $12: 00$.

No special processing was required for Seacats $927,1875,1877,1879,885,73,72$, or 1878 (at $2 \mathrm{~m}, 7.5 \mathrm{~m}, 12.5 \mathrm{~m}, 25 \mathrm{~m}, 35 \mathrm{~m}, 57.5 \mathrm{~m}, 62.5 \mathrm{~m}, 67.5 \mathrm{~m}$ ) or for VMCMs $1,3,41,27,42,43$, or 35 (at $10 \mathrm{~m}, 15 \mathrm{~m}, 20 \mathrm{~m}, 40 \mathrm{~m}, 50 \mathrm{~m}, 55 \mathrm{~m}, 65 \mathrm{~m})$.

\section{MTR $3250(4 \mathrm{~m})$}

This instrument recorded at 1800 seconds. Data was gridded to 7.5 minutes for merging with other Central site temperatures. Comparison with the other 3 top bins indicated a bias of $.04^{\circ} \mathrm{C}$, which was subtracted from this temperature record.

VMCM $54(4.5 \mathrm{~m})$

This instrument performed poorly. The record was short, 61862 records compared to an average of 64500 for other VMCMs at this site, and there were many tape and clock errors. The temperature data was edited using a window of $0^{\circ}$ to $22^{\circ} \mathrm{C}$ for the whole record. For a 1day period on 970106 , temperatures were windowed between $5^{\circ}$ and $10^{\circ} \mathrm{C}$ to remove a single multi-point spike. 242 temperature values were removed with this 2-part filter.

Seacat $1877(12.5 \mathrm{~m})$

The batteries in this Seacat failed, and the record ends at 970503 20:07:30 UTC.

VMCM $51(30 \mathrm{~m})$

Temperature was edited using a window of $0^{\circ}$ to $22^{\circ} \mathrm{C}$ for the whole time period, and a narrow window from $5^{\circ}$ to $10^{\circ} \mathrm{C}$ to remove a spike on 970106 .

Seacat $1882(45 \mathrm{~m})$

This SBE-16 was set up as a fast sampler, see note above. Temperatures began drifting before the battery died, so data was blanked after 96/11/12 15:40 UTC.

VMCM $50(60 \mathrm{~m})$

Temperature was windowed between $0^{\circ}$ and $15^{\circ} \mathrm{C}$ for the whole time, and from $5^{\circ}$ to $7^{\circ} \mathrm{C}$ from 970329 to 970401 , which removed a total of 18 spikes.

\subsection{0.b. Inshore Site}

Inshore instruments were deployed during the period 960802 19:22 to 970612 09:15. There are 60208 representing this time period and 14 bins of temperature data from 1 to 62 meters. All surface mooring data from the Inshore site were blanked during the off-station period from 960918 18:49 to $96092616: 00$.

No special processing other than blanking off-station data was required for TPODs 3830 and $3301(1 \mathrm{~m}$ and $25 \mathrm{~m})$, for Seacat $146(2 \mathrm{~m})$, or for VMCMs 10,45 , or $22(4.55 \mathrm{~m}, 15 \mathrm{~m}, 30 \mathrm{~m})$. No 
special processing was required for VMCM 28 or $30(42 \mathrm{~m}, 57 \mathrm{~m})$, TPOD $3271(47.5 \mathrm{~m})$, Seacat $1880(59.5 \mathrm{~m})$, and Seagauge $46(62 \mathrm{~m})$.

TPOD $4493(10 \mathrm{~m})$

This TPOD stopped recording earlier than the others, and was truncated at 970502 06:00.

Seacat $71(20 \mathrm{~m})$

Data from this SBE-16 ends early, truncated at 970502 06:00 UTC.

Seacat $1874(52.5 \mathrm{~m})$

Program editepic was used to de-spike the temperatures from this fast-sampler from 961118 00:00 to 961119 04:00.

\subsection{0.c. Offshore Site}

Temperatures are available from the Offshore site from 960731 20:00 to 970616 10:45. There are 61367 data points at 7.5 minute intervals from 16 depth bins from 1 to 84 meters. After normal processing of each bin, the 2 dimensional Offshore temperature file was edited using IDL to blank bin 10 after 970119 and to replace temperature values lower than $3^{\circ} \mathrm{C}$ with fill values.

No special processing was required for TPODs $3291,3763,3308,4228,(1 \mathrm{~m}, 10 \mathrm{~m}, 25 \mathrm{~m}$, $69.5 \mathrm{~m})$, for Seacats $141,1873,884 \mathrm{p}, 70,1876(2 \mathrm{~m}, 20 \mathrm{~m}, 35 \mathrm{~m}, 74.5 \mathrm{~m}, 81.5 \mathrm{~m})$, VMCM s34, 17, 40, 2 (at 4.55m, 30m, 64m, 79m).

$\operatorname{VMCM} 23(15 \mathrm{~m})$

Program Timecheck was used to correct the time base. Editepic was used to correct a single 1 point spike by windowing temperature between $5^{\circ}$ and $10^{\circ} \mathrm{C}$ from 961227 to 961228 .

Seacat $1881(50.5 \mathrm{~m})$

Temperatures were windowed between $4.2^{\circ}$ and $25^{\circ} \mathrm{C}$ from $96073119: 59$ to $97011916: 00$ to remove a single-point spike.

Seagauge $45(84 \mathrm{~m})$

A bias of $.013^{\circ} \mathrm{C}$ was applied to the temperature to force agreement with the $81.5 \mathrm{~m}$ Seacat.

\subsection{0.d. Alongshore Site}

Alongshore temperature data is available for the period from $96080321: 30$ to 970610 09:37 UTC. There are 59618 data points at 14 depth bins from 1 to 70 meters. The alongshore surface mooring broke free, was recovered and reset, so instruments above 30 meters have been blank-filled from 961009 06:00 to $96110221: 18$ to eliminate offstation data.

Data files from Brancker temperature recorders (Tpods) from this site were exported to a workstation for processing using ftp in binary mode, which left a $<$ CTRL-M $>$ character at the end of each line. The files were edited with a shell script to remove the trailing control characters before being run through standard processing. Most Brancker data from this site ends on 970601 00:00 UTC. 
No special processing was required for Seacat $142,68,883,882,144(2 \mathrm{~m}, 20 \mathrm{~m}, 40.5 \mathrm{~m}$, $60.5 \mathrm{~m}, 67.5 \mathrm{~m})$, TPOD 3837, 3299, 3833 (10m, 25m,55.5m), VMCM 55, 12, 44 (15m,50m, $65 \mathrm{~m})$, or Seagauge $9(70 \mathrm{~m})$.

TPOD $3274(1 \mathrm{~m})$

This tpod's record ends on 961206.

VMCM $53(4.55 \mathrm{~m})$

There were many timing errors in the data from this instrument, especially in the data from the second deployment; however, the temperature sensor performed well.

MTR 3242

This instrument, a mini-temperature recorder developed by the Pacific Marine Environmental Lab (PMEL), was clamped to the cage in which VMCM 53 was held. It was meant to provide a spare temperature record in case of any problem with the current meter's temperature, but it was not needed. The data it recorded has not been processed.

VMCM 24

This instrument performed very poorly. Because of numerous interval counter errors, data from this current meter was omitted from the site file.

\subsection{VMCM Velocity}

Standard Processing of VMCMs: All VMCM tapes were read on a NEC 286 PC using standard SeaData Reader software. Files were then run through programs VMCM_cdf, VMCM_cal, and putinepic on a Sun IPC workstation. Timecheck was then run to correct any interval counter errors.

Despiking was performed as needed using program editepic, and then files were merged to produce a single two-dimensional file for each site, using program zmerge. Any re-blanking or final despiking was done with IDL programs.

Time and VMCMs: Because of a new understanding of the sampling and recording strategy in the VMCM, these instruments were processed twice. Time is calculated using a reset time and an interval counter recorded in each scan. The interval counter resets to the value 1 , and then increments before writing to tape, so that the counter for the first record written to tape is 2 .

The temperature is sampled at the start of the record interval, and the VMCM processing software now assigns that time to each record. This is done by subtracting 1 sample interval from the reset time and then adding the product of the interval counter less 1 and the sample rate. Velocity is sampled over the full record interval, so the time value for the center of the velocity sample can be generated by adding $1 / 2$ sample period to the time word.

Data Return: The processing system in use for this experiment does not provide an accurate count of missing records. Data return has been inferred from running a time-checking program, 
but some interval counter errors are corrected before this step is run. Information is provided here as an indicator of problems, not as an exact count of missing records.

\subsection{1.a. Central Site}

Central site data was truncated to 60861 records between 1996/07/30 19:03 and 1997/06/12 18:33. There were $10 \mathrm{VMCMs}$ at this site, but the velocities from the lowest current meter had to be discarded due to rotor failure.

VMCM $54(4.55 \mathrm{~m})$

This instrument performed poorly. The record was short, 61862 points compared to about 64500 for other VMCMs at this site, and there were many tape and clock errors. Timecheck reported 2497 gaps and 8041 records interpolated. Velocities were windowed to $+/-100 \mathrm{~cm} / \mathrm{s}$ for the whole time period, which removed 3 spikes.

$\operatorname{VMCM} 1(10 \mathrm{~m})$

This instrument performed well and required no special processing. Timecheck reported 261 gaps and 318 records interpolated.

$\operatorname{VMCM} 3(15 \mathrm{~m})$

This instrument performed exceptionally well and required no special processing. Timecheck program reported 151 gaps and 177 records interpolated.

VMCM $41(20 \mathrm{~m})$

This instrument performed well and required no special processing. Timecheck program reported 252 gaps and 315 records interpolated.

VMCM $51(30 \mathrm{~m})$

This instrument performed exceptionally well. There were 2 spikes in the velocities that were removed using the editepic C program. Timecheck program reported 160 gaps and 193 records interpolated.

VMCM $27(40 \mathrm{~m})$

This instrument performed exceptionally well and required no special processing. Timecheck program reported 163 gaps and 197 records interpolated.

VMCM $42(50 \mathrm{~m})$

This instrument performed well and required no special processing. Timecheck program reported 232 gaps and 285 records interpolated.

$\operatorname{VMCM} 43(55 \mathrm{~m})$

This current meter worked fairly well. There were spikes in the compass, which were left in the record. The instrument slipped in its cage. Timecheck program reported 242 gaps and 286 records interpolated. 
VMCM $50(60 \mathrm{~m})$

This instrument performed poorly, primarily in terms of interval counter errors. There were 2 spikes in the velocities that were removed using editepic, windowing to $+/-100 \mathrm{~cm} / \mathrm{s}$. Timecheck program reported 499 gaps and 541 records interpolated.

VMCM $35(65 \mathrm{~m})$

Rotor 2 did not perform well. After a close inspection of the rotor data, it was decided that velocities from the entire VMCM 35 record should be discarded. Timecheck program reported 295 gaps and 361 records interpolated.

\subsection{1.b. Inshore Site}

Inshore site data was truncated to 60310 records from 1996/08/02 19:22:30 to 1997/06/12 09:30:00. There are 5 VMCMs with good velocitiy data. The surface mooring was adrift for 8 days and was redeployed without stopping the instruments. VMCMs on the surface mooring $(10,45,22)$ were blanked during the period the mooring was adrift, 1996/09/18 18:49 to 1996/09/26 16:00.

VMCM $10(4.55 \mathrm{~m})$

This instrument performed well, except that rope in the rotors forced us to discard the velocity data after 1996/12/05. Program timecheck interpolated over 214 records due to interval counter gaps.

VMCM $45(15 \mathrm{~m})$

This instrument performed exceptionally well. Program timecheck interpolated over 148 records due to interval counter gaps.

VMCM $22(30 \mathrm{~m})$

This instrument performed exceptionally well. Program timecheck interpolated over 116 records due to interval counter gaps.

VMCM $28(42 \mathrm{~m})$

This instrument performed exceptionally well. Program timecheck interpolated over 179 records due to interval counter gaps.

VMCM $30(57 \mathrm{~m})$

This instrument performed well. Program timecheck interpolated over 355 records due to interval counter gaps.

\subsection{1.c. Offshore Site}

Offshore data was truncated to 61368 records from 1996/07/31 20:00 to 1997/06/16 10:52. There are 5 VMCMs of good velocity data from 4.5 to 79 meters.

$\operatorname{VMCM} 34(4.55 \mathrm{~m})$

This instrument performed well. Program timecheck found and repaired 314 gaps, and interpolated 387 records. 
VMCM $23(15 \mathrm{~m})$

This instrument performed well. Program timecheck found and repaired 147 gaps, and interpolated 175 records.

VMCM $17(30 \mathrm{~m})$

This instrument performed exceptionally well. Editepic was used to window velocities between -100 and $100 \mathrm{~cm} / \mathrm{s}$ after 1996/07/31 16:16. Program timecheck found and repaired 153 gaps, and interpolated 178 records.

VMCM $40(64 \mathrm{~m})$

This instrument performed well. Program timecheck found and repaired 319 gaps and interpolated 402 records.

VMCM $002(79 m)$

This instrument performed exceptionally. Program timecheck found and repaired 202 gaps and interpolated 254 records.

\subsection{1.d. Alongshore Site}

The Alongshore velocities were truncated to 59620 records between 1996/08/03 21:30 and 1997/06/10 09:52. There were 5 VMCMs deployed, but the 30 meter instrument, the lowest VMCM on the toroid, performed so poorly that its data has been discarded, leaving 4 VMCMs between 4.5 and 65 meters.

The surface mooring went adrift sometime after an Argos fix at 96/10/08 22:38. The mooring was recovered and instrument data was collected before the mooring was reset. Data from the two deployments was merged and filled with 4751 flag values from 1996/10/08 22:30 to $1996 / 11 / 03$ 00:00, a period that includes all time during which the mooring was adrift.

The rotors on the top two VMCMs were fouled with rope after 1996/12/25, so those records are padded with fill values after that point.

\section{VMCM 53 (4.55m)}

There were many timing errors in the record from this instrument, especially in the data from the second deployment. In the 18415 records produced in the first deployment, there were 20 gaps and 23 records interpolated. During deployment 2, there were 43961 records written, 150 gaps, and 175 records interpolated. Data was blanked from 1996/10/08 to 1996/11/03 because of the mooring failure, and from 1996/12/25 to the end of the deployment because of rope fouling the rotors. An MTR was strapped to the instrument's cage.

\section{VMCM 55 (15m)}

The compass on this unit malfunctioned, and velocity data had to be blanked starting on 961112. Although velocities looked reasonable throughout the deployments, histograms of compass values showed many 0 values were recorded after this date. In the record for the first deployment, there were 13 gaps and 15 records interpolated. In the second deployment, there were 161 gaps and 197 records interpolated. 
VMCM $24(30 \mathrm{~m})$

Because of the number of interval errors, the data from this instrument was omitted from the alongshore record. The distribution of interval counter errors made it impossible to reconcile the time base of this data with that of surrounding instruments. Rotor 1 died partway thru deployment 1 , and the compass failed on 960901 .

VMCM $12(50 \mathrm{~m})$

This instrument performed well. There was a reset at record 221 which required some special time handling. A note on the Current Meter Operation Information log indicates that the upper hub was intermittently sticky before deployment, but this apparently did not impact velocity measurement. Program timecheck found 133 gaps and interpolated 162 records.

VMCM $44(65 \mathrm{~m})$

This instrument performed well. Program timecheck found 248 gaps and interpolated over 309 records.

\subsection{Conductivity and Salinity}

The moored conductivity cells typically exhibited offsets and drifts during the deployment, presumably due to fouling. This problem was generally small near the surface and more severe closer to the bottom, suggesting it was primarily due to suspended particles rather than biofouling. As described below these offsets and drifts were identified and corrected (to the extent possible) by comparisons with adjacent instruments on the same mooring. Salinity was then estimated from the corrected temperature (Section 3.10) and conductivity data following Fofonoff and Millard (1983).

\subsection{2.a. Central Site}

Seacat $927(2.0 \mathrm{~m})$

The conductivities from Seacat 927 had two problems - a drift and high frequency noise starting around October 1996.

Filtering was unsuccessful at removing 2-3 day excursions in salinity caused by lower frequency errors in conductivity. As a result, all conductivity measurements after 09/03/96 11:00:00 UTC were removed.

Seacat $1875(7.5 \mathrm{~m})$

A small drift in conductivity $(<0.002 \mathrm{~S} / \mathrm{m})$ was detected in the comparison of Seacats 1875 and 1877. The drift was removed using a linear correction of the form:

Cond $=$ Cond $+[0.00059001915+3.9658057 \mathrm{e}-06 * \mathrm{x}] \quad$.

where $\mathrm{x}=$ number of days since 07/30/96 19:07:30 UTC. 
Seacat $1877(12.5 \mathrm{~m})$

The batteries in this Seacat failed so that no data is available after 05/03/97 20:07:30 UTC. Seacat 1877 agrees very well with 1879 and with the adjusted 1875 , so no adjustment was necessary.

Seacat $1879(25.0 \mathrm{~m})$

Seacats 1877 and 1879 agree very well, so no adjustment was necessary.

Seacat $885(35.0 \mathrm{~m})$

This instrument had a 15 minute sample rate, and was gridded using $\mathrm{DL}$ for inclusion in the central salinity file. A drift in conductivity $(<0.007 \mathrm{~S} / \mathrm{m})$ was detected in the comparison of Seacats 1879 and 885 . The drift was not quite linear, especially at the beginning of the drift. The drift correction was developed from two non-linear fits of the following form:

$$
\mathrm{y} 1=\mathrm{c}-\mathrm{b} * \mathrm{c} /(\mathrm{ax}+\mathrm{b})
$$

where $\mathrm{a}=0.72905066, \mathrm{~b}=0.95063280, \mathrm{c}=-0.0028500265$ and

$\mathrm{x}=$ number of days since 11/14/96 00:00 UTC

$$
\mathrm{y} 2=\mathrm{c}+1 /(\mathrm{ax}+\mathrm{b})
$$

where $\mathrm{a}=0.99999997, \mathrm{~b}=114.10044, \mathrm{c}=-0.0088093893$ and

$\mathrm{x}=$ number of days since 11/14/96 00:00 UTC

The final correction, y, was taken from y1 between 11/14/96 00:00 and 1/5/97 00:00 UTC and from y 2 between 1/25/97 00:00 UTC and the end of the deployment. From 1/5/97 to 1/25/97, a linear ramp ranging from 1 to 0 was applied as $\mathrm{y}=[\mathrm{y} 1 *$ ramp $]+[\mathrm{y} 2 *(1-$ ramp $)]$. y was set to zero from the deployment to $11 / 14 / 9600: 00$ UTC. The correction was applied as follows:

$$
\text { Cond }=\text { Cond }-\mathrm{y}
$$

\section{Seacat $1882(45.0 \mathrm{~m})$}

This instrument had a 45 second sample rate until 10/30/96, then $7.5 \mathrm{~min}$. The battery failed in Seacat 1882 . Both the conductivity and temperature started drifting about $2-3$ weeks before instrument failed. Data after 96/11/12 15:40:00 UTC was removed.

Seacat $73(57.5 \mathrm{~m})$

A drift in conductivity $(<0.015 \mathrm{~S} / \mathrm{m})$ was detected when Seacat 73 was compared to the corrected conductivity of Seacat 885 . A correction for the drift was derived from both a linear and a non-linear fit to the data of the following form:

$$
\mathrm{y} 1=\mathrm{ax}+\mathrm{b}
$$

where $\mathrm{a}=-0.00052595380, \mathrm{~b}=-6.4245248 \mathrm{e}-05$ and $\mathrm{x}=$ number of days since 10/10/96 00:00 UTC

$$
\begin{gathered}
\mathrm{y} 2=\mathrm{c}+1 /(\mathrm{ax}+\mathrm{b}) \\
\text { where } \mathrm{a}=1.0000000, \mathrm{~b}=12.615262, \mathrm{c}=-0.016915549 \text { and } \\
\mathrm{x}=\text { number of days since } 10 / 10 / 9600: 00 \text { UTC }
\end{gathered}
$$


The final correction, $\mathrm{y}$, was taken from y1 between 10/10/96 00:00 and 12/20/96 00:00 UTC and from y2 between 12/26/96 00:00 UTC and the end of the deployment. From 12/20/96 to $12 / 26 / 96$, a linear ramp ranging from 1 to 0 was applied as $y=[y 1 *$ ramp $]+[y 2 *(1-\operatorname{ramp})]$. $\mathrm{y}$ was set to zero from the deployment to 10/10/96 00:00 UTC. The correction was applied as follows:

$$
\text { Cond }=\text { Cond }-\mathrm{y}
$$

Although the linear fit to the data is quite good, the non-linear curve was used to force the correction to be near constant at the end of the deployment period (May and June). The linear drift correction continues to decrease over this period and may result in over-correcting conductivity (although without any well-mixed data in May or June, this is just a guess).

\section{Seacat $72(62.5 \mathrm{~m})$}

A large drift in conductivity $(<0.05 \mathrm{~S} / \mathrm{m})$ was detected in the comparison of Seacats 72 and 73 . These shifts appear to be episodic rather than gradual, which makes the application of simple mathematical (functional) adjustment schemes nearly impossible. To force agreement during well mixed periods, a correction based directly on the difference between Seacats 72 and 73 was applied.

The conductivity difference $C=$ Seacat 72 - Seacat 73 was first computed. A three day running median filter was passed over $\mathrm{C}$ so that only centered medians were computed when $20 \%$ or more of the 3 day period ( 14.4 hours or more) was well mixed (i.e., the temperature difference between the two Seacats was less than or equal to $0.01 \mathrm{C}$ ). The differences between these well mixed periods were linearly interpolated.

The time series of conductivity difference was then subtracted from the Seacat 72 conductivity. This adjustment scheme assured that during well mixed periods, Seacat 72 and 73 would agree. During stratified periods, the adjustment to the conductivity changed linearly in time between the last well-mixed offset and the next well-mixed offset. If the shifts in conductivity are indeed episodic and occur during times of stratification, then this adjustment scheme will be incorrect. Without any other information during stratified periods, however, it seems to be the "least incorrect" approach (when compared, say, to guessing when there is an abrupt change in the conductivity calibration).

As an aside, it would be interesting to know what is causing these drifts and offsets. The shifts are often quite sudden, which suggests that some real oceanographic event is the cause. Since Seacats 73 and 72 had similar shifts and these are near the bottom, perhaps sediment from the bottom is getting in the conductivity cell and affecting the measurement. Sediment in the cell would change the volume of water in the cell and hence, the "dimensions" of the cell used in the conductivity calibration.

\section{Seacat $1878(67.5 \mathrm{~m})$}

Seacat 1878 also had large conductivity shifts $(<0.06 \mathrm{~S} / \mathrm{m})$ when compared to the adjusted Seacat 72. The shifts were similar in character to those found in Seacat 72 , that is, episodic and large. 
The approach to adjusting the Seacat 1878 conductivities was the same as in the adjustment of Seacat 72. A three day running median filter of the well mixed differences between Seacats 1878 and the adjusted 72 (when more than $20 \%$ of the three day boxcar window contained well mixed points) was used as the basis of the adjustment curve. These differences were linearly interpolated in time to provide adjustments during stratified periods. The adjustment time series was then subtracted from the Seacat 1878 conductivity.

\subsection{2.b. Inshore Site}

Seacat $146(2.0 \mathrm{~m})$

The comparison between Seacats 146 and 71 showed a slight drift in conductivity after 1 March 1997, but it isn't immediately obvious from the data which instrument should be adjusted. The post-cal report from Seabird reported a drift of 0.00120 and .00390 PSU per month for Seacats 146 and 71, respectively. Based on these post-cal results, Seacat 71 was assumed to be the one that drifted and so it was the one to be adjusted. No adjustments were made to Seacat 146.

Seacat $71(20.0 \mathrm{~m})$

The battery failed in Seacat 71 so that the data after 05/06/97 14:30:00 UTC was discarded. The conductivity and temperature data contained some bad points interspersed with good data after 05/02/97 and these bad points were edited out.

A slight conductivity drift $(<0.005 \mathrm{~S} / \mathrm{m})$ was detected in the Seacat 71 conductivity after 03/05/97 (see above). The adjustment offset was as follows:

$$
\begin{aligned}
& \text { offset }=0.0 \text { before } 03 / 05 / 9713: 16: 43 \\
& \text { offset }=5.8739608 \mathrm{e}-05 * x-0.00026745742 \text { after } 03 / 05 / 9713: 16: 43
\end{aligned}
$$

where $\mathrm{x}=$ number of days since 03/01/97 00:00:00 UTC.

The adjustment to the Seacat 71 conductivity was

$$
\text { New Conductivity = Old Conductivity - offset }
$$

After adjusting the conductivity, there is an apparent $0.001 \mathrm{~S} / \mathrm{m}$ bias in the Seacat 71 conductivity when compared to the Seacat 146 conductivity. This bias is due to the pressure difference between the two instruments ( $20 \mathrm{dbar})$ and was NOT removed. The resulting salinities from Seacats 71 and 146 agree very well.

\section{Seacat $1874(52.5 \mathrm{~m})$}

The battery failed in Seacat 1874 . Both the conductivity and temperature started drifting about 2-3 weeks before instrument failed. Data after 12/06/96 23:40:00 UTC was removed.

A drift in Seacat $1874(<0.004 \mathrm{~S} / \mathrm{m})$ conductivity was detected when compared to Seacat 71 . The adjustment was as follows:

$$
\text { offset }=0.0 \text { before 08/02/96 23:23:34 UTC }
$$


offset $=-2.4291928 \mathrm{e}-05 * \mathrm{x}+0.0052221500$ after 08/02/96 23:23:34

where $\mathrm{x}=$ number of days since 01/01/96 00:00:00 UTC.

The adjustment to the Seacat 1874 conductivity was

New Conductivity $=$ Old Conductivity - offset

An apparent bias of $0.001 \mathrm{~S} / \mathrm{m}$ remains between Seacats 1874 and 71 , however this bias is due to the pressure differences between the two instruments $(-32.5 \mathrm{dbar})$.

Seacat $1880(59.5 \mathrm{~m})$

This Seacat was compared to both Seacat 71 and 1874 and a drift was detected $(<0.03 \mathrm{~S} / \mathrm{m})$. Since the first 3 months of the deployment were stratified, no well mixed periods existed between Seacats 1880 and 71 . However, since 1880 and 1874 were only $6.5 \mathrm{~m}$ apart, there was plenty of well mixed data to compare during this time. Seacat 1874 failed in early December, so the remainder of the adjustment was based on well mixed periods between 1880 and 71 during the winter. The adjustment was as follows:

The conductivity differences $\mathrm{C} 1=$ Seacat $1880-71$ and $\mathrm{C} 2=$ Seacat $1880-1874$ were computed. A bias of $0.002 \mathrm{~S} / \mathrm{m}$ was applied to $\mathrm{C} 1$ since these instruments were almost $40 \mathrm{~m}$ apart (to account for the pressure difference of $40 \mathrm{dbar}$ ). The difference time series $\mathrm{C}$ was filled first with the conductivity differences from $\mathrm{C} 1$ during well mixed times only (prescribed as temperature differences less than $0.01^{\circ} \mathrm{C}$ ). $\mathrm{C}$ was then filled in with conductivity differences from C2 during periods when Seacats 1880 and 1874 were well mixed and there was no well mixed data from $\mathrm{C} 1$. A three day boxcar median filter was applied to $\mathrm{C}$ with the restriction that a median value would only be computed when $20 \%$ of the data contained in the three day window were well mixed. The gaps in C (stratified periods) were then linearly interpolated.

The adjusted 1880 conductivity time series was computed as $\mathrm{C}$ subtracted from the old conductivity. This adjustment scheme assured that during well mixed periods Seacats 1880,71 and 1874 would agree. During stratified periods, the adjustment is a "best guess" at how the calibrations are changing. If the calibration changes abruptly during a stratified period, this approach will be less than ideal. Without any other basis for comparison during these periods, though, this approach seems reasonable enough.

Seagauge $46(62.0 \mathrm{~m})$ This instrument had a large drift in conductivity $(<0.35 \mathrm{~S} / \mathrm{m})$ when compared to the adjusted Seacat 1880 . The adjustment was similar to that for Seacat 1880 . A three day boxcar median was used to filter the differences in conductivity between Seagauge 46 and Seacat 1880 . The stratified periods in the filtered difference time series were linearly interpolated. The adjustment was as follows:

New conductivity $=$ Old conductivity $-[$ median filtered $46-1880$ ] 


\subsection{2.c. Offshore Site}

Seacat $141(2.0 \mathrm{~m})$

This Seacat agreed very well with Seacat 1873 . A slight offset in conductivity from March to the end of the deployment was attributed to Seacat 1873. No adjustments were necessary for this instrument.

Seacat $1873(20.0 \mathrm{~m})$

A slight drift was detected in Seacat 1873 conductivity $(<0.01 \mathrm{~S} / \mathrm{m})$ starting in late March 1997 when compared to Seacat 141 . The drift was also apparent in a comparison with Seacat 884. The adjustment was as follows:

offset $=0.0$ before $03 / 21 / 9707: 22: 06$

offset $=-0.00011838607 * x+0.0093888463$ from $03 / 21 / 9707: 22: 06$ to $04 / 19 / 97$

$06: 52: 45$

offset $=0.00023779074 * x-0.029180341$ after 04/19/97 06:52:45

New conductivity $=$ Old conductivity - offset

where $\mathrm{x}=$ number of days since 01/01/97 00:00:00 UTC.

An apparent bias of $0.001 \mathrm{~S} / \mathrm{m}$ remains between Seacats 1873 and 141, however this bias is due to the pressure differences between the two instruments ( $18 \mathrm{dbar})$.

Seacat $884(35.0 \mathrm{~m})$

A bias in conductivity was detected in Seacat 884 when compared to the adjusted Seacat 884 .

This bias was removed as follows:

New conductivity $=$ Old conductivity +0.0015

Seacat $1881(50.5 \mathrm{~m})$

The batteries in Seacat 1881 failed on 01/19/97, but the qualityof the conductivity data began to deteriorate over 3 weeks prior to this. The conductivity values were edited out after 12/24/96 04:20:00 UTC.

This instrument agreed well with the adjusted Seacats 884 and 70 . No adjustment to 1881 was necessary.

Seacat $70(74.5 \mathrm{~m})$

A slight drift in conductivity was detected in Seacat $70(<0.003 \mathrm{~S} / \mathrm{m})$ when compared to Seacat 884 . There were only a few times when both 70 and 884 were in a mixed layer, however the offset between them did not vary significantly and was small relative to some of the other errors detected in the CMO Seacats.

A three day boxcar median was used to filter the differences in conductivity between Seacat 70 and 884 with the restriction that a median value was only computed when $20 \%$ of the data contained in the three day window were well mixed (prescribed as a difference in temperature 
of less than 0.01C). Since the two instruments were seldom in a well mixed layer, only a few median differences were computed. The differences during the stratified period were linearly interpolated from the well mixed median values. The earliest and latest median value in the time series were used to fill in the offsets at the beginning and end of the deployment respectively. A bias of $0.002 \mathrm{~S} / \mathrm{m}$ was removed from the difference time series to account for the pressure difference ( $40 \mathrm{dbar}$ ) between the two instruments. The difference time series was used as the adjustment as follows:

New conductivity $=$ Old conductivity $-[$ median filtered Seacat $70-884]-0.002$

This adjustment scheme assured that during well mixed periods Seacats 70 and 884 would agree. During stratified periods, the adjustment is a "best guess" at how the calibrations are changing. If the calibration changes abruptly during a stratified period, this approach will be less than ideal. Without any other basis for comparison during these periods, though, this approach seems reasonable enough.

Seacat $1876(81.5 \mathrm{~m})$

A drift in conductivity was detected in Seacat $1876(<0.023 \mathrm{~S} / \mathrm{m})$ when compared to the adjusted Seacat 70 . The drift appears episodic in nature, so the median filter approach was used.

The adjustment was the same as for Seacat 70, except that no bias was removed from the difference time series to account for pressure differences (Seacats 1876 and 70 are only separated by $7 \mathrm{~m}$ ).

Seagauge $45(84.0 \mathrm{~m})$

Both the temperature and conductivity were adjusted for Seagauge 45 . A temperature bias of $0.0132 \mathrm{C}$ was detected when Seagauge 45 was compared to Seacat 1876 . These instruments are only separated by $2.5 \mathrm{~m}$ and are almost always within the well mixed bottom boundary layer, so the bias was easily detected. This bias was removed from the Seagauge 45 temperature.

A large drift in conductivity was also detected for Seagauge $45(<0.26 \mathrm{~S} / \mathrm{m})$ when compared to the adjusted Seacat 1876. The adjustment for this drift was the same as for Seacat 70, except no bias was removed from the difference time series to account for pressure differences.

\subsection{2.d. Alongshore Site}

Seacat $142(2.0 \mathrm{~m})$

This Seacat agreed very well with Seacat 68 . A slight offset in conductivity from March to the end of the deployment was attributed to Seacat 68. No adjustments were necessary for this instrument.

Seacat $68(20.0 \mathrm{~m})$

A drift in conductivity was detected in Seacat $68(<0.08 \mathrm{~S} / \mathrm{m})$ when compared to Seacat 142. The drift began in late February and persisted until the end of the deployment. The adjustment was as follows: 
offset $=0.0$ before $02 / 23 / 9722: 41: 06$

offset $=0.00054863941 * x-0.029596466$ from $02 / 23 / 9722: 41: 06$ to $03 / 05 / 9705: 12: 55$

offset $=-0.00011772303 * x+0.012529170$ from $03 / 05 / 9705: 12: 55$ to $04 / 03 / 9704: 31: 42$

offset $=-2.0594906 \mathrm{e}-05 * \mathrm{x}+0.0035750568$ after 04/03/97 04:31:42

New conductivity $=$ Old conductivity - offset

where $\mathrm{x}=$ number of days since 01/01/97 00:00:00 UTC.

An apparent bias of $0.001 \mathrm{~S} / \mathrm{m}$ remains between Seacats 68 and 142, however this bias is due to the pressure differences between the two instruments (18 dbar).

Seacat $883(40.5 \mathrm{~m})$

A conductivity drift was detected in Seacat $883(<0.16 \mathrm{~S} / \mathrm{m})$ when compared to the adjusted Seacat 68. This drift was adjusted using the median filter approach.

A three day boxcar median was used to filter the differences in conductivity between Seacat 883 and 68 with the restriction that a median value was only computed when $10 \%$ of the data contained in the three day window were well mixed (prescribed as a difference in temperature of less than $0.01 \mathrm{C}$ ). The differences during the stratified period were linearly interpolated from the well mixed median values. The last median value in the time series was used to fill in the offsets at the end of the deployment. A bias of $0.0015 \mathrm{~S} / \mathrm{m}$ was removed from the difference time series to account for the pressure difference $(\sim 20 \mathrm{dbar})$ between the two instruments. The difference time series was used as the adjustment as follows:

New conductivity $=$ Old conductivity $-[$ median filtered Seacat $883-68]-0.0015$

The alongshore surface buoy broke free from its moorings in early October and was not reset until early November. This period spans the destruction of the stratification between Seacats 883 and 68 , so no well mixed data is available before early November. Based on a comparison with Seacat 882 , it was estimated that Seacat 883 began to change its calibration around 10/15/96. As a result, a linear adjustment was made between 10/16 and 11/12/96 and a constant bias was applied prior to $10 / 16$ as follows:

offset $=-0.005$ before $10 / 16 / 9621: 44: 51$

offset $=-0.0013814112 * x+0.39547961$ from $10 / 16 / 9621: 44: 51$ to $11 / 12 / 96$ 03:22:30

offset $=$ [median filtered Seacat $883-68]-0.0015$ after 11/12/96 03:22:30

New conductivity $=$ Old conductivity - offset

where $\mathrm{x}=$ number of days since 01/01/96 00:00:00 UTC.

This adjustment scheme assured that during well mixed periods Seacats 883 and 68 would agree. During stratified periods, the adjustment is a "best guess" at how the calibrations are changing. If the calibration changes abruptly during a stratified period, this approach will be 
less than ideal. Without any other basis for comparison during these periods, though, this approach seems reasonable enough.

Seacat $882(60.5 \mathrm{~m})$

Seacat 882 had a drift in conductivity $(<0.20)$ similar to that of Seacat 883 . The adjustment was also similar.

A three day boxcar median filter was applied to the well mixed Seacat differences between 882 and the adjusted 883 with the restriction that a median value would be computed only when $10 \%$ of the data within a three day window were well mixed. A $0.0015 \mathrm{~S} / \mathrm{m}$ bias was removed from the difference to account for the pressure difference between the two instruments (20 dbar). Differences during stratified periods were linearly interpolated. The adjustment was then

New conductivity $=$ Old conductivity $-[$ median filtered Seacat $882-883]-0.0015$

A constant and linear adjustment was used to approximate the changes in calibration for Seacat 882 's conductivity in exactly the same fashion as for Seacat 883 . These adjustments were as follows:

offset $=-0.016$ before $10 / 21 / 9614: 55: 30$

offset $=-0.0017983009 * \mathrm{x}+0.51381877$ from $10 / 21 / 9614: 55: 30$ to $11 / 15 / 9619: 00: 00$

offset $=[$ median filtered Seacat $882-883$ ] - 0.0015 after 11/15/96 19:00:00

New conductivity $=$ Old conductivity - offset

where $\mathrm{x}=$ number of days since 01/01/96 00:00:00 UTC.

Seacat $144(67.5 \mathrm{~m})$

This Seacat had a drift in conductivity $(<0.07 \mathrm{~S} / \mathrm{m})$ which was detected when compared to the adjusted Seacat 882. The adjustment for this Seacat involved the boxcar median approach.

A three day boxcar median filter was applied to the well mixed Seacat differences between 144 and the adjusted 882 with the restriction that a median value would be computed only when $10 \%$ of the data within a three day window were well mixed. Differences during stratified periods were linearly interpolated. A $0.0005 \mathrm{~S} / \mathrm{m}$ bias was removed from the differences to assure that the salinity and density differences were near zero. This bias may be due the pressure difference between the instruments $(7 \mathrm{dbar})$. The adjustment was then

New conductivity $=$ Old conductivity $-[$ median filtered Seacat $144-882]-0.0005$

Seagauge $49(70.0 \mathrm{~m})$

This seagauge had a drift in conductivity $(<0.30 \mathrm{~S} / \mathrm{m})$ which was detected when compared to the adjusted Seacat 144. The adjustment for this tidegauge involved the boxcar median approach. 
A three day boxcar median filter was applied to the well mixed Seacat differences between 49 and the adjusted 144 with the restriction that a median value would be computed only when $10 \%$ of the data within a three day window were well mixed. Differences during stratified periods were linearly interpolated. The adjustment was then

New conductivity = Old conductivity - [median filtered Seagauge 49 - 144]

\subsection{Pressure}

Seaguage note: The Seagauges were SBE 26 units, all set up to record pressure at 5 minutes. Wave sampling was disabled to save internal storage space. Pressure from Seagauges was only minimally processed, essentially only inventoried.

Seacat-p note: There were SBE-16 Profilers at 35 meters on Central and Offshore surface moorings. There are no plans to make use of any pressure data from these instruments.

\subsection{3.a. Central Site}

There was no Seaguage at the Central site.

\subsection{3.b. Inshore Site}

Seagauge $46(62 \mathrm{~m})$

This SBE 26, with pressure sensor 61776, was set up to record pressure at 5 minutes. The pressure data from this instrument required no special processing.

\subsection{3.c. Offshore Site}

Seagauge $45(84 \mathrm{~m}) \quad 5 \mathrm{~m}$

This SBE 26, with pressure sensor 61768, recorded pressure at 5 minutes. Pressure from this instrument required no special processing.

\subsection{3.d. Alongshore Site}

Seagauge $49(70 \mathrm{~m}) \quad 5 \mathrm{~m}$

This SBE 26, with pressure sensor 61777, recorded pressure at 5 minutes. Pressure from this instrument required no special processing.

\subsection{Surface Waves}

The Seatex Wavescan buoy was deployed at the Central site of the CMO array (40.4933 N, $70.5047 \mathrm{~W}$ ) between July 1996 and June 1997. The buoy is designed as a wave rider, with a flotation system on its tether that is meant to minimize any restriction of the buoy's motion.

\subsection{4.a. Seatex deployment summary}

The data record was not continuous due to two failures of the surface tether which necessitated recovery and re-deployment of the buoy. The buoy was deployed three times during CMO, as described in Table III.14.1. The first deployment started on 30 July 1996, 21:30 (all times UTC). The buoy broke free on 01 September, sometime after 18:30 during hurricane Edouard. It was recovered on 04 September, 21:00. The second deployment started on 26 September 
1996, 22:30 UTC. The buoy broke free again on 24 January 1997, sometime after 21:00. Recovery from the second deployment was on 6 February, 17:00. The third deployment started on 17 April 1997, 04:30 and continued without incident until 12 June 1997, 21:30 when the buoy was recovered along with the rest of the CMO moored array.

It appeared that data obtained during periods of free drift were of good quality. Thus, the start and stop times of good data for each deployment are:

\begin{tabular}{|l|l|l|}
\hline Deployment & Start & Stop \\
\hline 1 & $96-07-302200$ & $96-09-042100$ \\
\hline 2 & $96-09-262200$ & $97-02-061700$ \\
\hline 3 & $97-04-170500$ & $97-06-122100$ \\
\hline
\end{tabular}

Table 3.14.1. Seatex Data Dates

\subsection{4.b. Data acquisition system sampling scheme}

The Data Acquisition System (DAS) was configured to burst sample once per hour for a duration of (approximately) $17 \mathrm{~min}$. Each burst consisted of 1024 samples obtained at a rate of $1 \mathrm{~Hz}$ (sample interval $=1024 / 60=17.067 \mathrm{~min})$. Each DAS file contained "raw" data (1024 points of heave, pitch, roll, compass), plus scalar wavefield parameters, spectral data, and statistics derived from the raw data.

The DAS clock was "adjusted" so that even though sampling started "on the hour" for the DAS, the actual interval was (approximately) centered on the hour. This was done by setting the DAS clock 8 minutes slow. The time recorded by the DAS appears to be the start time of the burst. Thus, since we want the center time for the sample interval (start time plus $8 \mathrm{~min}$ ), the erroneous DAS clock time is actually the time we want.

The time base is UTC. Times in the ASCII data files are decimal yearday. Days for the first deployment are yearday 1996. The second deployment spans 1996-1997, but yearday is continuous starting in 1996 (note that 1996 is leap year, 366 days). Days in the third deployment are yearday 1997. By convention, yearday 1.5 is noon on January 1.

\subsection{4.c. Initial processing}

Binary files uploaded from the Seatex DAS were unpacked and converted to ASCII by the program seatex.c (Nan Galbraith, March 1997). Four types of ASCII output files were created: (1) "high-speed" data, consisting of $1 \mathrm{~Hz}$ heave, roll, pitch, and compass during each $17 \mathrm{~min}$ burst, (2) "results", consisting of mean wavefield parameters for each burst, (3) "standards", consisting of heave, roll, pitch and compass statistics for each burst, and (4) "spectral" data, consisting of frequency spectra of heave, direction, and directional spread for each burst.

The high-speed data were left as ASCII files. The results, standards, and spectral data were converted to EPIC. Deployment 1 and 3 EPIC data were continuous in time and of high quality; no further processing was done. 
Data from the second deployment were found to have a significant number of timing and data errors. Most of the timing errors consisted of day 15 or hour 15 of the date being replaced by zero. The timing errors could be easily identified, but the wave field parameters for those records appeared to be corrupted as well. Thus, it was decided to eliminate all records that had timing errors. Remaining wave field parameters that were clearly out of range were interpolated using editepicf.c. There were some bad points in the maximum wave height parameter that were not detected by editepicf. These were flagged (set to $1 e+35)$ using program pplus. Despite these efforts, the deployment 2 data remain noisy.

\subsection{4.d. Recorded parameters}

The parameters recorded in different file types are outlined in Table 3.14.2.

Results files:

\begin{tabular}{|l|l|l|}
\hline VARIABLE & DESCRIPTION & UNITS \\
\hline HM0 & significant wave height & $(\mathrm{m})$ \\
\hline H_MAX & height of maximum wave & $(\mathrm{m})$ \\
\hline HM0LF & sig wave ht of swell & $(\mathrm{m})$ \\
\hline SFP & energy density at T & $\left(\mathrm{m}^{\wedge} 2 / \mathrm{Hz}\right)$ \\
\hline RB & spectral width & $(\mathrm{Hz})$ \\
\hline & & \\
\hline MDIR & "main" wave direction & $(\mathrm{deg})$ \\
\hline THTP & vector mean dir at TP & $(\mathrm{deg})$ \\
\hline THHF & mean dir at high freq & $(\mathrm{deg})$ \\
\hline THLF & mean dir at low freq & $(\mathrm{deg})$ \\
\hline UI & unidirectivity index & $\mathrm{n} / \mathrm{a}$ \\
\hline & & \\
\hline TP & period of spectral peak & $(\mathrm{s})$ \\
\hline TPC & TP from spectral moments & $(\mathrm{s})$ \\
\hline TM02 & spectral mean period & $(\mathrm{s})$ \\
\hline & & \\
\hline COMPM & vector mean compass & $(\mathrm{deg})$ \\
\hline
\end{tabular}


Standards files:

\begin{tabular}{|l|l|l|}
\hline VARIABLE & DESCRIPTION & UNITS \\
\hline hmin, hmax & min/max heave & $(\mathrm{m})$ \\
\hline hmean & mean heave & $(\mathrm{m})$ \\
\hline hstdev & heave standard deviation & $(\mathrm{m})$ \\
\hline & & \\
\hline rmin, rmax & min/max roll & $(\mathrm{deg})$ \\
\hline rmean & mean roll & $(\mathrm{deg})$ \\
\hline rstdev & roll standard deviation & $(\mathrm{deg})$ \\
\hline pmin, pmax & min/max pitch & $(\mathrm{deg})$ \\
\hline pmean & mean pitch & $(\mathrm{deg})$ \\
\hline pstdev & pitch standard deviation & $(\mathrm{deg})$ \\
\hline & & \\
\hline cmin, cmax & min/max compass & $(\mathrm{deg})$ \\
\hline cmean & mean compass & $(\mathrm{deg})$ \\
\hline cstdev & compass standard deviation & $(\mathrm{deg})$ \\
\hline
\end{tabular}

Spectral files:

\begin{tabular}{|l|l|l|}
\hline VARIABLE & DESCRIPTION & UNITS \\
\hline depth $(*)$ & frequency & $(\mathrm{Hz})$ \\
\hline hsp & heave spectrum & $\left(\mathrm{m}^{\wedge} 2 / \mathrm{Hz}\right)$ \\
\hline hspr & directional spread & $(\mathrm{rad})$ \\
\hline hth & directional spectrum & $(\mathrm{deg})$ \\
\hline
\end{tabular}

Table 3.14.2. Recorded Parameters of Seatex Wavescan Files

* To maintain compliance with EPIC standards (allowing existing EPIC tools to be used to process the files) the frequency is stored in the 'depth' variable. This variable has the long_name 'Frequency' and units of ' $\mathrm{Hz}$ ' in an attempt to flag this for the user.

3.14.e. Cleanup of "Results" files (November 1997)

EPIC files of "results", "standards", and "spectra" were read into Matlab and converted to binary files. Subsequent processing was done using Matlab, and final versions of the data files are in Matlab binary (.mat) format.

Deployments 1 and 3: Start and end dates of good data were determined for each deployment and the records were truncated accordingly. Yeardays in deployment 3 had 366 days added to produce continuous yearday (1996). No de-spiking or interpolation was needed.

Deployment 2: Start and end dates for good data were determined and an evenly spaced timebase was generated between the start/end dates. Records contained both gaps and bad points. Gaps were mostly related to the "fifteens" problem: Data were garbled for hour 15 or day 15 (see above). Thus, there were one hour gaps each day (at hr 15), plus a few 
unexplained gaps of 1-3 hr, which could be interpolated with good results. In addition, there were 6 gaps of $>3$ hours (see Table 3.14.3). To provide a continuous timebase, these were also interpolated, but the effect of the missing data is noticeable.

\begin{tabular}{|l|l|l|}
\hline yearday & length of gap & cause \\
\hline 289 & $\sim 1$ day & date problem, Oct 15 \\
\hline 320 & $\sim 1$ day & date problem, Nov 15 \\
\hline 350 & $\sim 1$ day & date problem, Dec 15 \\
\hline $376-377$ & 0.7 day & unknown \\
\hline 381 & $\sim 1$ day & date problem, Jan 15 \\
\hline $395-6$ & 0.7 day & unknown \\
\hline
\end{tabular}

Table 3.14.3. Gaps in Seatex Wavescan Data Record

Bad points were cleaned up by examining histograms of each variable to find $\mathrm{min} / \mathrm{max}$ limits, flagging points outside the limits, and eliminating the flagged points. Flagged points and gaps were then filled by interpolation to the uniform (hourly) time base.

\subsection{4.f. Cleanup of "Spectral" files (August 1998)}

Deployments 1 and 3: Start and end dates of good data were determined for each deployment and the records were truncated accordingly. Yeardays in deployment 3 had 366 days added to produce continuous yearday (1996).

Deployment 2: Start and end dates for good data were determined and an evenly spaced timebase was generated between the start/end dates. Records contained both gaps and bad points. Gaps were mostly related to the "fifteens" problem (see above). Bad points were identified by values of heave spectrum (hsp) $>20$ in the first frequency bin. This turned out to be a good index for all frequency bins and also for the other spectral files. Bad points were eliminated from the record, then bad points and gaps were filled by interpolation to the uniform (hourly) timebase.

Heave spectra: Timing errors were fixed in steps 1 and 2 above, but the spectral data needed some further editing. Deployments 1 and 3 showed "drop-outs" where a frequency bin had spectral level $=0.0$. The minimum "good" value appeared to be 0.0031 . Thus, the simple approach was to find the zeros and set them to 0.0031 . For deployment 2 , both drop-outs (spectral level $=0.0$ ) and "noise" (frequency bins with very low amplitude) were found.

Setting all values less than 0.0031 equal to 0.0031 was not effective. The low amplitude points needed to be interpolated.

The approach taken was as follows: Find the bad points (hsp<0.0031) in the first 5 frequency bins and set them equal to 0.0031 . This was a reasonable fix for the "zeros" found at low frequency. At the same time, look for bad points in the last frequency bin and set them equal to the mean for bin $64(=0.03)$. This ensured that the bins between 6 and 64 could be properly interpolated on the next pass. On the next pass, eliminate the remaining bad points and interpolate any gaps using the original frequency bin spacing. 
Directional spectra: Timing errors were fixed in steps 1 and 2 above, but the spectral data needed some further editing. Deployments 1 and 3 did not have distinguishable bad points. For deployment 2, "drop-outs" (direction dropping to $<10$ degrees in individual frequency bins) were distinguishable, Histograms indicated a "tail" on the distribution (more points than would be expected) between $0-6$ degrees.

Detection and interpolation of "bad" points was attempted, but the "cleaned" data appeared worse than the original. Thus, deployment 2 directional data remain "noisy" and an effective procedure to clean up the data remains to be implemented.

\subsection{4.g. Magnetic variation and compass correction (September 1998)}

Background: Magnetic variation correction was not applied to the Seatex compass during initial processing. Significant differences (10-15 degrees) between high-frequency wave direction and wind direction were observed, even after magnetic variation was accounted for. A post-cruise compass calibration showed unanticipated compass error (up to 12 degrees) due to placement of lantern batteries in Seatex well. Thus, both magnetic variation and compass correction must be done.

Evaluation: Two different corrections were evaluated. The first was based on a fit to the buoy spin data collected by Neil McPhee, the second was based on a fit to the difference between the Seatex parameter mean direction at high frequency and the wind direction (THHF - WDIR). In each case a fit of the form

$$
\text { error }=A+B \sin (\text { compass }+ \text { phi) }
$$

was used. The residual after correcting using both fits was also evaluated. The results were as follows (all values in degrees):

\begin{tabular}{|l|r|r|r|}
\hline method & $\mathrm{A}$ & $\mathrm{B}$ & phi \\
\hline buoy spin & 0.8 & 11.8 & -61.6 \\
\hline wind error & 6.1 & 5.7 & -61.2 \\
\hline & & & \\
\hline spin residual & 4.8 & 4.8 & 19.3 \\
\hline wind residual & -0.2 & 2.1 & -18.3 \\
\hline
\end{tabular}

Table 3.14.4. Seatex Wavescan Compass Correction Evaluation

The fit to the difference between thhf and the wind direction was used for the correction using the following justification.

1. There is no known physical basis for a mean offset or sinusoidal deviation of the highfrequency wave direction relative to the wind.

2. The wind direction has been subjected to several independent checks by Baumgartner and Anderson.

3. The difference between thhf and wind shows sinusoidal variation with the same phase as the spin error. This supports the supposition that the difference is due to compass error (although wind error amplitude is only $1 / 2$ of spin error). 
4. The spin was not conducted under actual deployment conditions (the buoy was reconstructed after recovery and down-cruise), thus it is only "indicative" of the error in the field.

5. Correction using spin_error is not very effective (offset $=5$, amp $=5$ ) compared to no correction at all (offset=6, amp $=6$ ).

Applying the correction: Magnetic variation and compass correction were applied to results files (four directional parameters, thhf, thlf, thtp, mdir plus compass) and the directional spectra (hth array in hth_xx.mat). The correction consists of three steps:

1. rotation through 180 degrees (met to ocean convention).

2. magnetic variation correction (magvar $=-15.417 \mathrm{deg}$ ).

3. compass error correction (based on wind direction).

All corrections are done to data after "cleaning" (editing) as described above. The compass is a special case since the rotation through $180 \mathrm{deg}$ (met to ocean convention) is not desired. The compass values the standards files (cmin, cmax, cmean, cstdev) are not corrected.

\subsection{4.h. Combined non-directional wave data}

Three data sources were used to form a continuous time series of significant wave height (HMO), peak wave period (PWP) and average wave period (AWP) during the Coastal Mixing and Optics Experiment. The primary data were a subset of non-directional wave parameters from the three deployments of the Seatex Wavescan buoy. When Seatex data were not available, wave parameters from NDBC buoys 44008 and 44025 were used. Buoy 44008 is located at $40.50 \mathrm{~N}, 69.42 \mathrm{~W}$, about $90 \mathrm{~km}$ east of the CMO site. Buoy 44025 is located at 40.25 $\mathrm{N}, 73.17 \mathrm{~W}$, about $225 \mathrm{~km}$ west and $25 \mathrm{~km}$ south of the CMO site.

The second Seatex deployment was the longest continuous time period where both Seatex and NDBC data were available. This period was used to assess the relationship between Seatex and NDBC wave parameters. Wave parameters from NDBC buoy 44008 showed the best correlation with those from the Seatex, and could be used reliably (see rms errors below) to fill Seatex data gaps. Unfortunately, the record from buoy 44008 ended before the end of the CMO experiment and could not be used to completely fill the gap between Seatex deployments 2 and 3. Parameters from buoy 44025 showed the next best correlation with the Seatex, and were used during the short ( 7.5 day) period that neither Seatex nor buoy 44008 data were available.

Coefficients from a linear regression analysis between NDBC and Seatex records during deployment 2 were used to adjust the NDBC data prior to merging with the Seatex record. 
The correlation coefficients and rms error of the fits for each variable were:

\begin{tabular}{|l|c|c|c|c|c|c|}
\hline & \multicolumn{3}{|c|}{ CORRELATION } & \multicolumn{3}{c|}{ RMS ERROR } \\
\hline SEATEX & HM0 & PWP & AWP & HM0 & PWP & AWP \\
\hline NDBC 44008 & 0.93 & 0.74 & 0.91 & $0.37 \mathrm{~m}$ & $1.68 \mathrm{~s}$ & $0.47 \mathrm{~s}$ \\
\hline NDBC 44025 & 0.79 & 0.67 & 0.77 & $0.61 \mathrm{~m}$ & $1.86 \mathrm{~s}$ & $0.73 \mathrm{~s}$ \\
\hline
\end{tabular}

Table 3.14.5. Seatex Wavescan and NDBC Comparison

The gap between Seatex deployments 1 and 2 was filled completely with NDBC 44008 data. Six gaps in the Seatex deployment 2 record of greater than 3 hours, but less than 1 day, were also filled with NDBC 44008 data. The gap between Seatex deployments 2 and 3 was only partially filled since the NDBC 44008 record ended prior to the start of deployment 3 . The remaining gap of about 7.5 days was filled with NDBC 44025 data.

The data sources for various time periods in the continuous record are noted below.

\begin{tabular}{|c|l|}
\hline TIME PERIOD & \multicolumn{1}{|c|}{ DATA SOURCE } \\
\hline $212.9167-248.8750$ & Seatex (deployment 1) \\
\hline $248.9167-270.8750$ & NDBC 44008 \\
\hline $270.9167-403.7083$ & Seatex (deployment 2) \\
\hline $403.7500-465.6667$ & NDBC 44008 \\
\hline $465.7083-473.1667$ & NDBC 44025 \\
\hline $473.2083-529.8750$ & Seatex (deployment 3) \\
\hline
\end{tabular}

Table 3.14.6. Sources of Non-directional Wave Parameters

\subsection{ADCP Velocity}

Three types of ADCPs were deployed at three sites. A BroadBand Workhorse was deployed on the Inshore subsurface mooring, a NarrowBand ADCP on the Offshore subsurface mooring, and a modified BroadBand on a dedicated subsurface mooring at the Central site. All were upward-facing, each required a slightly different processing system.

\subsection{5.a. Inshore ADCP: $300 \mathrm{kHz}$ workHorse}

A $300 \mathrm{kHz}$ RD Instruments "WorkHorse" BroadBand ADCP (SN 100) with a dual-axis electrolytic tilt sensor, a RDI designed flux gate compass, and 20 Mbytes of PCMCIA solid state memory was deployed on the CMO Inshore subsurface mooring. The mooring was deployed on 02 August 1996 and recovered on 02 June 1997. Water depth was 63m and the $\mathrm{ADCP}$ beams were pointed upwards from $55.5 \mathrm{~m}$ depth. A "standard" ensemble sampling scheme was used (no burst sampling). A sequence of 22 acoustic transmissions (pings) separated by $8.15 \mathrm{sec}$ were averaged together to form one ensemble every $3 \mathrm{~min}$. The backscattered signal was processed over time intervals corresponding to a $4 \mathrm{~m}$ depth cell length. The depth resolution of the transmitted pulse (pulse length) was also $4 \mathrm{~m}$ (no oversampling in depth). Twelve depth cells were recorded, giving a nominal profiling range of 
$50 \mathrm{~m}$ to $5 \mathrm{~m}$ depth. Velocities were corrected for tilt and converted to geographic coordinates by the ADCP firmware prior to ensemble averaging. The manufacturer's estimate of velocity precision for the $3 \mathrm{~min}$ ensembles is about $0.6 \mathrm{~cm} / \mathrm{s}$.

Data files containing header information, velocity profiles, and echo amplitude profiles were created in NetCDF EPIC format. Bin depths and velocity magnitudes were corrected for the in-situ soundspeed. A magnetic variation correction of -15.417 degrees was applied to the horizontal velocity vectors. Good data start on 08-02-96, 20:27 UTC, just after deployment. Data end on 11-27-96 01:57, prior to the mooring recovery, due to power and memory limitations. The depth bin nearest the transducer was unusable, and was eliminated from the final data files.

Corruption from the sidelobe surface hit was expected at about $3 \mathrm{~m}$ from the surface. Mean intensity profiles showed that the influence of the surface hit extended to the $5 \mathrm{~m}$ depth bin, but not below. The $37 \mathrm{~m}$ depth bin was also corrupted, presumably due to the steel sphere at $38 \mathrm{~m}$ on the inshore subsurface mooring. Thus, WorkHorse ADCP bins 1 and 9 should not be used in scientific analyses.

Comparison of WorkHorse ADCP velocity to the Inshore VMCM at $15 \mathrm{~m}$ showed periods of 1-5 days with large discrepancies. Large error velocity variance was associated with the large discrepancies. It was determined that surface wave orbital velocities were aliased into the WorkHorse ADCP ensemble average velocities because the ping interval (8.15s) was long compared to surface wave periods. This effect decreased with increasing depth, and was small below $30 \mathrm{~m}$. WorkHorse ADCP velocities above $30 \mathrm{~m}$ depth must be treated with care.

\subsection{5.b. Offshore ADCP: $300 \mathrm{kHz}$ narrowBand}

A $300 \mathrm{kHz}$ RD Instruments NarrowBand ADCP (SN 593) with Humphries pendulum tilt sensors, a KVH flux gate compass, and 18 Mbytes of EEPROM solid state memory was deployed on the CMO Offshore subsurface mooring. The mooring was deployed on 31 July 1996 and recovered on 16 June 1997 from R/V Oceanus. The water depth was $86 \mathrm{~m}$ and the $\mathrm{ADCP}$ beams were pointed upwards from $77 \mathrm{~m}$ depth. A "standard" ensemble sampling scheme was used. A sequence of 100 pings separated by $1.64 \mathrm{sec}$ were averaged together to form one ensemble every $3 \mathrm{~min}$. The depth cell length was $4 \mathrm{~m}$, while the nominal depth resolution of the transmitted pulse was $8 \mathrm{~m}$. Thus, the data were over-sampled in depth and successive depth cells were not independent. Eighteen cells were recorded, giving a nominal profiling range of $70 \mathrm{~m}$ depth to the surface $(0 \mathrm{~m}$ depth). Velocities were corrected for tilt and converted to geographic coordinates by the $\mathrm{ADCP}$ firmware prior to ensemble averaging. The manufacturer's estimate of velocity precision for the $3 \mathrm{~min}$ ensembles is about $0.7 \mathrm{~cm} / \mathrm{s}$.

Data files containing header information, and velocity, percent good, and echo amplitude profiles were created in NetCDF EPIC format. Bin depths and velocity magnitudes were corrected for the in-situ soundspeed. A magnetic variation correction of -15.417 degrees was applied to the horizontal velocity vectors. Good data start on 07-31-96, 19:15 UTC, just after deployment. Data end on 11-24-96 01:42 UTC, prior to the mooring recovery, due to power and memory limitations. 
Corruption from the sidelobe surface hit was expected at about $10 \mathrm{~m}$ from the surface. Mean intensity profiles showed that bins shallower than $8 \mathrm{~m}$ were clearly influenced by the surface hit. It was more difficult to determine whether data at $12 \mathrm{~m}$ were corrupted. There was no evidence of corruption from the steel sphere at $47 \mathrm{~m}$ on the offshore subsurface mooring. Thus, NarrowBand ADCP bins 1-3 should not be used in scientific analysis, and bin 4 should be treated with caution.

Comparison of NarrowBand ADCP velocity to the Offshore VMCM at $15 \mathrm{~m}$ showed good agreement (within a few $\mathrm{cm} / \mathrm{s}$ ). There was no indication of corruption from surface wave aliasing (note ping interval of $1.64 \mathrm{~s}$ ).

\subsection{5.c. Central ADCP: $300 \mathrm{kHz}$ broadBand fanbeam}

A $300 \mathrm{kHz} \mathrm{RD}$ Instruments BroadBand ADCP (SN 1486) modified for use as a surfacescanning "fanbeam" sonar was deployed on a dedicated subsurface mooring at the CMO Central site $4029.50^{\prime} \mathrm{N}, 7030.60^{\prime} \mathrm{W}$. There were two deployments of the fanbeam ADCP. The first deployment was on 27 September 1996 with recovery on 09 February 1997, both from R/V Oceanus. The second deployment was on 17 April 1997 from the R/V Knorr with recovery on 12 June 1997 from $R / V$ Oceanus.

The instrument consisted of standard RD Instruments $300 \mathrm{kHz}$ BroadBand ADCP electronics attached to a custom designed transducer head. The BroadBand sensors included a dual-axis electrolytic tilt sensor and a Precision Navigation TCM-2 flux gate compass. The transducer head contained four bar-shaped transducers (approximately $250 \mathrm{~mm}$ by $45 \mathrm{~mm}$ by $10 \mathrm{~mm}$ ) oriented so that the beams were narrow (about 3 degrees) in azimuth and broad (about 24 degrees) in elevation. The beam center lines were angled upwards by 12 degrees and separated by 30 degree increments in azimuth.

The instrument was housed in a 60 inch syntactic foam sphere. A specially designed plate and collar held the instrument housing vertically in a hole through the center of the sphere with the transducer head on top. The mooring was deployed in $70 \mathrm{~m}$ of water with the top of the sphere at $30 \mathrm{~m}$ depth.

A burst sampling scheme was used. For the first deployment, 37 acoustic transmissions (pings) separated by 1.3 seconds were averaged together to form an ensemble, and 20 ensembles separated by $1 \mathrm{~min}$ were recorded to memory during $20 \mathrm{~min}$ bursts. The burst repetition time was one hour, and the burst interval was centered on the hour. For the second deployment 60 pings separated by $1.0 \mathrm{~s}$ were averaged for each ensemble, and 30 ensembles separated by 1 min were recorded during 30 min bursts. Ping-by-ping heading and tilt correction could not be done by the instrument firmware due to the unconventional geometry of the beams. Instead, the averaged "beam" velocities were recorded along with heading, pitch, and roll information (mean and standard deviation) for each ensemble.

Binary data files were extracted directly from the internal PCMCIA recorder. These data can be examined and extracted in ASCI format using the RD Instruments BBLIST program. 


\section{Section 4. Data Presentation}

The processed time series are summarized in sections 4.1-4.5. Surface forcing data are presented in section 4.1, water temperatures in section 4.2 , salinities in section 4.3 , bottom pressures in section 4.4, and water velocities in section 4.5. Each section includes a summary of the data return, basic statistics (means, standard deviations, minimums and maximums), plots of the time series, and representative spectra (typically from the Central site). 


\subsection{Surface Forcing}

The surface forcing section includes time series of the measured meteorological variables, wind stress and surface heat flux, and surface wave characteristics. Wind stress and surface heat flux were estimated using the formulation described in Fairall et al. (1996), including the cool skin, but not the warm layer corrections. Complete composite time series of meteorological variables and fluxes are presented for the Central site where redundant sensors were deployed.

Time series of the meteorological parameters from the WeatherPaks at the Inshore, Offshore, and Alongshore sites are included for completeness. The WeatherPak data has not been processed to remove bad values because of the poor data return from these instruments. 


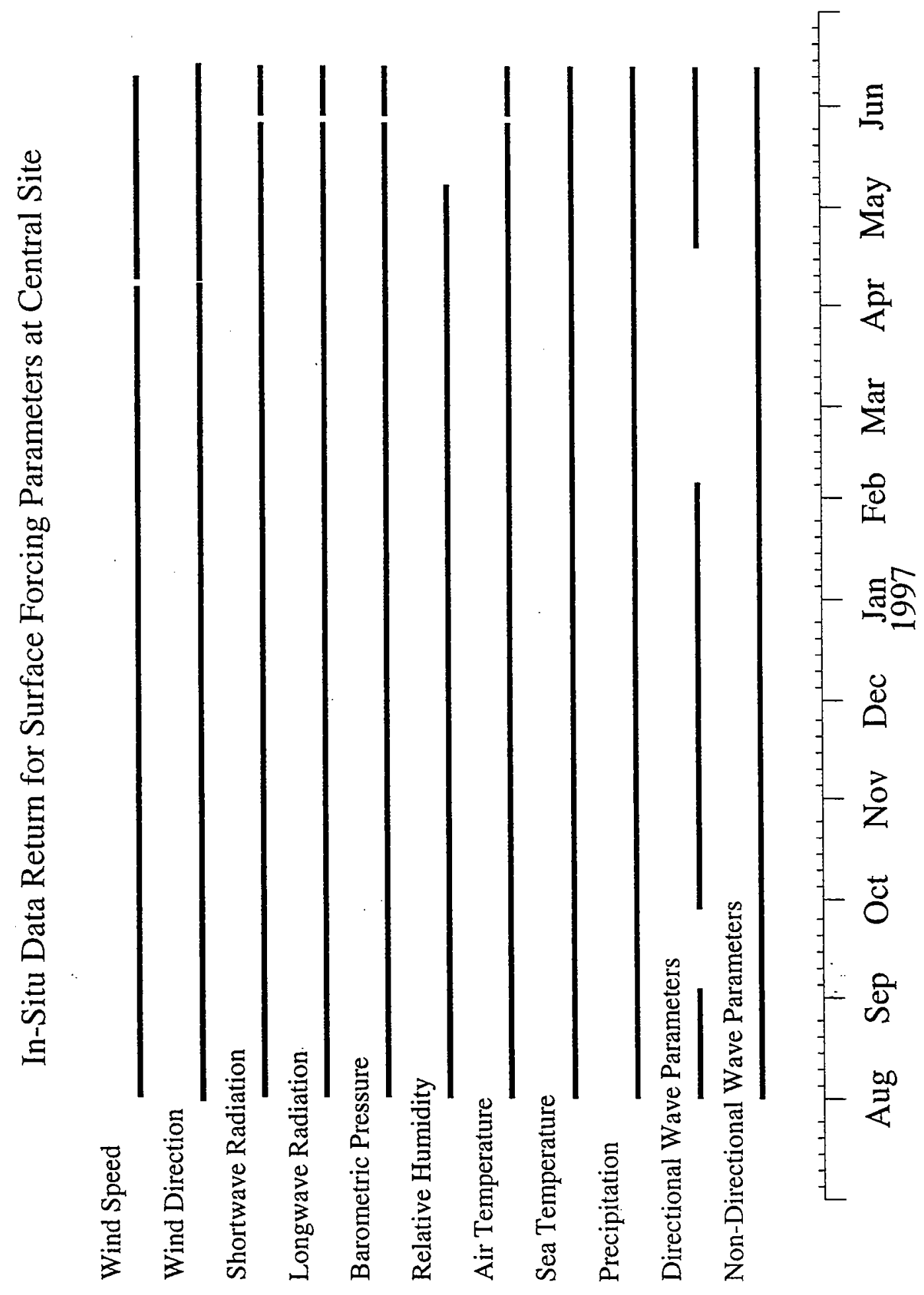

Figure 4.1.1. Surface Forcing Data Return, Central Site 


\section{Central Surface Forcing Statistics}

Dates: $1996 / 07 / 3015: 15$ to $1997 / 06 / 1314: 00,30524$ Records

Measured Meteorological Parameters

\begin{tabular}{|l|r|r|r|r|}
\hline Variable & \multicolumn{1}{l|}{ Mean } & \multicolumn{1}{|l|}{ StdDey } & Minimum & Maximum \\
\hline wnde & 1.43 & 5.35 & -20.17 & 18.58 \\
\hline wndn & -0.21 & 5.09 & -20.68 & 16.87 \\
\hline srad & 142.50 & 232.44 & 0.00 & 1039.55 \\
\hline hrh & 84.84 & 11.76 & 41.44 & 103.11 \\
\hline bpr & 1016.18 & 9.15 & 977.35 & 1039.95 \\
\hline stmp & 9.92 & 4.34 & 3.87 & 21.68 \\
\hline atmp & 9.24 & 5.60 & -9.54 & 25.69 \\
\hline lrad & 324.05 & 48.39 & 211.01 & 428.21 \\
\hline precip & 469.97 & 207.83 & -0.46 & 794.42 \\
\hline
\end{tabular}

Key:

\begin{tabular}{|l|l|l|}
\hline wnde & wind velocity east & $\mathrm{m} / \mathrm{s}$ \\
\hline wndn & wind velocity north & $\mathrm{m} / \mathrm{s}$ \\
\hline srad & shortwave radiation & watts $/ \mathrm{m}^{2}$ \\
\hline hrh & relative humidity & $\%$ \\
\hline bpr & barometric pressure & millibars \\
\hline stmp & water temperature & ${ }^{\circ} \mathrm{C}$ \\
\hline atmp & air temperature & ${ }^{\circ} \mathrm{C}$ \\
\hline lrad & longwave radiation & watts $/ \mathrm{m}^{2}$ \\
\hline precip & accumulated precipitation & $\mathrm{mm}$ \\
\hline
\end{tabular}

Derived Flux Parameters

\begin{tabular}{|l|r|r|r|r|}
\hline Variable & \multicolumn{1}{|l|}{ Mean } & \multicolumn{1}{l}{ StdDev } & Minimum & Maximum \\
\hline QH & -35.02 & 58.63 & -269.23 & 159.61 \\
\hline QB & -12.23 & 45.87 & -317.29 & 119.64 \\
\hline Qs & 134.66 & 219.66 & 0.00 & 982.37 \\
\hline Q1 & -39.31 & 37.81 & -125.28 & 43.37 \\
\hline QN & 48.10 & 249.30 & -648.66 & 939.64 \\
\hline taue & 0.03 & 0.13 & -1.24 & 1.00 \\
\hline taun & -0.02 & 0.12 & -1.28 & 0.76 \\
\hline taumag & 0.12 & 0.14 & 0.00 & 1.29 \\
\hline prate & $2.9 \mathrm{e}-08$ & $2.1 \mathrm{e}-07$ & $-4.5 \mathrm{e}-06$ & $8.4 \mathrm{e}-06$ \\
\hline evap & $1.4 \mathrm{e}-08$ & $2.4 \mathrm{e}-08$ & $-6.5 \mathrm{e}-08$ & $1.1 \mathrm{e}-07$ \\
\hline
\end{tabular}

Key:

\begin{tabular}{|l|l|l|}
\hline QH & latent heat flux & $\mathrm{W} / \mathrm{m}^{2}$ \\
\hline QB & sensible heat flux & $\mathrm{W} / \mathrm{m}^{2}$ \\
\hline Qs & net sw radiation & $\mathrm{W} / \mathrm{m}^{2}$ \\
\hline Q1 & net lw radiation & $\mathrm{W} / \mathrm{m}^{2}$ \\
\hline QN & net total heat & $\mathrm{W} / \mathrm{m}^{2}$ \\
\hline taue & wind stress east & $\mathrm{N} / \mathrm{m}^{2}$ \\
\hline taun & wind stress north & $\mathrm{N} / \mathrm{m}^{2}$ \\
\hline taumag & wind stress magnitude & $\mathrm{N} / \mathrm{m}^{2}$ \\
\hline prate & precipitation rate & $\mathrm{m} / \mathrm{s}$ \\
\hline evap & evaporation rate & $\mathrm{m} / \mathrm{s}$ \\
\hline
\end{tabular}

Tab1e 4.1.1. 
Seatex Wavescan Statistics

Deployment 1: start 1996/07/30 22:00 end 1996/09/04 21:00 864 records

\begin{tabular}{|l|r|r|r|r|}
\hline Variable & \multicolumn{1}{|c|}{ Mean } & \multicolumn{1}{l|}{ StdDev } & Minimum & \multicolumn{1}{c|}{ Maximum } \\
\hline HM0 & 1.11 & 0.96 & 0.41 & 7.34 \\
\hline H_MAX & 1.62 & 1.36 & 0.53 & 9.86 \\
\hline HMOLF & 0.47 & 0.67 & 0.11 & 5.11 \\
\hline MDIR & 271.01 & 103.87 & 0.57 & 359.21 \\
\hline THTP & 265.09 & 110.02 & 0.23 & 359.84 \\
\hline THHF & 180.70 & 107.44 & 0.80 & 359.96 \\
\hline THLF & 298.82 & 59.88 & 1.67 & 359.69 \\
\hline UI & 0.80 & 0.15 & 0.30 & 0.98 \\
\hline TP & 8.62 & 2.98 & 3.12 & 16.00 \\
\hline TPC & 10.39 & 2.82 & 6.36 & 18.85 \\
\hline TM02 & 5.57 & 1.28 & 3.43 & 10.98 \\
\hline
\end{tabular}

Deployment 2: start 1996/09/26 22:00 end 1997/02/06 17:00 3188 records

\begin{tabular}{|l|r|r|r|r|}
\hline Variable & \multicolumn{1}{|l|}{ Mean } & \multicolumn{1}{l|}{ StdDev } & Minimum & \multicolumn{1}{c|}{ Maximum } \\
\hline HM0 & 1.95 & 1.00 & 0.45 & 6.05 \\
\hline H_MAX & 2.89 & 1.54 & 0.61 & 10.00 \\
\hline HMOLF & 0.64 & 0.63 & 0.09 & 4.18 \\
\hline MDIR & 187.23 & 117.78 & 0.19 & 359.99 \\
\hline THTP & 190.89 & 120.05 & 0.36 & 359.94 \\
\hline THHF & 168.44 & 99.07 & 0.06 & 359.98 \\
\hline THLF & 243.93 & 108.66 & 0.02 & 360.00 \\
\hline UI & 0.80 & 0.19 & 0.10 & 0.99 \\
\hline TP & 7.95 & 2.51 & 2.51 & 14.22 \\
\hline TPC & 9.18 & 2.10 & 5.23 & 16.60 \\
\hline TM02 & 5.40 & 1.14 & 3.25 & 10.29 \\
\hline
\end{tabular}

Deployment 3: start 1997/04/17 05:00 end 1997/06/12 21:00 1361 records

\begin{tabular}{|c|c|c|c|c|}
\hline Variable & Mean & StdDev & Minimum & Maximum \\
\hline HMO & 1.70 & 0.71 & 0.47 & 4.65 \\
\hline H_MAX & 2.54 & 1.12 & 0.54 & $\overline{7.24}$ \\
\hline$\overline{\mathrm{HMOLF}}$ & 0.48 & 0.40 & 0.08 & 2.52 \\
\hline MDIR & 170.11 & 130.13 & 0.00 & 359.98 \\
\hline THTP & 183.35 & 130.43 & 0.02 & 359.98 \\
\hline THHF & 141.29 & 101.34 & 0.27 & 359.86 \\
\hline THLF & 236.04 & 114.20 & 0.13 & 359.86 \\
\hline $\mathrm{UI}$ & 0.86 & 0.13 & 0.26 & 0.99 \\
\hline TP & 7.98 & 1.87 & 3.66 & 14.22 \\
\hline TPC & 8.97 & 1.64 & 5.48 & 16.39 \\
\hline TMO2 & 5.50 & 0.97 & 3.59 & 8.27 \\
\hline
\end{tabular}

Wave Parameters Key:
\begin{tabular}{|l|l|l|}
\hline HM0 & significant wave height & $\mathrm{m}$ \\
\hline H_MAX & height of maximum wave & $\mathrm{m}$ \\
\hline HMOLF & significant height of swell & $\mathrm{m}$ \\
\hline MDIR & main wave direction & $\circ$ \\
\hline THTP & vector mean direction at TP & $\circ$ \\
\hline THHF & mean direction at high freq & $\circ$ \\
\hline THLF & mean direction at low freq & $\circ$ \\
\hline UI & unidirectivity index & n/a \\
\hline TP & period of spectral peak & s \\
\hline TPC & TP from spectral moments & s \\
\hline TM02 & spectral mean period & s \\
\hline
\end{tabular}

Table 4.1.2. 


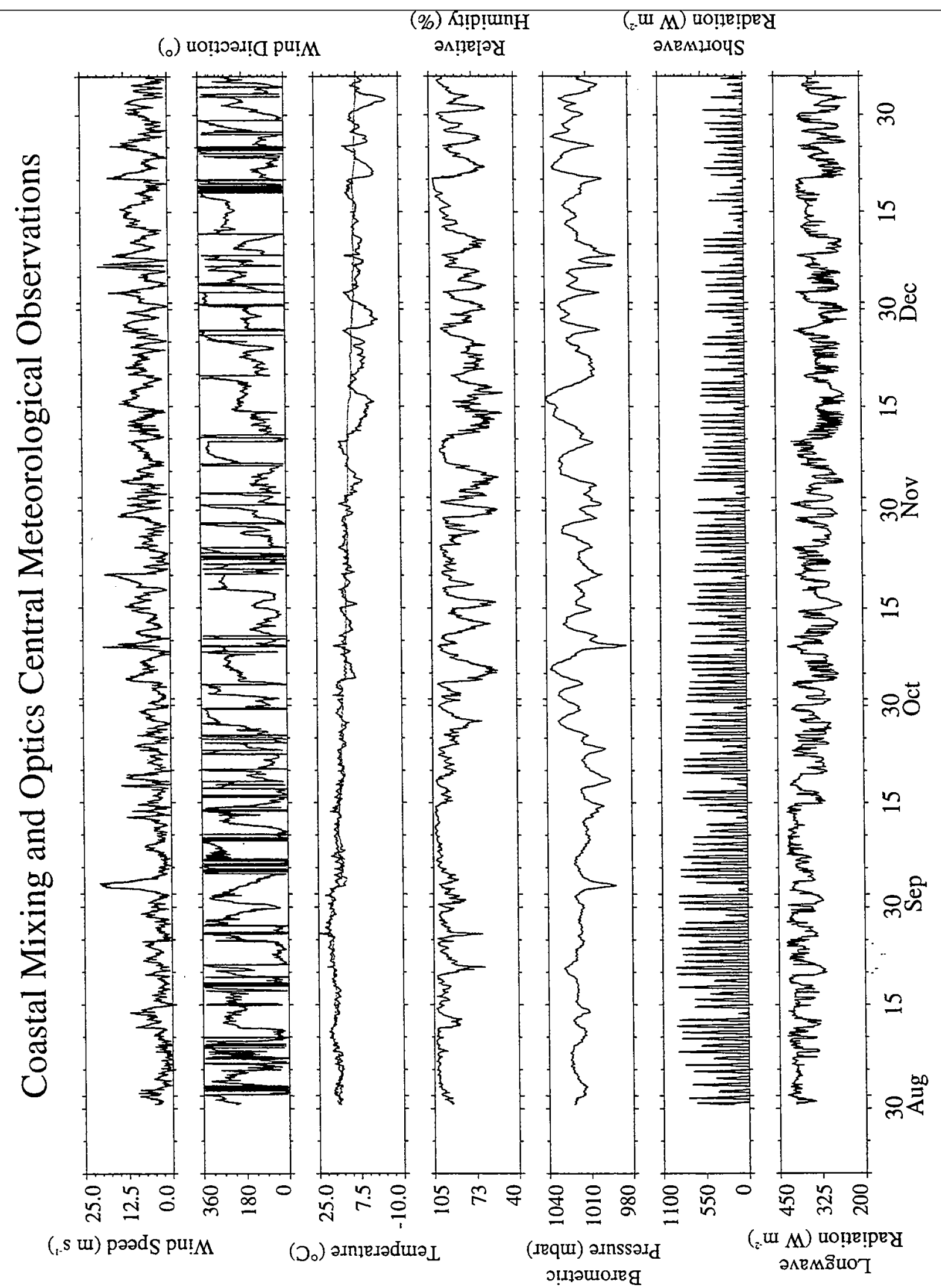

Figure 4.1.2. Meteorology time series, Central Site, August-December. 
(。) uo!noal! pu!M

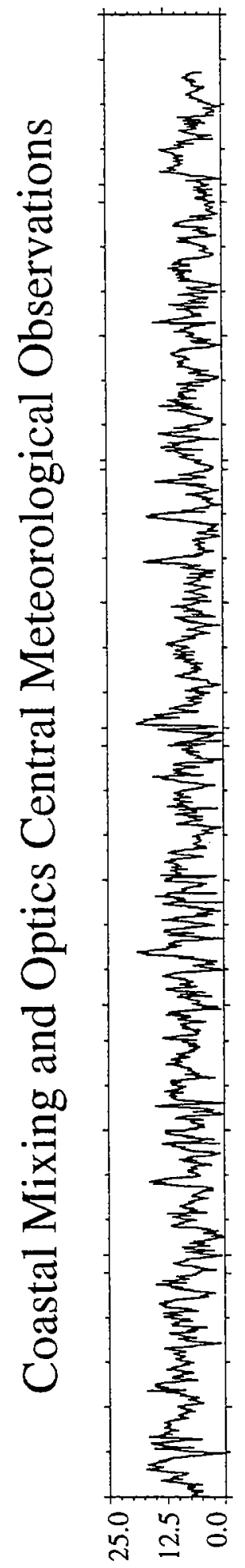

$(, \mathrm{s}$ w) paəds putM

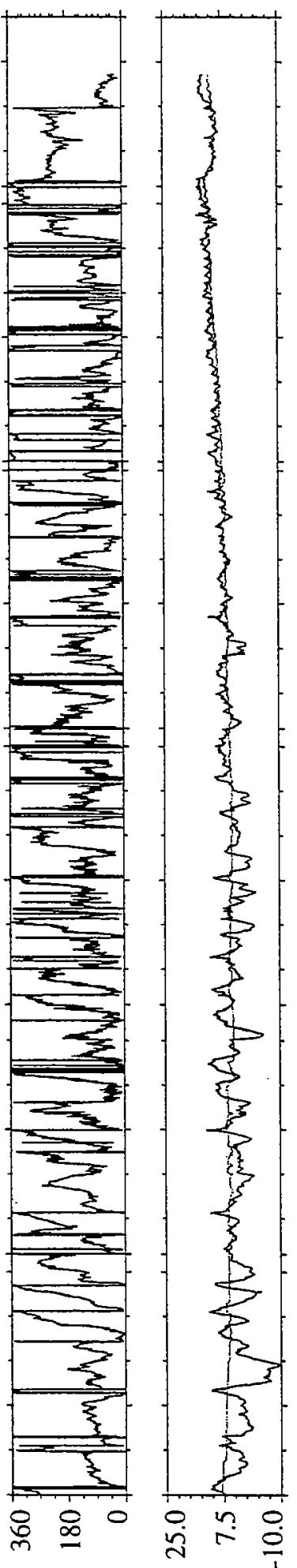

(つ。) วImBIədนวL
(\%) Kł!̣!unH

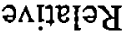

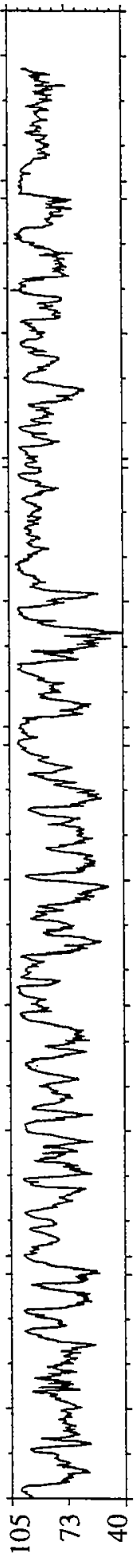

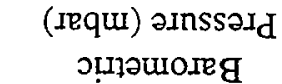

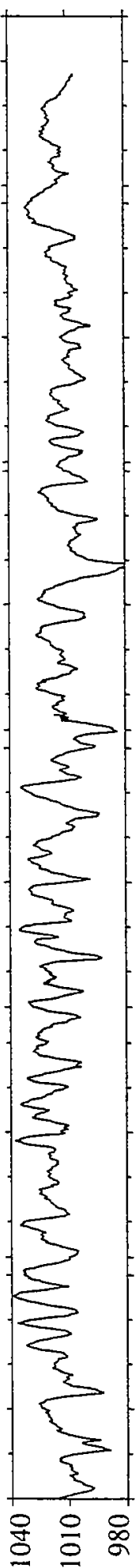

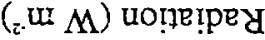

2АRMIIOUS

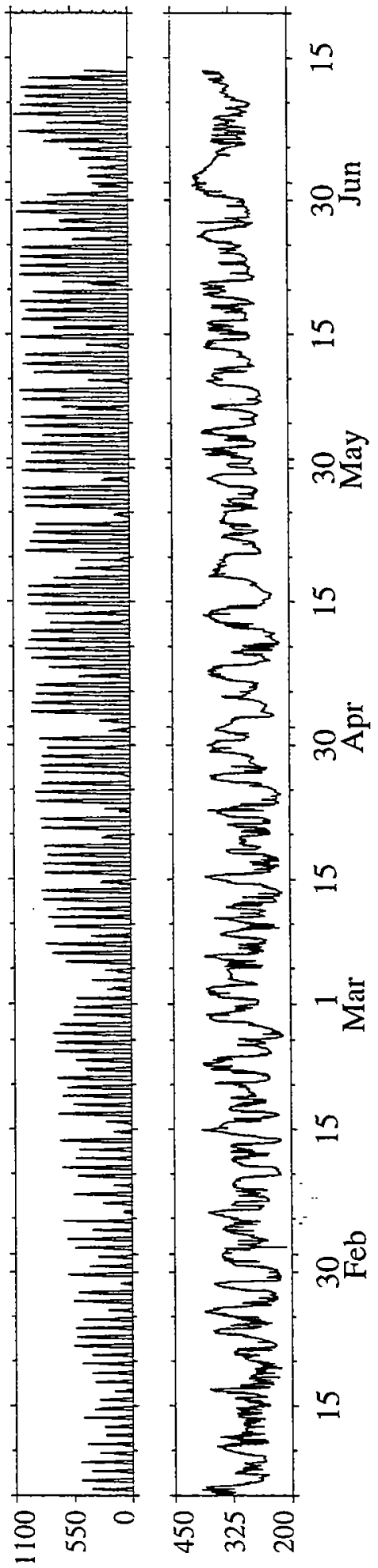

$\left({ }_{i}\right.$ u $M$ ) uotpe!pey

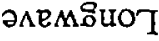

Figure 4.1.3. Meteorology time series, Central Site, January-June. 


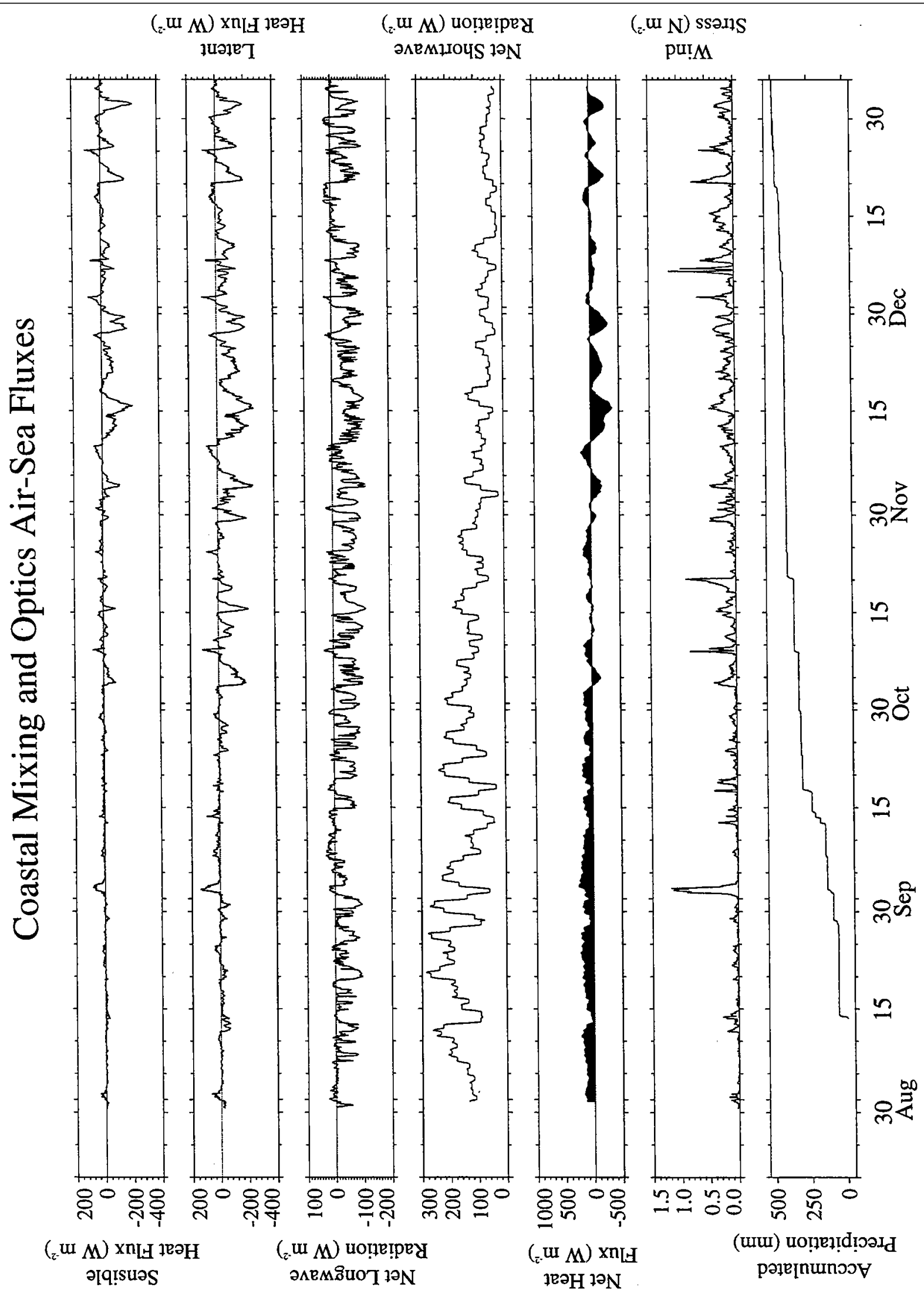

Figure 4.1.4. Air-Sea Flux time series, Central Site, August-December. 


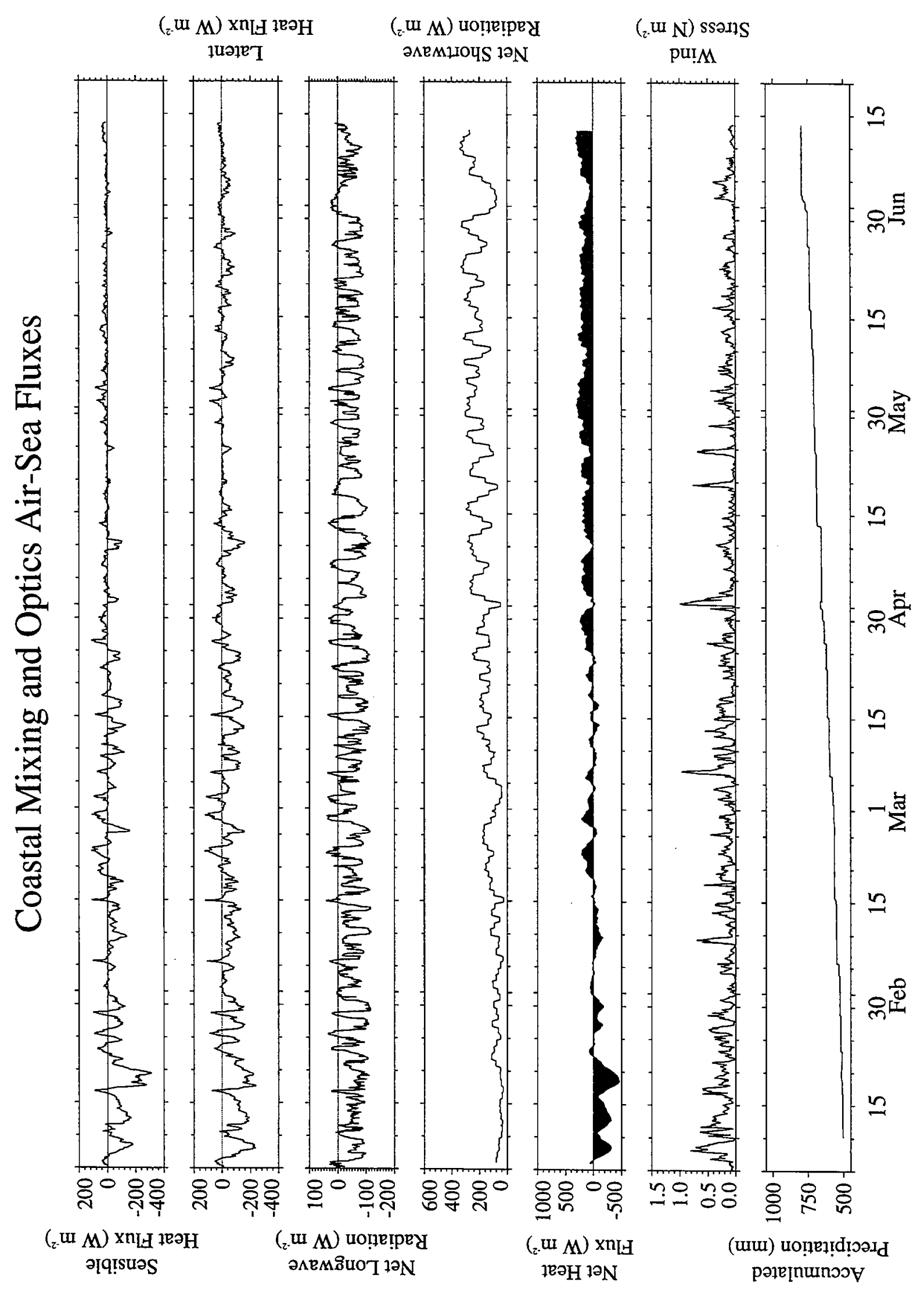

Figure 4.1.5. Air-Sea time series, Central Site, January-June. 


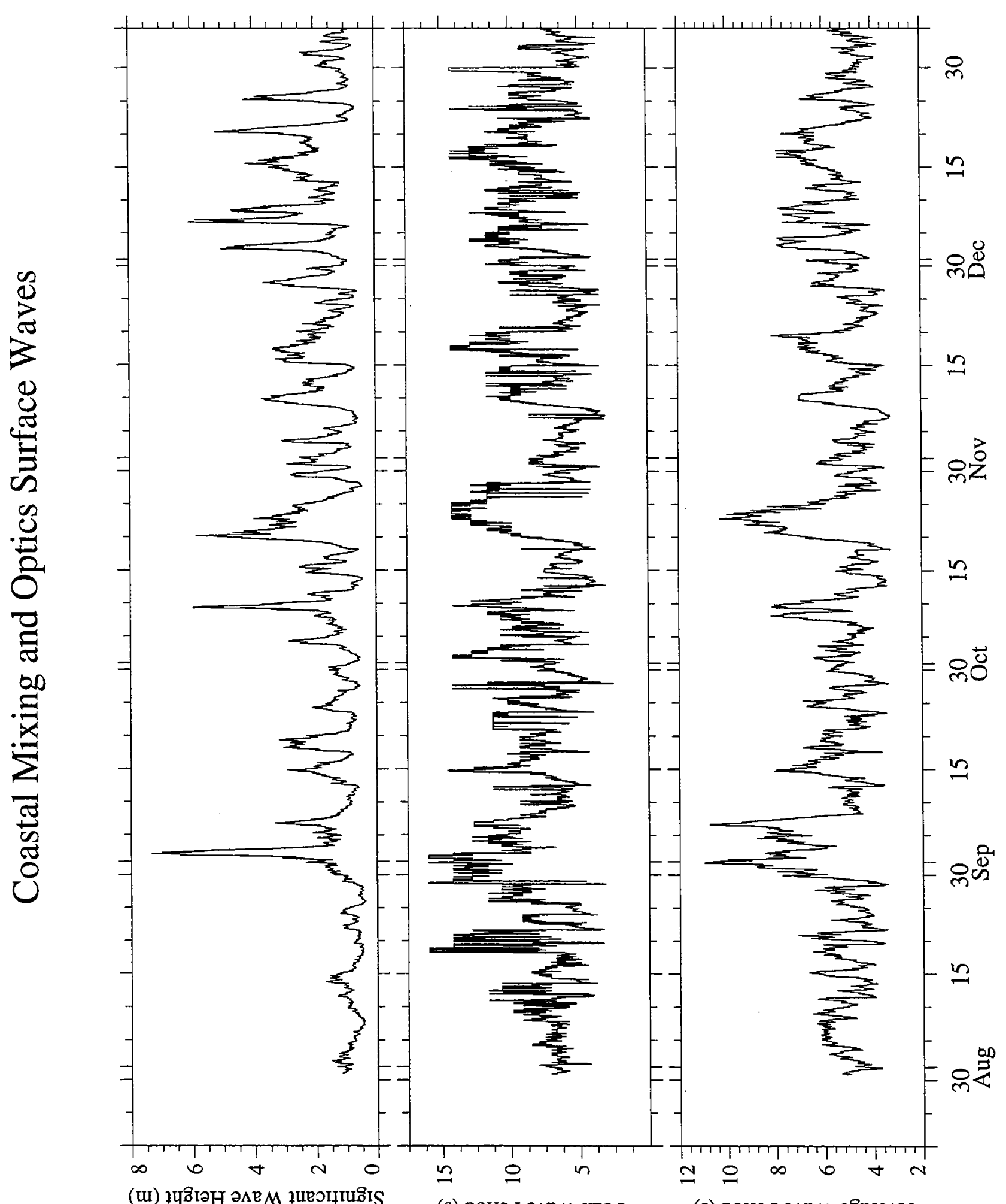

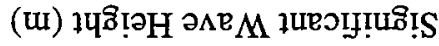

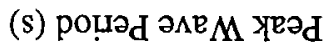

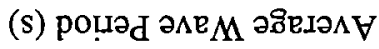

Figure 4.1.6. Surface Waves time series, Central Site, August-December. 


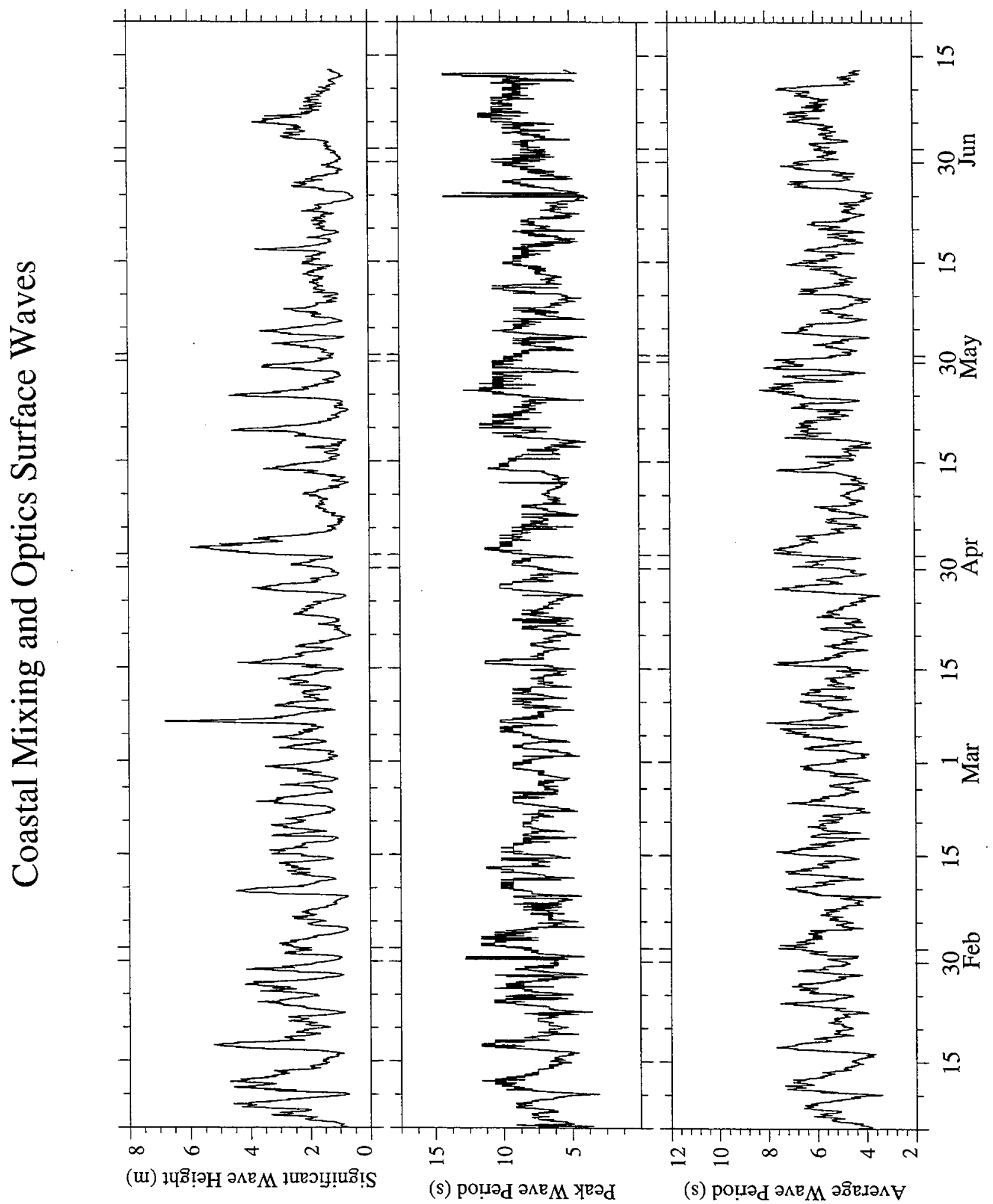

Figure 4.1.7. Surface Waves time series, Central Site, January-June. 


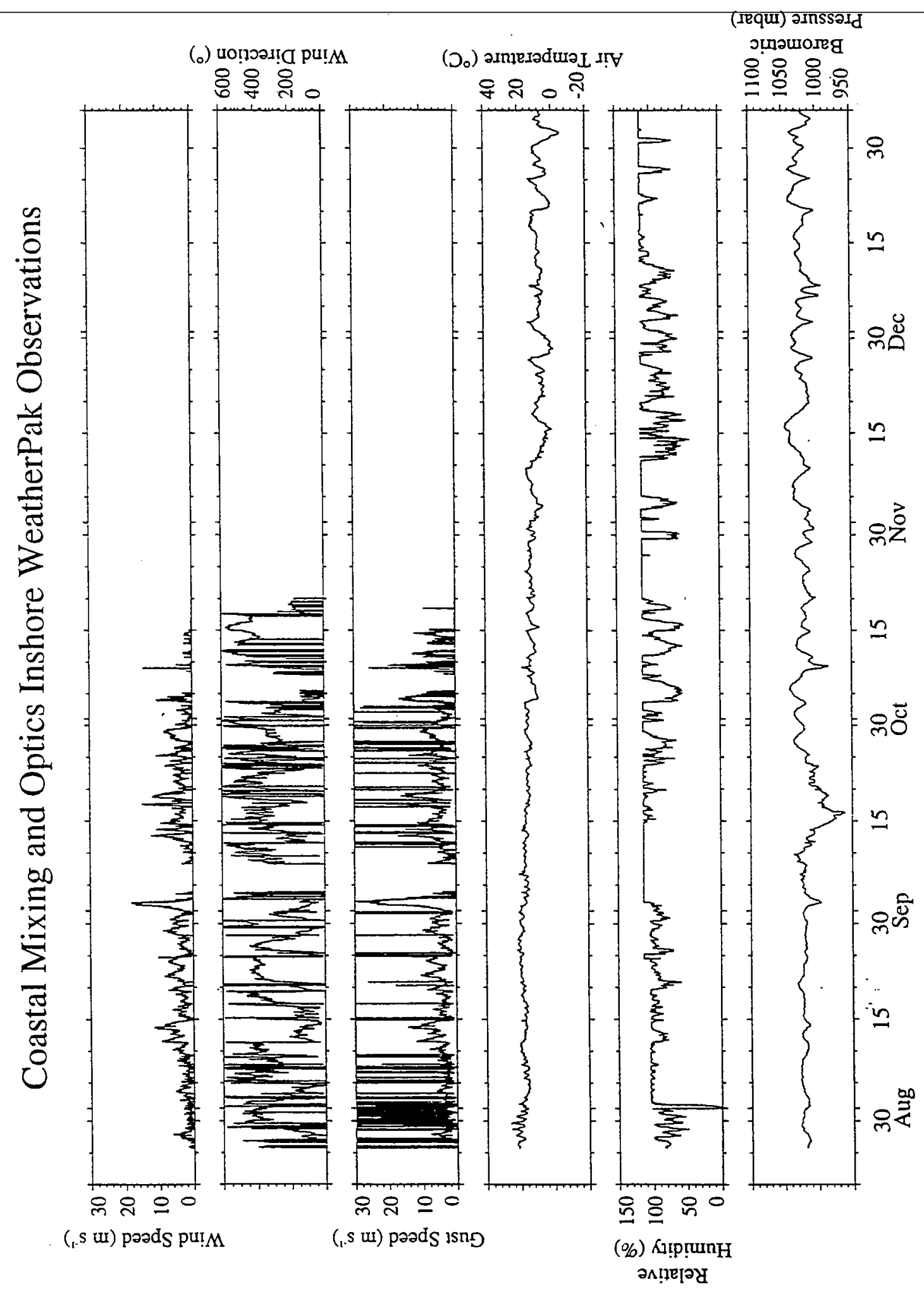

Figure 4.1.8. Meteorology time series, Inshore Site, August-December. 


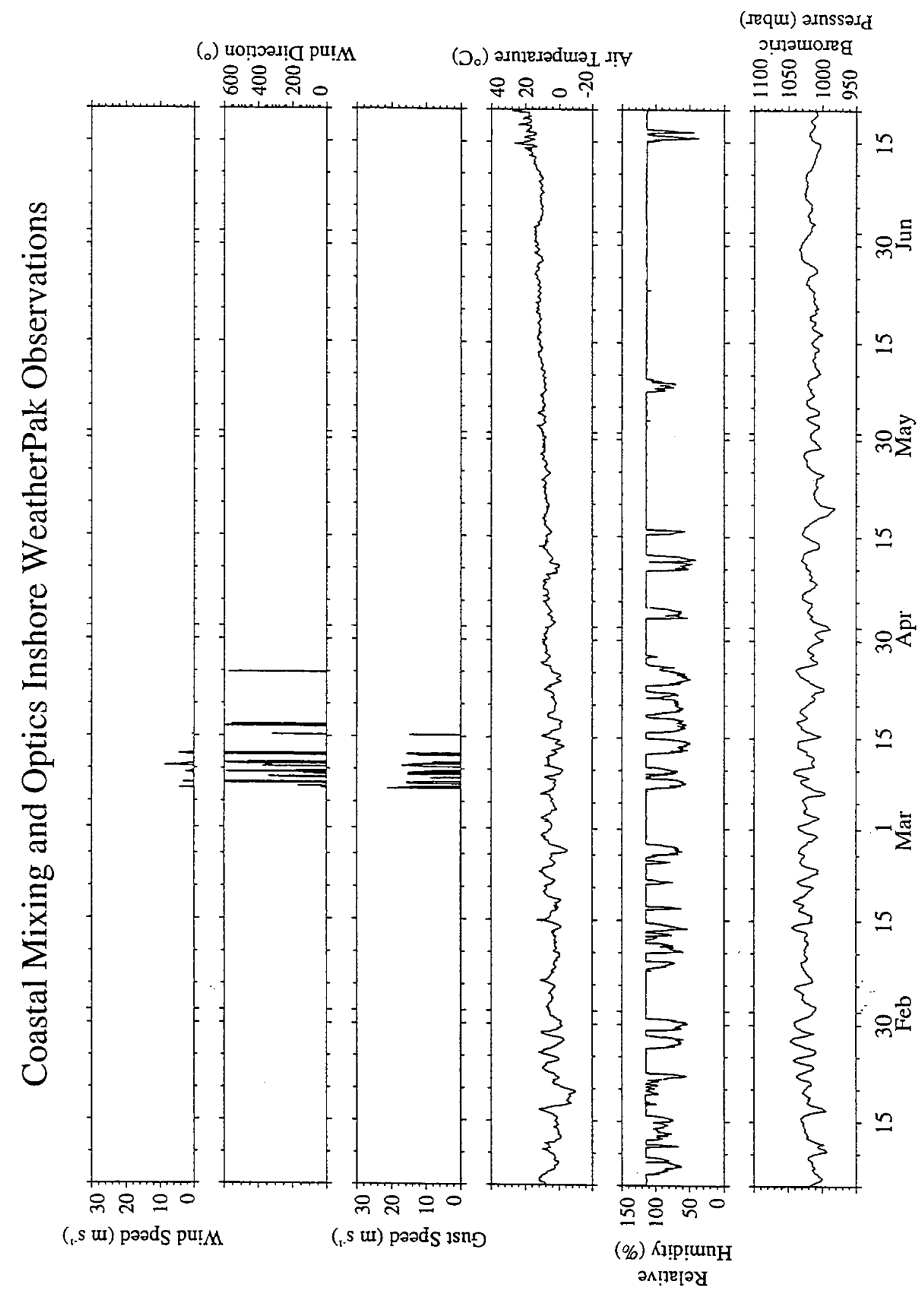

Figure 4.1.9. Meteorology time series, Inshore Site, January-June. 


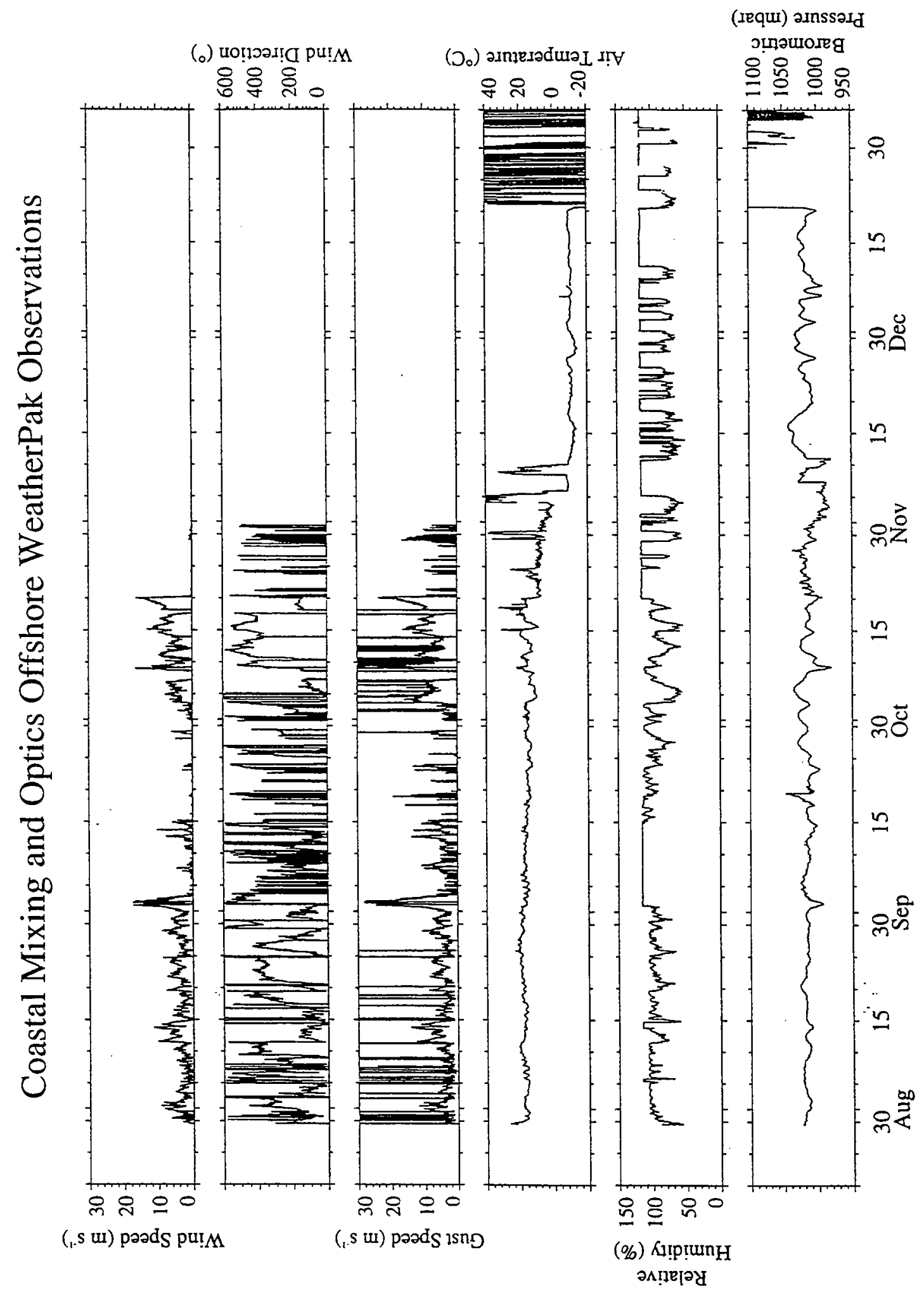

Figure 4.1.10. Meteorology time series, Offshore Site, August-December. 


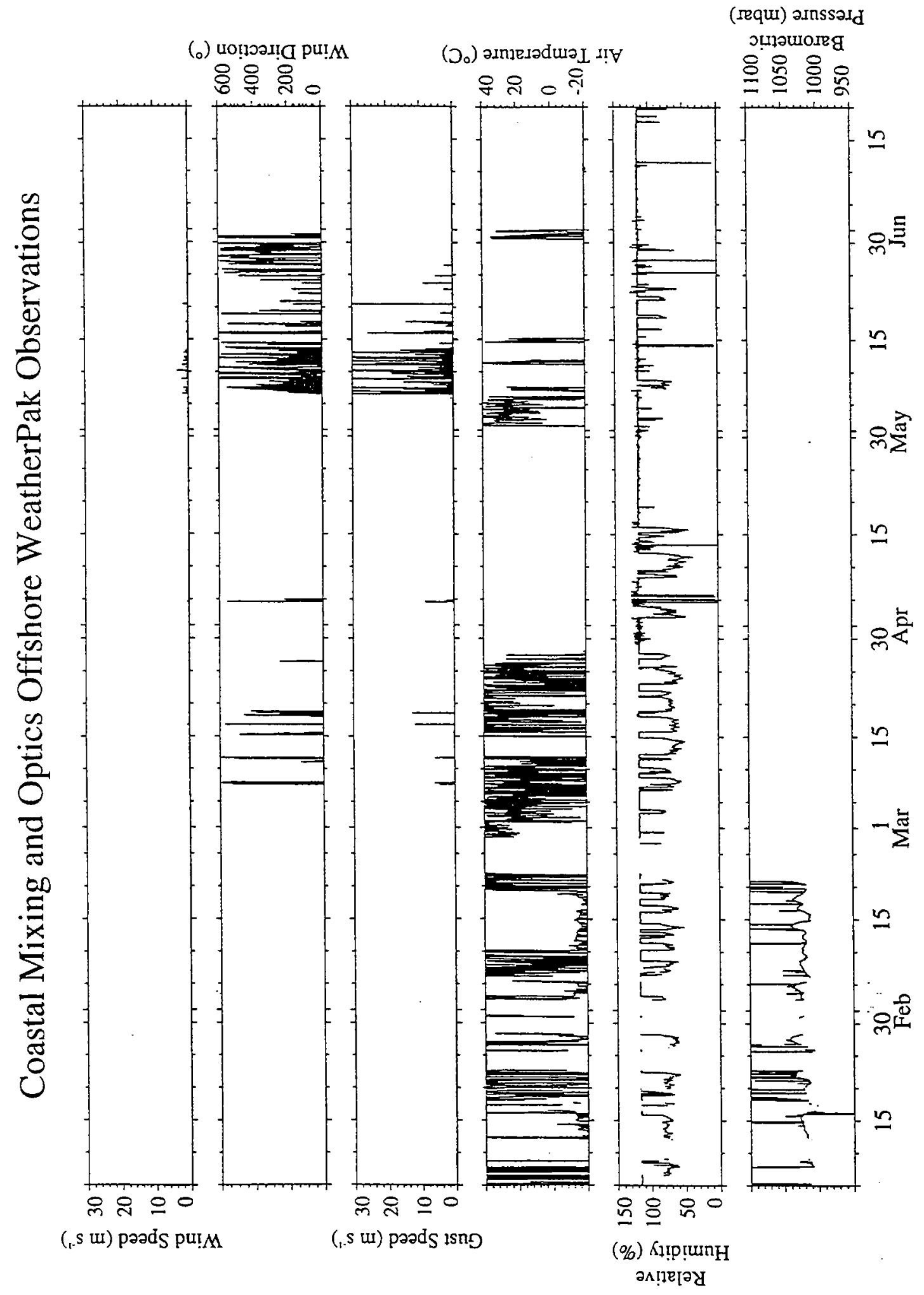

Figure 4.1.11. Meteorology time series, offshore Site, January-June. 


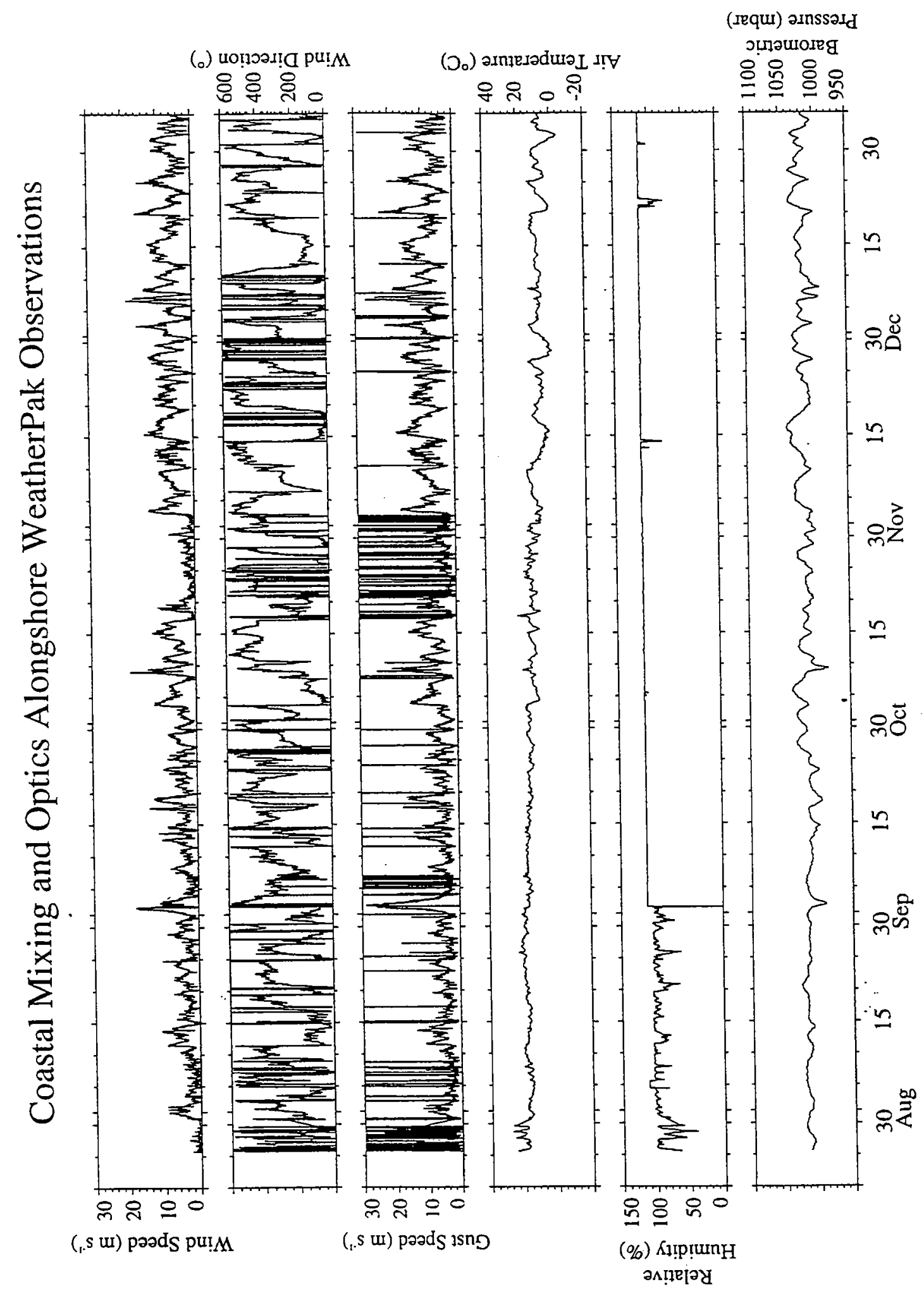

Figure 4.1.12. Meteorology time series, Alongshore Site, August-December. 


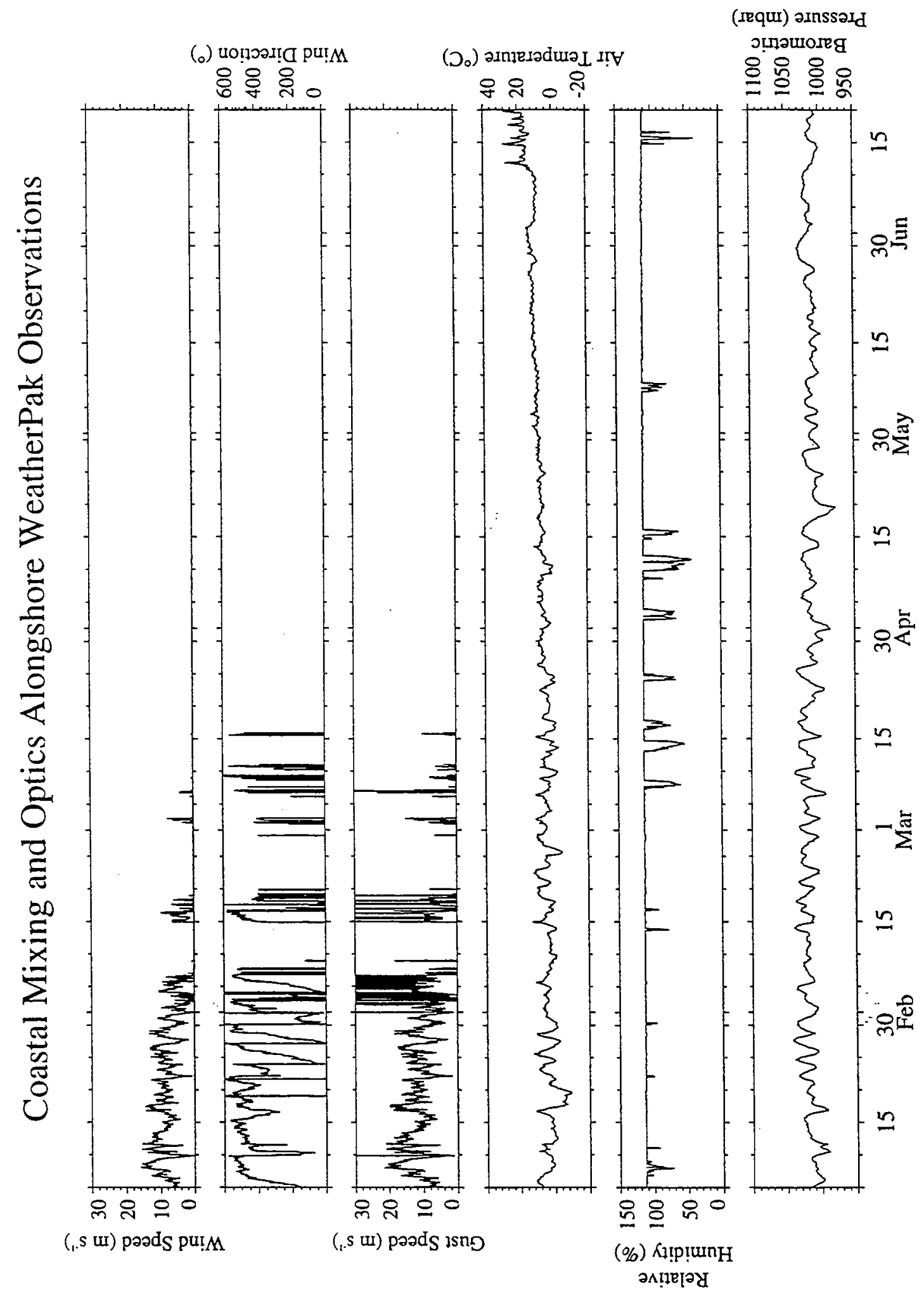

Figure 4.1.13. Meteorology time series, Alongshore Site, January-June. 

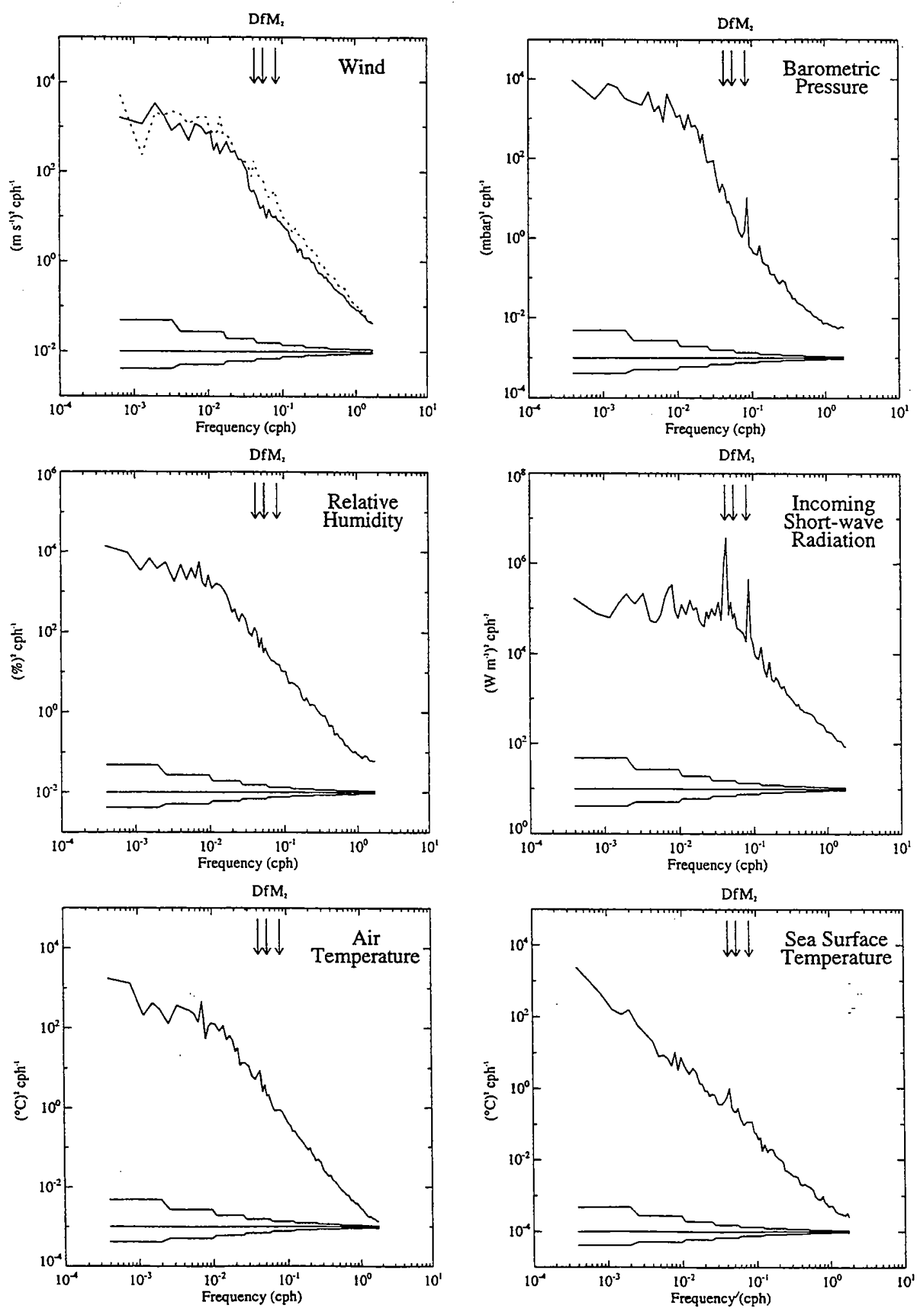

Figure 4.1.14. Autospectra of meteorological parameters at Central Site. Rotary autospectra of the wind provides both clockwise (solid) and counter-clockwise (dotted) spectras. Diurnal (D), semi-diurnal (M2), and inertial (f) frequencies are indicated. 

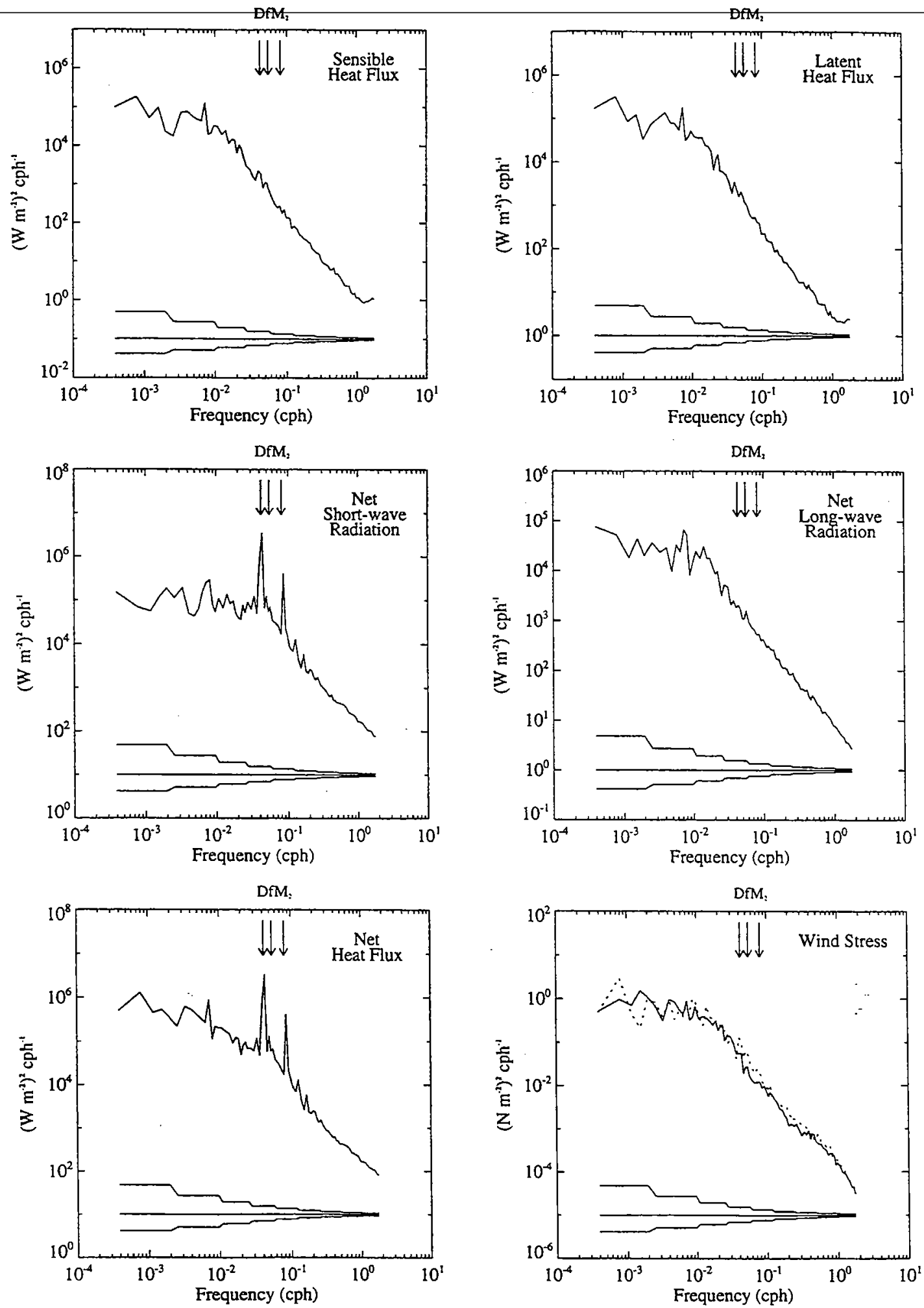

Figure 4.1.15. Autospectra of air-sea flux parameters at Central Site. Rotary autospectra of the wind stress provides both clockwise (solid) and counter-clockwise (dotted) spectras. Diurnal (D), semi-diurnal (M2), and inertial (f) frequencies are indicated. 


\subsection{Water Temperature}

The water temperature data are presented as offset time series plots. Spectra from selected depths at the Central site are shown. 


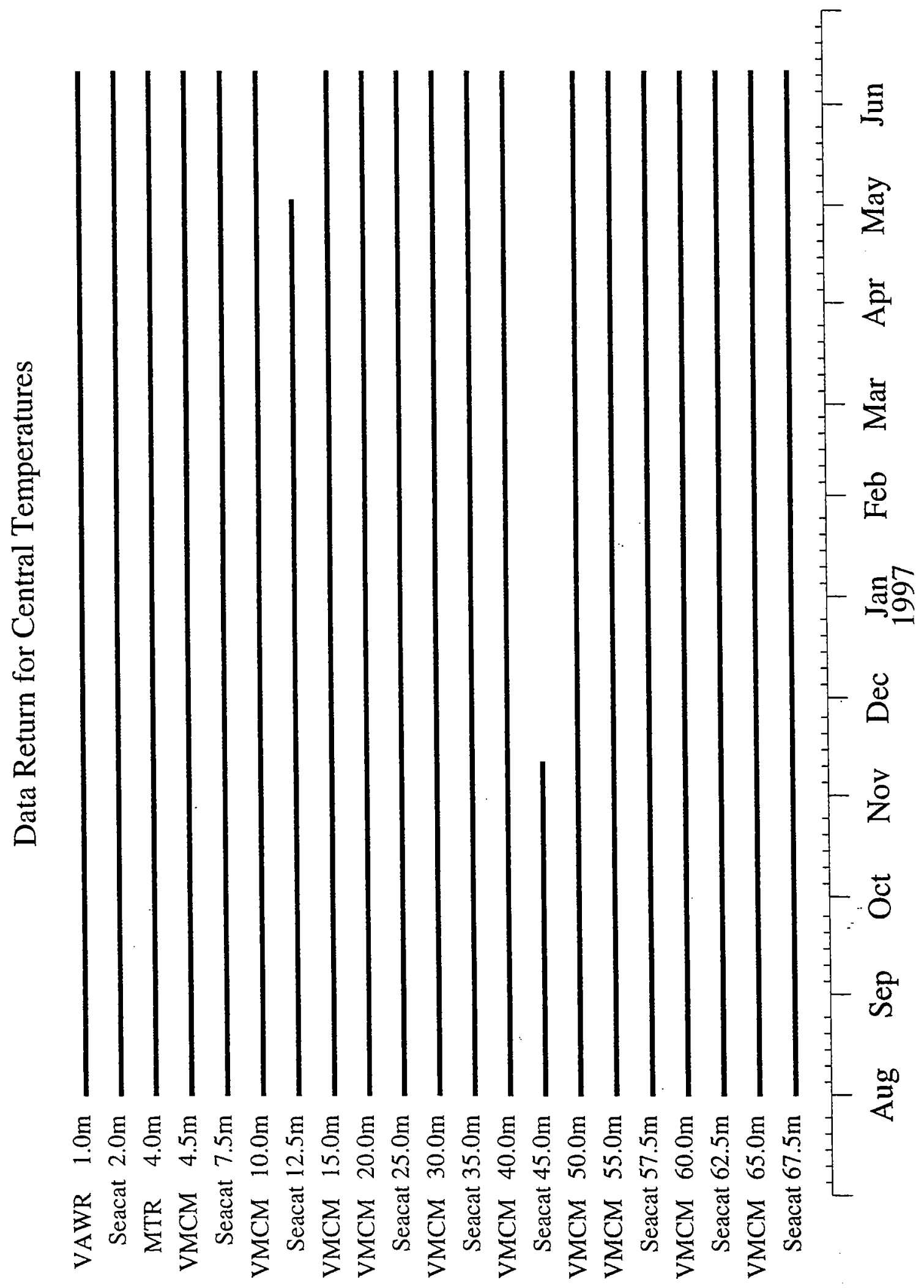

Figure 4.2.1. Water Temperature Data return, Central Site 


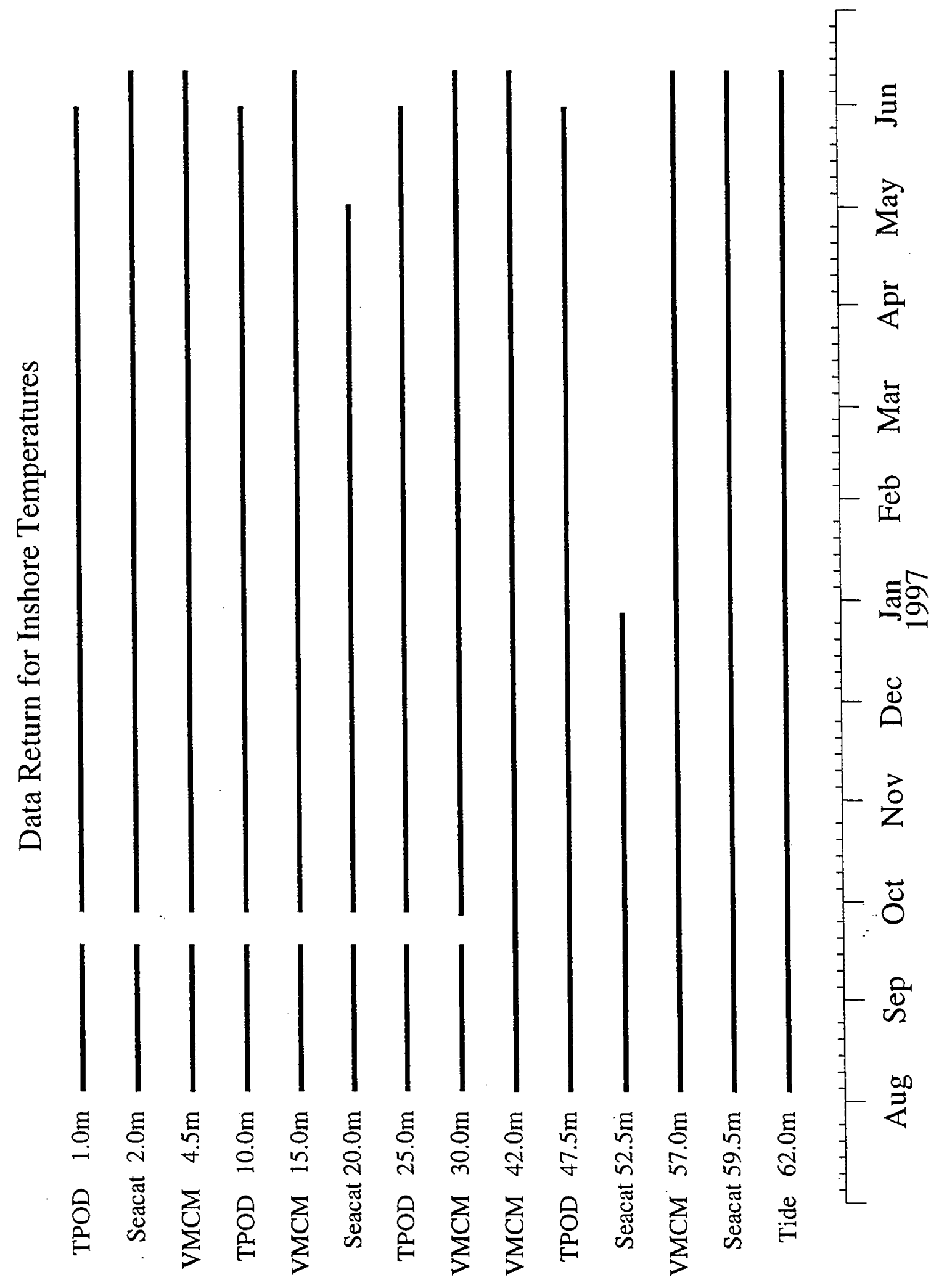

Figure 4.2.2. Water Temperature Data return, Inshore Site 


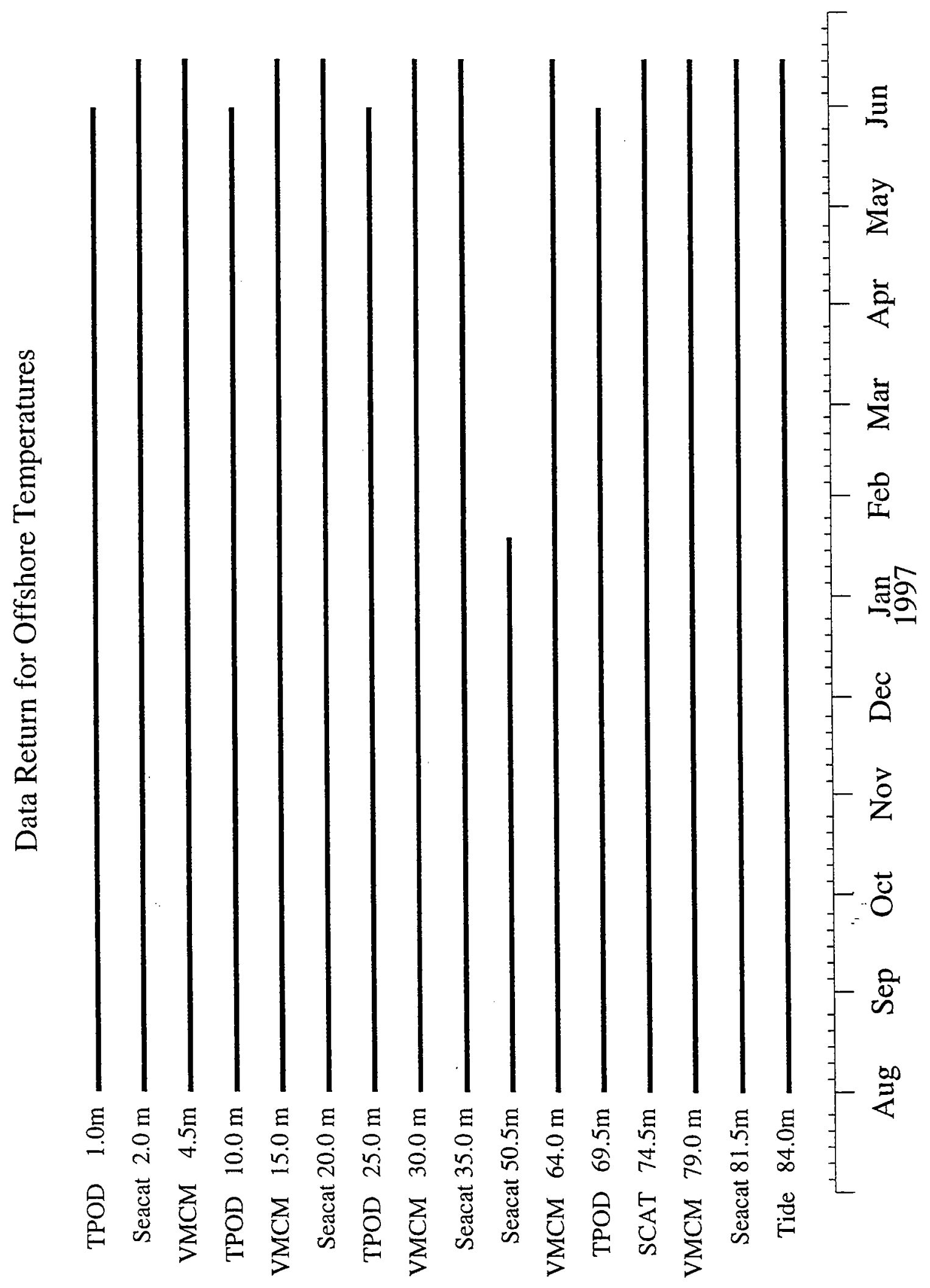

Figure 4.2.3. Water Temperature Data return, Offshore Site 


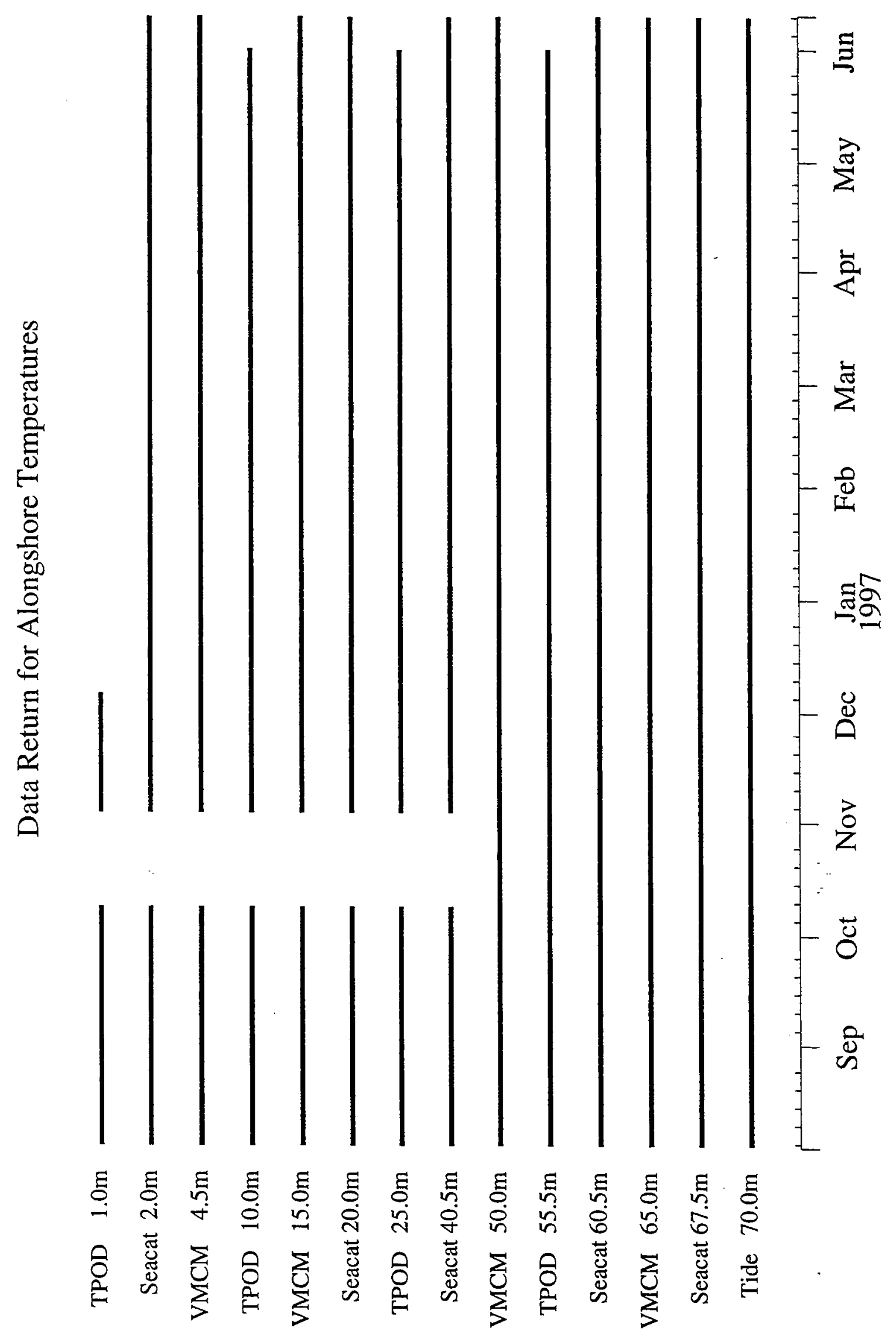

Figure 4.2.4. Water Temperature Data return, Alongshore Site 
Statistics: Water Temperature (degrees C)

Central: Dates: $1996 / 07 / 3019: 07$ to $1997 / 06 / 1218: 22,60859$ Records

\begin{tabular}{|r|r|r|r|r|r|r|r|}
\hline Bin & \multicolumn{1}{|l|}{ Depth } & \multicolumn{1}{l|}{ End Date } & \multicolumn{1}{l|}{ Mean } & \multicolumn{1}{l|}{ StdDev } & \multicolumn{1}{l|}{ Min } & \multicolumn{1}{l|}{ Max } & \multicolumn{1}{l|}{ \#Pts } \\
\hline 1 & 1.0 & $1997 / 06 / 1218: 22$ & 9.91 & 4.35 & 3.87 & 21.68 & 60859 \\
\hline 2 & 2.0 & $1997 / 06 / 1218: 22$ & 9.90 & 4.33 & 3.86 & 21.46 & 60859 \\
\hline 3 & 4.0 & $1997 / 06 / 1218: 22$ & 9.84 & 4.27 & 3.86 & 20.83 & 60859 \\
\hline 4 & 4.5 & $1997 / 06 / 1218: 22$ & 9.81 & 4.23 & 3.85 & 20.85 & 60859 \\
\hline 5 & 7.5 & $1997 / 06 / 1218: 22$ & 9.74 & 4.14 & 3.84 & 20.81 & 60859 \\
\hline 6 & 10.0 & $1997 / 06 / 1218: 22$ & 9.59 & 3.94 & 3.82 & 20.52 & 60859 \\
\hline 7 & 12.5 & $1997 / 05 / 0320: 07$ & 9.50 & 4.01 & 3.83 & 20.79 & 53193 \\
\hline 8 & 15.0 & $1997 / 06 / 1218: 22$ & 9.26 & 3.48 & 3.82 & 20.14 & 60859 \\
\hline 9 & 20.0 & $1997 / 06 / 1218: 22$ & 8.96 & 3.15 & 3.93 & 19.89 & 60859 \\
\hline 10 & 25.0 & $1997 / 06 / 1218: 22$ & 8.70 & 2.92 & 4.12 & 18.81 & 60859 \\
\hline 11 & 30.0 & $1997 / 06 / 1218: 22$ & 8.47 & 2.74 & 4.13 & 16.84 & 60859 \\
\hline 12 & 35.0 & $1997 / 06 / 1218: 22$ & 8.34 & 2.63 & 4.15 & 14.54 & 60859 \\
\hline 13 & 40.0 & $1997 / 06 / 1218: 22$ & 8.22 & 2.49 & 4.44 & 14.52 & 60859 \\
\hline 14 & 45.0 & $1996 / 11 / 1215: 37$ & 10.78 & 1.49 & 7.30 & 14.38 & 20133 \\
\hline 15 & 50.0 & $1997 / 06 / 1218: 22$ & 8.10 & 2.27 & 4.68 & 13.86 & 60859 \\
\hline 16 & 55.0 & $1997 / 06 / 1218: 22$ & 8.11 & 2.14 & 4.69 & 13.51 & 60859 \\
\hline 17 & 57.5 & $1997 / 06 / 1218: 22$ & 8.14 & 2.10 & 4.70 & 13.50 & 60859 \\
\hline 18 & 60.0 & $1997 / 06 / 1218: 22$ & 8.17 & 2.05 & 4.70 & 13.92 & 60859 \\
\hline 19 & 62.5 & $1997 / 06 / 1218: 22$ & 8.19 & 2.03 & 4.70 & 14.49 & 60859 \\
\hline 20 & 65.0 & $1997 / 06 / 1218: 22$ & 8.20 & 1.99 & 4.70 & 14.34 & 60859 \\
\hline 21 & 67.5 & $1997 / 06 / 1218: 22$ & 8.18 & 1.96 & 4.70 & 13.27 & 60859 \\
\hline
\end{tabular}

Inshore: Dates: 1996/08/02 19:22 to 1997/06/12 09:15, 60208 Records

\begin{tabular}{|r|r|r|r|r|r|r|r|}
\hline Bin & \multicolumn{1}{|c|}{ Depth } & End Date & \multicolumn{1}{l|}{ Mean } & \multicolumn{1}{l|}{ StdDev } & \multicolumn{1}{l|}{ Min } & Max & \#Pts \\
\hline 1 & 1.0 & $1997 / 06 / 0109: 22$ & 9.63 & 4.51 & 3.47 & 21.26 & 56370 \\
\hline 2 & 2.0 & $1997 / 06 / 1209: 15$ & 9.63 & 4.41 & 3.46 & 20.93 & 58481 \\
\hline 3 & 4.5 & $1997 / 06 / 1209: 15$ & 9.54 & 4.32 & 3.43 & 20.56 & 58481 \\
\hline 4 & 10.0 & $1997 / 06 / 0109: 22$ & 9.36 & 4.15 & 3.43 & 19.99 & 56370 \\
\hline 5 & 15.0 & $1997 / 06 / 1209: 15$ & 9.02 & 3.57 & 3.50 & 19.64 & 58481 \\
\hline 6 & 20.0 & $1997 / 05 / 0205: 52$ & 8.77 & 3.47 & 3.50 & 19.40 & 50582 \\
\hline 7 & 25.0 & $1997 / 06 / 0109: 22$ & 8.46 & 3.07 & 3.61 & 17.67 & 56370 \\
\hline 8 & 30.0 & $1997 / 06 / 1209: 15$ & 8.28 & 2.92 & 3.69 & 17.15 & 58481 \\
\hline 9 & 42.0 & $1997 / 06 / 1209: 15$ & 8.21 & 2.76 & 3.87 & 14.71 & 60208 \\
\hline 10 & 47.5 & $1997 / 06 / 0109: 22$ & 8.23 & 2.66 & 3.93 & 13.85 & 58097 \\
\hline 11 & 52.5 & $1996 / 12 / 2723: 52$ & 10.50 & 1.45 & 7.64 & 13.59 & 28261 \\
\hline 12 & 57.0 & $1997 / 06 / 1209: 15$ & 8.19 & 2.38 & 3.92 & 13.52 & 60208 \\
\hline 13 & 59.0 & $1997 / 06 / 1209: 15$ & 8.19 & 2.35 & 3.93 & 13.52 & 60208 \\
\hline 14 & 62.0 & $1997 / 06 / 1209: 15$ & 8.18 & 2.34 & 3.94 & 13.45 & 60208 \\
\hline
\end{tabular}

Table 4.2.1. Water Temperature Statistics 
Offshore: Dates: $1996 / 07 / 3120: 00$ to $1997 / 06 / 1610: 45,61367$ Records

\begin{tabular}{|r|r|r|r|r|r|r|r|}
\hline Bin & \multicolumn{1}{|l|}{ Depth } & \multicolumn{1}{l|}{ End Date } & \multicolumn{1}{l|}{ Mean } & \multicolumn{1}{l|}{ StdDev } & \multicolumn{1}{l|}{ Min } & \multicolumn{1}{l|}{ Max } & \#Pts \\
\hline 1 & 1.0 & $1997 / 06 / 0109: 22$ & 10.06 & 4.32 & 4.49 & 22.21 & 58476 \\
\hline 2 & 2.0 & $1997 / 06 / 1610: 37$ & 10.05 & 4.19 & 4.49 & 21.74 & 61366 \\
\hline 3 & 4.5 & $1997 / 06 / 1610: 37$ & 9.97 & 4.09 & 4.50 & 22.80 & 61366 \\
\hline 4 & 10.0 & $1997 / 06 / 0109: 22$ & 9.80 & 3.97 & 4.49 & 24.17 & 58476 \\
\hline 5 & 15.0 & $1997 / 06 / 1610: 37$ & 9.46 & 3.45 & 4.48 & 24.36 & 61366 \\
\hline 6 & 20.0 & $1997 / 06 / 1610: 37$ & 9.18 & 3.11 & 4.50 & 24.34 & 61366 \\
\hline 7 & 25.0 & $1997 / 06 / 0109: 22$ & 8.87 & 2.87 & 4.55 & 23.99 & 58476 \\
\hline 8 & 30.0 & $1997 / 06 / 1610: 37$ & 8.60 & 2.61 & 4.60 & 22.26 & 61366 \\
\hline 9 & 35.0 & $1997 / 06 / 1610: 37$ & 8.42 & 2.46 & 4.75 & 20.64 & 61366 \\
\hline 10 & 50.5 & $1997 / 01 / 1916: 00$ & 9.38 & 1.32 & 6.06 & 15.78 & 32993 \\
\hline 11 & 64.0 & $1997 / 06 / 1610: 37$ & 8.09 & 1.84 & 4.98 & 15.24 & 61366 \\
\hline 12 & 69.5 & $1997 / 06 / 0109: 22$ & 8.28 & 1.83 & 4.98 & 14.31 & 58476 \\
\hline 13 & 74.5 & $1997 / 06 / 1610: 37$ & 8.36 & 1.84 & 4.98 & 13.55 & 61366 \\
\hline 14 & 79.0 & $1997 / 06 / 1610: 37$ & 8.52 & 1.84 & 4.97 & 13.57 & 61366 \\
\hline 15 & 81.5 & $1997 / 06 / 1610: 37$ & 8.59 & 1.83 & 4.99 & 13.59 & 61366 \\
\hline 16 & 84.0 & $1997 / 06 / 1610: 37$ & 8.59 & 1.83 & 4.97 & 13.57 & 61366 \\
\hline
\end{tabular}

Alongshore: Dates: $1996 / 08 / 03$ 21:30 to $1997 / 06 / 10$ 09:37, 59618 Records

\begin{tabular}{|r|r|r|r|r|r|r|r|}
\hline Bin & \multicolumn{1}{|l|}{ Depth } & \multicolumn{1}{l|}{ End Date } & \multicolumn{1}{l|}{ Mean } & \multicolumn{1}{l|}{ StdDev } & \multicolumn{1}{l|}{ Min } & \multicolumn{1}{l|}{ Max } & \#Pts \\
\hline 1 & 1.0 & $1996 / 12 / 0605: 52$ & 14.52 & 3.46 & 8.51 & 21.08 & 19056 \\
\hline 2 & 2.0 & $1997 / 06 / 1009: 22$ & 9.53 & 4.42 & 3.79 & 20.66 & 54803 \\
\hline 3 & 4.5 & $1997 / 06 / 1009: 22$ & 9.44 & 4.31 & 3.78 & 20.53 & 54803 \\
\hline 4 & 10.0 & $1997 / 06 / 0105: 52$ & 9.23 & 4.08 & 3.77 & 19.54 & 53047 \\
\hline 5 & 15.0 & $1997 / 06 / 1009: 22$ & 8.87 & 3.51 & 3.76 & 19.76 & 54803 \\
\hline 6 & 20.0 & $1997 / 06 / 1009: 22$ & 8.60 & 3.16 & 3.82 & 19.31 & 54803 \\
\hline 7 & 25.0 & $1997 / 06 / 0105: 52$ & 8.32 & 2.91 & 4.01 & 17.39 & 53047 \\
\hline 8 & 40.5 & $1997 / 06 / 1009: 22$ & 7.91 & 2.45 & 4.32 & 15.00 & 54865 \\
\hline 9 & 50.0 & $1997 / 06 / 1009: 22$ & 8.08 & 2.35 & 4.45 & 14.09 & 59616 \\
\hline 10 & 55.5 & $1997 / 06 / 0105: 52$ & 8.13 & 2.21 & 4.72 & 13.81 & 57860 \\
\hline 11 & 60.5 & $1997 / 06 / 1009: 22$ & 8.14 & 2.07 & 4.71 & 13.36 & 59616 \\
\hline 12 & 65.0 & $1997 / 06 / 1009: 22$ & 8.15 & 2.02 & 4.70 & 12.96 & 59616 \\
\hline 13 & 67.5 & $1997 / 06 / 1009: 22$ & 8.14 & 2.00 & 4.70 & 12.87 & 59616 \\
\hline 14 & 70.0 & $1997 / 06 / 1009: 22$ & 8.13 & 1.99 & 4.70 & 12.85 & 59616 \\
\hline
\end{tabular}




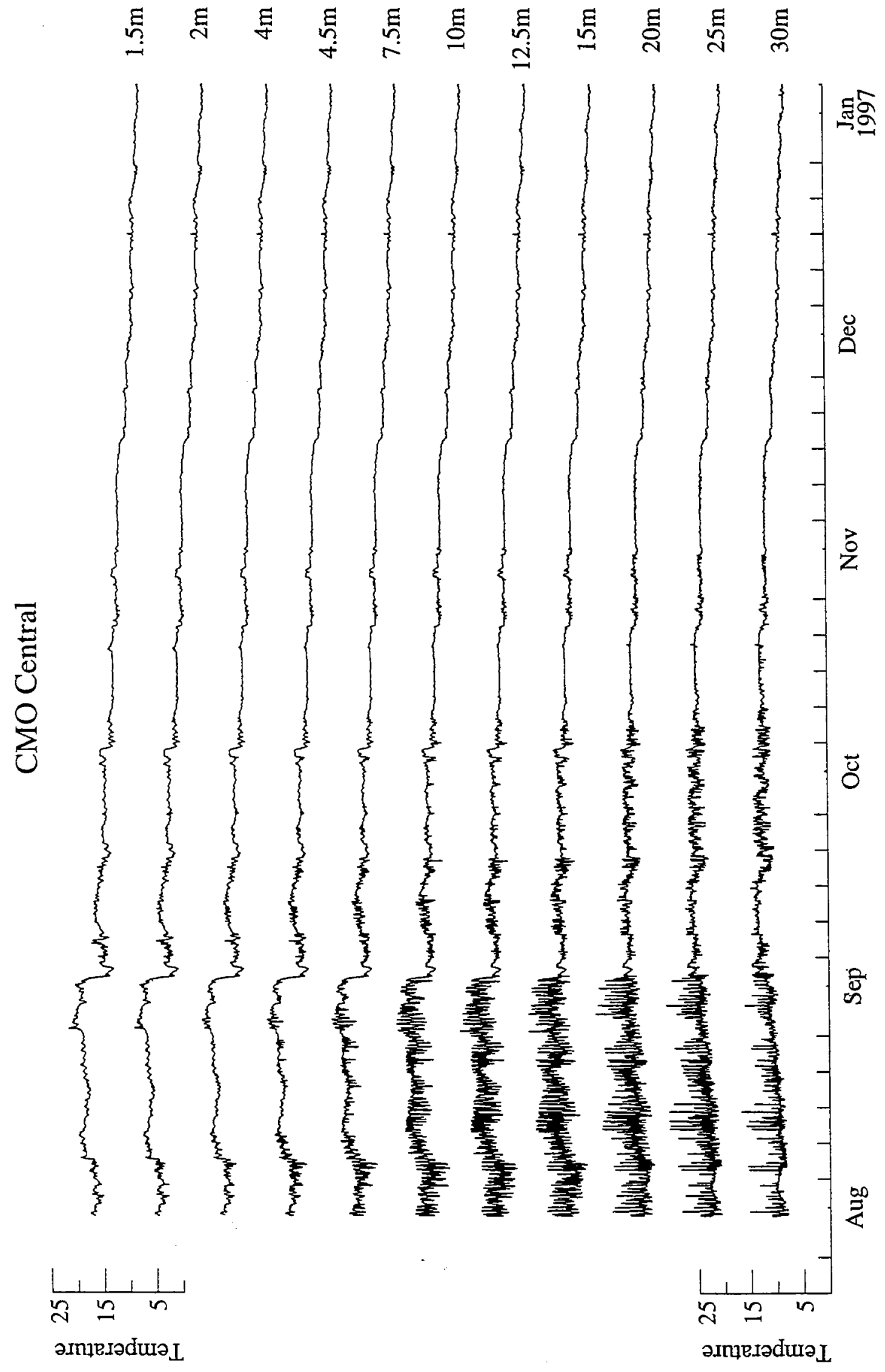

Figure 4.2.5. Shallow temperature time series, Central Site, August - December 


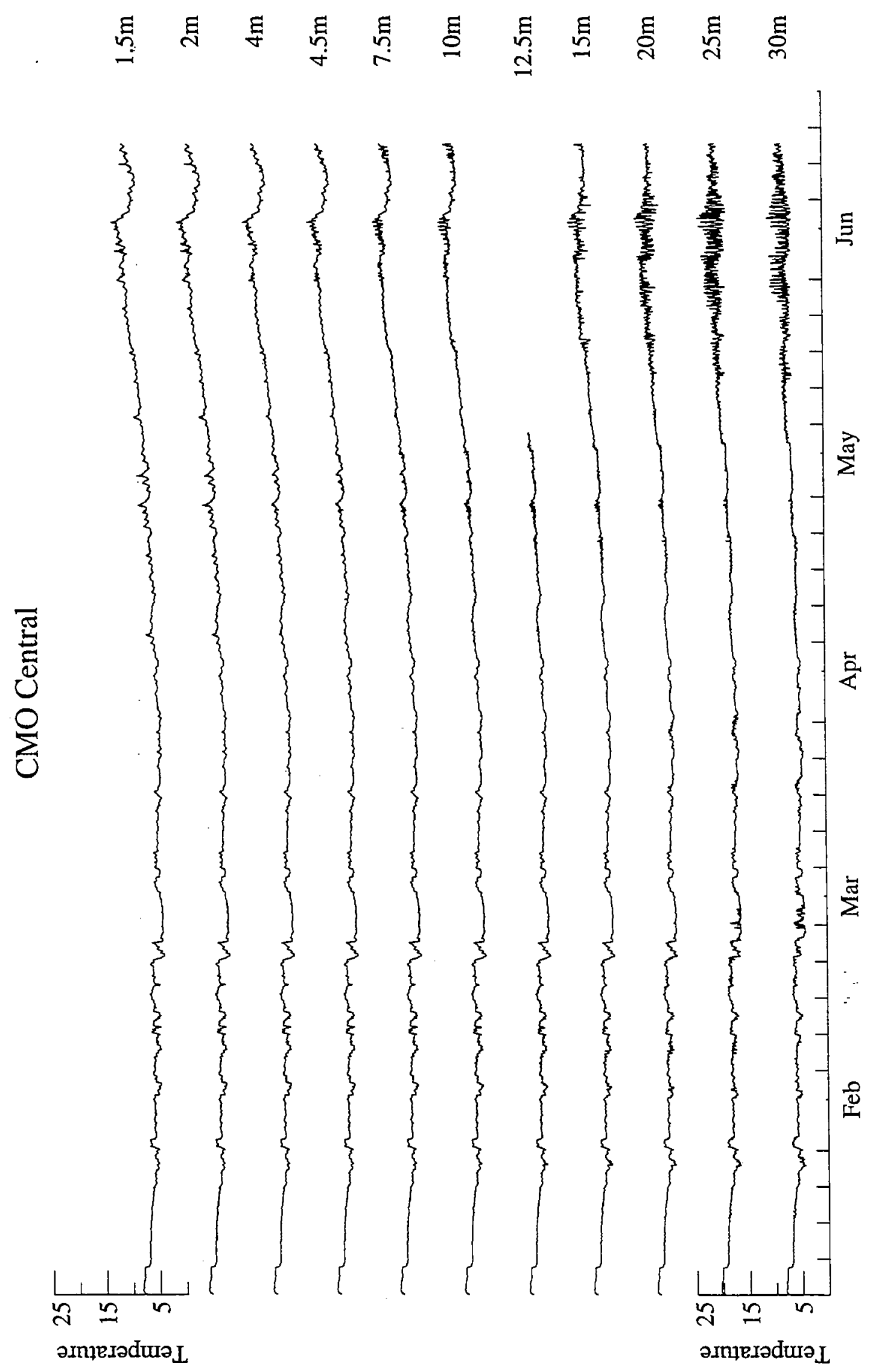

Figure 4.2.6. Deep temperature time series, Central Site, August - December 


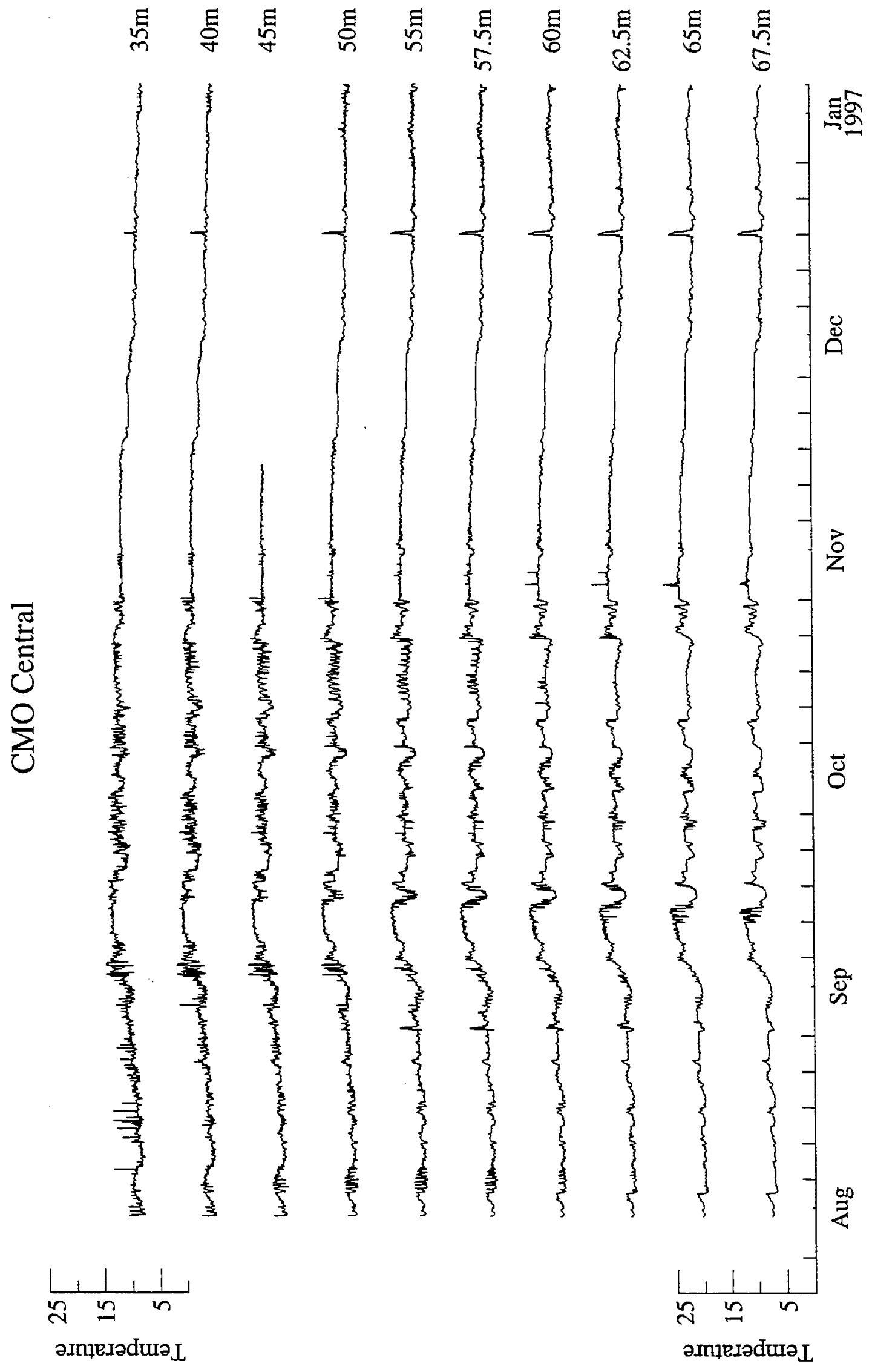

Figure 4.2.7. Shallow temperature time series, Central Site, January - June 


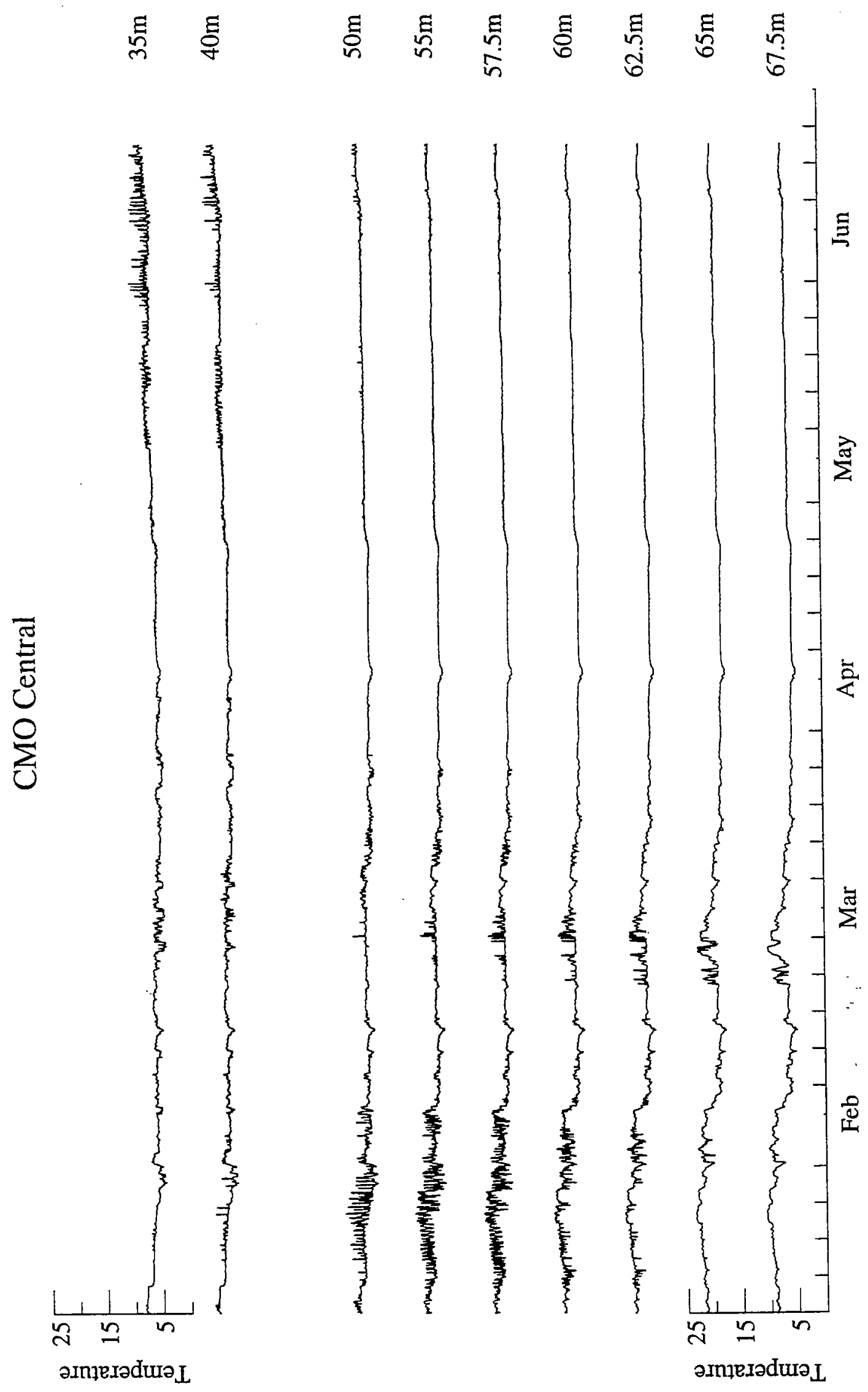

Figure 4.2.8. Deep temperature time series, Central Site, January - June 


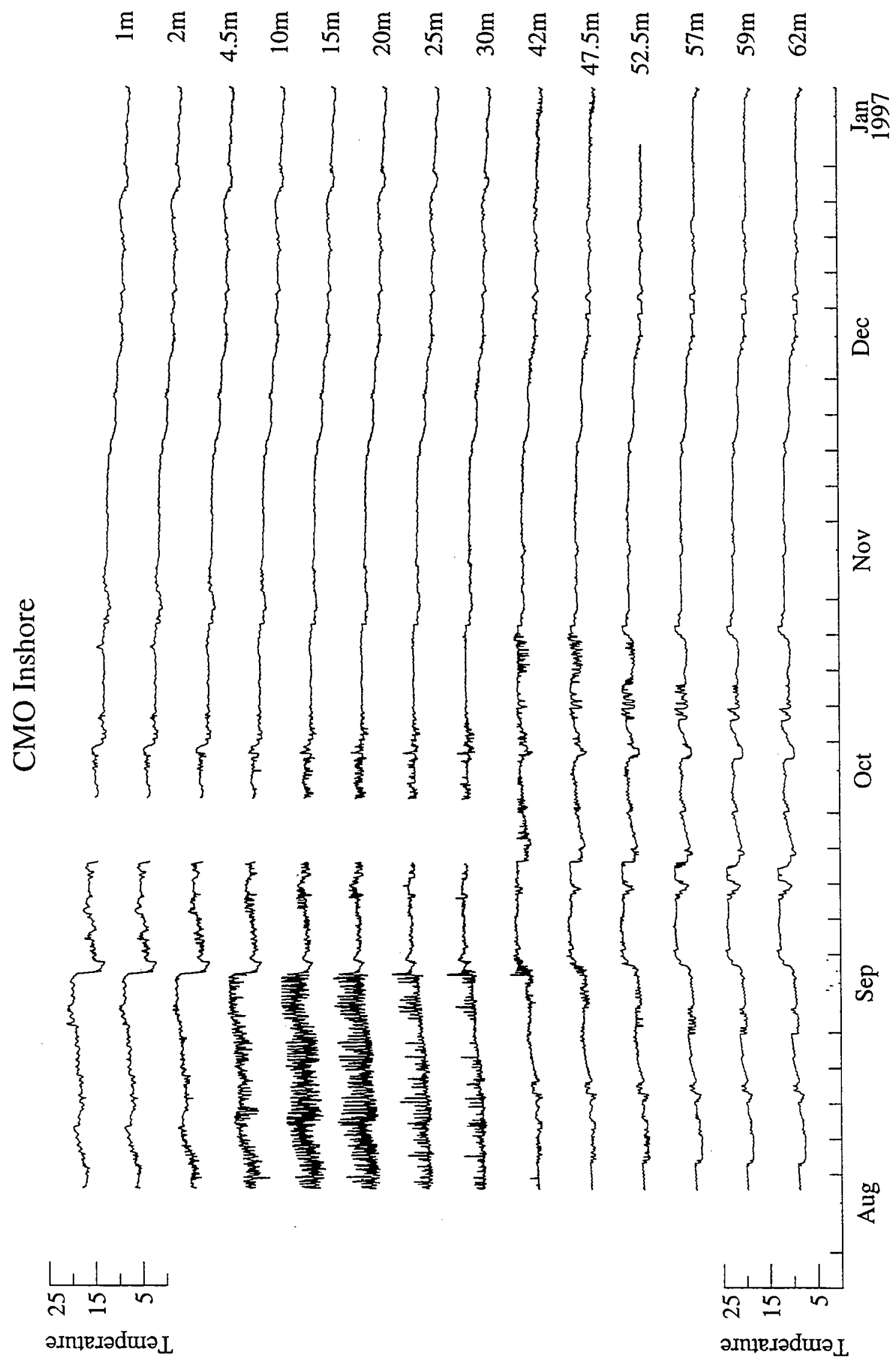

Figure 4.2.9. Temperature time series, Inshore Site, August - December 


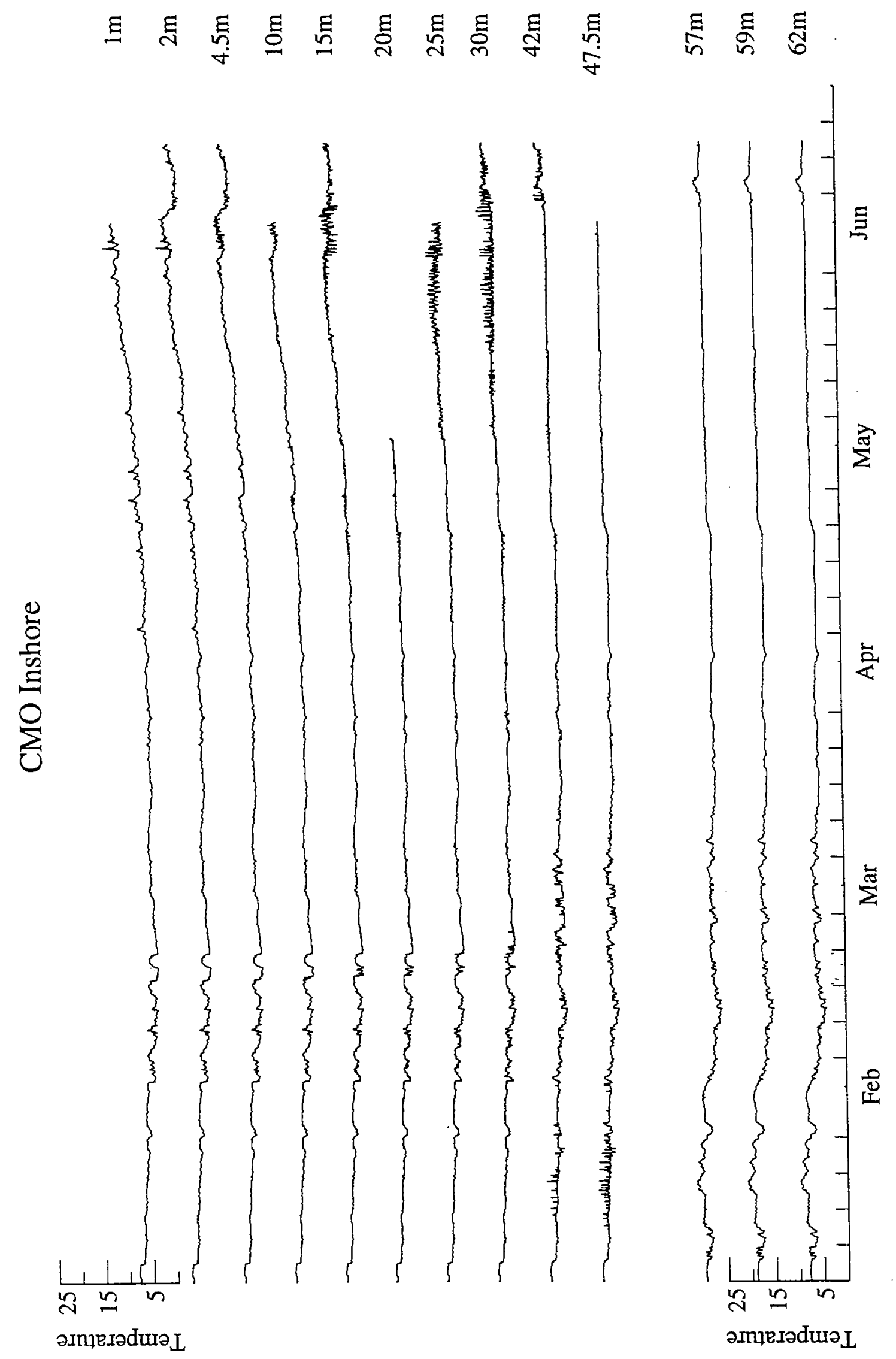

Figure 4.2.10. Temperature time series, Inshore Site, January - June 


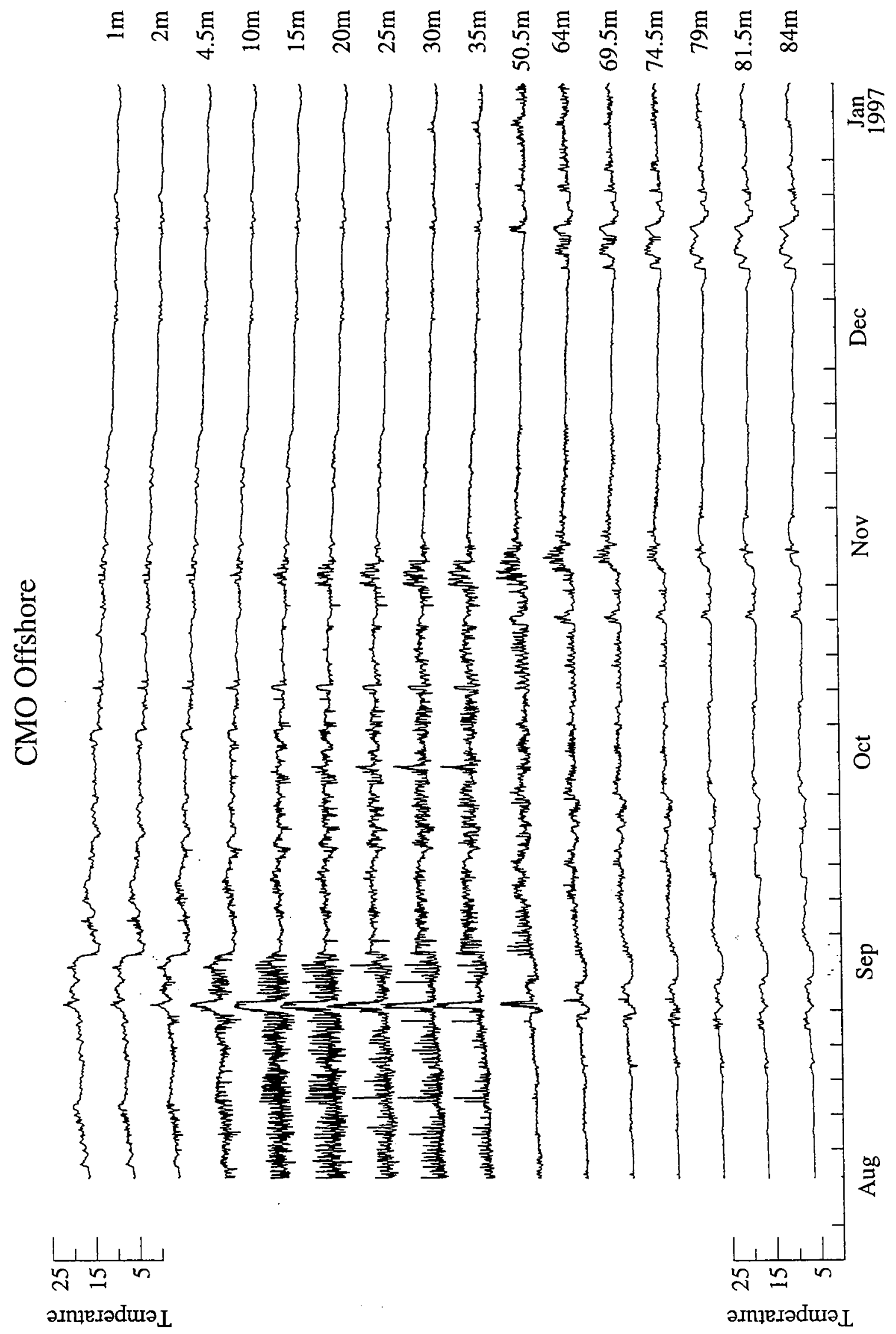

Figure 4.2.11. Temperature time series, Offshore Site, August - December 


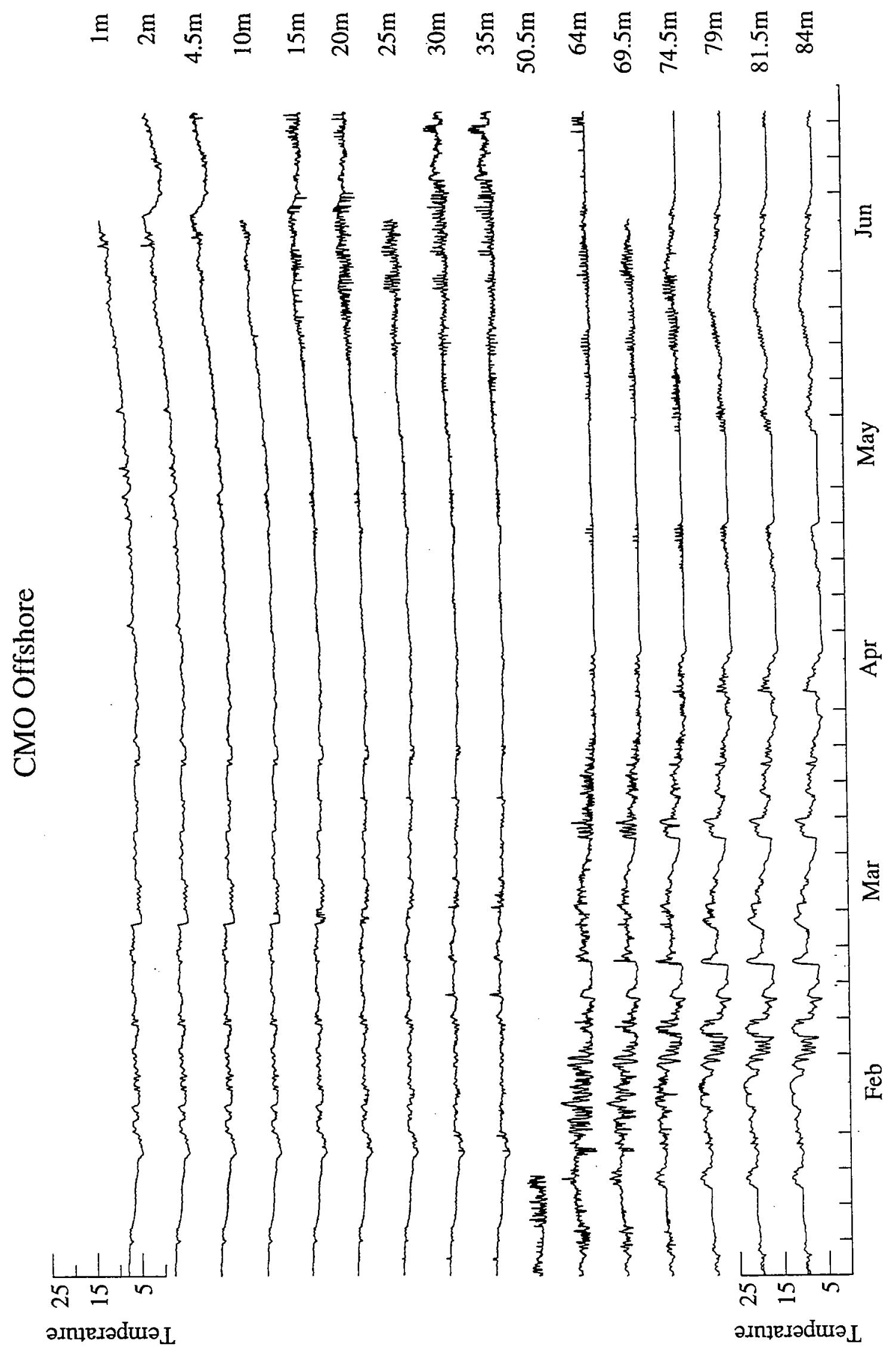

Figure 4.2.12. Temperature time series, Offshore Site, January - June 


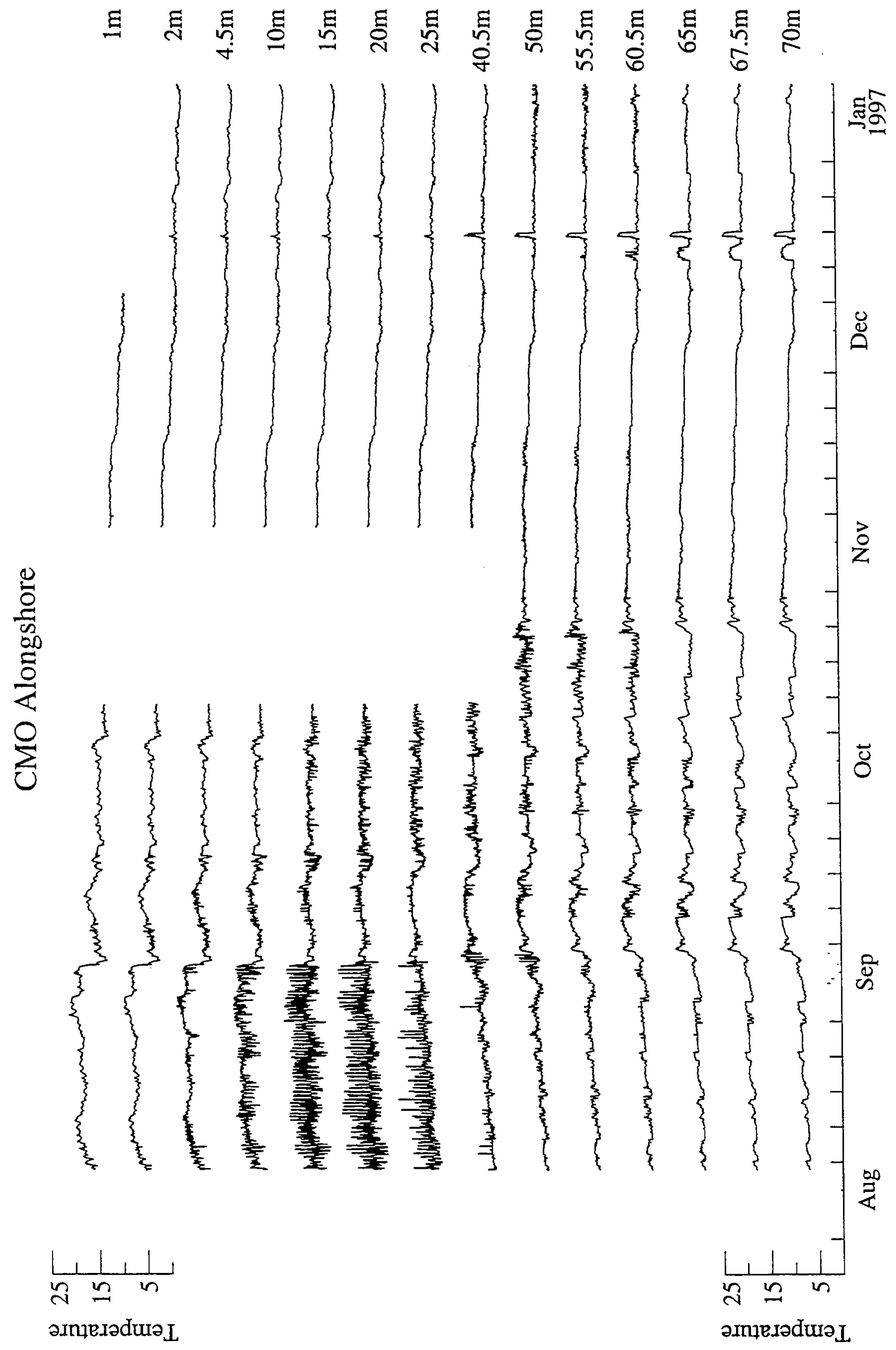

Figure. 4.2.13. Temperature time series, Alongshore Site, August - December 


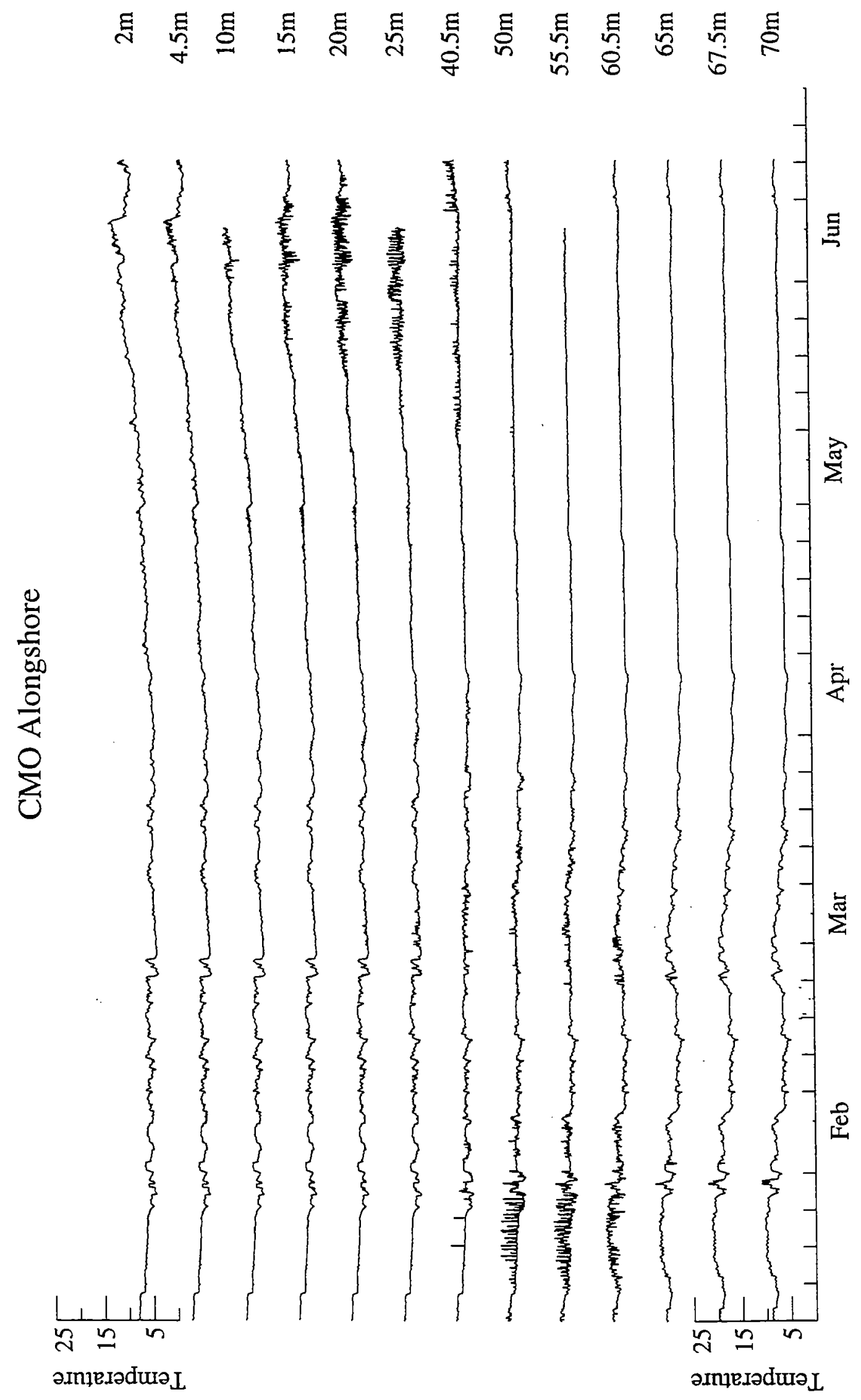

Figure. 4.2.14. Temperature time series, Alongshore Site, January - June 

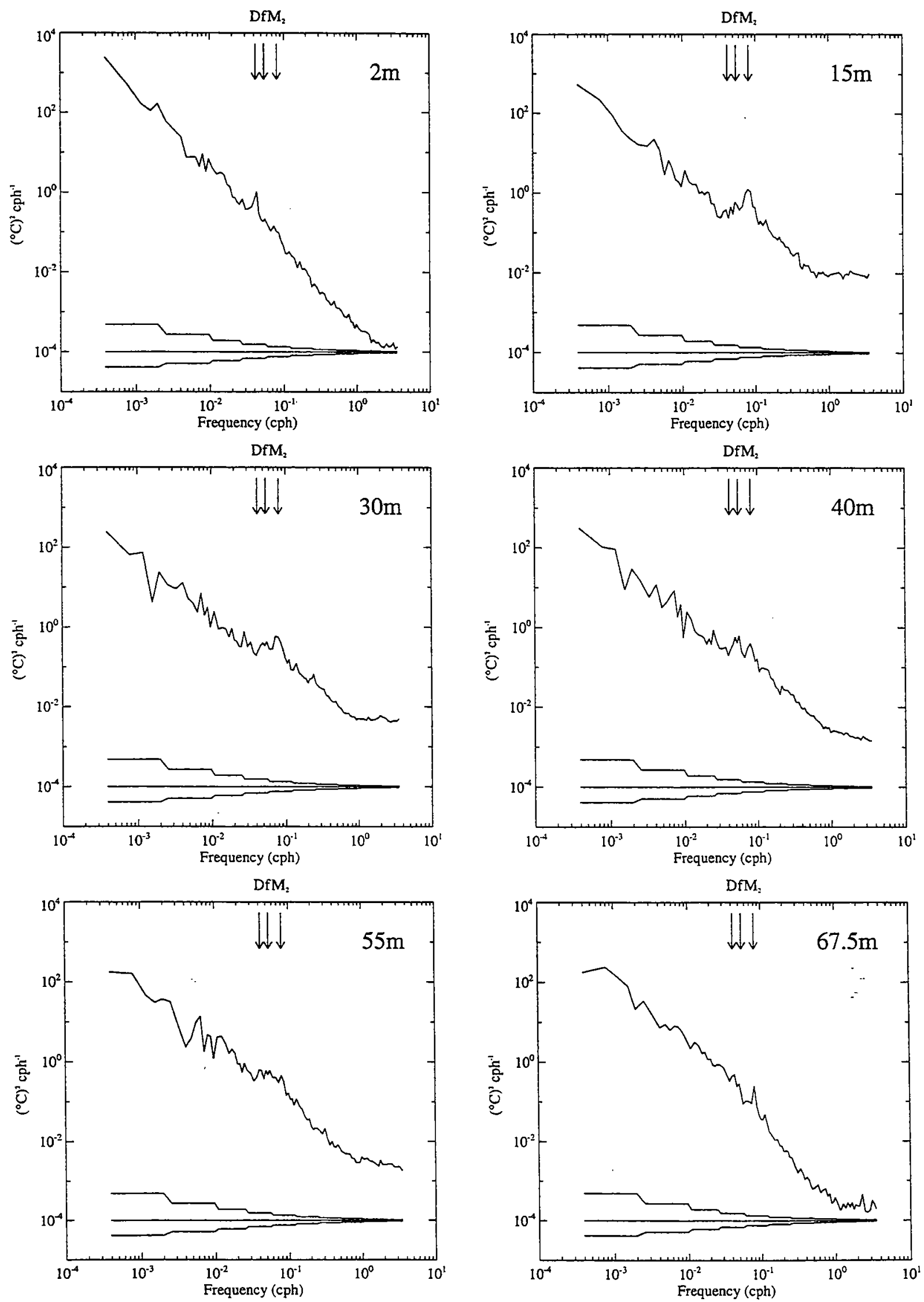

Figure 4.2.15. Autospectra of temperatures at Central Site at various depths. The tidal M2 and inertial frequencies are indicated with arrows. 


\subsection{Salinity}

The salinity data are presented as offset time series plots. Spectra from selected depths at the Central site are shown. 


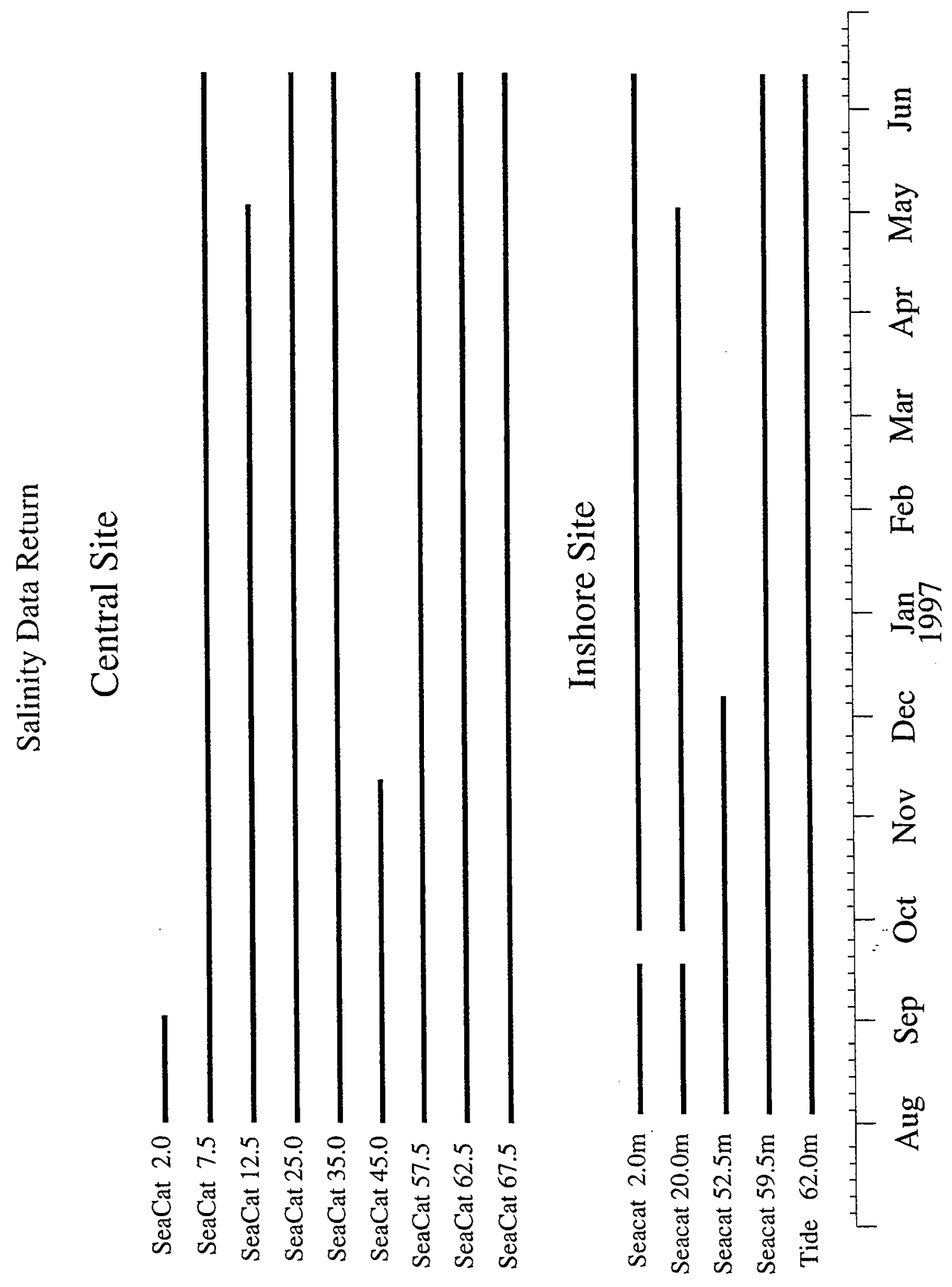

Figure.4.3.1. Salinity Data Return, Central and Inshore sites 


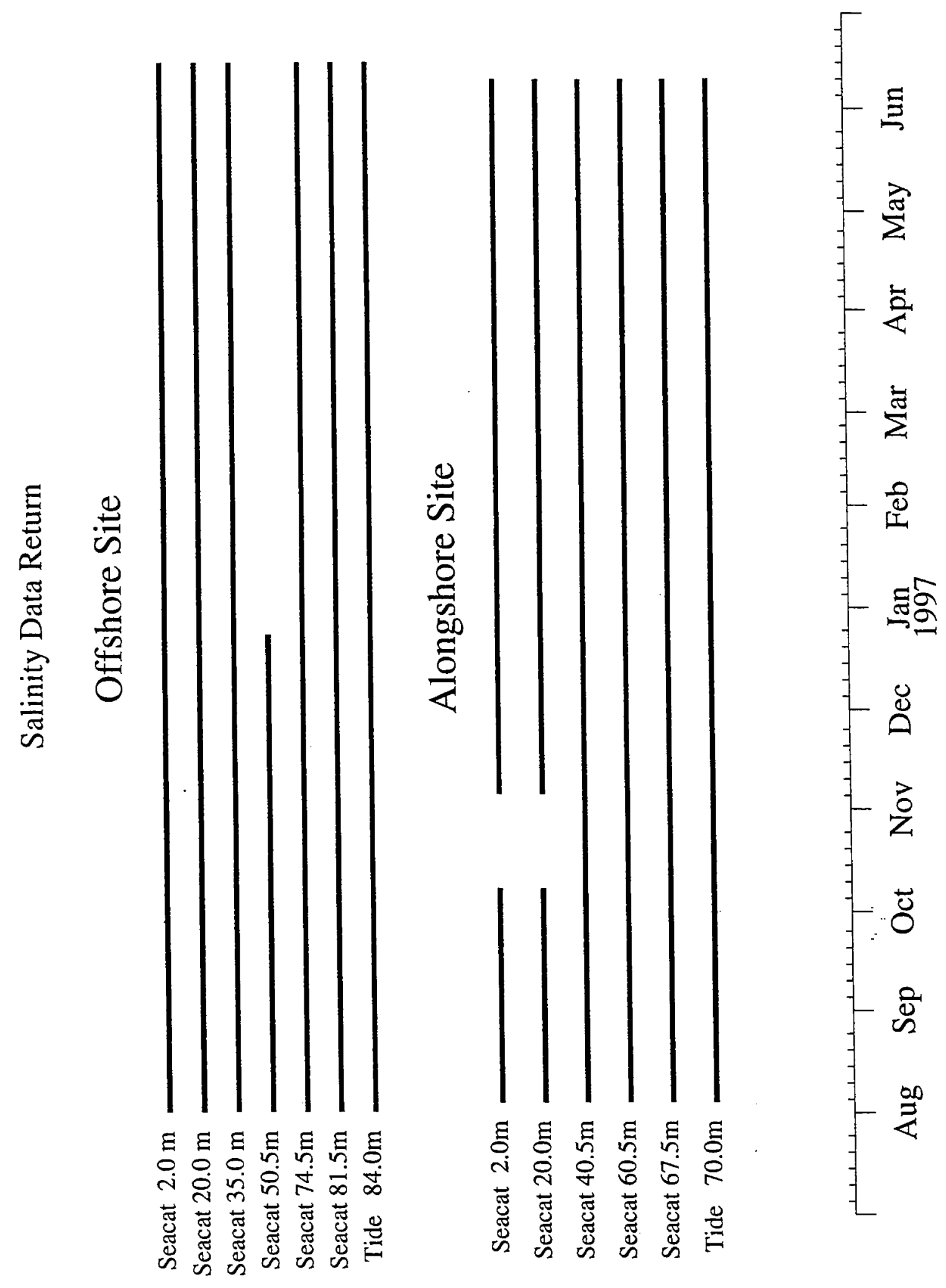

Figure 4.3.2. Salinity Data Return, Offshore and Alongshore sites 


\section{Statistics: Salinity (PSU)}

Central: Dates: 1996/07/30 19:07:30 to $1997 / 06 / 12$ 18:30:00, 60860 Records

\begin{tabular}{|r|r|c|r|r|r|r|r|}
\hline Bin & Depth & End Date & Mean & StdDev & \multicolumn{1}{c|}{ Min } & Max & \multicolumn{1}{c|}{ NPts } \\
\hline 1 & 2.0 & $1996 / 09 / 0310: 52$ & 31.77 & 0.21 & 31.17 & 32.38 & 6655 \\
\hline 2 & 7.5 & $1997 / 06 / 1218: 30$ & 31.88 & 0.27 & 30.58 & 32.88 & 60860 \\
\hline 3 & 12.5 & $1997 / 05 / 0320: 07$ & 31.92 & 0.22 & 30.87 & 33.37 & 53193 \\
\hline 4 & 25.0 & $1997 / 06 / 1218: 30$ & 32.01 & 0.21 & 31.01 & 33.27 & 60860 \\
\hline 5 & 35.0 & $1997 / 06 / 1218: 22$ & 32.09 & 0.21 & 30.63 & 33.53 & 60859 \\
\hline 6 & 45.0 & $1996 / 11 / 1215: 37$ & 32.18 & 0.18 & 31.19 & 33.31 & 20133 \\
\hline 7 & 57.5 & $1997 / 06 / 1218: 30$ & 32.36 & 0.27 & 31.09 & 34.84 & 60860 \\
\hline 8 & 62.5 & $1997 / 06 / 1218: 30$ & 32.44 & 0.35 & 30.93 & 34.69 & 60624 \\
\hline 9 & 67.5 & $1997 / 06 / 1218: 30$ & 32.49 & 0.39 & 31.02 & 33.99 & 60860 \\
\hline
\end{tabular}

Inshore: Dates: 1996/08/02 19:22:30 to 1997/06/12 09:22:30, 60209 Records

\begin{tabular}{|r|r|c|r|r|r|r|r|}
\hline Bin & Depth & End Date & Mean & StdDev & Min & Max & NPts \\
\hline 1 & 2.0 & $1997 / 06 / 1209: 22$ & 31.77 & 0.25 & 30.57 & 32.50 & 58694 \\
\hline 2 & 20.0 & $1997 / 05 / 0205: 52$ & 31.85 & 0.22 & 30.94 & 33.05 & 50795 \\
\hline 3 & 52.5 & $1996 / 12 / 0623: 37$ & 32.10 & 0.19 & 31.51 & 33.01 & 24226 \\
\hline 4 & 59.0 & $1997 / 06 / 1209: 22$ & 32.22 & 0.22 & 31.60 & 33.19 & 60208 \\
\hline 5 & 62.0 & $1997 / 06 / 1209: 22$ & 32.22 & 0.21 & 31.61 & $33: 14$ & 60209 \\
\hline
\end{tabular}

Offshore: Dates: $1996 / 07 / 3120: 00: 00$ to $1997 / 06 / 1610: 52: 30,61368$ Records

\begin{tabular}{|r|r|c|r|r|r|r|r|}
\hline Bin & Depth & End Date & Mean & StdDev & Min & Max & NPts \\
\hline 1 & 2.0 & $1997 / 06 / 1610: 52$ & 31.98 & 0.30 & 30.47 & 32.86 & 61368 \\
\hline 2 & 20.0 & $1997 / 06 / 1610: 52$ & 32.09 & 0.27 & 30.64 & 34.87 & 61368 \\
\hline 3 & 35.0 & $1997 / 06 / 1610: 52$ & 32.25 & 0.26 & 30.85 & 35.57 & 61368 \\
\hline 4 & 50.5 & $1996 / 12 / 2404: 15$ & 32.42 & 0.33 & 30.73 & 35.19 & 27907 \\
\hline 5 & 74.5 & $1997 / 06 / 1610: 52$ & 32.97 & 0.57 & 31.20 & 35.25 & 61368 \\
\hline 6 & 81.5 & $1997 / 06 / 1610: 52$ & 33.13 & 0.62 & 32.00 & 35.45 & 61368 \\
\hline 7 & 84.0 & $1997 / 06 / 1610: 52$ & 33.14 & 0.62 & 32.01 & 35.18 & 61368 \\
\hline
\end{tabular}

Alongshore: Dates: 1996/08/03 21:07:30 to 1997/06/10 09:52:30, 59622 Records

\begin{tabular}{|r|r|c|r|r|r|r|r|}
\hline Bin & \multicolumn{1}{|c|}{ Depth } & End Date & \multicolumn{1}{c|}{ Mean } & StdDev & \multicolumn{1}{l|}{ Min } & Max & \multicolumn{1}{c|}{ NPts } \\
\hline 1 & 2.0 & $1997 / 06 / 1009: 52$ & 31.92 & 0.26 & 29.00 & 33.07 & 54315 \\
\hline 2 & 20.0 & $1997 / 06 / 1009: 52$ & 32.00 & 0.22 & 31.10 & 33.95 & 54321 \\
\hline 3 & 40.5 & $1997 / 06 / 1009: 52$ & 32.12 & 0.21 & 30.41 & 33.86 & 59622 \\
\hline 4 & 60.5 & $1997 / 06 / 1009: 52$ & 32.33 & 0.27 & 31.18 & 33.84 & 59622 \\
\hline 5 & 67.5 & $1997 / 06 / 1009: 52$ & 32.41 & 0.34 & 30.16 & 33.97 & 59622 \\
\hline 6 & 70.0 & $1997 / 06 / 1009: 52$ & 32.42 & 0.34 & 31.76 & 33.80 & 59622 \\
\hline
\end{tabular}

Table 4.3.1. Salinity Statistics 


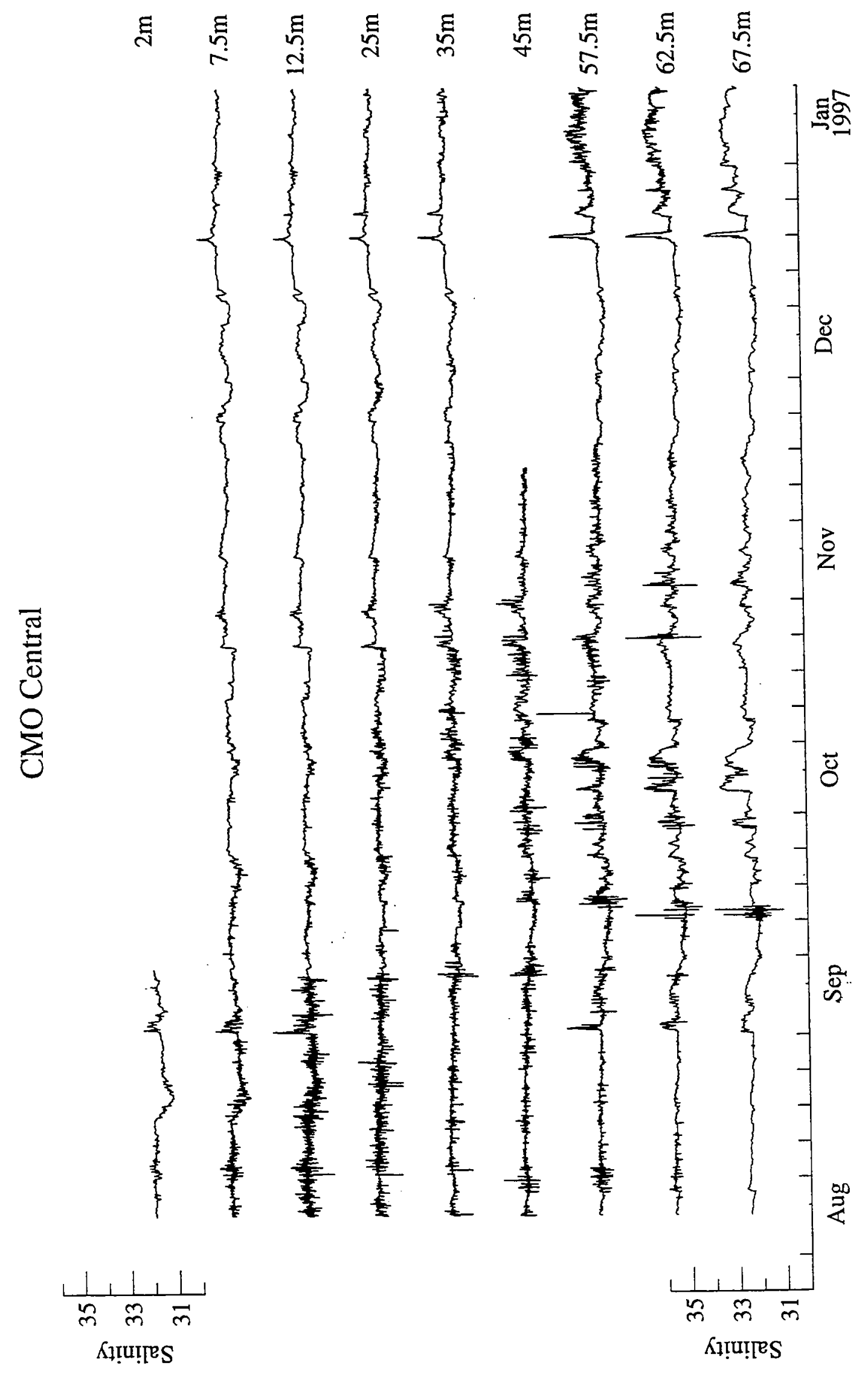

Figure 4.3.3. Salinity time series, Central Site, August - December 

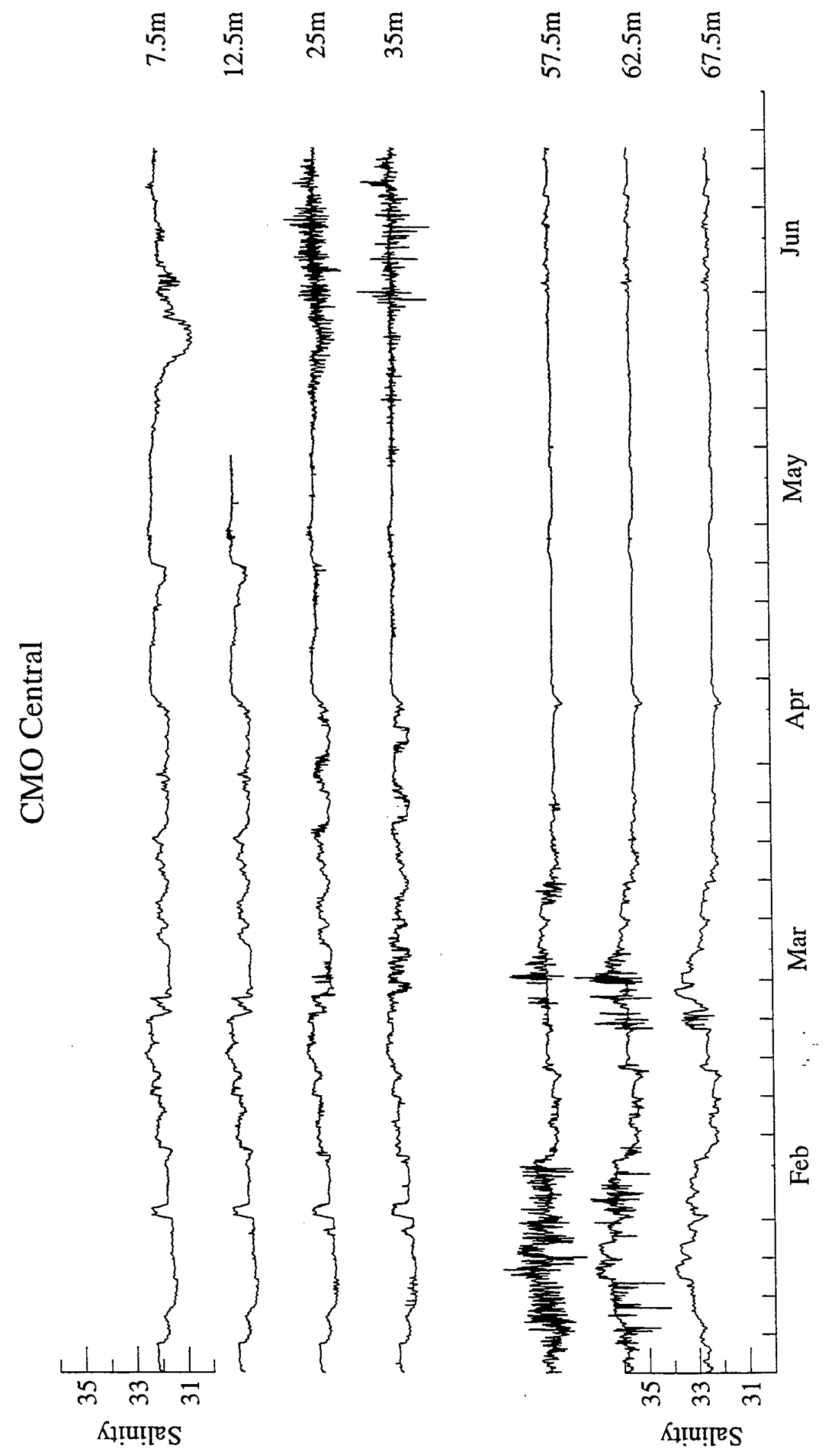

Figure 4.3.4. Salinity time series, Central Site, January - June 


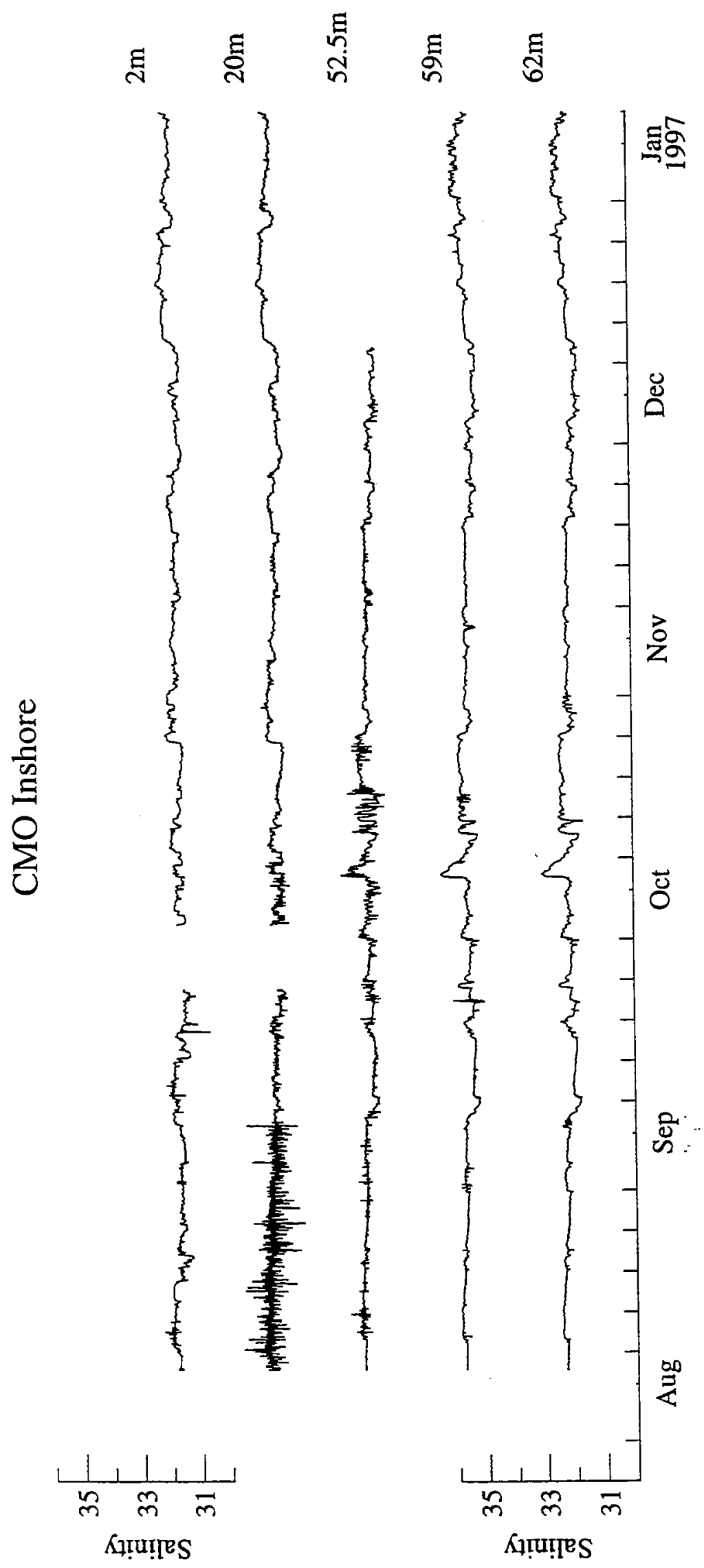

Figure 4.3.5. Salinity time series, Inshore Site, August - December 


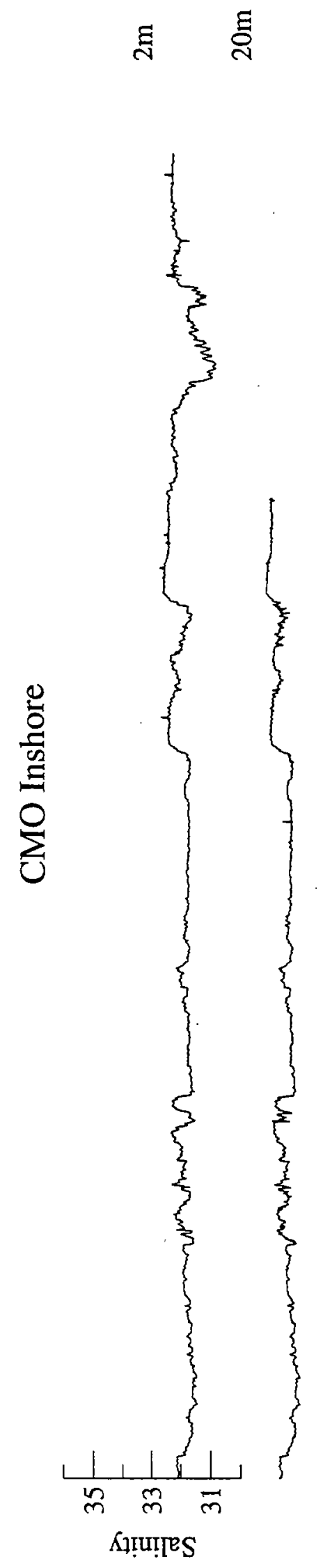

동 ह

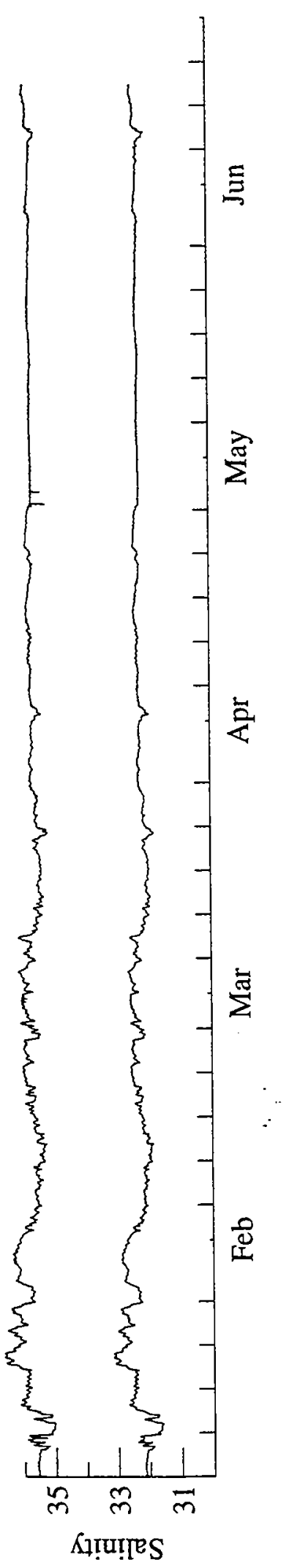

Figure 4.3.6. Salinity time series, Inshore Site, January - June 


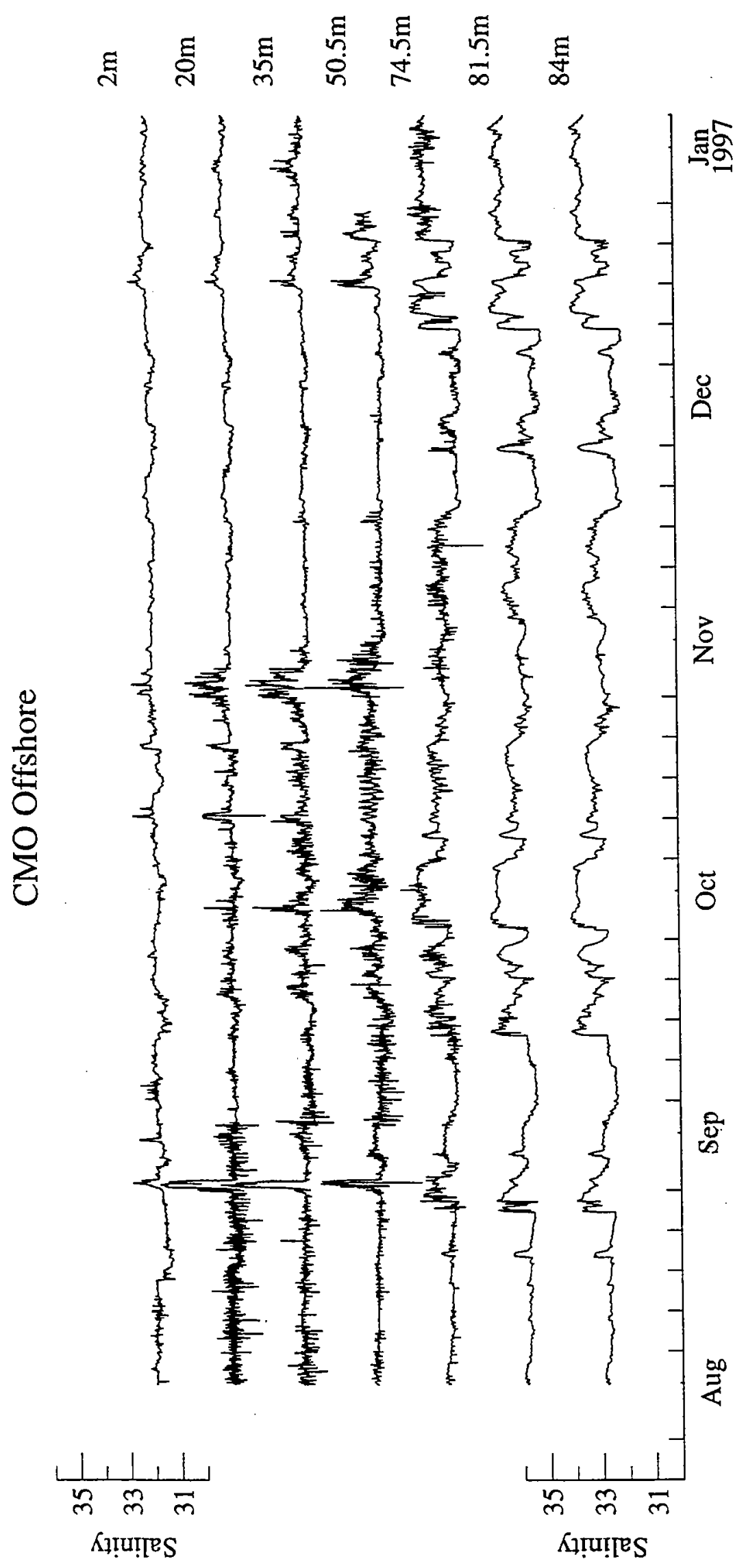

Figure 4.3:7. Salinity time series, Offshore Site, August - December 


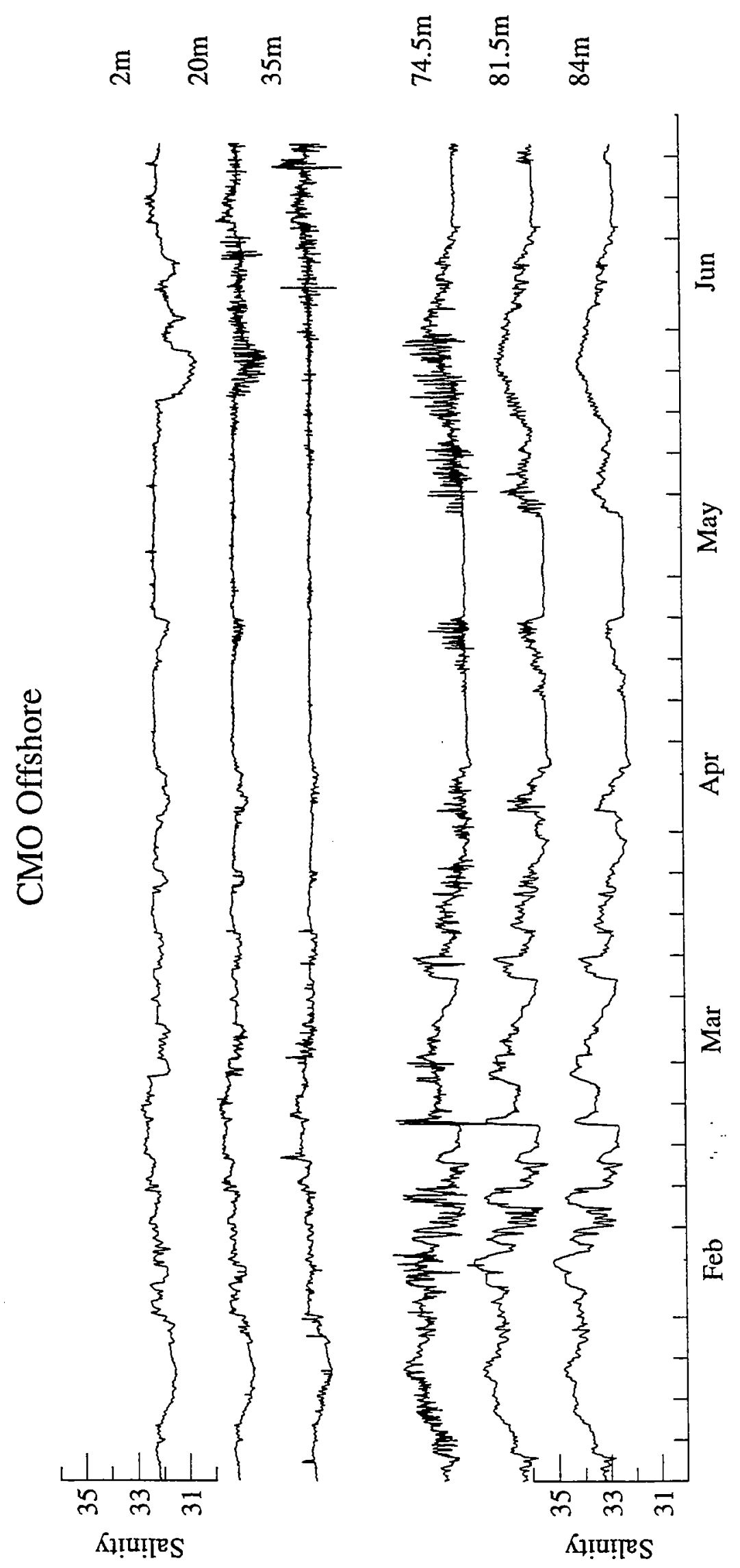

Figure 4.3.8. Salinity time series, Offshore Site, January - June 


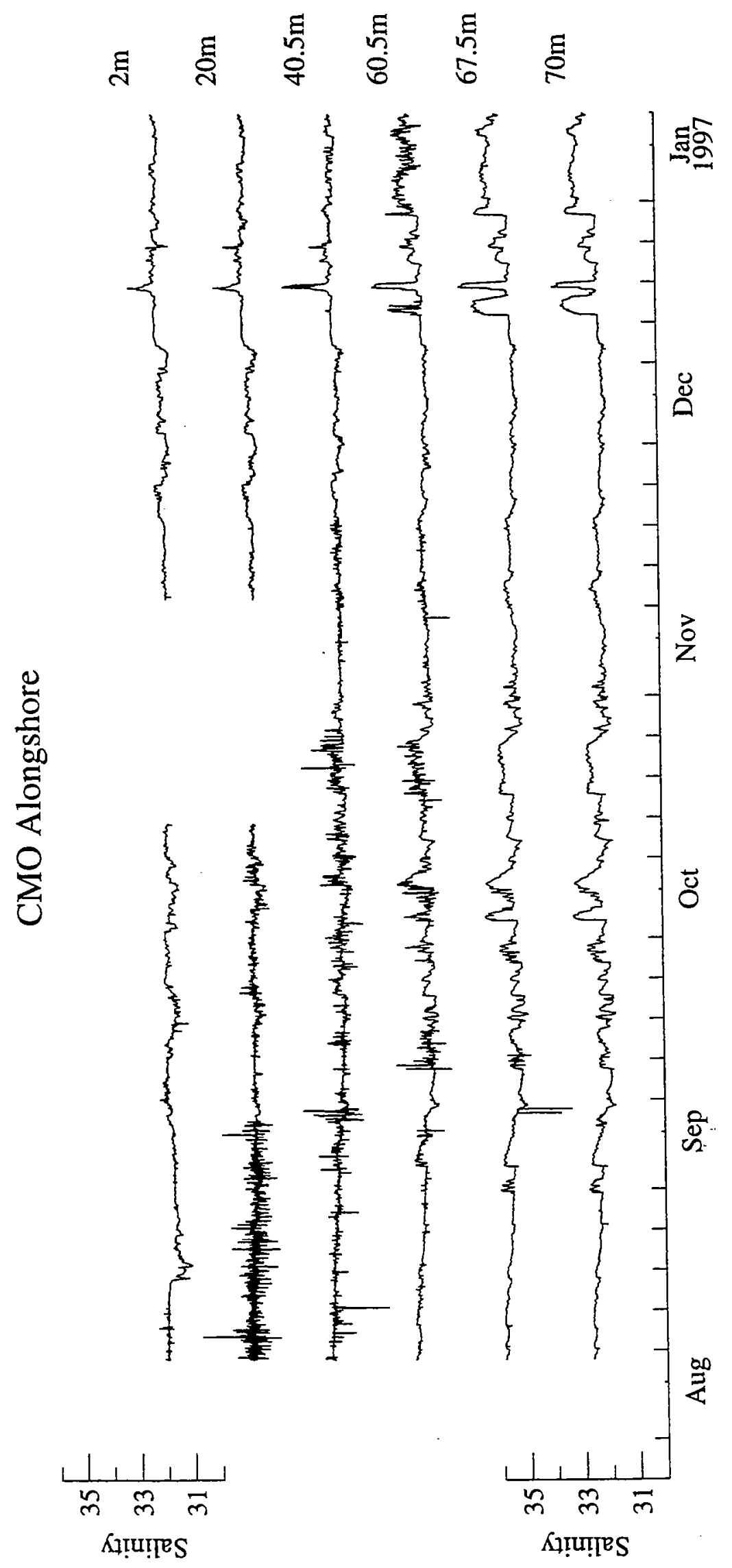

Figure 4.3.9. Salinity time series, Alongshore Site, August - December 


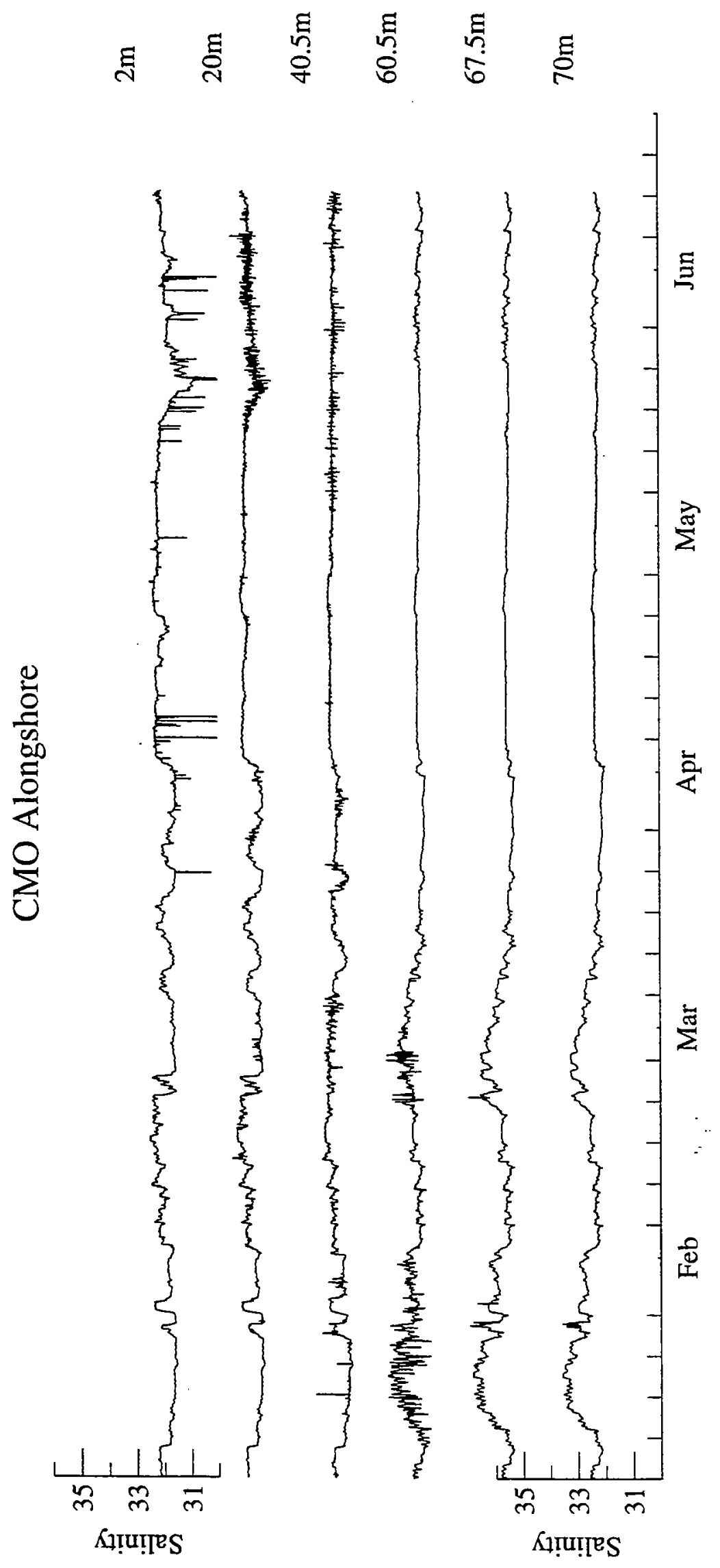

Figure 4.3.10. Salinity time series, Alongshore Site, January - June 

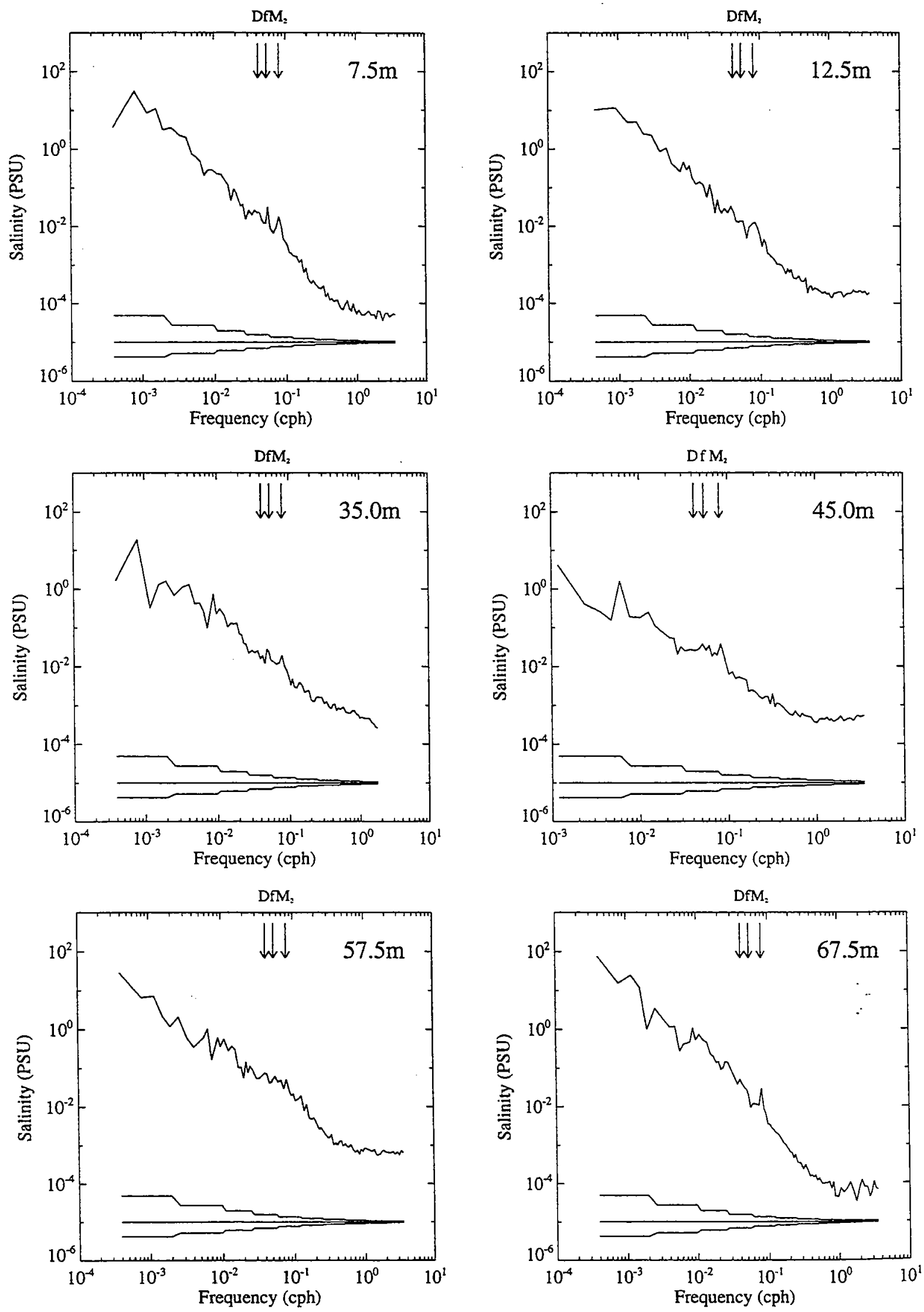

Figure 4.3.11. Autospectra of salinity at Central Site at various depths. Diurnal (D), semidiurnal (M2), and inertial ( $f$ ) frequencies are indicated. 


\subsection{Bottom Pessure}

Bottom pressure data from the Tidegauges at the Inshore, Offshore, and Alongshore sites are presented as time series plots. Spectra are also shown. 
$\Xi$
0
0
0
0
0
0
0
0
0
0
0
0
0
0

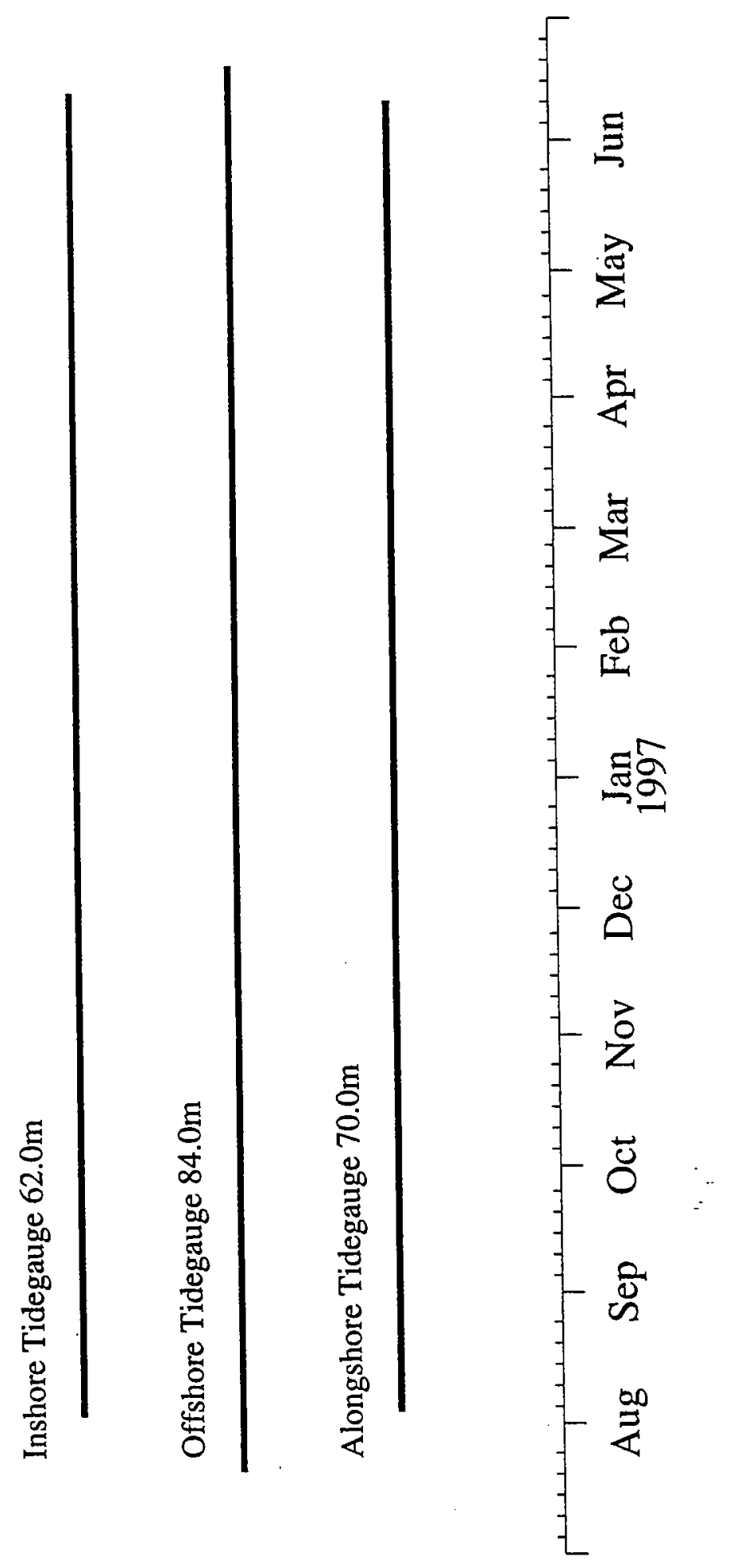

Figure 4.4.1. Bottom Pressure Data Return 


\section{Statistics: Bottom Pressure}

Inshore Seagauge: 1996/08/02 19:20 to 1997/06/12 09:10, 90311 Records

\begin{tabular}{|c|r|r|r|r|l|}
\hline End Date & Mean (mbar) & StdDev & Min & Max & \#Pts \\
\hline $1997 / 06 / 1209: 09$ & 7324.4 & 33.2 & 7243.6 & 7412.2 & 90311 \\
\hline
\end{tabular}

Offshore Seagauge: $1996 / 07 / 3120: 00$ to $1997 / 06 / 1610: 40$, 92049 Records

\begin{tabular}{|c|r|r|r|r|c|}
\hline End Date & Mean (mbar) & StdDev & Min & Max & \#Pts \\
\hline 1997/06/16 10:39 & 9594.6 & 33.6 & 9518.1 & 9682.5 & 92049 \\
\hline
\end{tabular}

Alongshore Seagauge: 1996/08/03 21:30 to $1997 / 06 / 10$ 00:35, 89318 Records

\begin{tabular}{|c|r|r|r|r|l|}
\hline End Date & Mean (mbar) & StdDev & Min & Max & \#Pts \\
\hline $1997 / 06 / 1000: 35$ & 7908.4 & 33.2 & 7829.0 & 7995.4 & 89318 \\
\hline
\end{tabular}

Table 4.4.1. Pressure Statistics 

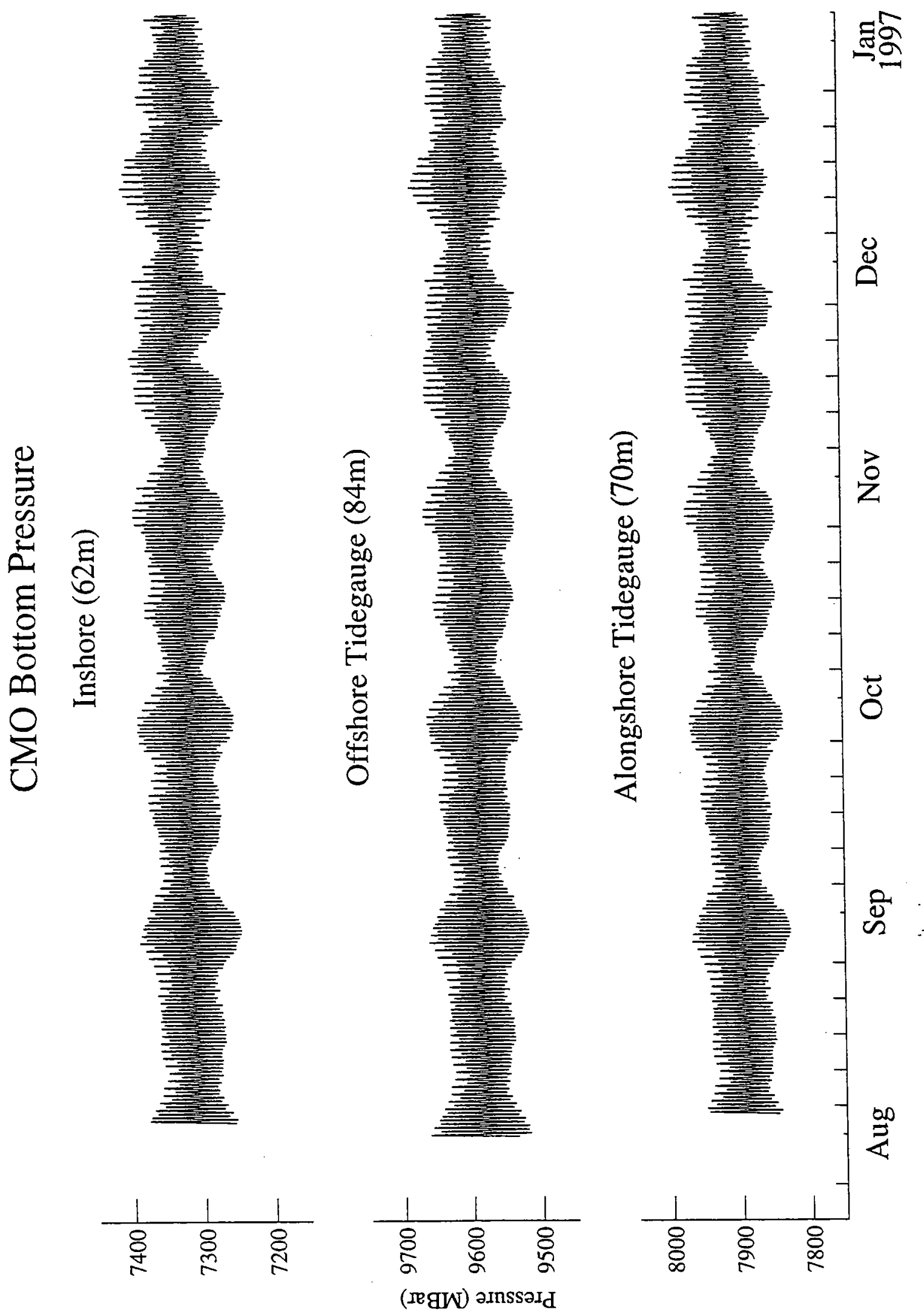

Figure 4.4.2. Pressure time series, August - December 

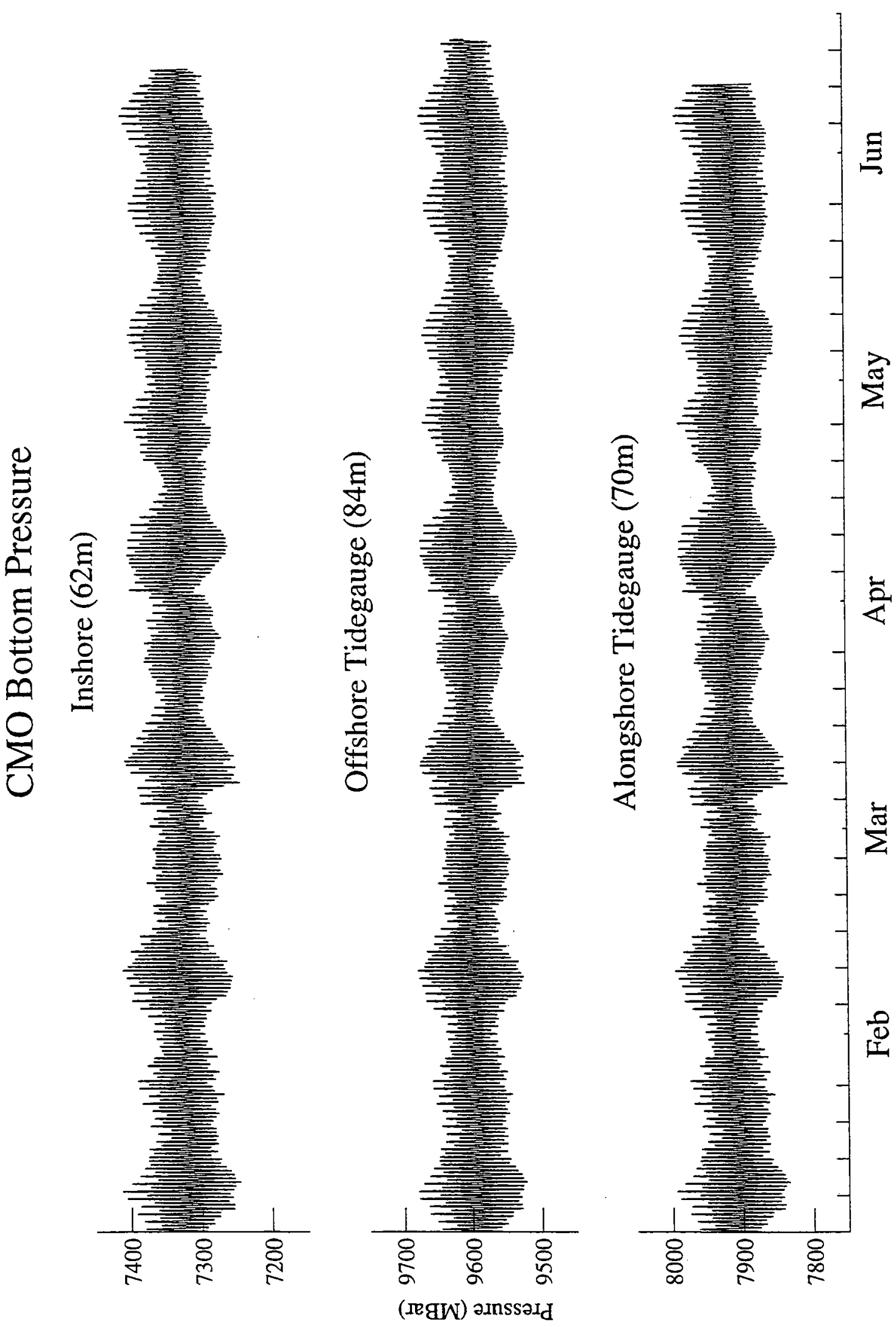

Figure 4.4.3. Pressure time series, January - June 

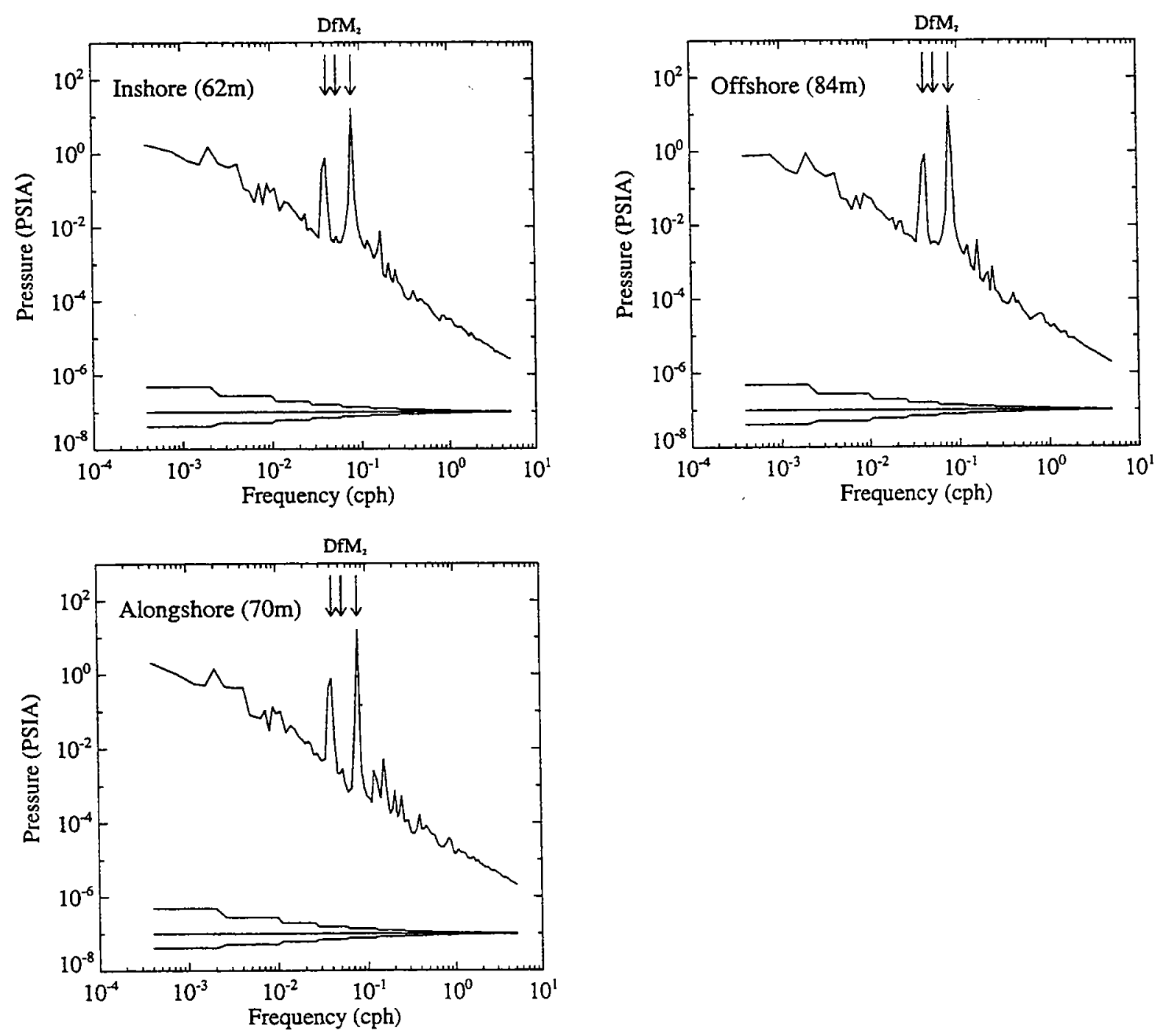

Figure 4.4.4. Autospectra of bottom pressure at various sites. Diurnal (D), semi-diurnal (M2), and inertial (f) frequencies are indicated. 


\subsection{Water Velocity}

The water velocity time series are presented as vector plots of low-pass filtered data with a 3 day cutoff and decimated to a vector every 12 hours for clarity. Thus the water velocity time series plots do not include tidal, inertial and higher frequency motions. The corresponding statistics are for the complete (unfiltered) time series.

VMCM data are presented for all instrumented depths at each site. ADCP velocity data time series plots and rotary spectra from selected depths are presented for the Inshore and Offshore sites. Progressive vectors of VMCM data are also shown for selected depths at the Central site. 


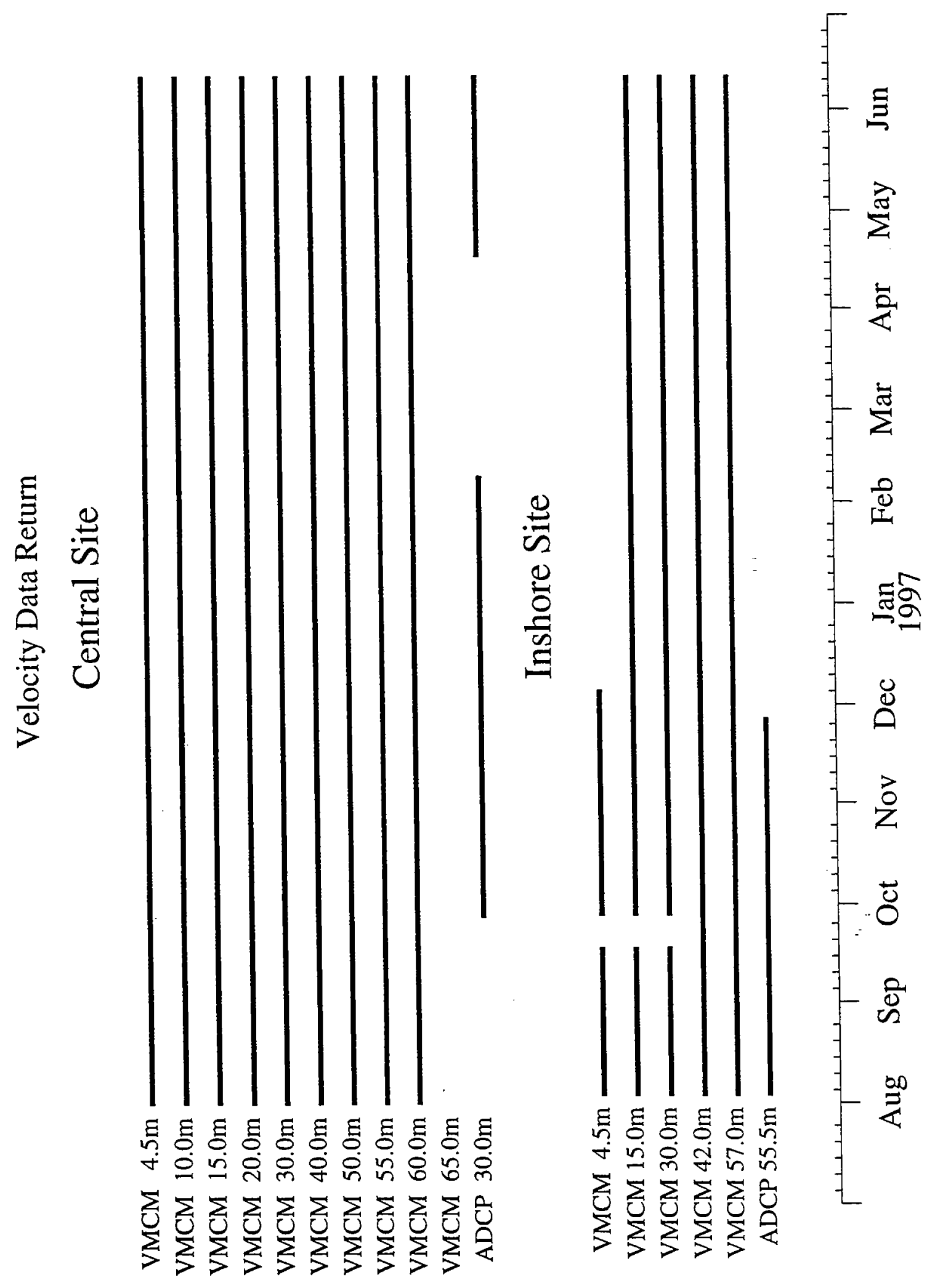

Figure 4.5.1. Water Velocity Data Return, Central and Inshore sites 


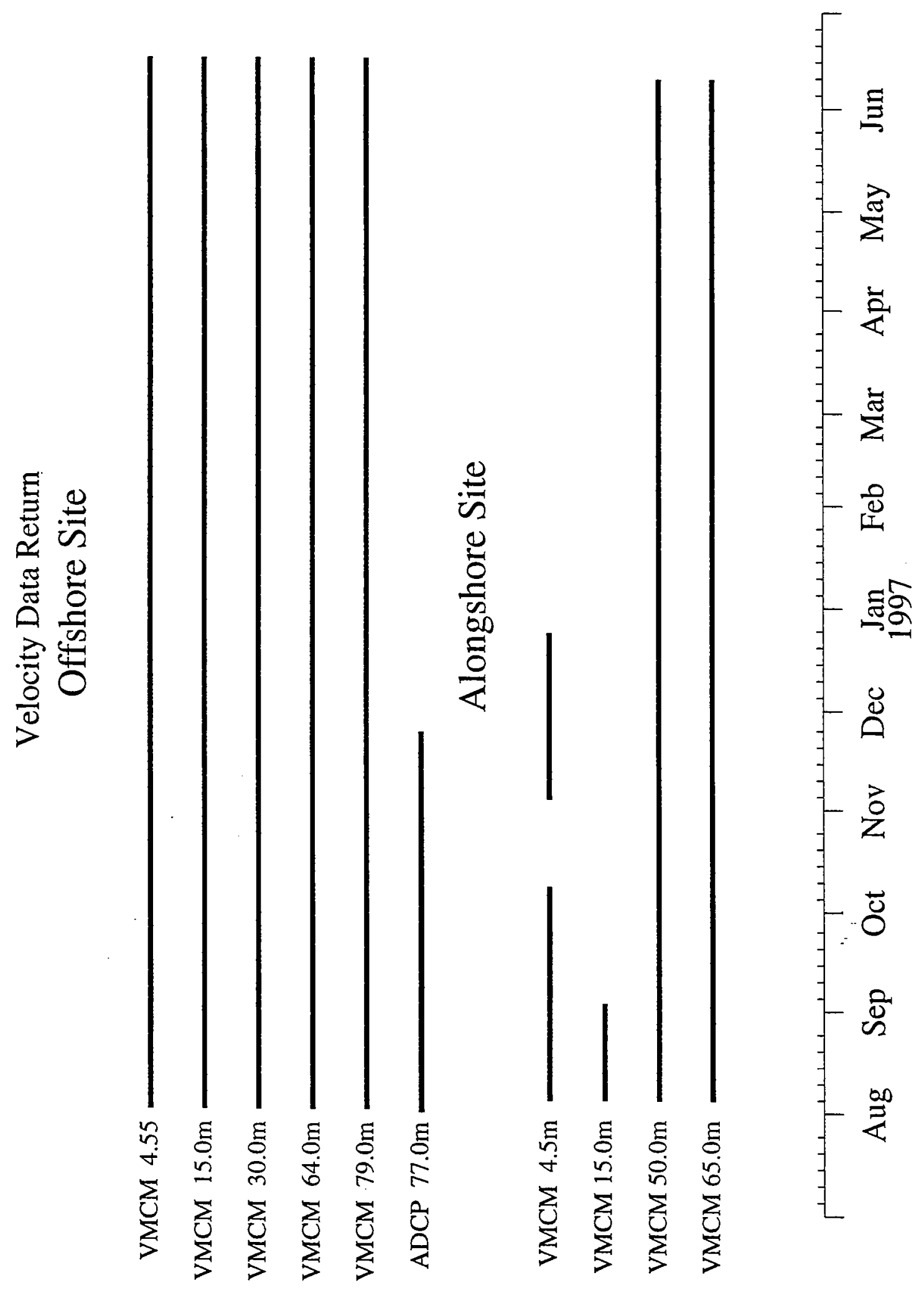

Figure 4.5.2. Water Velocity Data Return, Offshore and Alongshore sites 
Central VMCMs: 1996/07/30 19:07 to 1997/06/12 18:30, 60860 Records Velocity East (cm/second)

\begin{tabular}{|r|r|l|r|r|r|r|r|}
\hline Bin & Depth & End Date & \multicolumn{1}{l|}{ Mean } & \multicolumn{1}{l|}{ StdDev } & \multicolumn{1}{l|}{ Min } & Max & \multicolumn{1}{l|}{ NPts } \\
\hline 1 & 4.5 & $1997 / 06 / 1218: 30$ & -7.90 & 17.03 & -92.47 & 58.19 & 60860 \\
\hline 2 & 10.0 & $1997 / 06 / 1218: 30$ & -9.56 & 17.06 & -91.23 & 59.79 & 60860 \\
\hline 3 & 15.0 & $1997 / 06 / 1218: 30$ & -9.41 & 15.61 & -74.07 & 52.76 & 60860 \\
\hline 4 & 20.0 & $1997 / 06 / 1218: 30$ & -9.15 & 14.83 & -71.89 & 52.77 & 60860 \\
\hline 5 & 30.0 & $1997 / 06 / 1218: 30$ & -8.00 & 13.62 & -63.48 & 46.76 & $6086 !$ \\
\hline 6 & 40.0 & $1997 / 06 / 1218: 30$ & -7.72 & 15.06 & -68.12 & 50.15 & 60860 \\
\hline 7 & 50.0 & $1997 / 06 / 1218: 30$ & -6.79 & 15.19 & -66.87 & 44.75 & 60860 \\
\hline 8 & 55.0 & $1997 / 06 / 1218: 30$ & -5.95 & 14.83 & -65.39 & 43.87 & $6086 !$ \\
\hline 9 & 60.0 & $1997 / 06 / 1218: 30$ & -5.40 & 14.48 & -75.60 & 46.84 & $6086 !$ \\
\hline
\end{tabular}

Velocity North ( $\mathrm{cm} /$ second)

\begin{tabular}{|r|r|l|r|r|r|r|r|}
\hline Bin & Depth & End Date & Mean & StdDev & \multicolumn{1}{l|}{ Min } & \multicolumn{1}{l|}{ Max } & \multicolumn{1}{l|}{ Nts } \\
\hline 1 & 4.5 & $1997 / 06 / 1218: 30$ & -3.52 & 13.65 & -68.93 & 53.96 & 60860 \\
\hline 2 & 10.0 & $1997 / 06 / 1218: 30$ & -1.42 & 13.78 & -67.74 & 53.84 & 60860 \\
\hline 3 & 15.0 & $1997 / 06 / 1218: 30$ & -0.48 & 12.47 & -58.77 & 57.68 & 60860 \\
\hline 4 & 20.0 & $1997 / 06 / 1218: 30$ & 0.32 & 11.62 & -44.98 & 48.27 & 60860 \\
\hline 5 & 30.0 & $1997 / 06 / 1218: 30$ & 0.50 & 10.41 & -40.32 & 44.72 & 60860 \\
\hline 6 & 40.0 & $1997 / 06 / 1218: 30$ & 1.34 & 11.51 & -43.20 & 51.98 & 60860 \\
\hline 7 & 50.0 & $1997 / 06 / 1218: 30$ & 1.36 & 11.69 & -52.61 & 48.57 & 60860 \\
\hline 8 & 55.0 & $1997 / 06 / 1218: 30$ & 1.30 & 11.50 & -49.20 & 48.44 & 6.0860 \\
\hline 9 & 60.0 & $1997 / 06 / 1218: 30$ & 0.01 & 10.94 & -53.89 & 39.12 & 60860 \\
\hline
\end{tabular}

Inshore VMCMs: $1996 / 08 / 02$ 19:22 to $1997 / 06 / 12$ 09:30, 60210 Records Velocity East (cm/second)

\begin{tabular}{|r|r|l|r|r|r|r|r|}
\hline Bin & Depth & End Date & \multicolumn{1}{l|}{ Mean } & StdDev & \multicolumn{1}{l|}{ Min } & Max & IPis \\
\hline 1 & 4.5 & $1996 / 12 / 0623: 52$ & -8.40 & 15.96 & -78.17 & 40.83 & 22715 \\
\hline 2 & 15.0 & $1997 / 06 / 1209: 30$ & -6.25 & 15.03 & -70.83 & 53.24 & 58655 \\
\hline 3 & 30.0 & $1997 / 06 / 1209: 30$ & -5.74 & 13.62 & -63.87 & 45.94 & 58695 \\
\hline 4 & 42.0 & $1997 / 06 / 1209: 30$ & -4.81 & 15.35 & -63.94 & 52.78 & $6021)$ \\
\hline 5 & 57.0 & $1997 / 06 / 1209: 30$ & -2.69 & 13.62 & -55.61 & 43.64 & $602 ! \mathrm{J}$ \\
\hline
\end{tabular}

Velocity North (cm/second)

\begin{tabular}{|r|r|l|r|r|r|r|r|}
\hline Bin & Depth & End Date & \multicolumn{1}{l|}{ Mean } & \multicolumn{1}{l|}{ StdDev } & \multicolumn{1}{l|}{ Min } & Max & \multicolumn{1}{l|}{ NPis } \\
\hline 1 & 4.5 & $1996 / 12 / 0623: 52$ & -2.56 & 14.22 & -46.28 & 53.15 & $227 ! 5$ \\
\hline 2 & 15.0 & $1997 / 06 / 1209: 30$ & -0.77 & 13.07 & -50.86 & 52.99 & 5865.5 \\
\hline 3 & 30.0 & $1997 / 06 / 1209: 30$ & 0.43 & 11.31 & -41.65 & 38.50 & 58655 \\
\hline 4 & 42.0 & $1997 / 06 / 1209: 30$ & 1.30 & 12.58 & -46.85 & 41.59 & $602:)$. \\
\hline 5 & 57.0 & $1997 / 06 / 1209: 30$ & 0.49 & 10.26 & -37.93 & 43.57 & $602:)$ \\
\hline
\end{tabular}

Table 4.5.1. VMCM Water Velocity Statistics at Central and Inshore sites 
Offshore VMCMs: 1996/07/31 20:00 to 1997/06/16 10:52, 61368 Records Velocity East (cm/second)

\begin{tabular}{|r|r|l|r|r|r|r|r|}
\hline Bin & Depth & End Date & \multicolumn{1}{|l|}{ Mean } & StdDev & \multicolumn{1}{l|}{ Min } & \multicolumn{1}{l|}{ Max } & \multicolumn{1}{l|}{ NPts } \\
\hline 1 & 4.5 & $1997 / 06 / 1610: 52$ & -9.67 & 18.16 & -101.74 & 50.28 & 61368 \\
\hline 2 & 15.0 & $1997 / 06 / 1610: 52$ & -10.84 & 15.98 & -95.87 & 44.39 & 61368 \\
\hline 3 & 30.0 & $1997 / 06 / 1610: 52$ & -10.10 & 14.14 & -66.50 & 38.34 & 61368 \\
\hline 4 & 64.0 & $1997 / 06 / 1610: 52$ & -6.76 & 15.35 & -61.26 & 43.22 & 61368 \\
\hline 5 & 79.0 & $1997 / 06 / 1610: 52$ & -3.81 & 12.23 & -57.58 & 33.83 & 61368 \\
\hline
\end{tabular}

Velocity North ( $\mathrm{cm} / \mathrm{second})$

\begin{tabular}{|r|r|l|r|r|r|r|r|}
\hline Bin & Depth & End Date & \multicolumn{1}{l|}{ Mean } & StdDev & \multicolumn{1}{l|}{ Min } & Max & NPts \\
\hline 1 & 4.5 & $1997 / 06 / 1610: 52$ & -4.01 & 14.88 & -59.96 & 51.19 & 61368 \\
\hline 2 & 15.0 & $1997 / 06 / 1610: 52$ & -1.38 & 12.11 & -46.44 & 48.22 & 61368 \\
\hline 3 & 30.0 & $1997 / 06 / 1610: 52$ & 1.25 & 9.76 & -40.22 & 41.57 & 61368 \\
\hline 4 & 64.0 & $1997 / 06 / 1610: 52$ & 0.92 & 11.07 & -46.11 & 44.29 & 61368 \\
\hline 5 & 79.0 & $1997 / 06 / 1610: 52$ & -0.59 & 8.74 & -40.64 & 40.40 & 61368 \\
\hline
\end{tabular}

Alongshore VMCMs: 1996/08/03 21:30 to 1997/06/10 09:52, 59620 Records Velocity East (cm/second)

\begin{tabular}{|r|r|c|r|r|r|r|r|}
\hline Bin & Depth & End Date & \multicolumn{1}{l|}{ Mean } & StdDev & \multicolumn{1}{l|}{ Min } & Max & NPts \\
\hline 1 & 4.55 & $1996 / 12 / 2500: 00$ & -13.12 & 19.43 & -85.22 & 59.93 & 22666 \\
\hline 2 & 15.00 & $1996 / 11 / 1200: 00$ & -6.99 & 16.08 & -78.71 & 39.55 & 14410 \\
\hline 3 & 50.0 & $1997 / 06 / 1009: 52$ & -7.24 & 16.72 & -71.99 & 45.33 & 59620 \\
\hline 4 & 65.0 & $1997 / 06 / 1009: 52$ & -5.14 & 14.83 & -73.01 & 40.59 & 59620 \\
\hline
\end{tabular}

Velocity North (cm/second)

\begin{tabular}{|r|r|l|r|r|r|r|r|}
\hline Bin & Depth & End Date & \multicolumn{1}{l|}{ Mean } & \multicolumn{1}{|c|}{ StdDev } & \multicolumn{1}{c|}{ Min } & Max & NPts \\
\hline 1 & 4.5 & $1996 / 12 / 2500: 00$ & -2.06 & 15.44 & -56.4 & 55.01 & 22666 \\
\hline 2 & 15.0 & $1996 / 11 / 1200: 00$ & 0.04 & 12.11 & -36.67 & 53.47 & 14410 \\
\hline 3 & 50.0 & $1997 / 06 / 1009: 52$ & 1.89 & 12.48 & -45.05 & 49.90 & 59620 \\
\hline 4 & 65.0 & $1997 / 06 / 1009: 52$ & 0.33 & 10.29 & -50.49 & 37.81 & 59620 \\
\hline
\end{tabular}

Table 4.5.2. VMCM Water Velocity Statistics at Offshore and Alongshore sites 


\section{ADCP Velocity Statistics}

WorkHorse 100 at Inshore Site

$1996 / 08 / 0220: 26$ to $1996 / 11 / 2701: 56,55791$ records

Velocity East (cm/second)

\begin{tabular}{|r|r|r|r|r|r|}
\hline \multicolumn{1}{|c|}{ Bin } & Depth(m) & \multicolumn{1}{c|}{ Mean } & \multicolumn{1}{c|}{ StdDev } & \multicolumn{1}{c|}{ Min } & \multicolumn{1}{c|}{ Max } \\
\hline 2 & 9.0 & -11.35 & 17.95 & -99.77 & 93.63 \\
\hline 3 & 13.0 & -11.11 & 17.19 & -99.98 & 60.22 \\
\hline 4 & 17.0 & -10.77 & 16.54 & -99.49 & 39.35 \\
\hline 5 & 21.0 & -10.33 & 16.11 & -95.20 & 35.86 \\
\hline 6 & 25.0 & -9.87 & 15.85 & -89.32 & 37.91 \\
\hline 7 & 29.0 & -9.36 & 15.75 & -80.85 & 35.86 \\
\hline 8 & 33.0 & -8.72 & 15.66 & -70.81 & 37.40 \\
\hline 9 & 37.0 & -5.76 & 11.86 & -63.82 & 29.69 \\
\hline 10 & 41.0 & -7.13 & 15.10 & -64.61 & 43.83 \\
\hline 11 & 45.0 & -6.95 & 15.59 & -61.75 & 48.85 \\
\hline
\end{tabular}

Velocity North (cm/second)

\begin{tabular}{|r|r|r|r|r|r|}
\hline \multicolumn{1}{|c|}{ Bin } & Depth(m) & \multicolumn{1}{c|}{ Mean } & \multicolumn{1}{c|}{ StdDev } & \multicolumn{1}{c|}{ Min } & \multicolumn{1}{c|}{ Max } \\
\hline 2 & 9.0 & 1.90 & 16.02 & -99.56 & 98.20 \\
\hline 3 & 13.0 & 2.34 & 14.83 & -99.28 & 85.80 \\
\hline 4 & 17.0 & 2.77 & 13.90 & -81.97 & 79.08 \\
\hline 5 & 21.0 & 2.96 & 13.35 & -60.61 & 64.71 \\
\hline 6 & 25.0 & 3.01 & 13.16 & -39.54 & 58.36 \\
\hline 7 & 29.0 & 3.03 & 13.16 & -40.05 & 53.86 \\
\hline 8 & 33.0 & 3.00 & 13.12 & -42.69 & 51.36 \\
\hline $9^{1}$ & 37.0 & 2.01 & 9.51 & -38.90 & 45.42 \\
\hline 10 & 41.0 & 2.36 & 12.46 & -40.93 & 45.76 \\
\hline 11 & 45.0 & 1.89 & 12.71 & -44.07 & 42.38 \\
\hline
\end{tabular}

Table 4.5.3. ADCP Water Velocity Statistics at Inshore site

\footnotetext{
${ }^{1}$ Bin 9 data were corrupted by the presence of the steel sphere at $38 \mathrm{~m}$ depth on the Inshore subsurface mooring.
} 
NarrowBand 593 at Offshore Site

$1996 / 07 / 31 \quad 19: 12$ to $1996 / 11 / 2401: 39,55330$ records

Velocity East ( $\mathrm{cm} / \mathrm{second})$

\begin{tabular}{|r|r|r|r|r|r|}
\hline \multicolumn{1}{|c|}{ Bin } & Depth(m) & \multicolumn{1}{c|}{ Mean } & \multicolumn{1}{c|}{ StdDev } & \multicolumn{1}{c|}{ Min } & \multicolumn{1}{c|}{ Max } \\
\hline 5 & 15.6 & -17.99 & 17.84 & -106.97 & 43.66 \\
\hline 6 & 19.6 & -17.60 & 17.43 & -98.32 & 37.35 \\
\hline 7 & 23.6 & -17.06 & 17.04 & -91.63 & 38.75 \\
\hline 8 & 27.7 & -16.49 & 16.71 & -80.64 & 40.12 \\
\hline 9 & 31.7 & -15.91 & 16.48 & -73.55 & 40.99 \\
\hline 10 & 35.7 & -15.28 & 16.32 & -71.33 & 39.88 \\
\hline 11 & 39.7 & -14.49 & 16.25 & -70.69 & 38.01 \\
\hline 12 & 43.8 & -13.61 & 16.33 & -68.52 & 35.71 \\
\hline 13 & 47.8 & -12.77 & 16.51 & -68.95 & 36.60 \\
\hline 14 & 51.8 & -11.93 & 16.66 & -70.94 & 38.65 \\
\hline 15 & 55.9 & -11.06 & 16.68 & -69.00 & 37.36 \\
\hline 16 & 59.9 & -10.27 & 16.49 & -65.47 & 39.64 \\
\hline 17 & 63.9 & -9.60 & 16.22 & -66.26 & 39.45 \\
\hline 18 & 68.0 & -8.88 & 15.91 & -65.48 & 40.97 \\
\hline
\end{tabular}

Velocity North (cm/second)

\begin{tabular}{|r|r|r|r|r|r|}
\hline \multicolumn{1}{|c|}{ Bin } & Depth(m) & \multicolumn{1}{c|}{ Mean } & \multicolumn{1}{c|}{ StdDev } & \multicolumn{1}{c|}{ Min } & \multicolumn{1}{c|}{ Max } \\
\hline 5 & 15.6 & 1.28 & 14.05 & -47.01 & 52.94 \\
\hline 6 & 19.6 & 1.71 & 13.05 & -50.52 & 50.67 \\
\hline 7 & 23.6 & 2.08 & 12.42 & -49.39 & 50.23 \\
\hline 8 & 27.7 & 2.41 & 12.05 & -46.22 & 47.43 \\
\hline 9 & 31.7 & 2.63 & 11.80 & -41.52 & 45.84 \\
\hline 10 & 35.7 & 2.73 & 11.54 & -37.49 & 47.16 \\
\hline 11 & 39.7 & 2.69 & 11.32 & -36.72 & 48.34 \\
\hline 12 & 43.8 & 2.56 & 11.30 & -43.63 & 47.60 \\
\hline 13 & 47.8 & 2.27 & 11.52 & -47.86 & 52.16 \\
\hline 14 & 51.8 & 1.84 & 11.89 & -49.72 & 56.80 \\
\hline 15 & 55.9 & 1.41 & 12.28 & -51.22 & 54.70 \\
\hline 16 & 59.9 & 0.99 & 12.56 & -50.75 & 51.27 \\
\hline 17 & 63.9 & 0.52 & 12.63 & -48.43 & 47.59 \\
\hline 18 & 68.0 & -0.07 & 12.43 & -51.59 & 42.87 \\
\hline
\end{tabular}

Table 4.5.4. ADCP Water Velocity Statistics at Offshore sites 


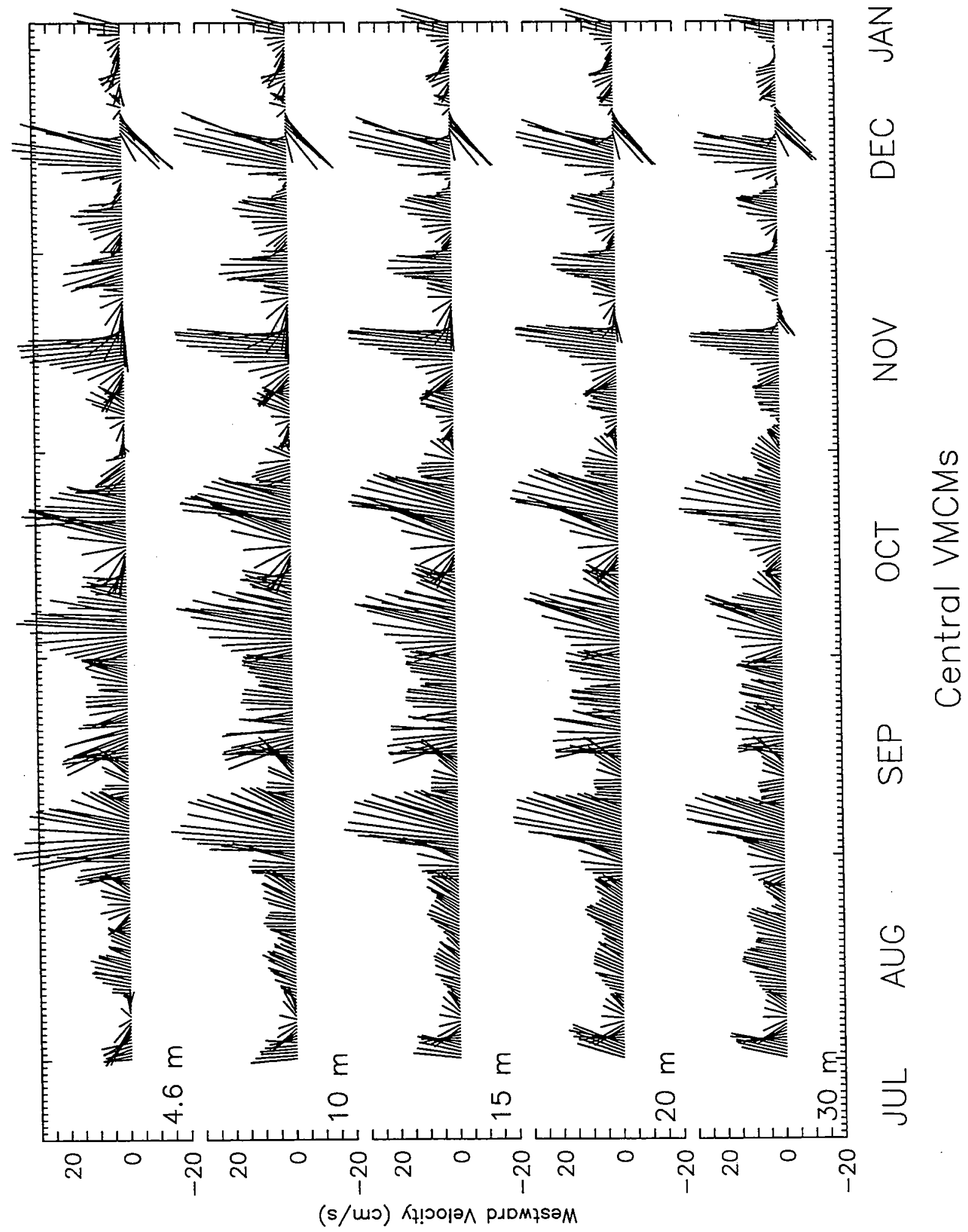

Figure 4.5.3. VMCM Water Velocity time series, Central Site, August - December, shallow instruments. Data is filtered over 576 points ( 3 days) and decimated over 96 points (12 hours). 


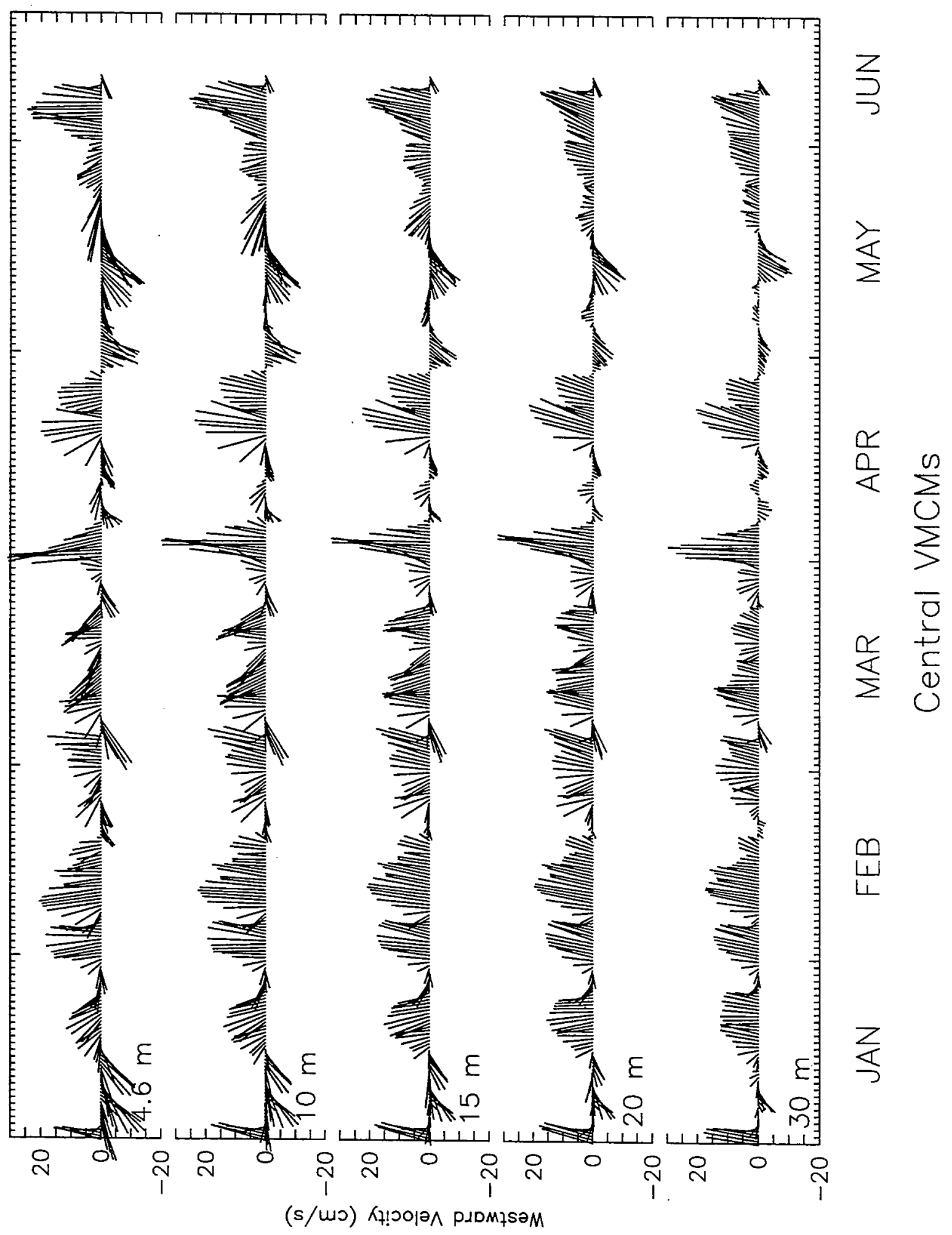

Figure 4.5.4. VMCM Water Velocity time series, Central Site, August - December, deep instruments. Data is filtered over 576 points (3 days) and decimated over 96 points (12 hours). 


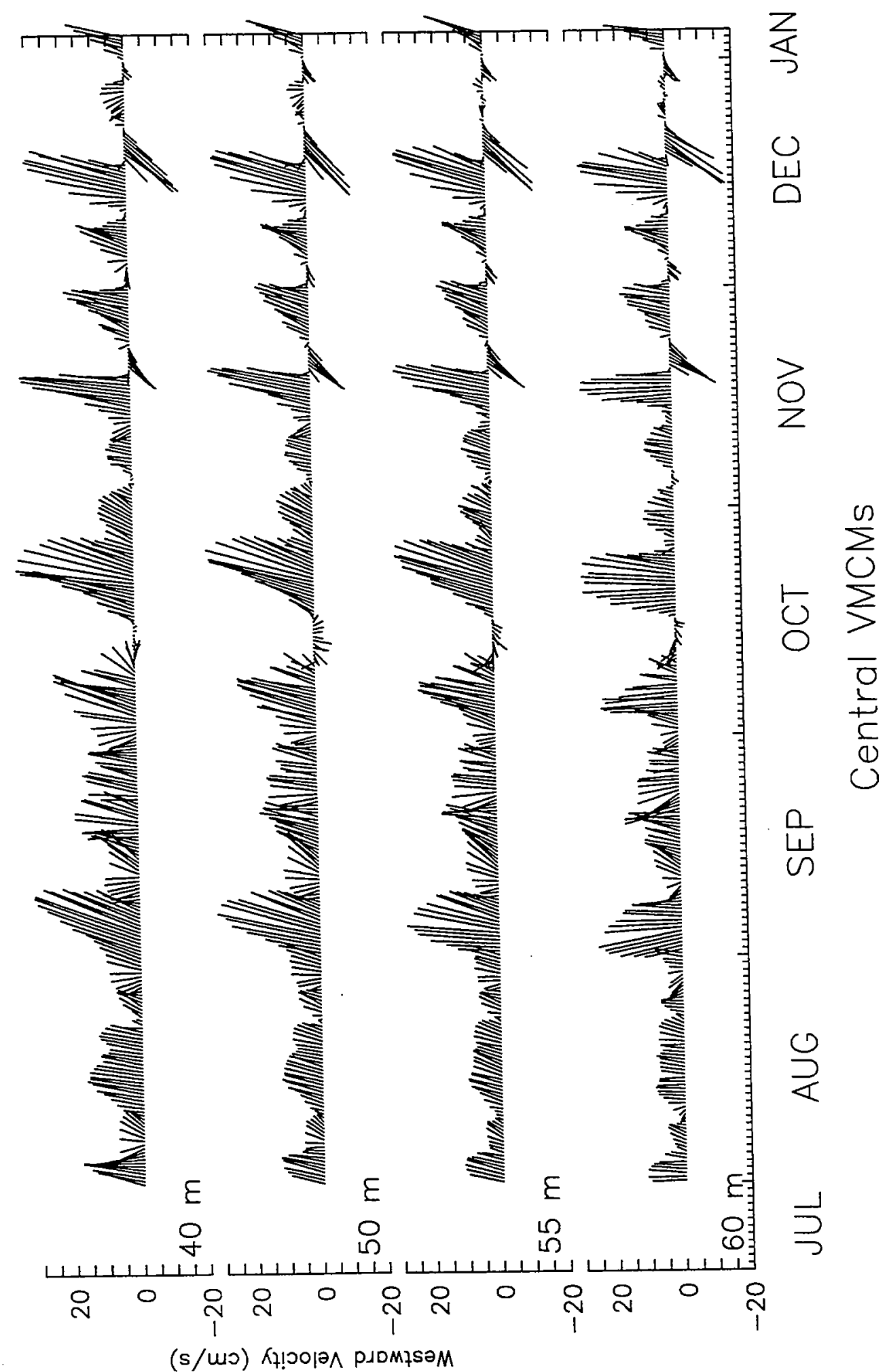

Figure 4.5.5. VMCM Water Velocity time series, Central Site, January - June, shallow instruments. Data is filtered over 576 points ( 3 days) and decimated over 96 points (12 hours). 


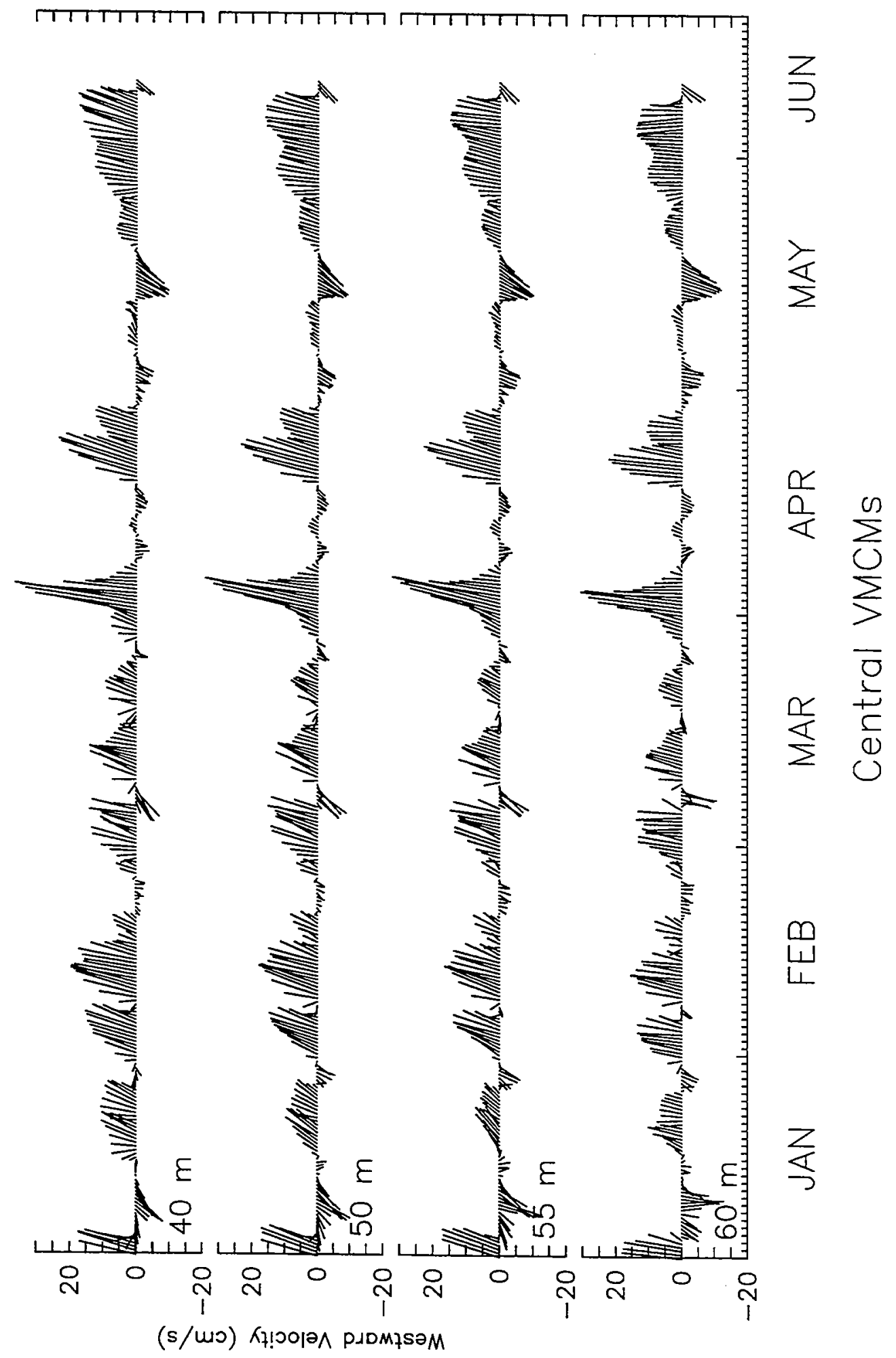

Figure 4.5.6. VMCM Water Velocity time series, Central Site, January - June, deep instruments. Data is filtered over 576 points ( 3 days) and decimated over 96 points (12 hours). 


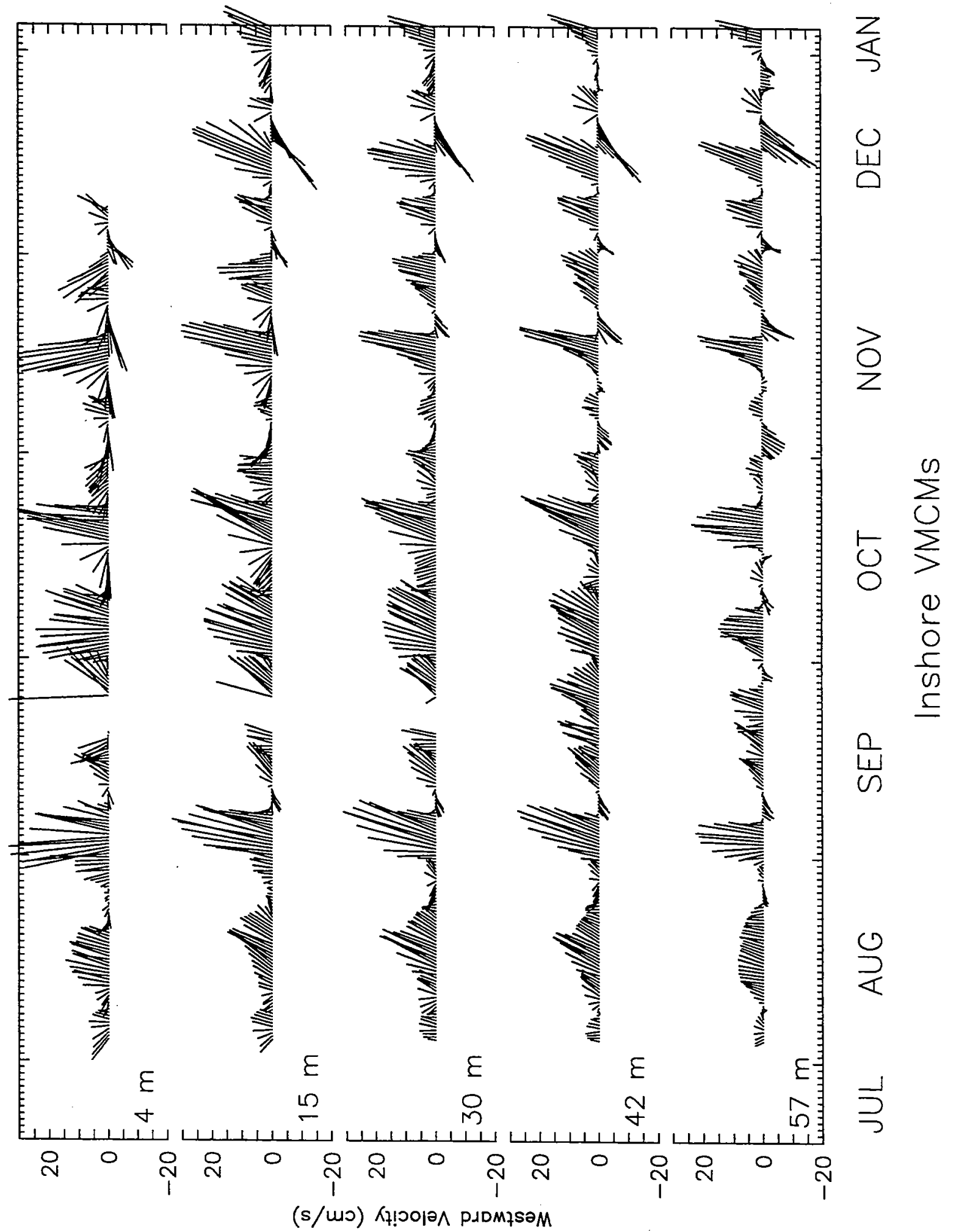

Figure 4.5.7. VMCM Water Velocity time series, Inshore Site, August - December. Data is filtered over 576 points ( 3 days) and decimated over 96 points ( 12 hours). 


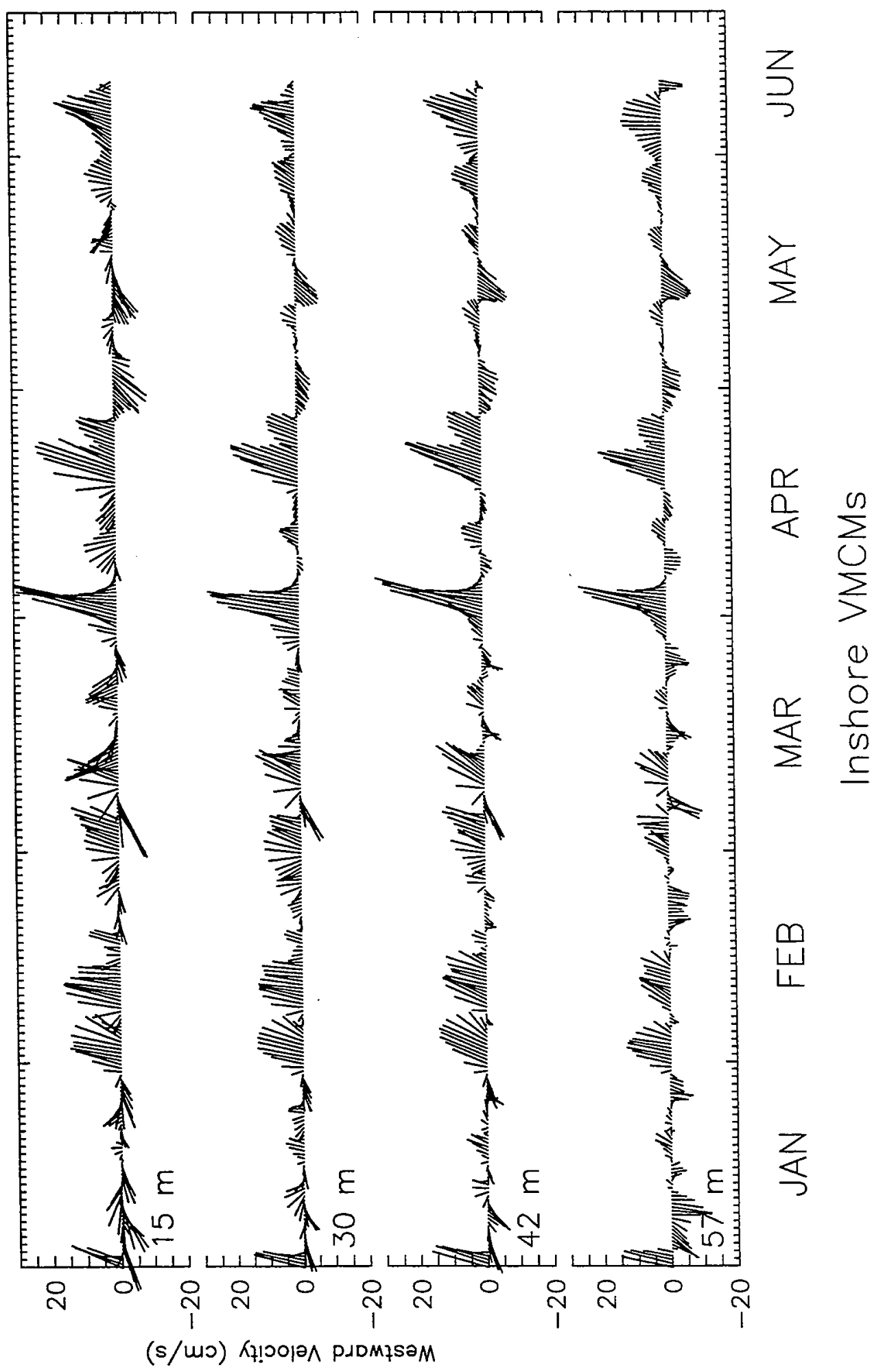

Figure 4.5.8. VMCM Water Velocity time series, Inshore Site, January - June. Data is filtered over 576 points ( 3 days) and decimated over 96 points (12 hours). 


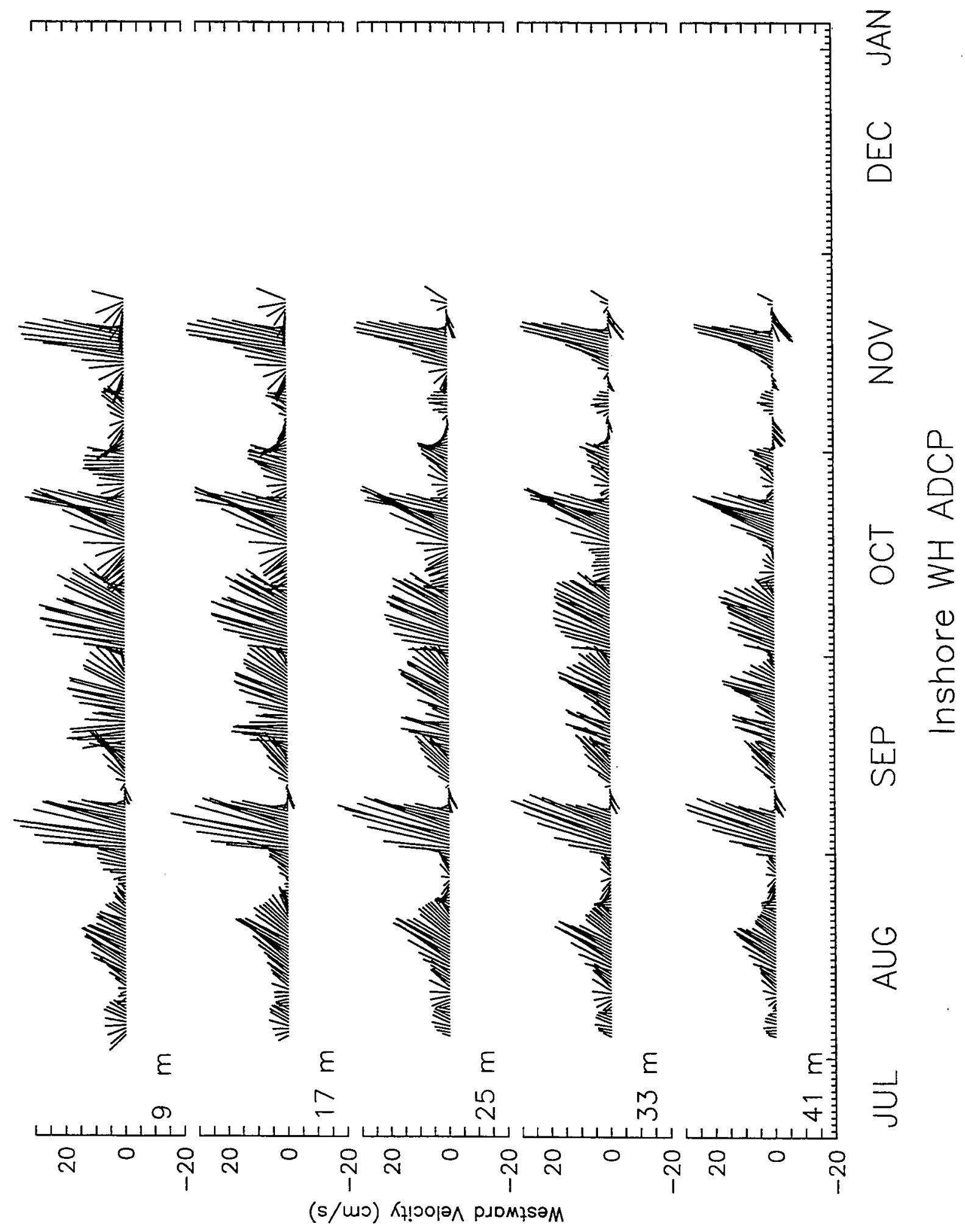

Figure 4.5.9. ADCP Water Velocity time series, Inshore Site, August - December. 


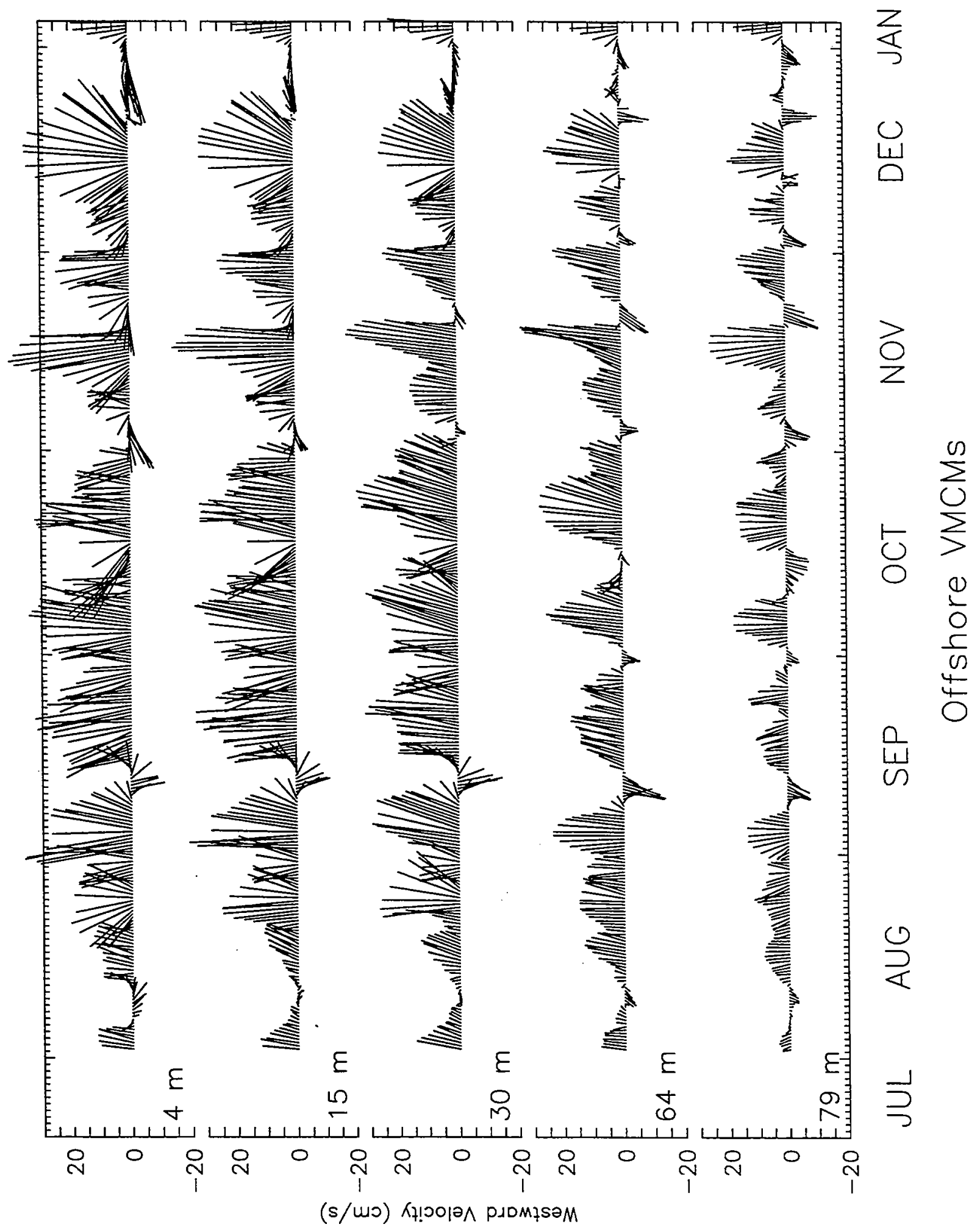

Figure 4.5.10. VMCM Water Velocity time series, Offshore Site, August - December. Data is filtered over 576 points ( 3 days) and decimated over 96 points ( 12 hours). 


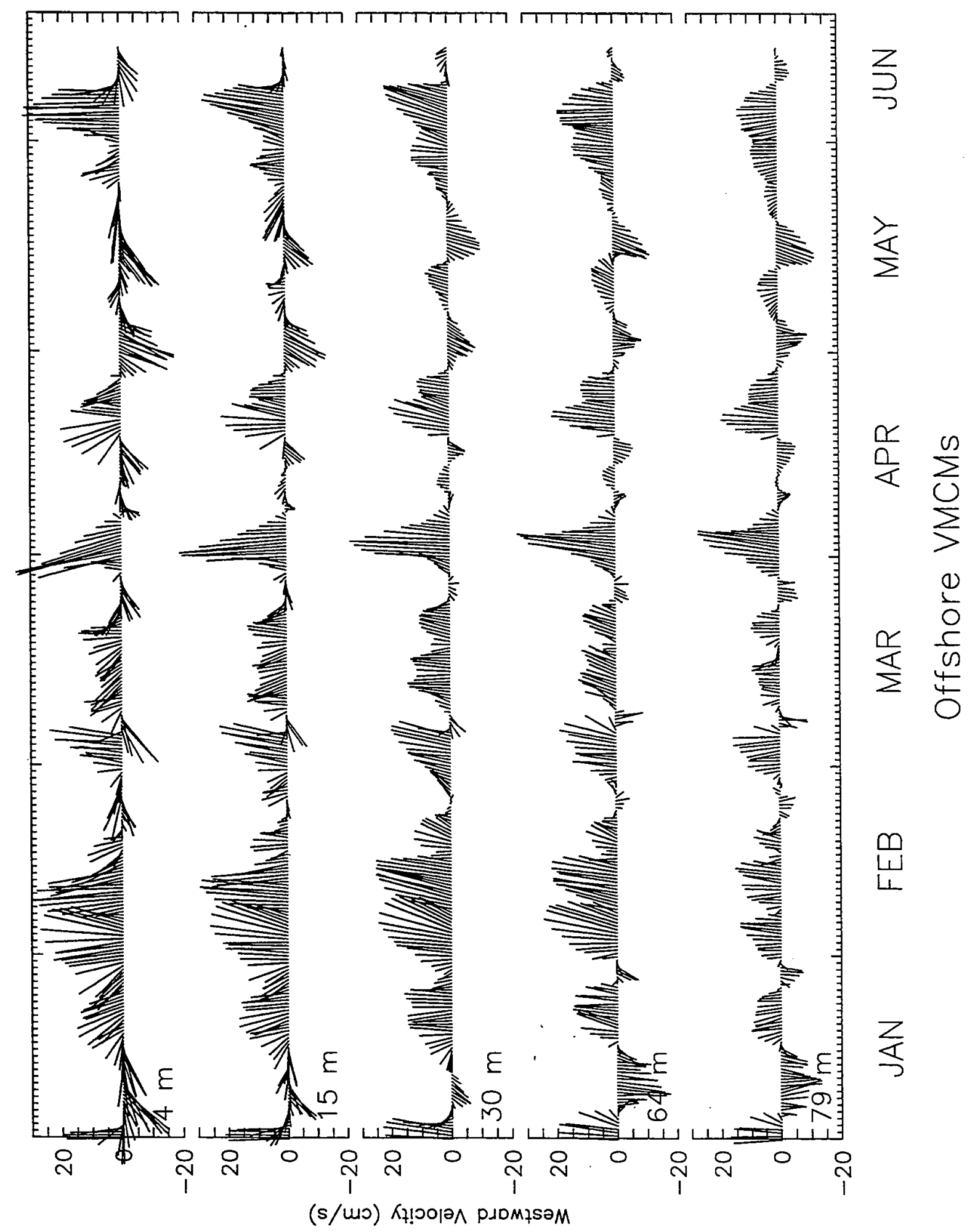

Figure 4.5.11. VMCM Water Velocity time series, Offshore Site, January - June. Data is filtered over 576 points ( 3 days) and decimated over 96 points ( 12 hours). 


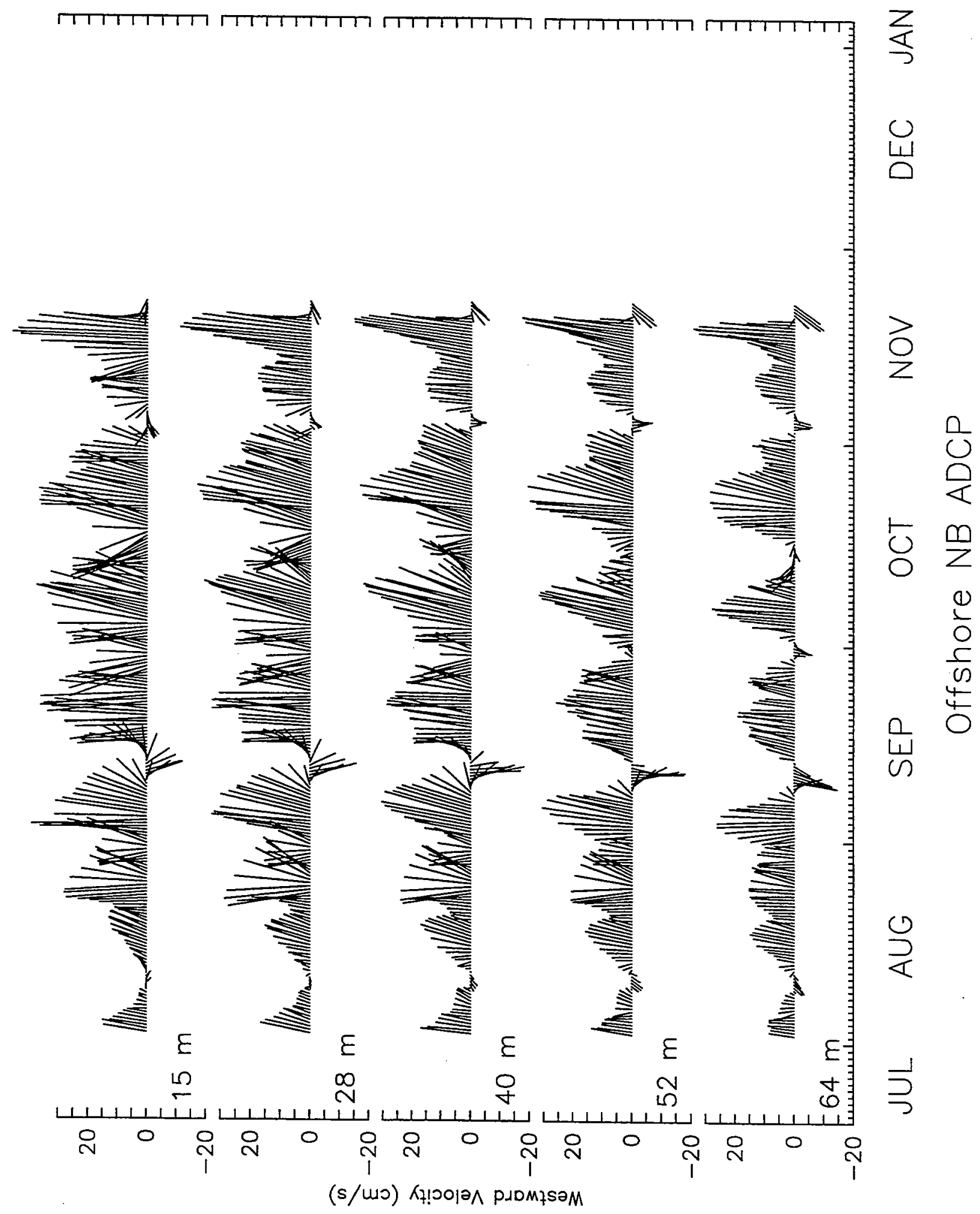

Figure 4.5.12. ADCP Water Velocity time series, Offshore Site, August - November. 


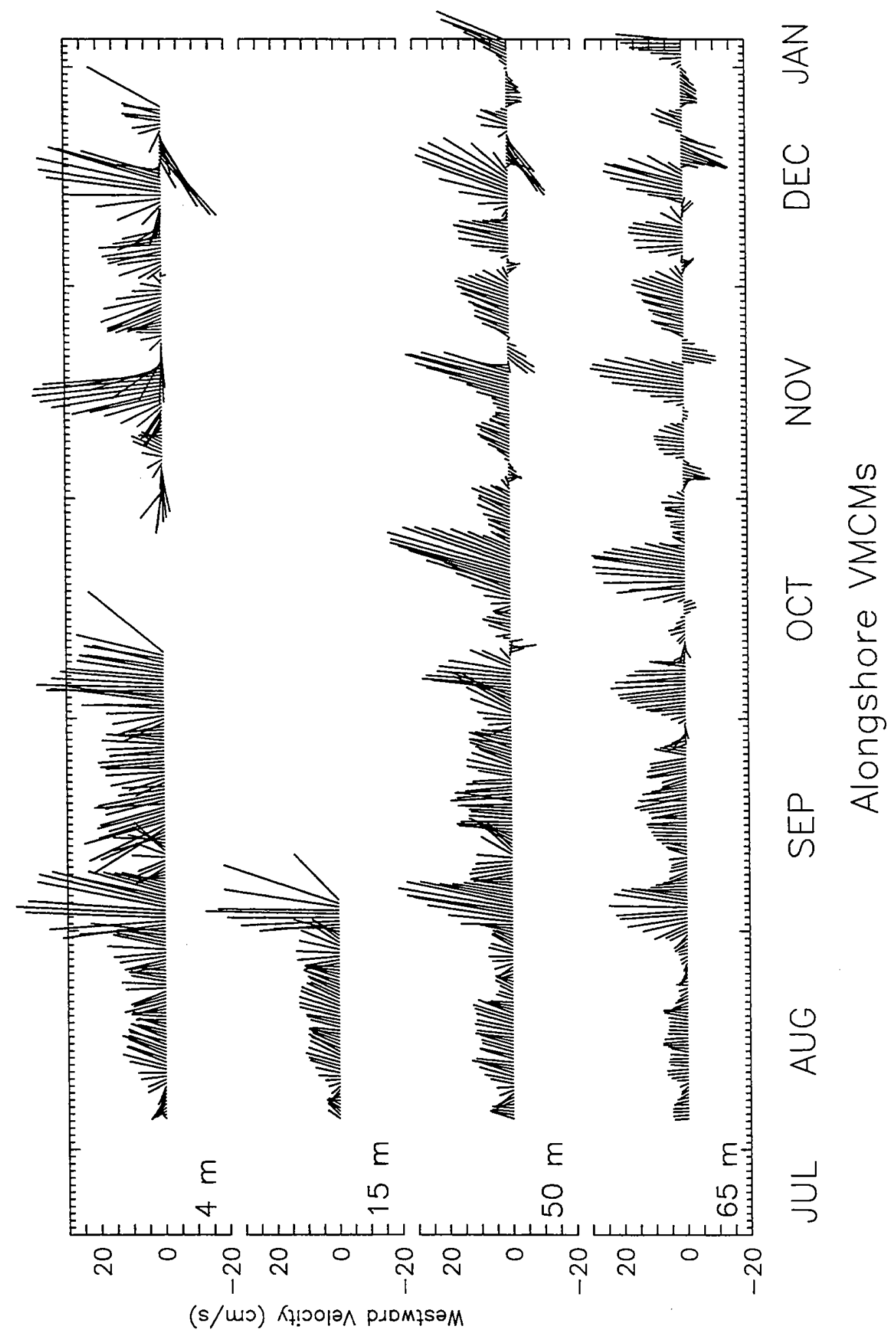

Figure 4.5.13. VMCM Water Velocity time series, Alongshore Site, August - December. Data is filtered over 576 points ( 3 days) and decimated over 96 points (12 hours). 


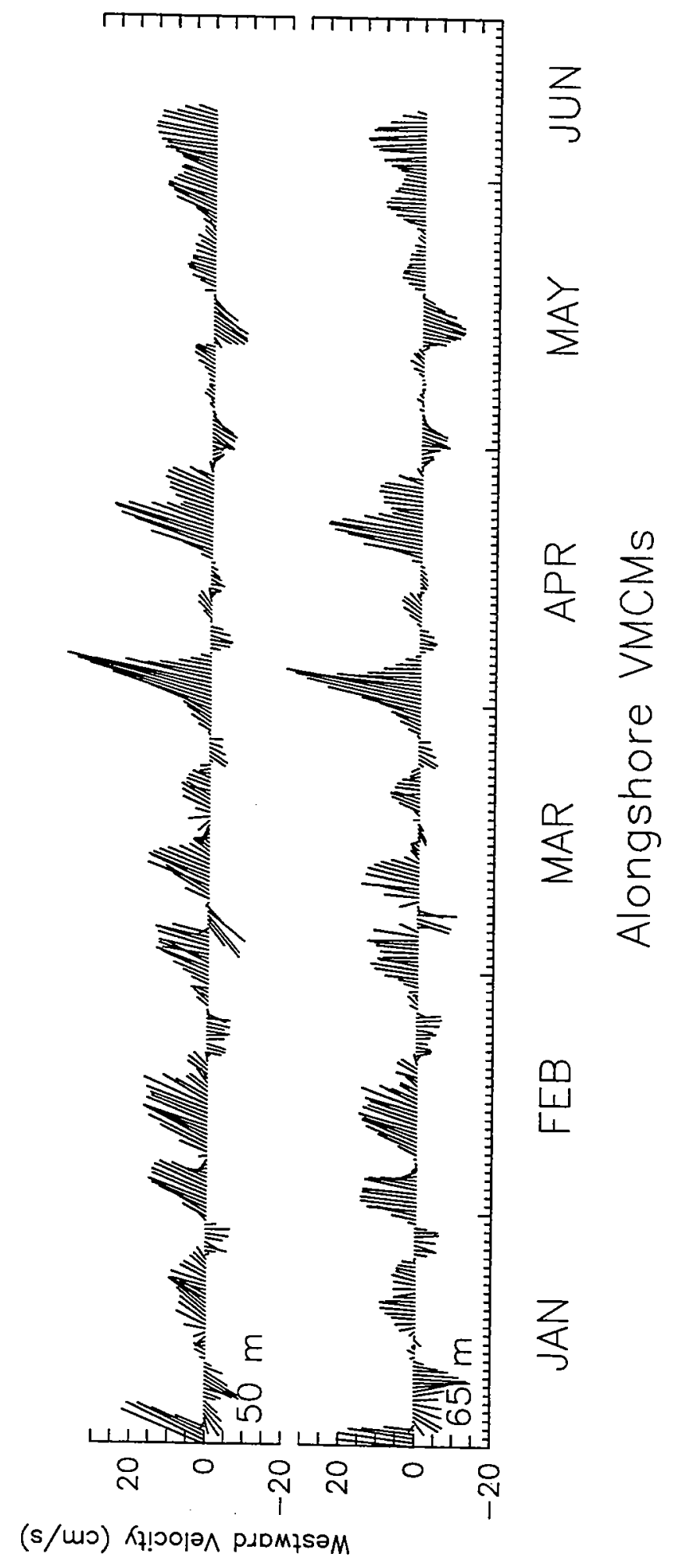

Figure 4.5.14. VMCM Water Velocity time series, Alongshore Site, January - June. Data is filtered over 576 points ( 3 days) and decimated over 96 points (12 hours). 


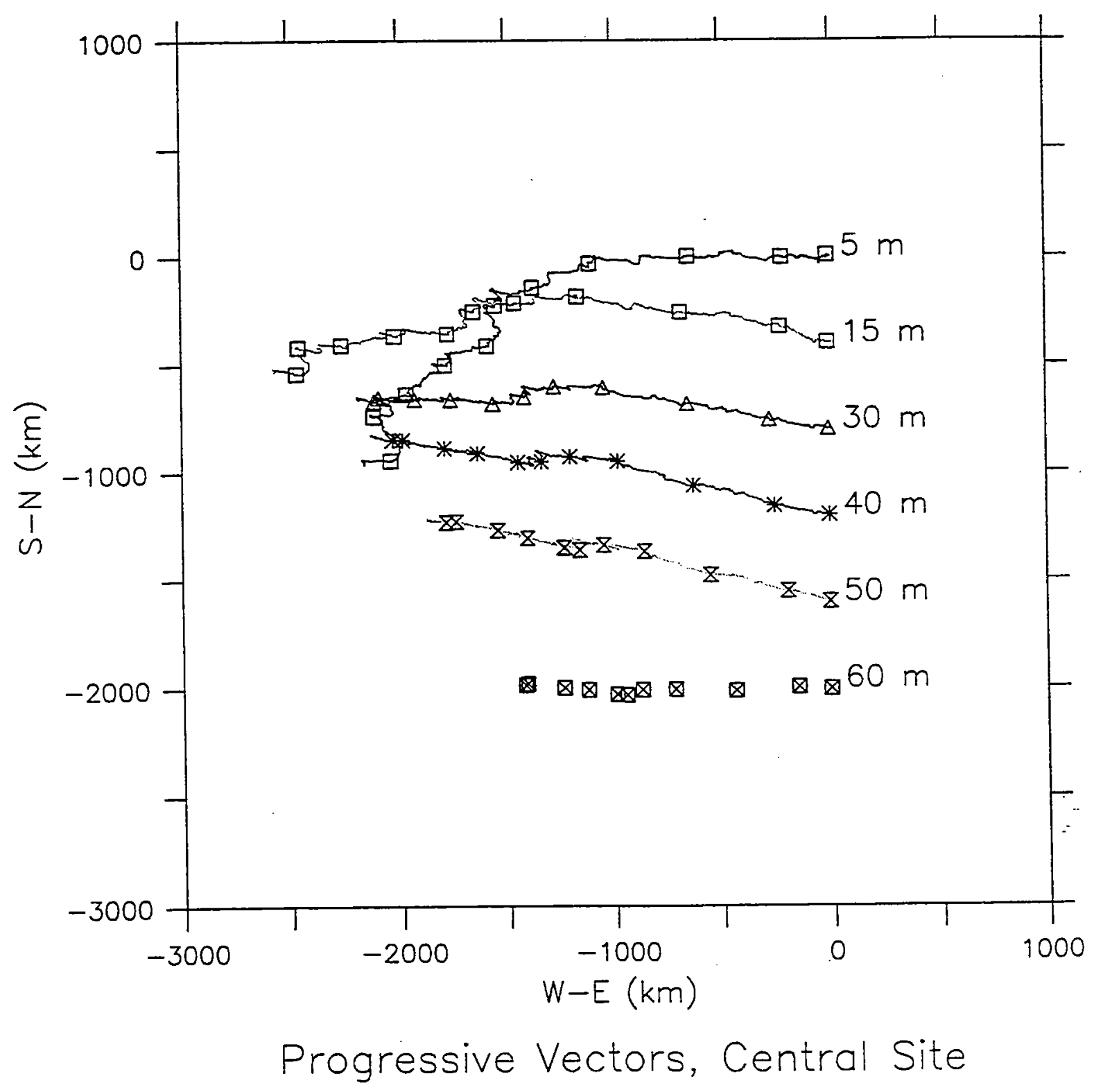

Figure 4.5.15. Progressive vectors from selected current meters at Central Site. 

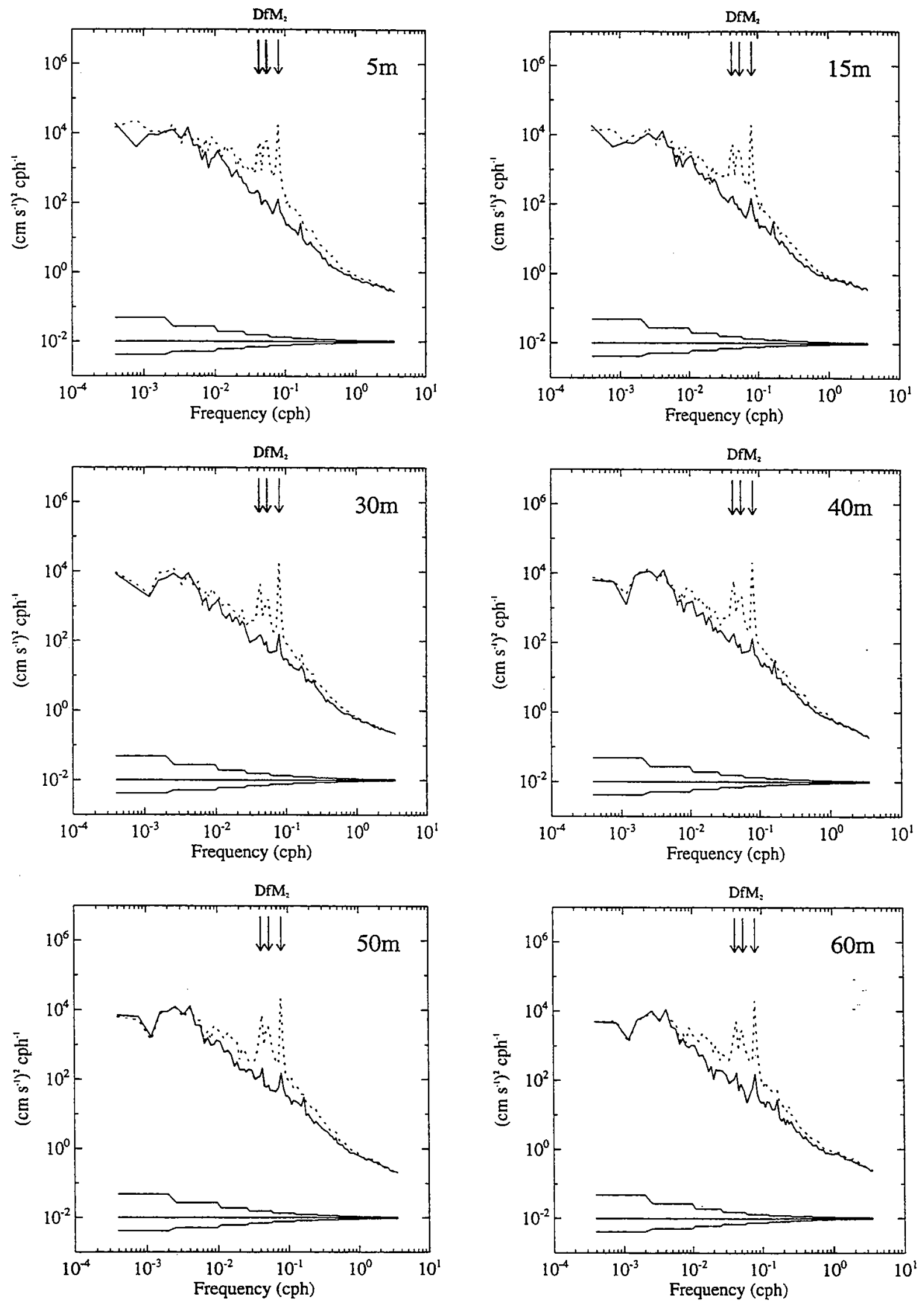

Figure 4.5.16. Rotary autospectra of water velocity measured by VMCMs at Central Site at various depths. Clockwise (solid) and counter-clockwise (dotted) spectras are shown. Diurnal (D), semi-diurnal (M2), and inertial (f) frequencies are indicated with arrows. 

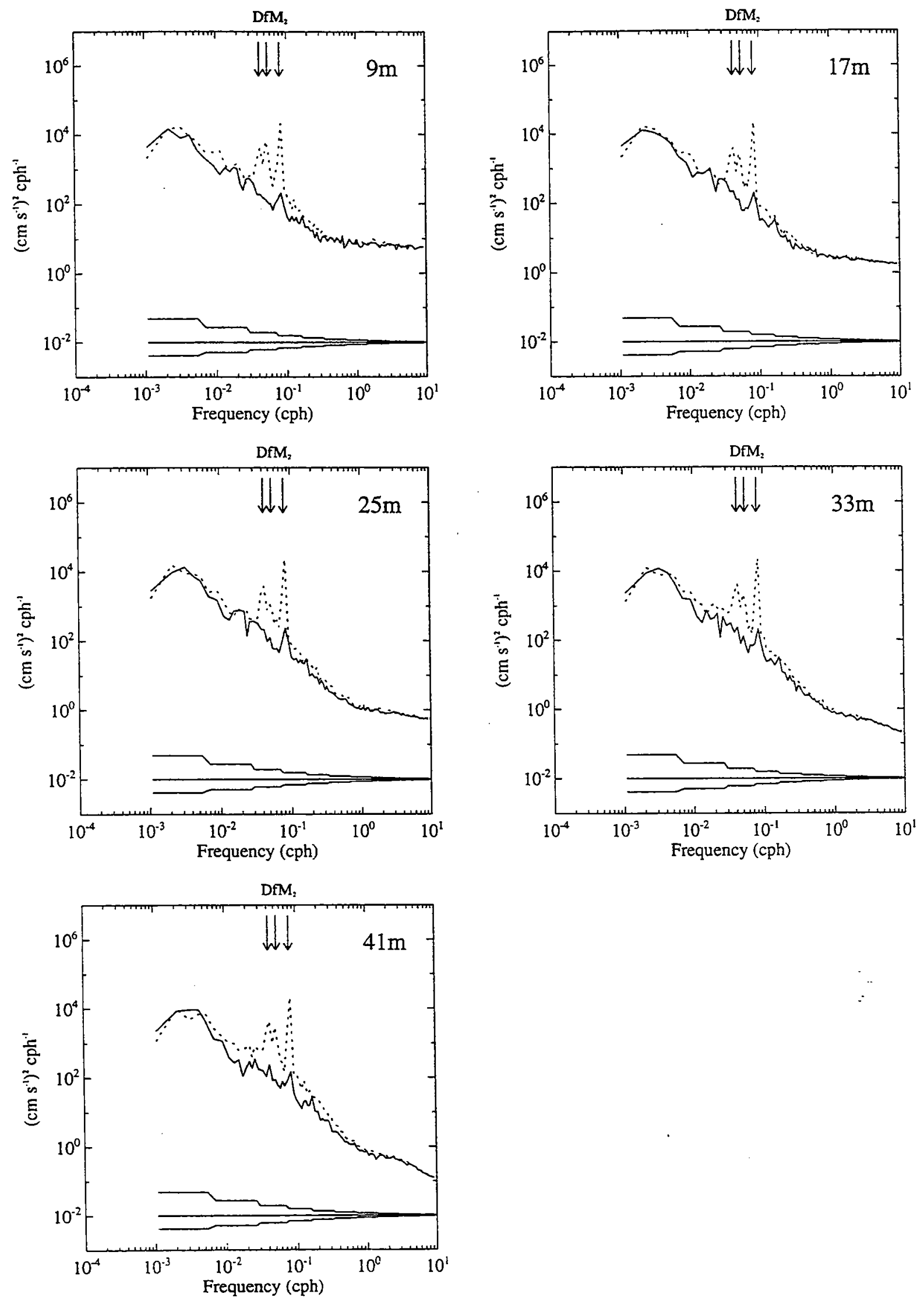

Figure 4.5.17. Rotary autospectra of water velocity measured by WorkHorse ADCP at Inshore Site at various depths. Clockwise (solid) and counter-clockwise (dotted) spectras are shown. Diurnal (D), semi-diurnal (M2), and inertial (f) frequencies are indicated with arrows. 

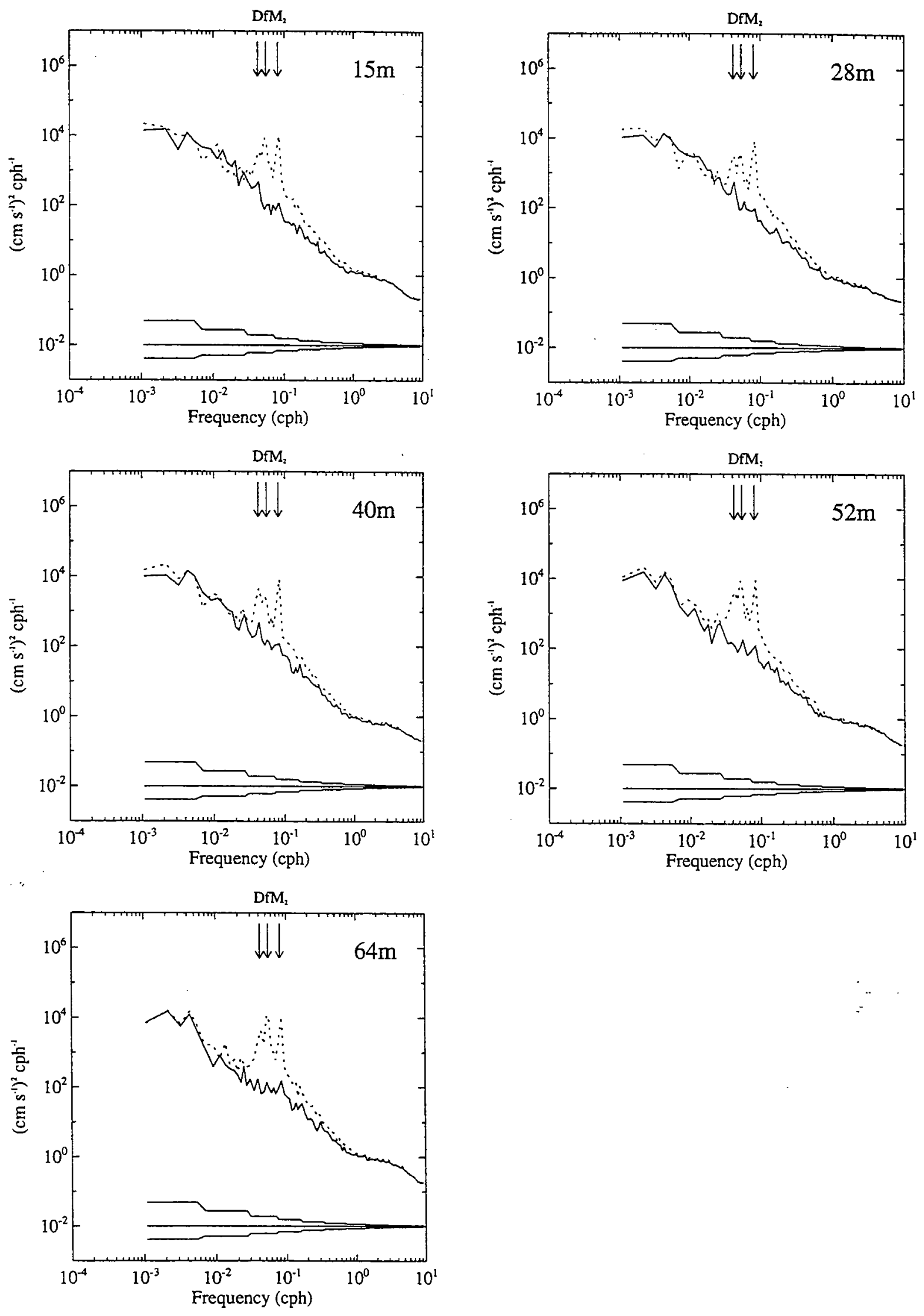

Figure 4.5.18. Rotary autospectra of water velocity measured by Narrowband ADCP at Offshore Site at various depths. Clockwise (solid) and counter-clockwise (dotted) spectras are shown. Diurnal (D), semi-diurnal (M2), and inertial (f) frequencies are indicated with arrows. 


\section{CMO Mooring Recoveries}

R/V Oceanus Voyage \#305, June 9-17, 1997, Steve Anderson, Chief Scientist

We had a very successful mooring recovery cruise and all instruments were recovered. The weather was calm and recoveries went smoothly thanks to the helpful crew of the Oceanus and the many cruise participants. The whole operation took place during three legs. In addition to the recoveries, we were able to occupy the CMO across shelf hydrographic transect twice, separated by 9 days. During this time we observed the formation of a warm surface mixed layer in response to strong solar heating during the long days and clear skies. We thank Derek Manov and Rocky Geyer for the loan of their CTD's during this cruise. At the end of the cruise we redeployed Sandy Williams' Tripod and a guard mooring to support Jim Ledwell's dye injection cruise in July.

The moored array group had over 80 scientific instruments deployed for over 10 months, with most recording several variables. Our most notable problem was wind sensor failures due, presumably, to large waves associated with several very strong storms (including Hurricane Edouard). Fortunately, Jim Edson's sonic anemometer worked the entire time and is consequently critical to our interpretation of both the meteorological and oceanographic observations. Fouling by fishing gear was limited to the top two current meters at the Alongshore site and the top current meter at the Inshore site. Although biofouling was heavy on some of the moorings, our antifouling worked well on the current meters and most of the conductivity sensors.

We are very excited about the good data return and about the fact that the deployment spanned the breakdown of stratification in the fall and its re-establishment in the spring. The breakdown of stratification in the fall primarily occurred during several strong storm events, including Edouard. Our concentration of instruments in the surface and bottom boundary layers appears to have been a wise choice, as both layers show significant variability during these strong forcing events. Indeed, the data set appears well suited to exploring our hypothesis that the evolution of stratification is principally controlled by processes in the surface and bottom boundaries.

\section{Primary objective:}

To recover all moorings and tripods deployed for the Coastal Mixing and Optics Program.

\section{Secondary objectives:}

To obtain hydrographic data across the shelf in the region and to redeploy the BASS-Tripod in support of the upcoming purposeful tracer studies. 
Leg 1: June 9-12

Alongshore site: recovered subsurface, 2 guards, toroid.

Central site: recovered Dickey (UCSB) mooring

Agrawal tripod

guard with wind

Williams tripod

Completed CMO hydrographic transect stations 1-23

Leg 2: June 12-15

First 14 CTD stations completed

Inshore site: recovered subsurface, 2 guards, toroid.

Central site: recovered Fan Beam ADCP mooring

2 guard moorings and guard with wind sensors

subsurface and Central discus

Completed Pickart's Shelf Break Front hydrographic transect with 20 CTD stations

Leg 3: June 15-16

Central site: Deployed Williams tripod and guard mooring

Offshore site: recovered 2 guard moorings, subsurface and toroid

Reoccupied all 23 CMO hydrographic stations

\section{Cruise Chronology}

\section{Leg 1:}

June 91997.

1445 Woods Hole. We hold safety meeting in main lab prior to departure from the dock

1645 Woods Hole. Finishing up lashing and securing. Lentz is preparing the wetlab to use as a staging area for the CTD. First station will be the Inshore side of the across shelf CTD transect.

1735 Underway to first CTD station

1758 Science meeting held in main lab to review objectives for Leg 1.

2215 At station for first CTD cast. After first profile with the UOP SBE 19, we notice that the profiles are noisy and steppy. We suspect the pressure resolution. The strain gauge pressure gauge is rated for 10,000 psi with a resolution of $0.015 \%$ of full scale. This translates to a $1.07 \mathrm{~m}$, resolution which is confirmed by looking at the ASCII file.

2342 At station \#2. We take another cast with the SBE19 and are still not satisfied with the results. Derik and Dave offer to deploy the UCSB SBE 25 CTD to compare with the SBE19 data.

June 101997

0040 Station \#3. We take 1 cast with the UCSB SBE25 and a second with the UOP SBE19. 0320 Station \#7. We have given up on the SBE19. Derek and Dave are installing new batteries into the SBE25. We plan to continue with transect with SBE25. Hill and Lentz will continue with CTD survey. The plan is to break off the surface in time to be at the Alongshore site by first light. 
0800 Station 14. Last CTD station. Have completed section past the Offshore site. Breaking off to go to Alongshore site.

1016 Alongshore site. Took 2 CTD casts to $64 \mathrm{~m}$ (water depth $70 \mathrm{~m}$ ). Ostrom, Trask and Way have staged deck for subsurface mooring recovery. Winds moderate at $6.5 \mathrm{~m} / \mathrm{s}$ from $239=\mathrm{B} 0$. SST at $10.5=\mathrm{B} 0 \mathrm{C}$.

1223 Alongshore site. Subsurface mooring has been recovered. All instruments look good. Next we recovered the Guard "O". Trask noted that the Alongshore south guard had maximum wear from $14 \mathrm{~m}$ above the anchor to $3 \mathrm{~m}$ below the swivel.

Alongshore site. All moorings recovered from this site. The toroid was last to come on board. We needed to back of about half a mile to fire the release. The top 2 VMCMs were fouled by half inch nylon line. The line was tangled on top $15 \mathrm{~m}$ of the mooring. All instruments were recovered, logged and photographed prior to washing. One shackle had a significantly enlarged cotter pin hole.

1812 Central site. UCSB group has taken a CTD cast is currently firing the release on their mooring.

1827 UCSB sphere sighted

1919 UCSB mooring on deck.

2007 Agrawal tripod float is spotted after release was fired.

2105 Agrawal tripod on deck. There was some trouble with the mooring line getting fouled on the stern but Horace and Will were able to grapple the line and continue with the recovery.

Slightly ahead of schedule. We decide to recover the guard with winds prior to dinner. The buoy and mooring hardware looks like new since the mooring was only deployed 7 weeks ago. We noticed that SeaCat $\sin 142$ has a broken glass tip.

June 11, 1997

0029 Central Site. Williams' SuperBass Tripod is now on deck and being secured. One of the top supports is broken. This is noticed as it comes out of the water and we do not know when it occurred. Sonteks look in good condition (we find out later that they did not work do to faulty cabling.)

Lentz and Hill continue with CTD survey and finish off the transect using the UCSB SBE25 completing the CTD line at the Offshore end at 0800 . Then we head straight for Woods Hole.

1630 Woods Hole. Just arrived at the dock. Unloading starts immediately. The large tripod comes off first followed by everything else. The toroid with WeatherPak is left on the dock, all other instruments are trucked up to the high bay. Lentz and Anderson go in search of a CTD to use for the rest of the cruise. Rocky Geyer offers his OS200 which is accepted and mounted to a piece of pipe with hose clamps. Also, some lead weight is clamped to the pipe.

After unloading, the science party is given leave for a few hours and we plan an early evening departure from Woods Hole.

\section{Leg 2:}

June 121997

0045 Depart Woods Hole.

0950 Inshore site. We conduct 2 CTD casts with CRC OS200 CTD. Then start recovery of subsurface mooring. One of the CTD casts stopped at $10 \mathrm{~m}$, the first looks good. Lentz going to review CTD setup. 
1112 Inshore site. Subsurface mooring on deck and instruments have been photographed and are now being cleaned. All looks good, props spinning and poison plugs in place.

Note: We saw a large container ship go north of the Inshore mooring site. This is clearly outside of the designated trans-Atlantic shipping lanes. This may be a regular occurrence.

1319 Inshore site. First guard recovered. This one was really stuck in the mud and the crane had a hard time pulling it out. $1.5 \mathrm{ft}$ of mud on the anchor when put on the deck.

1618. Inshore site. Toroid now on deck. Washing of the toroid has begun. Line around the bridle and top current meter. We plan to do a depth survey going toward the Central site to make sure the bottom is really as flat as we think. The survey confirms the flat slopping bottom.

1805 Central Site. Taking 2 CTD casts with OS200. The Fan Beam will be the first recovery.

1903 Central Site. Fan Beam mooring recovered. The CTD casts look better than those taken at the Inshore site. We suspect that the conductivity probe is taking a long time to "wet" as Rocky suggested. We should have put the probe in water before we left the dock but failed to do so.

2058 Central Site. The subsurface mooring is on deck and we are cleaning up. All looks pretty good and no surprises.

June 13

0000 Central Site. Lentz and Plueddemann do a pair of CTD casts at Central site. They put both SBE-19 and OS 200 on the same line. The OS 200 data has much less salinity spiking. There is a salinity offset between the two.

0955 Central Site. On deck ready to recover a guard mooring.

1050 Central Site. Northern Guard on deck. This one has been out since Levine set it 12 months ago. It clearly has the largest mussel population with almost no anti-fouling paint left on haul or bridle.

1306 Central Site. Guard with t-pod MTR is now on the deck. Cleaning up to get ready to recover discus.

1410. Central Site. Discus recovery started.

1750 Starting to rain. We are finishing up the last bit of clean up on deck. All instrument photographed and logged. Rick labeled and collected all hardware on discus mooring. We started Pickart's Shelf break front hydrographic Transect at 1545. Currently at station \#6. We plan to continue the line until the $500 \mathrm{~m}$ isobath and then return to WHOI.

June 15

1300 At WHOI dock. We will offload and stay in port overnight. We completed 20 CTD station in under 10 hours.

\section{Leg 3:}

June 15

0100 At Dock. Put Sandy's tripod over the side to get zero offset.

0200 Left dock for Central site.

0955 At Central site. Clear day flat seas. Best morning we have had yet for mooring operations. We deploy tripod first.

1003 Tripod set and guard " $T$ " set. now heading off to Offshore Site.

1245 Offshore Site. Took 2 CTD casts and recovered Offshore subsurface mooring. 
1453 Offshore Site. Recovered first guard mooring. Large goose necks now cleaning up. 1645 Offshore Site. Second guard is no on deck and cleaned up. Getting in position to pick up toroid.

1724 Offshore Site. Toroid release not responding at 0.1 and 0.25 miles. Moving off to 0.4 miles. Water depth is $84 \mathrm{~m}$.

1925 Toroid is now on deck and being cleaned. The release never fired. We recovered the mooring until the release then cut the anchor letting it and the chain drop to the bottom. We are now heading towards the Offshore end of the CTD line.

June 16

0800 Finished CTD line heading towards Woods Hole; expect to arrive at 1300.

\section{CMO Mooring Recovery Cruise Participant List}

Leg 1: 9-11 June

$\begin{array}{ll}\text { 1. Steven Anderson } & \text { WHOI } \\ \text { 2. Nan Galbraith } & \text { WHOI } \\ \text { 3. Steven Lentz } & \text { WHOI } \\ \text { 4. Will Ostrom } & \text { WHOI } \\ \text { 5. Rick Trask } & \text { WHOI } \\ \text { 6. Bryan Way } & \text { WHOI } \\ \text { 7. Derek Manov } & \text { UCSB } \\ \text { 8. Dave Sigurdson } & \text { UCSB } \\ \text { 9. Sandy Williams } & \text { WHOI } \\ \text { 10. Rebecca Latter } & \text { WHOI } \\ \text { 11. Paul Hill } & \text { Dalhousie University } \\ \text { 12. Chuck Pottsmith } & \text { Sequoia Scientific, Inc. }\end{array}$

Leg 2: 12-15 June

1. Steve Anderson

2. Jim Edson

WHOI

3. Nan Galbraith

WHOI

WHOI

4. Al Hinton

WHOI

5. Steven Lentz

WHOI

WHOI-MIT Joint Program student

WHOI Summer student fellow

6. Michiko Martin

7. Reina Nakamura

8. Will Ostrom

WHOI

WHOI Summer student employee

9. Erica Rhude

10. Al Plueddemann

WHOI

WHOI

11. Rick Trask

WHOI

Leg 3: 16-18 June

1. Steve Anderson

WHOI

2. Michele Berge

3. Jim Dunn

WHOI Summer student employee

WHOI

4. Jim Edson

WHOI

5. Nan Galbraith

WHOI

6. Michiko Martin

WHOI-MIT Joint Program student

7. Reina Nakamura

8. Will Ostrom

WHOI Summer student fellow

WHOI

9. Erica Rhude

10. Rick Trask

WHOI Summer student employee

WHOI

11. Bryan Way

WHOI 


\section{The CTD Transects}

Shipboard CTD surveys were conducted during the mooring deployment and recovery cruises to characterize the spatial structure of the temperature, salinity and density fields. Surveys included an along-isobath radiator pattern and repeated cross-shelf section along the central mooring line (Figure 6.1). Cross-shelf transects of temperature, salinity, and density are shown in Figures 6.2-6.9. Besides the transects in August 1996 on the deployment cruise and June 1997 on the recovery cruise, CTD transects were also taken on September 5, 1996, by Jim Ledwell and on February 24, 1997, by Bob Pickart.

\section{Acknowledgments}

The design and technical development of the Coastal Mixing and Optics (CMO) moored array, the preparation of instruments, and the deployment and recovery of moorings were done by W. Ostrom, R. Payne, R. Trask, J. Ware and B. Way of the WHOI Upper Ocean Processes Group (UOPG) with assistance from C. Marquette, N. McPhee, E. Terray and S. Worrilow. Moorings were designed by G. Tupper and fabricated by the WHOI Rigging Shop under the direction of D. Simoneau. The professionalism and expertise of the captain and crew of the R/V Oceanus and R/V Knorr contributed to successful deployment and recovery operations. We are indebted to Chief Scientists J. Ledwell, R. Pickart, M. Levine, and S. Chisholm, for their assistance with field operations.

This work was supported by the Office of Naval Research, Code 322, under Grant Number N00014-95-1-0339. 


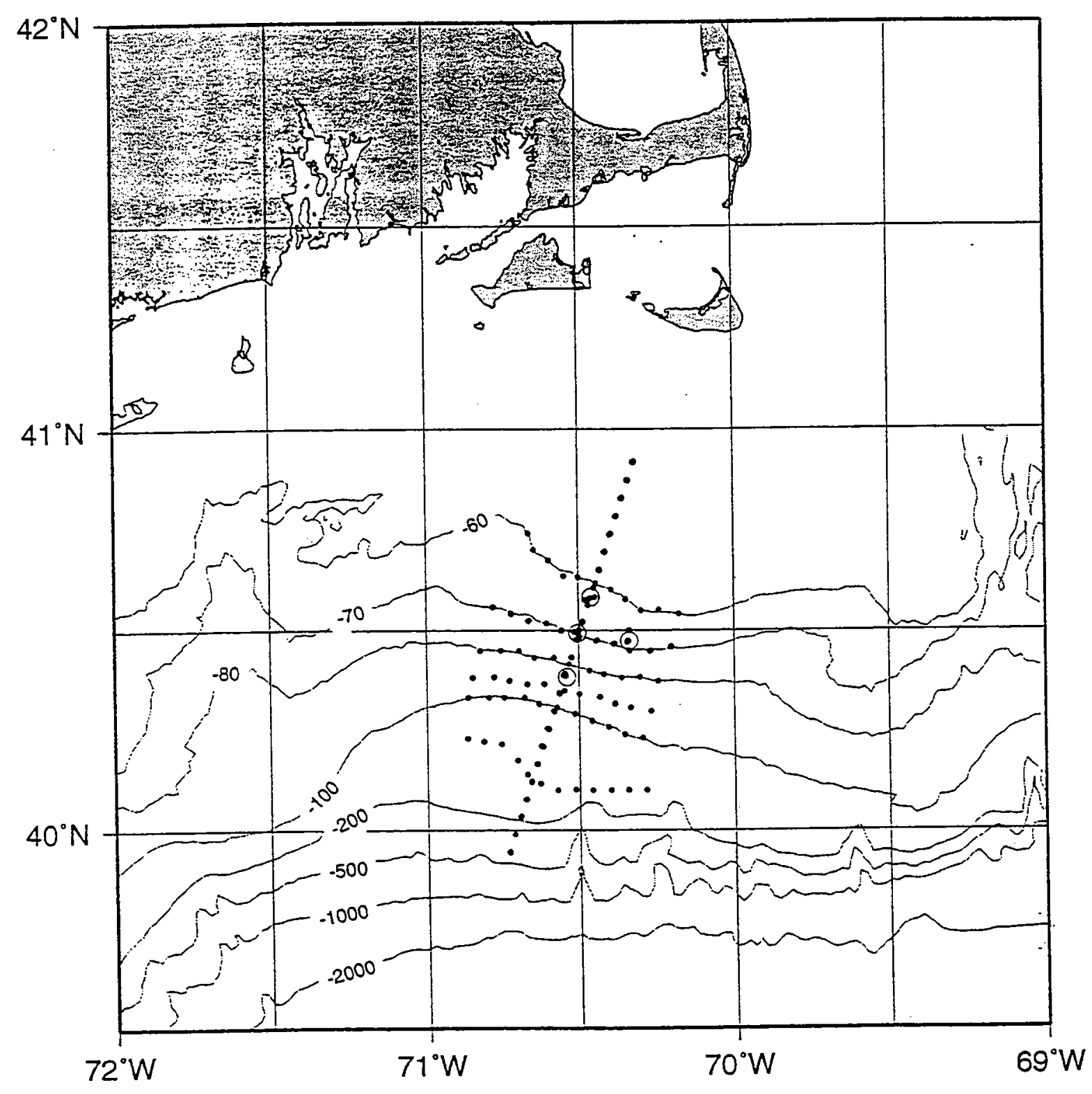

Figure 6.1. CTD Locations 

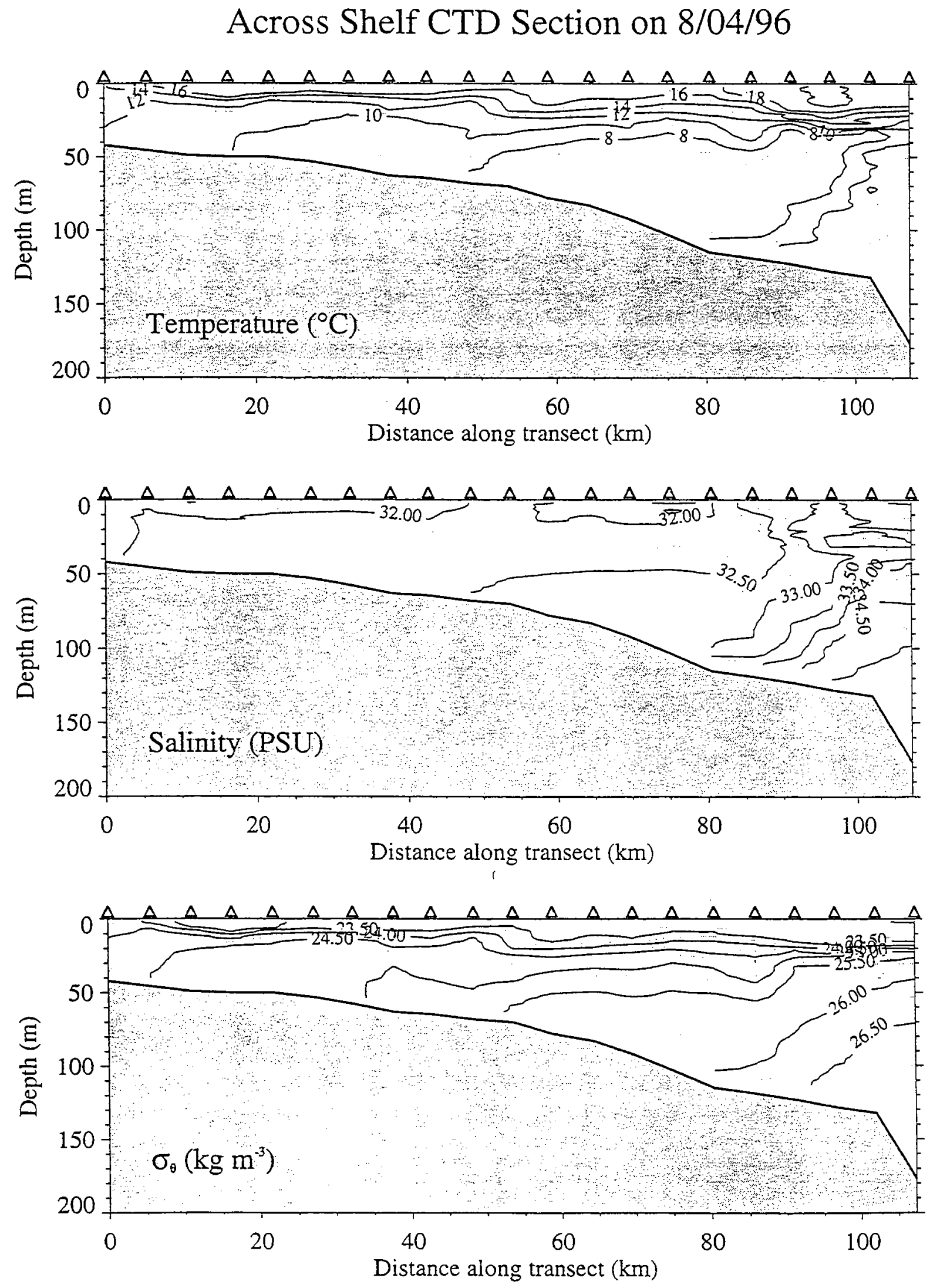

Figure 6.2. Cross-shelf CTD Section, deployment cruise, August 4, 1996 


\section{Across Shelf CTD Section on 8/07/96}
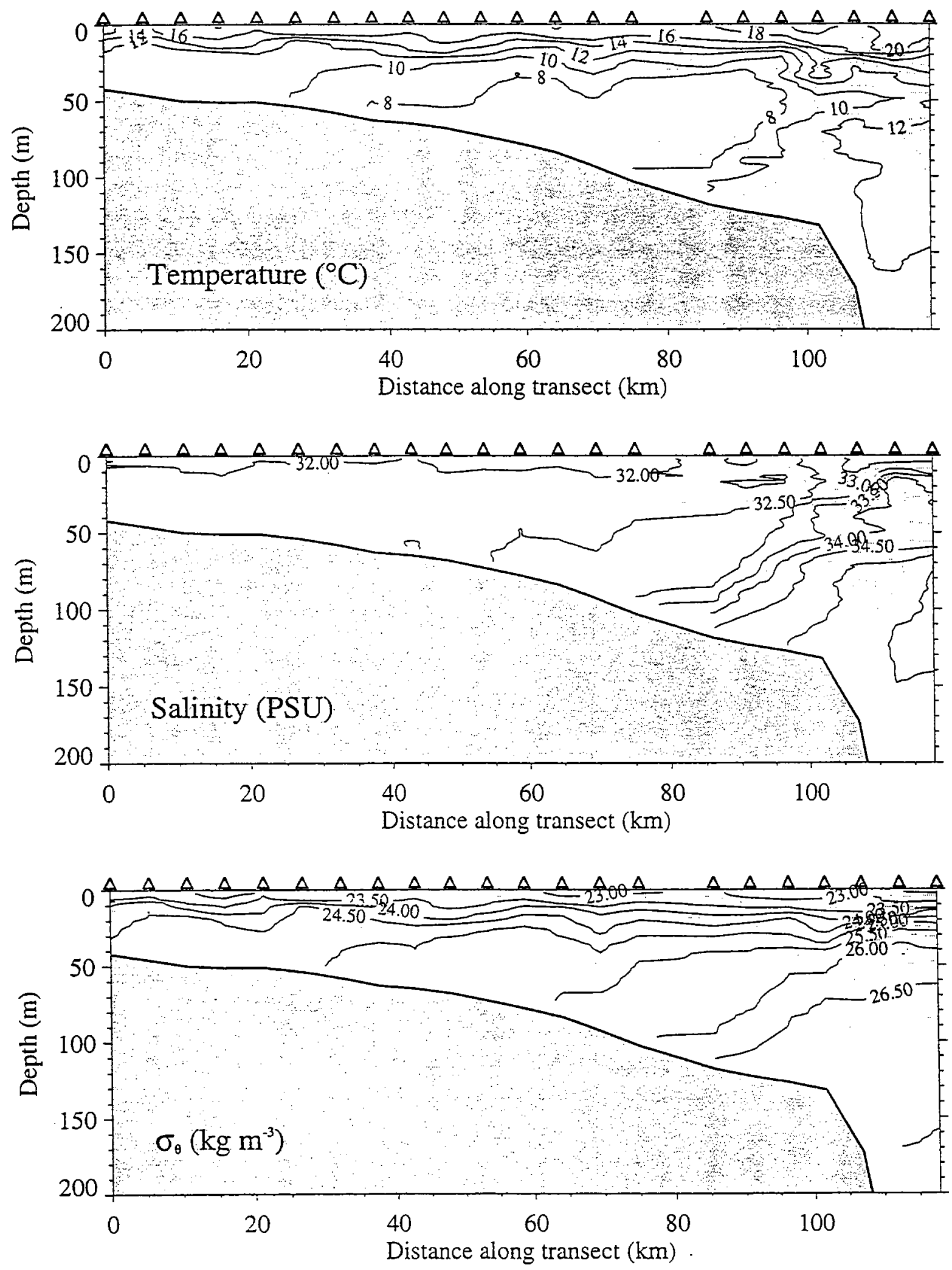

Figure 6.3. Cross-shelf CTD Section, deployment cruise, August 7, 1996 

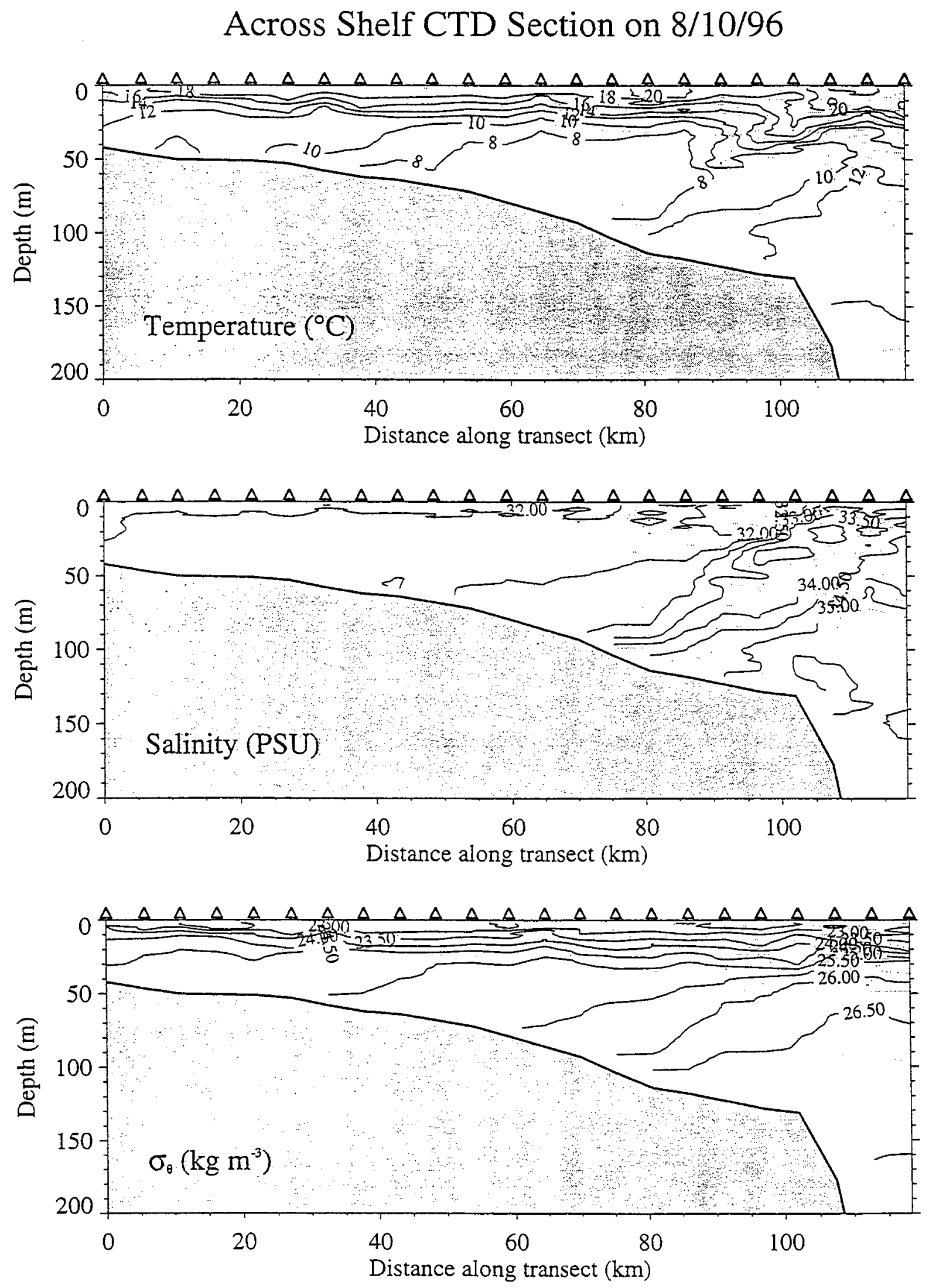

Figure 6.4. Cross-shelf CTD Section, deployment cruise, August 10,1996 


\section{Across Shelf CTD Section on 9/05/96}
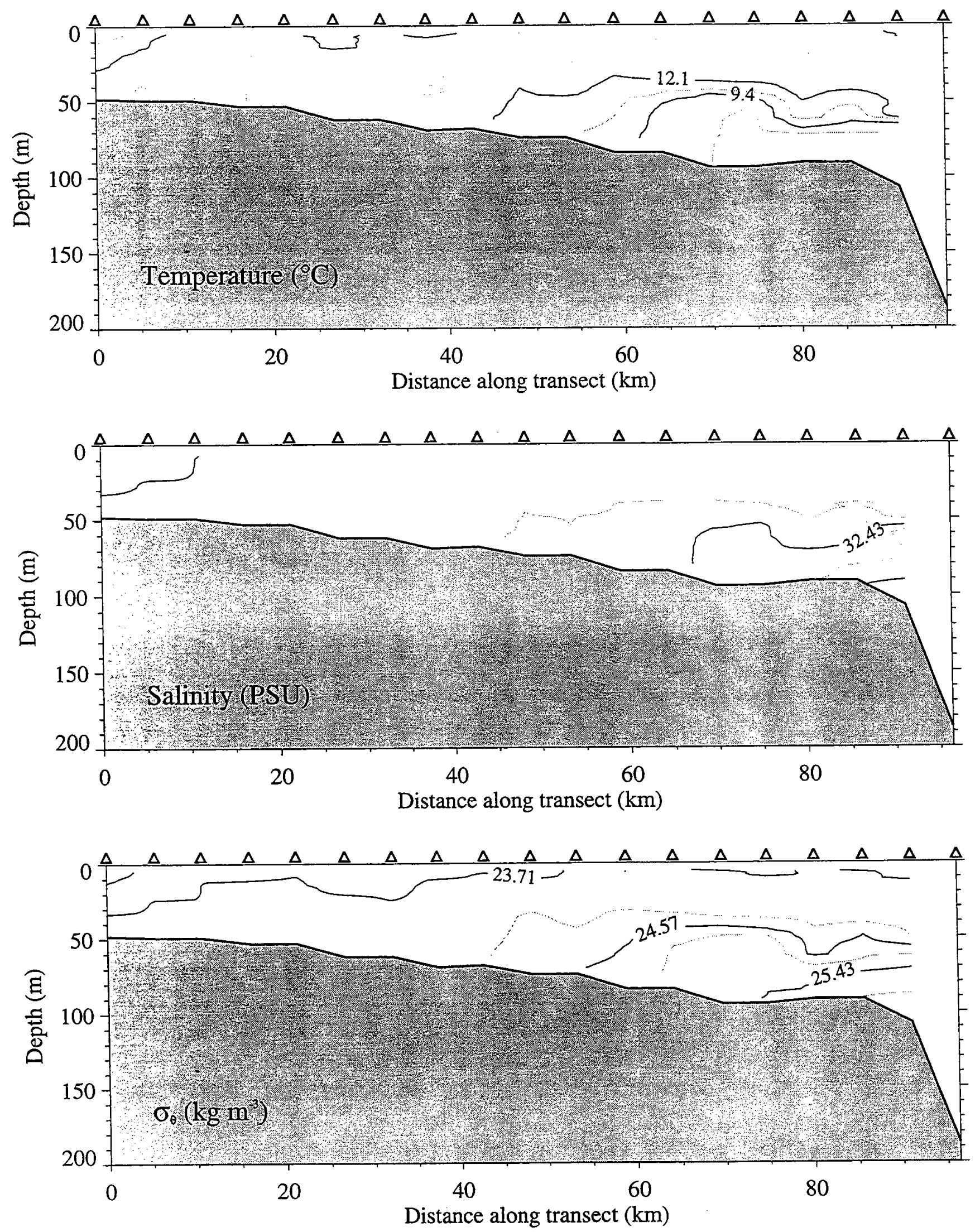

Figure 6.5. Cross-shelf CTD Section, R. Pickart cruise, September 5,1996 


\section{Across Shelf CTD Section on 2/24/97}
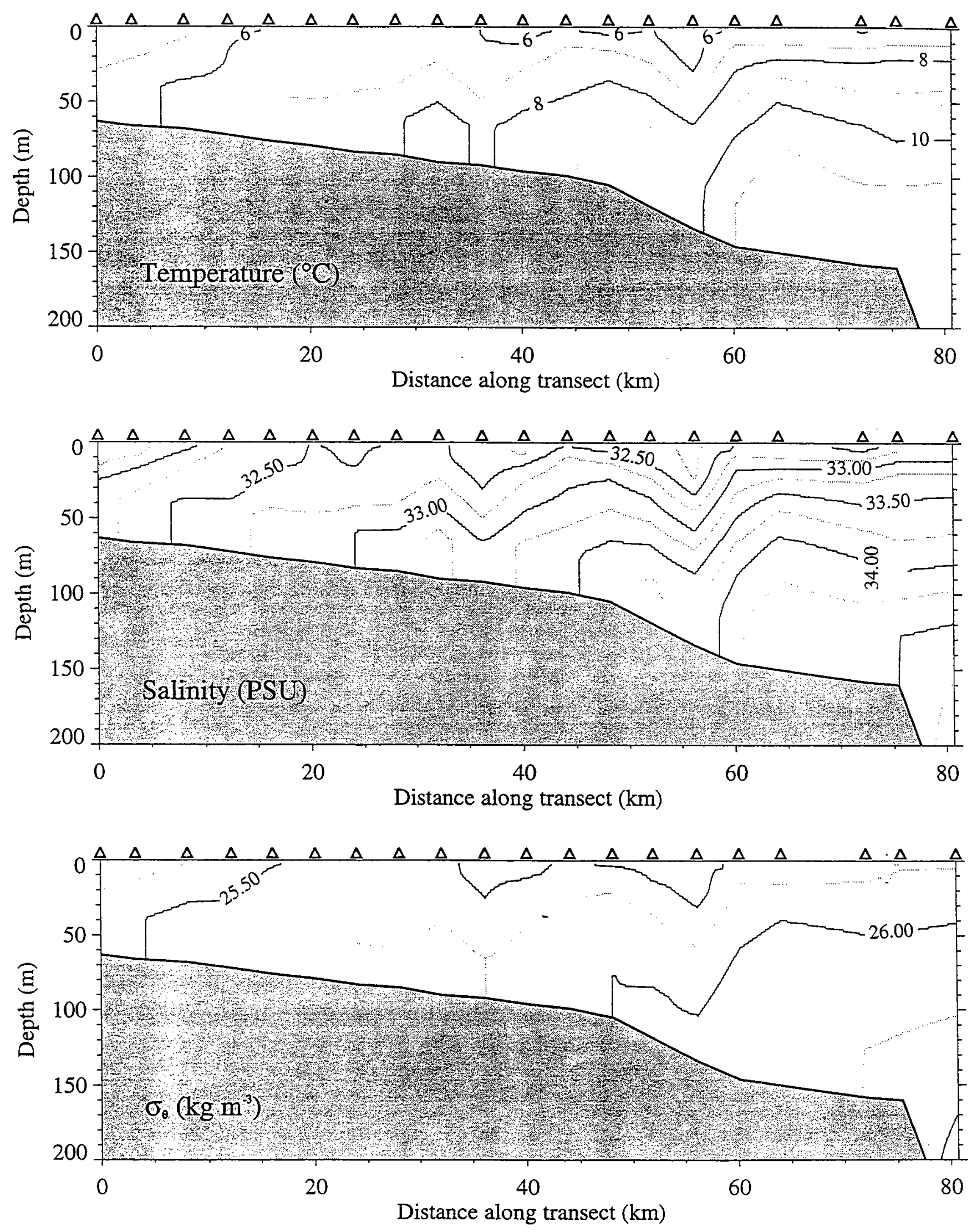

Figure 6.6 Cross-shelf CTD Section, J. Ledwell cruise, February 24. 1997. 


\section{Across Shelf CTD Section on 6/09/97}
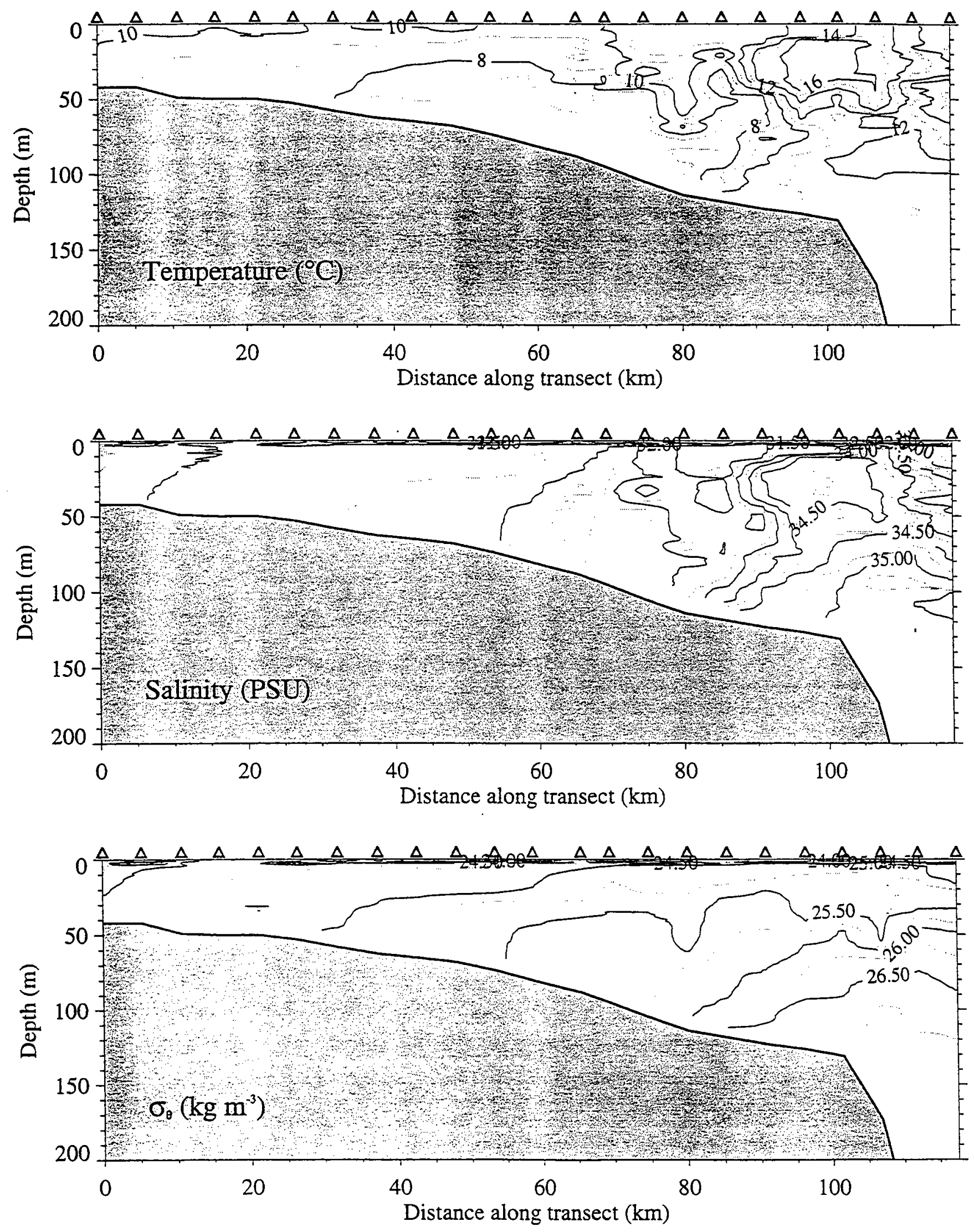

Figure 6.7. Cross-shelf CTD Section, recovery cruise, June 9,1997 

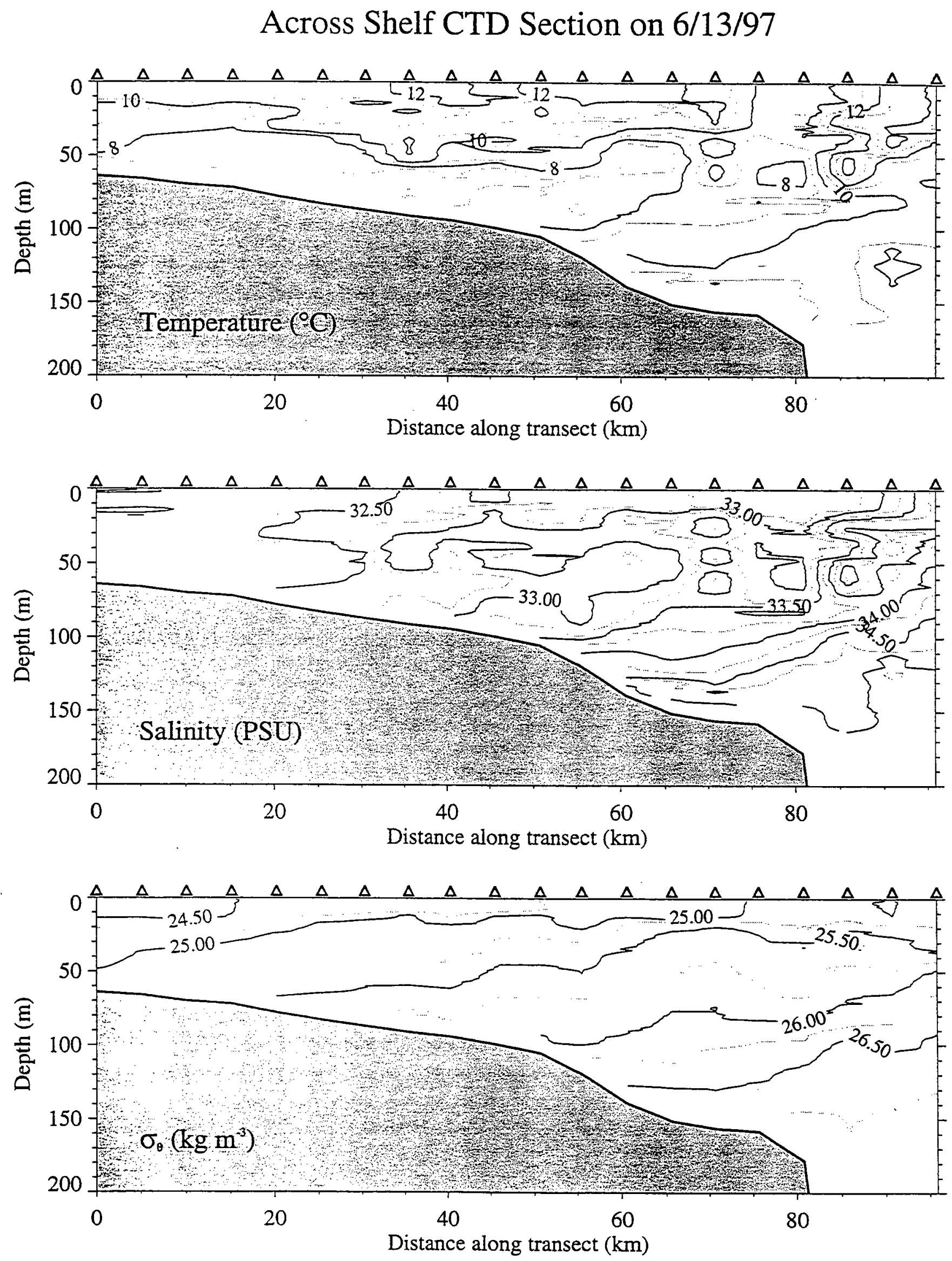

Figure 6.8. Cross-shelf CTD Section, recovery cruise, June 13, 1997 


\section{Across Shelf CTD Section on 6/17/97}
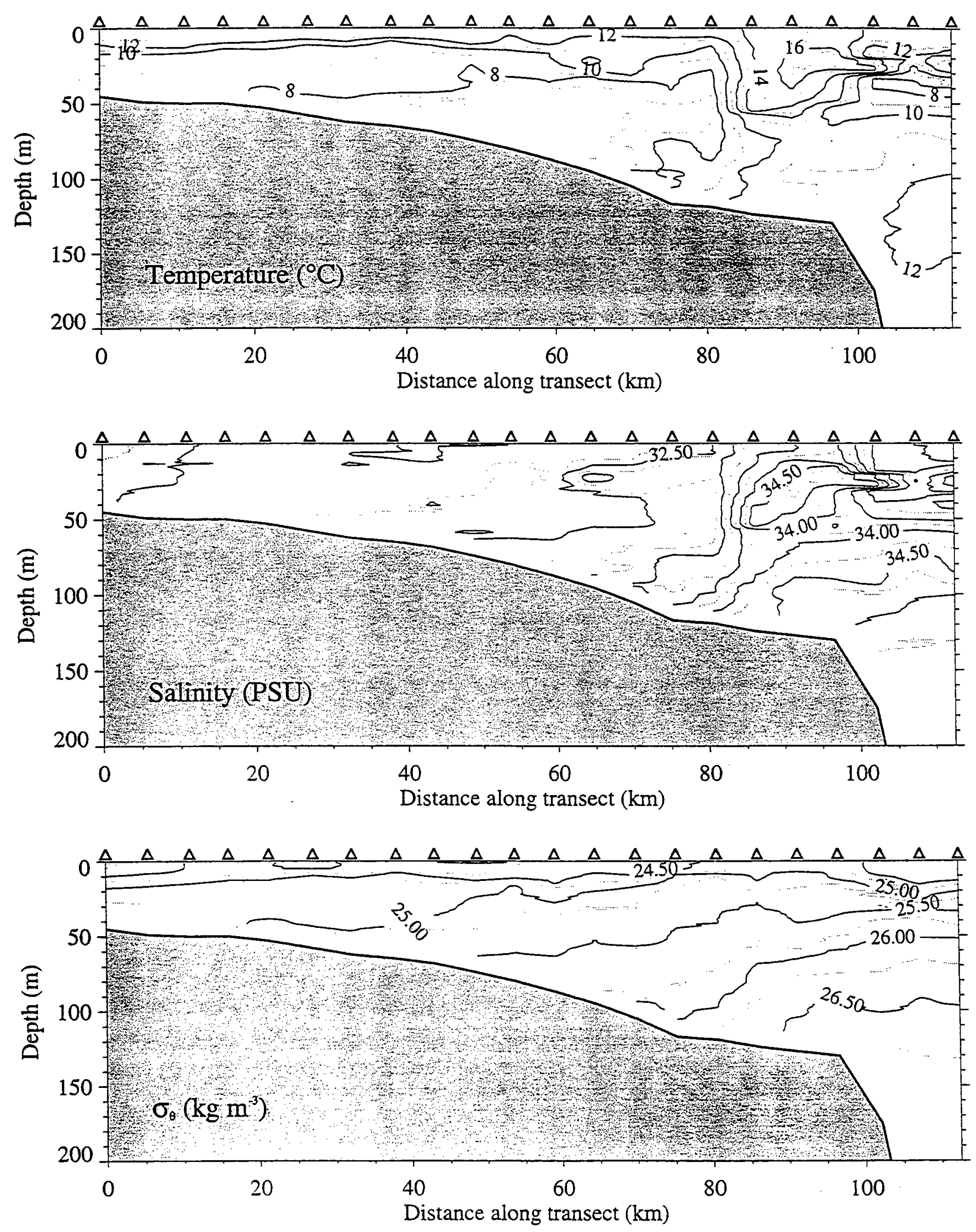

Figure 6.9. Cross-shelf CTD Section, recovery cruise, June 17, 1997 


\section{Bibliography}

Beardsley, R. C., and W. C. Boicourt, 1981. On estuarine and continental shelf circulation in the Middle Atlantic Bight. In: Evolution of Physical Oceanography, ed. B. A. Warren and C. Wunsch, MIT Press, Cambridge, Massachusetts, pp. 198-234.

Fairall, C. W., E. F. Bradley, D. P. Rogers, J. B. Edson, and G. S. Young, 1996. Bulk parameterization of air-sea fluxes for Tropical Ocean-Global Atmosphere CoupledOcean Atmosphere Response Experiment. Journal of Geophysical Research, 101(C2), 3747-3764.

Fofonoff, N. P., and R. C. Millard, Jr., 1983. Algorithms for computations of fundamental properties of seawater. UNESCO Technical Papers in Marine Science, No. 44, 53 pp.

Galbraith, N., W. Ostrom, B. Way, S. Lentz, S. Anderson, M. Baumgartner, A. Plueddemann, and J. Edson, 1997. Coastal Mixing and Optics mooring deployment cruise report. Woods Hole Oceanographic Institution Technical Report, WHOI-97-13, Woods Hole, Massachusetts, $81 \mathrm{pp}$.

Martin, M. J., 1998. An investigation of momentum exchange parameterizations and atmospheric forcing for the Coastal Mixing and Optics program. Master's Thesis, Woods Hole Oceanographic Institution/Massachusetts Institute of Technology, Woods Hole, Massachusetts, 83 pp. 


\section{DOCUMENT LIBRARY}

Distribution List for Technical Report Exchange - July 1998

University of California, San Diego

SIO Library 0175C

9500 Gilman Drive

La Jolla, CA 92093-0175

Hancock Library of Biology \& Oceanography

Alan Hancock Laboratory

University of Southern California

University Park

Los Angeles, CA 90089-0371

Gifts \& Exchanges

Library

Bedford Institute of Oceanography

P.O. Box 1006

Dartmouth, NS, B2Y 4A2, CANADA

NOAA/EDIS Miami Library Center

4301 Rickenbacker Causeway

Miami, FL 33149

Research Library

U.S. Army Corps of Engineers

Waterways Experiment Station

3909 Halls Ferry Road

Vicksburg, MS 39180-6199

Marine Resources Information Center

Building E38-320

MIT

Cambridge, MA 02139

Library

Lamont-Doherty Geological Observatory

Columbia University

Palisades, NY 10964

Library

Serials Department

Oregon State University

Corvallis, OR 97331

Pell Marine Science Library

University of Rhode Island

Narragansett Bay Campus

Narragansett, RI 02882

Working Collection

Texas A\&M University

Dept. of Oceanography

College Station, TX 77843
Fisheries-Oceanography Library

151 Oceanography Teaching Bldg.

University of Washington

Seattle, WA 98195

Library

R.S.M.A.S.

University of Miami

4600 Rickenbacker Causeway

Miami, FL 33149

Maury Oceanographic Library

Naval Oceanographic Office

Building 1003 South

1002 Balch Blvd.

Stennis Space Center, MS, 39522-5001

Library

Institute of Ocean Sciences

P.O. Box 6000

Sidney, B.C. V8L 4B2

CANADA

National Oceanographic Library

Southampton Oceanography Centre

European Way

Southampton SO14 3ZH

UK

The Librarian

CSIRO Marine Laboratories

G.P.O. Box 1538

Hobart, Tasmania

AUSTRALIA 7001

Library

Proudman Oceanographic Laboratory

Bidston Observatory

Birkenhead

Merseyside L43 7 RA

UNITED KINGDOM

IFREMER

Centre de Brest

Service Documentation - Publications

BP 7029280 PLOUZANE

FRANCE 



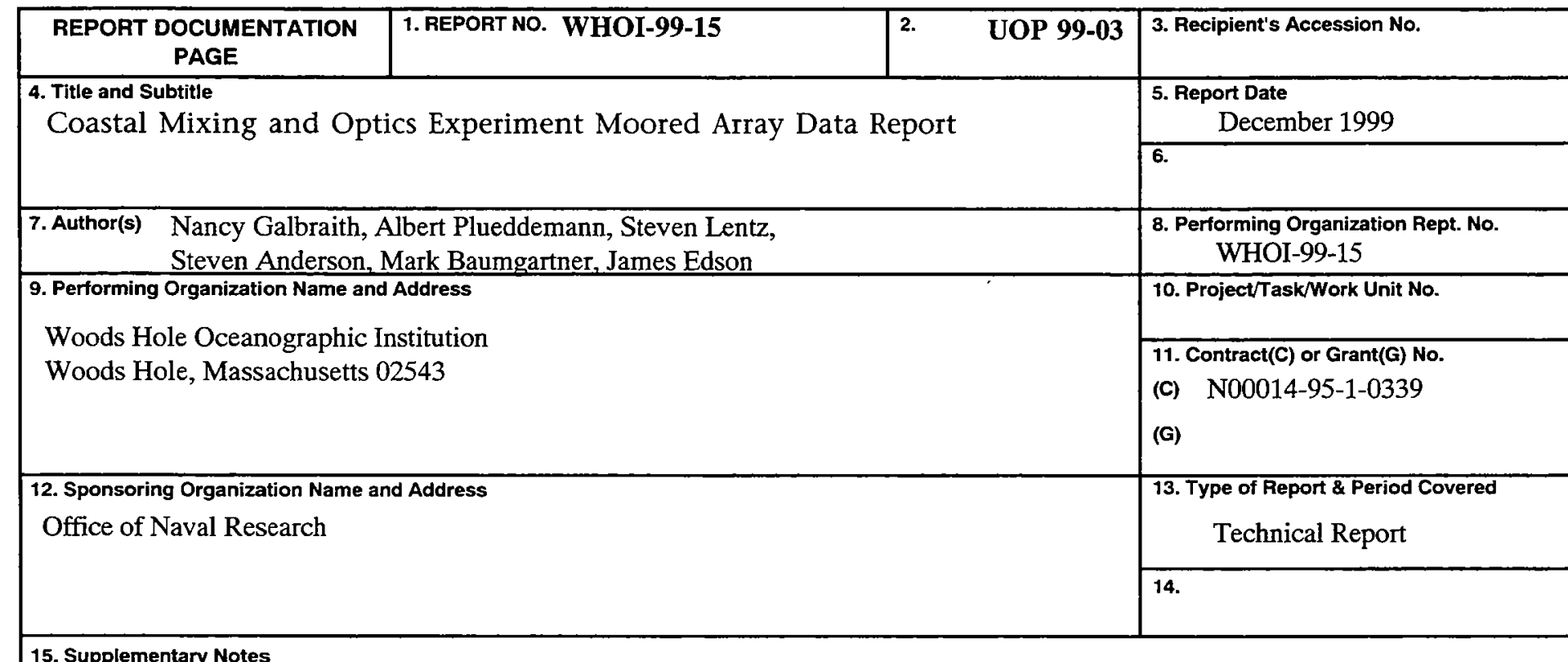

This report should be cited as: Woods Hole Oceanog. Inst. Tech. Rept., WHOI-99-15.

16. Abstract (Limit: 200 words)

To investigate vertical mixing processes influencing the evolution of the stratification over continental shelves, a moored array was deployed on the New England shelf from August 1996 to June 1997 as part of the Office of Naval Research's Coastal Mixing and Optics program. The array consisted of four mid-shelf sites instrumented to measure oceanic (currents, temperature, salinity, pressure, and surface gravity wave spectra) and meteorological (winds, surface heat flux, precipitation) variables. This report presents a description of the moored array, a summary of the data processing, and statistics and time-series plots summarizing the data. A report on the mooring recovery cruise and a summary of shipboard CTD surveys taken during the mooring deployment are also included.

\section{Document Analysis a. Descriptors}

Meteorology: North Atlantic

Oceanography: North Atlantic

Moored Instrument Measurements

b. Identifiers/Open-Ended Terms

$-\cdots$

c. COSATI Field/Group

18. Availability Statement

Approved for public release; distribution unlimited.

\begin{tabular}{|l|l|}
\hline $\begin{array}{c}\text { 19. Security Class (This Report) } \\
\text { UNCLASSIFIED }\end{array}$ & $\begin{array}{c}\text { 21. No. of Pages } \\
162\end{array}$ \\
\hline 20. Security Class (This Page) & 22. Price \\
\hline & $\begin{array}{l}\text { OPTIONAL FORM 272 (4-77) } \\
\text { (Formerly NTIS-35) } \\
\text { Department of Commerce }\end{array}$
\end{tabular}


